\title{
Tesis recomendada para su publicación. Modernos sin modernidad. Arquitectura de Guayaquil 1930-1948
}

Florencio Compte Guerrero *

\begin{abstract}
Resumen: La historiografía sobre la Arquitectura Moderna en el Ecuador es escasa y la que existe poco difundida. Hay abundante investigación sobre lo colonial, principalmente quiteño, que ha orientado la discusión sobre la arquitectura nacional desde finales del siglo XIX hasta el presente, sin embargo, es poco lo que se conoce sobre la Arquitectura Moderna del país. Algunos autores han considerado que el peso de la arquitectura colonial en los países andinos, como el Ecuador, impulsó el desarrollo de propuestas pintoresquistas, neovernaculares y neocoloniales antes que modernas, por lo que el racionalismo no llegó sino tardíamente, sin embargo, en Guayaquil, la Arquitectura Moderna surgió tempranamente a inicios de la década de 1930 a la par de países como Argentina, Brasil, Chile, Uruguay o México. Este proceso hay que entenderlo, primero, por las marcadas diferencias entre Guayaquil y Quito y, segundo, por la coyuntura de la crisis económica de finales de la década de 1920, cuando hubo necesidad de simplificar las formas, racionalizar el espacio y abaratar los costos de construcción.
\end{abstract}

Palabras clave: Modernidad - Arquitectura moderna - Arquitectura Neoclásica - Guayaquil - Racionalización.

[Resúmenes en inglés y portugués en las páginas 273-274]

${ }^{*}$ ) Doctor en Diseño por la Universidad de Palermo, Buenos Aires, Argentina (2017). Arquitecto, Universidad Católica de Santiago de Guayaquil, Ecuador.

\section{Introducción}

... somos modernos por el simple hecho de que vivimos en el presente. Nadie ha descubierto todavía el arte de vivir en el pasado, y ni siquiera los futuristas han descubierto el secreto de vivir en el futuro. Somos modernos, lo queramos o no (Borges, 2001, p. 142).

La historiografía sobre la arquitectura moderna en el Ecuador es escasa y la que existe poco difundida. Hay abundante investigación sobre el hecho colonial, principalmente quiteño, que en términos generales ha orientado la discusión sobre la arquitectura nacional desde finales del siglo XIX hasta el presente, con importantes trabajos de historiado- 
res como José Gabriel Navarro (1928), José María Vargas [(1949), (1956)], Alfonso Ortiz Crespo [(1982), (2004)], entre otros. Sin embargo son casi inexistentes las publicaciones en arte o arquitectura que se hayan editado en el país hasta bien entrado el siglo XX, baste conocer que no fue sino hasta 1977 cuando entró en circulación la revista Trama, primera publicación nacional especializada en temas de arquitectura y urbanismo, aunque existen algunos artículos aislados sobre temas de arquitectura y de problemas urbanos que fueron publicados en revistas universitarias de Guayaquil y Quito a partir de la década de 1940. Para muchos historiadores que han centrado su trabajo en Quito, la arquitectura y la investigación histórica urbana y arquitectónica del Ecuador surge y se agota en la capital, ya que consideran que lo que sucede en el resto del país es poco menos que marginal o puramente anecdótico.

Uno de los primeros análisis sobre la arquitectura del siglo XX en el Ecuador, realizado por el arquitecto quiteño José Gualberto Pérez, fue presentado en el Primer Congreso Panamericano de Arquitectos que se realizó en Montevideo en 1927. En ese breve artículo al que denominó Historia de la Arquitectura en la República del Ecuador, hacía un repaso sobre las características de la arquitectura del país desde el período aborigen hasta ese momento y le dedicaba casi la totalidad del texto a ejemplos coloniales y neoclásicos desarrollados en el primer tercio del siglo XX en la ciudad de Quito, mientras que Guayaquil merecía apenas unas pocas líneas.

El historiador quiteño Eduardo Kingman Garcés (1998) al hacer una revisión crítica sobre lo realizado en el campo de la investigación histórica urbana y arquitectónica del Ecuador, parte de la errada concepción de que esta debía estar al servicio de las actividades de restauración patrimonial de las edificaciones coloniales y desconoce los aportes que corresponden a períodos más recientes de la historia como los que a esa fecha ya se habían hecho desde Guayaquil.

Las primeras investigaciones sobre la Arquitectura Moderna de Guayaquil son tesis de grado universitarias desarrolladas en la Facultad de Arquitectura y Diseño de la Universidad Católica de Santiago de Guayaquil. La primera, Arquitectura Guayaquil 1930-1960 (Alcívar y otros, 1980) abarca el período entre 1930 y 1960 y la segunda, Los arquitectos, Movimiento Moderno. Guayaquil 1940-1970 (Mera y otros, 1991), con una mirada desde los protagonistas y las obras consideradas más relevantes de ese período. En ambas se parte de la comparación entre las propuestas locales con ejemplos paradigmáticos del período de estudio con algunos errores de datación y valoración.

En 1986 se creó el Programa de Investigación en Historia de la Arquitectura y la Ciudad (PROHA) en la Universidad Católica de Santiago de Guayaquil con el propósito de investigar sobre el patrimonio arquitectónico de la ciudad y sus características. El primer paso que desarrolló fue establecer la cantidad y ubicación de las edificaciones de valor patrimonial de la ciudad, lo que se realizó mediante el proyecto de Inventario de la arquitectura civil, pública y religiosa de Guayaquil, 1896- 1950 (Lee y otros, 1987) que culminó con el registro de cerca de setecientos edificios del área central. Posteriormente se realizó un segundo proyecto denominado Análisis y valoración de la arquitectura histórica de Guayaquil Siglo XIX-1950 (Lee, Compte y Peralta, 1988), con una interpretación del proceso de evolución de la ciudad y las características de su arquitectura patrimonial. Este trabajo dio como resultado la publicación de los libros Patrimonio arquitectónico y urbano de Gua- 
yaquil (Lee, Compte y Peralta, 1989), Testimonio y memoria de la arquitectura histórica de Guayaquil (Lee, Compte y Peralta, 1991) y Guayaquil: Lectura histórica de la ciudad (Lee y Compte, 1992).

En 1988 el Instituto Nacional de Patrimonio Cultural realizó su propio inventario de la arquitectura de valor patrimonial de la ciudad y estableció la existencia de ciento treinta edificaciones que reunían estas características, algunos de los cuales se incluyeron en la declaratoria de bien perteneciente al patrimonio histórico de la nación, realizada por el Ministerio de Educación y Cultura. Años más tarde, en el 2009, se amplió esta declaratoria al incluir edificaciones modernas del área central de la ciudad a partir del Estudio para la declaratoria patrimonial de la arquitectura del Siglo XX del área central de Guayaquil (Compte, 2009) y del Estudio para la declaratoria patrimonial de los barrios Orellana y del Salado de la ciudad de Guayaquil (Peralta, 2010), realizados por investigadores de la Facultad de Arquitectura y Diseño de la Universidad Católica de Santiago de Guayaquil. A finales de la década de 1980, la geógrafa francesa Marie Sophie Bock desarrolló una investigación sobre la arquitectura y el espacio urbano en el Ecuador, con el auspicio del Instituto Francés de Estudios Andinos. De este trabajo surgieron los libros Quito, Guayaquil: Identificación arquitectural y evolución socio-económica en el Ecuador (1850-1987) (1988) y Guayaquil. Arquitectura, espacio y sociedad, 1900-1940 (1992), en los que plantea una visión bastante descriptiva de la arquitectura de estas dos ciudades en su contexto espacial, geográfico y social.

En el año 2005 desde la Universidad Católica de Santiago de Guayaquil se desarrolló el proyecto Evaluación de bienes patrimoniales de la ciudad de Guayaquil, con el fin de establecer parámetros de evaluación y proponer políticas de protección y sustentabilidad de los inmuebles patrimoniales de la ciudad. En este estudio se analizaron y evaluaron noventa y cinco edificaciones de una lista proporcionada por la Municipalidad de Guayaquil y se propuso una metodología de valoración y clasificación de los edificios patrimoniales, acorde con las características históricas y tipológicas de la arquitectura de la ciudad.

En el año 2010 se realizó en la Facultad de Arquitectura y Diseño de la Universidad Católica de Santiago de Guayaquil el evento Reflexiones sobre Arquitectura Moderna, donde se presentaron una serie de ponencias sobre este período de la historia de la arquitectura del país principalmente en las ciudades de Quito, Guayaquil, Cuenca y Loja, que fueron recogidas en el número 28 de la revista AUC de esa universidad. En el caso específico de Guayaquil se publicó el artículo La Arquitectura Moderna en Guayaquil (Compte, 2010). Como se puede apreciar en este recorrido, la información e interpretación que se ha tenido sobre la arquitectura moderna de Guayaquil ha sido escasa y algunas veces errada. El propósito de esta investigación es precisamente superar esa carencia e ir llenando ese vacío historiográfico con el uso de nuevas herramientas metodológicas y analíticas que cuestionen las interpretaciones tradicionales.

La hipótesis de la investigación plantea que la Arquitectura Moderna en Guayaquil surgió tempranamente a inicios de la década de 1930 a la par de países como Argentina, Brasil, Chile, Uruguay o México. Este proceso hay que entenderlo, primero, por las marcadas diferencias entre Guayaquil y Quito o de otras ciudades de la sierra central ecuatoriana, donde el peso de lo colonial si retrasó el surgimiento de una arquitectura moderna hasta al menos la década de 1940; y, segundo, por la coyuntura de la crisis económica de finales 
de la década de 1920, cuando hubo necesidad de simplificar las formas, racionalizar el espacio y abaratar los costos de construcción.

A lo largo de su historia Quito y Guayaquil han sido ciudades con lógicas diferentes; la primera, una ciudad andina ubicada en un valle a 2800 metros de altitud, rodeada de montañas y con una alta población indígena; y, la otra, una ciudad portuaria y comercial, a nivel del mar, cercana a la costa del Pacífico y con una reducida población indígena, a la que se ha llamado "el último puerto del Caribe". Se le atribuye a Alexander Von Humboldt el llamar así a Guayaquil, aunque para el imaginario guayaquileño esta frase fue acuñada en la década de los cincuenta por el cantante rocolero puertorriqueño Daniel Santos.

A mediados del siglo XIX las dos principales ciudades del país, Guayaquil y Quito, eran percibidas de manera diferente: Guayaquil, como ciudad liberal, pujante y moderna, mientras Quito mantenía la imagen de ciudad tradicional y conservadora, anclada a su pasado colonial. Un hecho nos puede ayudar a ilustrar las diferencias marcadas en la manera de pensar de sus habitantes: en el año 1919 la obra El fauno y la bacante, que el escultor quiteño Luis Veloz había elaborado en Roma a pedido de la Municipalidad de Quito, fue instalada finalmente en Guayaquil, donde había arribado, debido al rechazo de los sectores conservadores quiteños. El propio Veloz declaraba que su intención había sido la de “... curar de espanto, con un desnudo radiante y voluptuoso de mujer, a la hipocresía y beatería de Quito" (Revista Caricatura, 22 de diciembre de 1918), sin embargo se impuso la visión mojigata de la burguesía y del clero de la capital.

A diferencia de Quito, en Guayaquil la representación de tipos y costumbres a través álbumes y estampas no se dio sino a partir de 1860, a través de fotografías y grabados realizados por extranjeros que llegaban a la ciudad. Alexandra Kennedy-Troya (2016) plantea que esa ausencia se habría debido a la definición de Guayaquil como sociedad moderna, por lo que se obvió “... cualquier tipo de representación que recordase o recogiese la tradición colonial, tan vigente aún en la región de Quito” (p. 135).

Pensadores ecuatorianos contemporáneos como Alfredo Espinoza Tamayo (1979 [1918]), Belisario Quevedo (1981 [1931]), Jorge Enrique Adoum (1997) o Miguel Donoso Pareja [(1998), (2006)] han puesto en evidencia las marcadas diferencias entre Quito y Guayaquil y, en general, entre las ciudades y el carácter de los pobladores de la región andina y la costa ecuatoriana. Espinosa Tamayo destacaba, por ejemplo, como “... las clases dirigentes de la Costa son de ideas más liberales y democráticas que las de la Sierra, más apegadas a los principios reaccionarios y tradicionalistas" (como ce cita en Donoso Pareja, 1998, p. 20), mientras para Quevedo el país era dual y esta ba conformado por dos tipos del pueblo ecuatoriano “... el costeño que habita en clima ardiente y por cuyas venas corre mucha sangre negra y el serrano del clima benigno que tiene cuatro quintos de sangre india, si acaso no es indio puro" (Como se cita en Donoso Pareja, 1998, p. 18). Donoso Pareja (2006) destaca como hacia el exterior el Ecuador es percibido como un país exclusivamente andino, cuando “... a partir de esa actitud excluyente, se dificulta el reconocimiento de una identidad procesual y dialógica que permitiría establecer una dinámica dentro de la diversidad, una identidad más rica y más real, más nosotros mismos” (p. 133).

Es curioso conocer, por ejemplo, que hasta el momento aún se conserven dos regímenes escolares entre costa y sierra, -el primero que va de mayo a enero y el segundo de octubre 
a junio- que fueron estructurados desde la Colonia en función de los ciclos de lluvia y de los períodos de siembra y cosecha.

El otro factor, de tipo coyuntural, es el económico. La crisis del Ecuador de la década de 1920, que se agudizó a partir de 1929, determinó que muchos de los incipientes procesos de modernización que se habían iniciado luego de la Revolución Liberal quedaran inconclusos y que se iniciara un período de deterioro de las condiciones sociales y de profunda inestabilidad política.

Dentro de este marco surgen algunas preguntas: ¿Es posible hablar de una arquitectura moderna en una sociedad considerada no moderna? ¿La idea tradicional de modernidad puede ser aplicada al desarrollo histórico del Ecuador desde finales del siglo XIX hasta la actualidad? ¿Se puede considerar a la Arquitectura Moderna como un marco bien delimitado de donde se deben excluir expresiones "atípicas" o periféricas? ¿El inicio de la Arquitectura Moderna de Guayaquil respondió a posiciones ideológicas progresistas o fue solamente asimilado como una renovación "estilística"?

Dos imágenes pueden caracterizar la presente investigación, la primera la del Palacio Municipal de Guayaquil inaugurado en 1929, que se constituyó en el último y más importante edificio neoclásico de la ciudad y la segunda, la de la casa Icaza Cornejo, diseñada en 1932 y construida un año después con patrones compositivos modernos. No solo llama la atención la separación de apenas tres años entre la una y la otra, además de la ornamentación de la primera -con capiteles corintios, cornisas, altorrelieves, estatuas clásicas, etc.- frente a la austeridad y limpieza formal de la segunda, sino, sobre todo, a que ambas fueron diseñadas por el mismo arquitecto, el italiano Simeone Francesco Maccaferri Colli.

¿Qué determinó que en un período tan corto de tiempo se dejara a un lado el neoclasicismo y se incorporara la modernidad en la arquitectura? Esta es la interrogante principal que alienta esta investigación.

Autores como Ramón Gutiérrez y Rodrigo Gutiérrez Viñuales (2012) han considerado que el peso de la arquitectura colonial en los países andinos como el Ecuador, Perú o Bolivia, impulsó el desarrollo de propuestas pintoresquistas, neovernaculares y neocoloniales antes que modernas, por lo que el racionalismo no llegó sino tardíamente.

En Guayaquil, sin embargo, al haber quedado destruida en su totalidad la arquitectura colonial por los incendios de 1896 y 1902, y ante la necesidad de evitar que nuevos flagelos afectaran lo que se iba edificando en la reconstrucción, el sistema constructivo tradicional en madera y caña guadúa fue sustituido rápidamente por el de hormigón armado (Ver Figura 1).

De este análisis preliminar surge una pregunta de investigación adicional vinculada al surgimiento de la arquitectura moderna en Guayaquil: ¿Por qué empezó a configurarse tempranamente la arquitectura moderna en Guayaquil en una sociedad con una incipiente modernización como la ecuatoriana de finales de la década de 1920? (Ver Figura 2) 


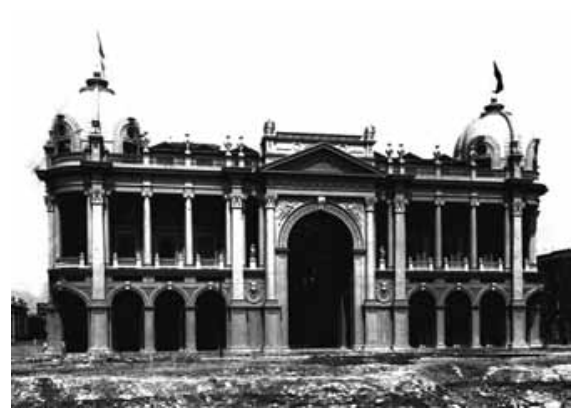

Figura 1.

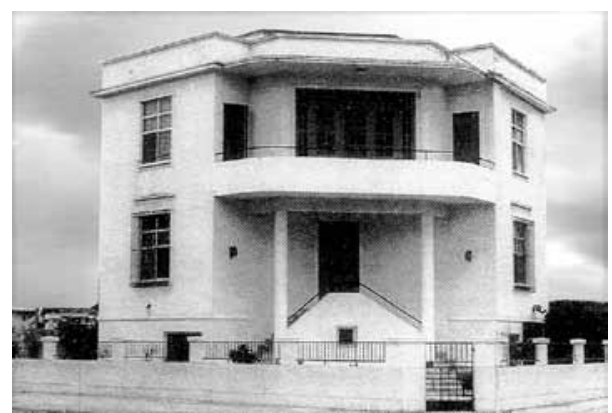

Figura 2.

Figura 1. Palacio Municipal de Guayaquil. Figura 2. Casa Icaza Cornejo. Arquitecto Francesco Maccaferri, 1932. Archivo Pablo Lee.

A lo largo de la tesis presentaremos las respuestas a estas preguntas que orientaron la investigación:

¿De qué manera se fue configurando el discurso moderno de la arquitectura de Guayaquil y cuáles fueron las relaciones con sus dimensiones social, cultural, política, económica, formal y técnica?

¿Cuáles fueron los procesos de modernización del país y de la ciudad de Guayaquil, desde la modernidad conservadora de finales del siglo XIX, la modernidad liberal de inicios del siglo XX hasta el desarrollismo de la década de 1950?

¿De qué manera la crisis mundial y local de la década de 1930 determinó cambios en lo espacial, técnico-constructivo y formal de la arquitectura?

¿De qué manera se reflejaron en la ciudad las ideas de modernidad?

¿Existió vinculación de los arquitectos del Guayaquil de la época con las vanguardias europeas y con la arquitectura moderna europea y latinoamericana?

De acuerdo a lo anterior se establece como objetivo principal de la investigación el analizar los factores que posibilitaron el temprano surgimiento del discurso moderno en la arquitectura de Guayaquil a inicios de la década de 1930. Adicionalmente, y como objetivos específicos, se establecen los siguientes:

a. Caracterizar los procesos de modernización del país y de la ciudad de Guayaquil, tanto urbanos como culturales, desde la modernidad conservadora de finales del siglo XIX, la modernidad liberal de inicios del siglo XX hasta el desarrollismo de la década de 1950.

b. Identificar los cambios tecnológicos más importantes en la arquitectura de Guayaquil, en cuanto a la incorporación de materiales de construcción, sistemas constructivos y formas de edificar, desde finales del siglo XIX hasta 1948. 
c. Analizar de qué manera la crisis mundial y local de la década de 1930 determinó cambios en lo funcional, técnico-constructivo y formal de la arquitectura.

d. Identificar los vínculos entre los arquitectos de Guayaquil con las vanguardias latinoamericanas y europeas en el período comprendido entre 1930 y 1948.

e. Establecer de qué manera se constituyó el campo disciplinar de la arquitectura en Guayaquil.

f. Analizar los cambios funcionales y formales en la arquitectura a partir de la modernidad.

La presente tesis está estructurada en cinco capítulos. En el primer capítulo, además de establecer la distinción entre modernidad, modernización y modernismo, se incorpora la visión sobre este tema desarrollada por el colectivo latinoamericano Modernidad/Colonialidad, quienes plantean que la modernidad europea no hubiera podido existir sin la explotación de las colonias, por lo que ambos conceptos son complementarios. Respecto a la Arquitectura Moderna se pasa de entenderla como "estilo" para abordarla como discurso, es decir como un conjunto de discusiones, debates, temas, problemas y preguntas, instituciones y argumentos, donde los proyectos, las obras, los manifiestos, las exposiciones, los libros, los artículos, etc., son constitutivos de ese discurso que se presenta a una comunidad de receptores para probar su validez. El análisis de la diferenciación y constitución del campo disciplinar se hace desde la teoría de los campos de Pierre Bourdieu y sus nociones de nomos, habitus e illusio, desde donde se aborda de qué manera se constituyó el campo disciplinar de la arquitectura en el Ecuador y en Guayaquil. Finalmente se hace un recorrido a través del surgimiento de la Arquitectura Moderna en algunos países latinoamericanos. En el segundo capítulo se aborda el proceso de desarrollo y modernización de la ciudad desde su fundación hasta finales de la década de 1940. Se incluyen como antecedentes los procesos modernizadores del siglo XIX y en el impacto que significó para el desarrollo de la ciudad el Gran Incendio del 5 y 6 de octubre de 1896 y los posteriores procesos de reconstrucción. Un punto destacado se refiere a las propuestas de la Junta Patriótica del Centenario, con miras a la celebración del Primer Centenario de Independencia de Guayaquil, que iban desde proyectos de sanidad pública hasta otros de estética urbana, además de un recorrido por las modificaciones urbanas que se emprendieron entre las décadas de 1930 y 1950.

En el tercer capítulo se establecen las dimensiones en las que se ha configurado el discurso moderno en la arquitectura de Guayaquil: social, política, económica y cultural. En lo social, los cambios en la vida cotidiana y los modos de habitar. En lo cultural, la relación de la arquitectura con las vanguardias artísticas y literarias y con su propia tradición. En lo político, las distintas ideas de modernidad que se han desarrollado en el Ecuador, desde la tradición conservadora de finales del siglo XIX hasta el desarrollismo de la década de 1950. En lo económico, con un recorrido desde el segundo boom cacaotero iniciado en 1880 hasta la crisis de las décadas de 1920 hasta 1940 y la recuperación con el boom bananero en los cincuenta. Se pone de relieve la figura del arquitecto Rafael Rivas Nevárez, precursor del diseño moderno a través de sus caricaturas, la ilustración de portadas de revistas y el diseño de juguetes.

El cuarto capítulo describe los cambios tecnológicos de la arquitectura y en la manera de edificar, a través del análisis de la incorporación de nuevos materiales de construcción, 
como el hormigón armado, los cambios en los procesos constructivos y del paso de una construcción artesanal a otra más tecnificada desarrollada por compañías constructoras, tanto extranjeras como locales. Se incluye el análisis de las organizaciones corporativas en la constitución del campo, desde las asociaciones de carpinteros hasta las organizaciones gremiales de arquitectos.

Finalmente, en el quinto capítulo se aborda la dimensión formal de la Arquitectura Moderna de Guayaquil. La participación de ecuatorianos en diferentes congresos de arquitectura latinoamericanos resulta fundamental para el conocimiento de la incorporación de los arquitectos y su arquitectura en los ámbitos académicos y profesionales del continente. Se aborda la constitución del campo de la arquitectura y de la profesión de arquitecto en Guayaquil, desde lo disciplinar, lo historiográfico y lo pedagógico-didáctico, a partir de las prácticas diferenciadoras, desde los carpinteros de ribera hasta la autonomía del campo y el desarrollo del habitus vinculado a la formación académica a partir de la Escuela de Artes y Oficios de la Sociedad Filantrópica del Guayas hasta la primera Escuela de Arquitectura en 1929. Las transformaciones espaciales y formales en la arquitectura de la época, tanto en la vivienda, individual y colectiva pública como privada, como en los edificios públicos. Resulta fundamental el análisis de la figura del arquitecto italiano Francesco Maccaferri, considerado pionero en el desarrollo de la Arquitectura Moderna del país. El surgimiento de las variables neocoloniales y el art Déco y, por último, la consolidación del discurso moderno a finales de la década de 1940.

Respecto al enfoque metodológico, algunos investigadores latinoamericanos en historia de la arquitectura como Margarita Gutman (1985), Silvia Arango (2012), Horacio Torrent (2012), entre otros, analizan los paradigmas que han orientado la historiografía de la Arquitectura Moderna en el sur de nuestro continente y defienden la necesidad del abordaje histórico desde sólidas bases metodológicas.

Arango (2012) plantea tres posibles abordajes sobre la historia de la arquitectura que desde este lado del continente es posible tener: el criterio de estilo o influencia, el criterio de alteridad o identidad y el criterio desde las generaciones de arquitectos. El primer criterio, desde un abordaje claramente positivista, es el más frecuente y presupone que el proceso de la arquitectura latinoamericana es similar al de la arquitectura europea, en el que se van dando, de manera secuencial, diferentes "estilos" caracterizados por sistemas de organización formal que se renuevan de manera lineal y lógica, liderados por un maestro creador. El segundo criterio plantea el análisis desde la dualidad tradición/vanguardia, donde subyace la búsqueda de identidad y sitúa a la arquitectura desde las intenciones del proyecto y su contexto político y social, destacando los proyectos excelsos. El tercer criterio sitúa al análisis histórico en la sucesión generacional de los arquitectos más que en su producción edilicia, por tanto la periodización se hace en el hecho de la pertenencia a una generación determinada de arquitectos. Concluye Arango en que estas tres interpretaciones no son las únicas posibles y que cada una de ellas posee una lógica interna que las vuelve coherentes y que tratan de ir superando los aspectos que las precedentes no lo hicieron.

En el presente problema de investigación el abordaje será tanto histórico como historiográfico, desde la distinción que establece Marina Waisman (1990), esto es, histórico en tanto atañe a la existencia misma del hecho histórico que se resuelve por medio de la investigación y donde la “... operación crítica se ejerce para asegurar la exactitud de los 
datos y su pertinencia" (p. 15) y es historiográfico en la medida en que atañe a la interpretación o caracterización del hecho histórico, que contienen un sentido crítico, y que compromete la ideología del historiador, pues hacen referencia “... a la selección de su objeto de estudio y de sus instrumentos críticos, a la definición de la estructura del texto historiográfico, a todo aquello, en fin, que le conducirá a la interpretación del significado de los hechos" (p. 15).

Para el abordaje histórico se identifican como objeto de estudio y fuentes primarias de la investigación al conjunto de edificios que pertenecen al período establecido, los cuales, pueden ser leídos como un texto cultural con un significado simbólico socio-histórico. El análisis toma como punto de partida el Inventario de la arquitectura civil, pública y religiosa de Guayaquil, siglo XIX-1950 (Lee, Compte, Palacios y Esparza, 1987) realizado entre los años 1986 y 1987, así como el Estudio para la declaratoria patrimonial de la arquitectura del siglo XX del área central de Guayaquil (Compte, 2009).

El abordaje historiográfico parte de la constatación del limitado desarrollo de la crítica y la escasa bibliografía sobre historia de la arquitectura que hay en el Ecuador. Conlleva también una complejidad mayor, ya que se ponen en cuestionamiento dos paradigmas: el primero de que la modernidad es desde una visión eurocéntrica, una continuidad orientada hacia el progreso que va desde la antigüedad clásica hasta nuestros días y que en América Latina se habría manifestado en un desarrollo tardío, reflejo de ese pensamiento irradiado desde la centralidad europea. El segundo paradigma en cuestionamiento es el de que la arquitectura moderna es un estilo, un marco con características formales claramente definidas y reproducibles en cualquier contexto geográfico o político, dentro del que las "anomalías" no tendrían cabida, tal como indica Sarah Williams Goldhagen (2008):

El estilo es de poca utilidad para el analista que busca desenterrar unas intenciones socio-éticas que se formulan a partir de convicciones heredadas acerca de las posibilidades y la naturaleza de la arquitectura -su papel social, su valor como herramienta política, su potencial como forma de conocimiento artístico y su potencial para la transformación personal-. Como tal, cualquier intención se puede discernir y entender sólo en el contexto en el cual se formó, a través de analizar la noción del arquitecto sobre qué significa hacer arquitectura en el mundo de la política, la sociedad, la economía, y la cultural (p. 28).

El abordaje metodológico parte de la superación de esos dos paradigmas.

Respecto al primer paradigma, esto es sobre la modernidad, se toma como punto de partida la distinción que Marshall Berman (2004) realiza entre modernización, modernismo y modernidad, donde modernización hace referencia a las transformaciones que definen a la vida moderna (proceso socio-económico), modernismo a las visiones de transformación del mundo (cuerpo de tendencias y movimientos que abrazan la modernidad) y modernidad a las maneras de experimentar la tensión dialéctica entre los dos conceptos anteriores (la condición de la vida). Adicionalmente se incorpora la visión sobre modernidad desarrollada por el colectivo latinoamericano Modernidad/Colonialidad, donde se plantea que ambas son visiones complementarias y que la modernidad europea no hubiera podido existir sin la explotación de las colonias, cuestionando, adicionalmente, 
las visiones que posicionan a América Latina como subsidiaria de un modernidad "otra", "incompleta", "apropiada" o "periférica".

Sobre el segundo paradigma, es decir sobre la Arquitectura Moderna, se pasa de entender a ésta como "estilo", para abordarla como un discurso, donde los proyectos, las obras, los manifiestos, las exposiciones, los libros, los artículos, etc., serían constitutivos de ese discurso que se presenta a una comunidad de receptores para probar su validez.

Si bien el considerar a la Arquitectura Moderna como un discurso superaría la periodización tradicional de la arquitectura del siglo XX, no es menos cierto que tal como lo propone el historiador ecuatoriano Enrique Ayala Mora (2014), "Una condición fundamental para escribir historia es contar con una división del tiempo, es decir, con una periodización" (p. 26).

Agustín Cueva (1997) plantea que la periodización de la historia debe partir de la comprensión de la sociedad en los siguientes términos:

Primero, como una sociedad articulada, es decir, como una estructura compleja en la cual cada elemento que la conforma no puede ser estudiado aisladamente, sino con relación a un todo que le confiere sentido.

Segundo, como una estructura jerarquizada, en la que hay un sistema regulado de determinaciones y predominios que confieren un diferente estatuto teórico a cada elemento o nivel.

Tercero, como una estructura dinámica, o sea, en perpetuo movimiento, lo cual pone de relieve la compleja cuestión de la relación entre estructura y procesos. Cuarto, como una estructura contradictoria, movida precisamente por el desarrollo de un conjunto siempre articulado, pero a la vez dinámico, de contradicciones (p. 202).

Aunque este análisis se hace en relación a la literatura, es perfectamente aplicable a la reflexión sobre la periodización en la arquitectura, entendiendo que esta es un fenómeno cultural que se da como respuesta tanto a necesidades individuales como colectivas y que se convierte en expresión y reflejo del transcurrir de una sociedad determinada. John B. Thompson lo explica de la siguiente manera:

... las formas simbólicas están arraigadas en contextos sociales estructurados que implican relaciones de poder, formas de conflicto, desigualdades en términos de la distribución de recursos y así sucesivamente (...) En este sentido, los fenómenos culturales pueden considerarse como formas simbólicas en contextos estructurados y el análisis cultural puede concebirse como el estudio de la constitución significativa y la contextualización social de las formas simbólicas (Thompson, 2002, p. 24).

Para Thompson las formas simbólicas son “...fenómenos significativos que a la vez son producidos y recibidos por individuos situados en contextos específicos" (2002, p. 25). Es así como cualquier periodización de la arquitectura debe considerarla como un fenómeno tanto urbano como social, como una expresión cultural y económica, así como un refe- 
rente histórico, aunque siempre “... cualquier fecha que se señala como comienzo o fin de un período será un mero punto de referencia, muy aproximativo, que nada quitará ni añadirá al contenido de la periodización" (Cueva, 1997, p. 209).

El horizonte temporal de esta investigación se inicia en 1930 y abarca hasta 1948, período al que el historiador Enrique Ayala Mora (2014) denomina de la crisis, inestabilidad e irrupción de las masas y al que describe “... bajo el signo de la recesión económica prolongada, una incipiente industrialización, la irrupción de las masas en la escena política y la creciente influencia del socialismo en la crítica ideológica y la cultura" (p. 134).

Respecto a las fuentes, uno de los problemas al que todo investigador de la historia de Guayaquil se enfrenta es la escasa información primaria disponible, tanto documental como de planos y mapas históricos, debido a la destrucción de archivos originada por catástrofes de diferentes índole que asolaron a la ciudad a lo largo de sus años de existencia. La fuente primaria fundamental la constituye la obra construida como el primer lugar del que extraer conocimiento. En los casos en que esto no ha sido posible se deberá sustituir la experiencia directa por los registros de los archivos profesionales de cada arquitecto, además de entrevistas realizadas a colaboradores y familiares del autor. Las actas del cabildo colonial, las crónicas y relatos de viajeros y piratas, las leyes y ordenanzas, los estudios e informes de autoridades de la época, los poemas y cantos, los mapas, los dibujos, grabados y fotografías, se constituyen no solo en el reflejo de cómo se veía a la ciudad a los largo de los siglos, sino también constituyen las fuentes de donde partirá la interpretación de su historia.

Adicionalmente se ha recurrido a materiales que revisan e interpretan las fuentes primarias, recogidos en libros y revistas realizados en el momento y con posterioridad al periodo de estudio, así como los trabajos de investigación y artículos sobre el tema. Las fotografías se constituyen también en documentos de gran valor para conocer la obra en su estado original, ya que muchas de las obras del período de estudio han sido gravemente transformadas, perdiendo parte de sus valores arquitectónicos iniciales.

\section{Capítulo 1. El discurso moderno y el campo disciplinar: la arquitectura}

La hipótesis más reiterada en la literatura sobre la modernidad latinoamericana puede resumirse así: hemos tenido un modernismo exuberante con una modernización deficiente (García Canclini, 2001, p. 65).

En el presente capítulo, además de establecer la distinción que el filósofo estadounidense Marshall Berman (2004) realiza entre modernización, modernismo y modernidad, se incorpora la visión que sobre este tema ha desarrollado el colectivo latinoamericano Modernidad/Colonialidad, quienes plantean que ambas son visiones complementarias, ya que la modernidad europea no hubiera podido existir sin la explotación de las colonias.

Respecto a la Arquitectura Moderna se pasa de entenderla como un estilo para abordarla como discurso. Se incluye una mirada sobre el surgimiento y desarrollo de la Arquitectura Moderna en algunos países latinoamericanos, en general, y en Ecuador, en particular, a partir de los edificios que significaron un punto de quiebre en el paso de una arquitectura academicista o ecléctica a otra racionalista. 
El análisis de la diferenciación y constitución del campo disciplinar de la arquitectura se hará desde la teoría de los campos que desarrolló el sociólogo Pierre Bourdieu, según las nociones de nomos -los principios de división y reglas de pertenencia a un campo-, habitus -los principios generadores de prácticas distintivas-e illusio -la adhesión no consciente de los actores al conjunto de reglas, polémicas y relaciones de fuerza en el juego del campo-, entendiendo que en el campo se establecen un conjunto de relaciones entre quienes desarrollan actividades semejantes de acuerdo a ciertas reglas.

\subsection{Una distinción necesaria: lo moderno, la modernidad, la modernización y el modernismo}

¿Qué ocurría en aquellas áreas fuera de Occidente donde, a pesar de las permanentes presiones del mercado mundial en expansión, y a pesar de una cultura moderna mundial que se desarrollaba junto con este "patrimonio común" de la humanidad moderna -como decía Marx en el Manifiesto Comunista- no se produjo la modernización? Es evidente que los significados de la modernidad tendrían que ser más complejos, escurridizos y paradójicos (Berman, 2004, p. 175).

Recién en el año 1734 la lengua española acoge oficialmente la palabra moderno, al incorporarla al Diccionario de la Lengua Castellana, comúnmente llamado Diccionario de Autoridades, donde se define a lo moderno como "Lo que es o sucede de poco tiempo a esta parte" (Tomo IV). Poco ha cambiado el diccionario actual para el que el término moderno significa "1. Perteneciente o relativo al tiempo de quien habla o a una época reciente. 2. Contrapuesto a lo antiguo o a lo clásico y establecido" (Diccionario de la Real Academia Española). Según el Breve diccionario etimológico de la lengua castellana, la palabra latina modernus "... es un derivado de modo, "hace un momento, ahora mismo"” (Corominas, 1961, p. 398).

Se piensa que el término latino modernus habría sido usado por primera vez a finales del siglo $\mathrm{V}$, en lugar del hasta ese momento más frecuente novus, para distinguir la transición del pasado pagano del romano al cristianismo como religión oficial y obligatoria del Imperio. En general cuando nos referimos a lo moderno estamos pensando en algo actual o reciente, de vanguardia, innovador, contrario a la tradición o adecuado al gusto y a las necesidades del momento.

Para el filósofo Jürgen Habermas, lo moderno expresa la conciencia de una época “... que se mira a sí misma en relación con el pasado, considerándose resultado de una transición desde lo viejo hacia lo nuevo" (1989, p. 131). Habermas, quien vincula la idea de lo moderno con la vanguardia, es decir, con lo avanzado de una época y con el mirar hacia adelante, indica que la vanguardia “... se ve a sí misma invadiendo territorios desconocidos, exponiéndose al peligro de encuentros inesperados, conquistando un futuro, trazando huellas en un paisaje que todavía nadie ha pisado" (1989, p. 133).

Si es poca la claridad respecto al término moderno, la es aún menos cuando el mismo Diccionario de la Real Academia Española describe a la modernidad como "cualidad de lo moderno". 
Hilde Heynen (2015) plantea que se puede establecer una distinción entre los diferentes conceptos de modernidad. Por un lado, están los defensores de un concepto programático que interpreta a la modernidad como un proyecto de progreso y emancipación que distingue a la época actual de la que la precedió y, por otro lado, quienes ven a la modernidad como algo transitorio y no como un proyecto, sino más bien como una moda.

Un defensor de la primera aproximación es Habermas en lo que él llama el proyecto incompleto de la modernidad, al que caracteriza por su autonomía en los ámbitos de la ciencia, el arte y la moral. En contraste con esta visión programática, otros autores como el francés Jean Baudillard sostienen que la modernidad establece el cambio y la crisis como valores, pero que estos valores pierden cada su relación inmediata con cualquier perspectiva progresista, por lo que la modernidad empieza a huir de sí misma y sienta las bases de su propia caída, dando paso a una condición posmoderna.

Marshall Berman (2004), por su parte, establece también una clara distinción entre la idea de modernidad, a la que relaciona con la condición de la vida, la modernización, vinculada con el proceso socio-económico, y el modernismo, al que define como el cuerpo de tendencias y movimientos que abrazan la modernidad.

Para el argentino Nicolás Casullo (1993) la modernidad, en tanto construcción de la historia, centra al sujeto como conductor de los procesos de cambio y de los conflictos que estos generaron. Casullo describe a la modernidad como un mundo de representaciones que desde la razón ordenadora

... refundó valores, saberes y certezas. Estableció paradigmas para la acción y la reflexión, para la crítica y la utopía. Fijó identidades para la multiplicidad de lo real, denominadores comunes para el acceso al conocimiento y códigos de alcance universal para interrogarse sobre las cosas y los fenómenos (p. 18).

Si la modernidad se asume como representativa de lo nuevo, lo innovador y la audacia -que supone una ruptura con el pasado y con la tradición- y como un “... proceso interminable de rupturas y fragmentaciones internas" (Harvey, 1990, p. 26), queda menos claro el poder encontrar una descripción de la modernidad que aborde la complejidad de todas sus dimensiones, por lo que se sugiere analizarla “... simultáneamente como época, estructura institucional, experiencia vital y discurso” (Altamirano, 2002, p. 174).

$\mathrm{El}$ análisis de la modernidad como época supone encarar el primer problema: determinar desde cuándo empieza y hasta cuándo termina. Para la mayoría de los autores que han abordado el inicio de la modernidad, este se liga a diferentes sucesos históricos que se dieron en el antiguo continente, como “... la Reforma protestante, la Ilustración, la Revolución Francesa, la Revolución Industrial o el modernismo estético”, por lo que “... su comienzo se fechará, respectivamente, a comienzos del siglo XVI, durante el siglo XVII, a fines del siglo XVIII, a caballo entre éste y el siguiente o al iniciarse el siglo XX, con la década cubista" (Altamirano, 2002, p. 174).

El sociólogo polaco Zygmunt Bauman (2008) fijaba de manera arbitraria el origen de la modernidad en el terremoto de Lisboa de 1755, al que siguió un incendio y un tsunami que destruyeron la ciudad, que fue una catástrofe tanto material como intelectual, ya que significó percatarse que hay una naturaleza hostil a la especie humana sobre la que era 
posible confiar y que había la necesidad de crear un nuevo orden bajo los principios de la racionalidad y un nuevo mundo bajo la administración humana. Como explica Bauman, era necesario crear un mundo moderno y sólido que durara para siempre.

Para un conjunto de pensadores latinoamericanos agrupados en el colectivo Modernidad/ Colonialidad, la modernidad, tanto en lo ideológico como en lo económico, se inicia con el descubrimiento de América. En lo ideológico, cuando a partir del Descubrimiento se “... produce un brutal cambio de sentido en el imaginario europeo y un transporte de la (... 'edad dorada' desde el pasado hacia el futuro" (Ubidia, 1998, p. 59) y en lo económico porque la producción “... principalmente metalífera de América, estuvo en la base de la acumulación originaria del capital (...) fundamento material de la producción de la modernidad europea" (Quijano, 1988, p. 11).

El filósofo peruano Aníbal Quijano (2014), miembro de dicho colectivo, plantea que la globalización es la culminación de un proceso que se inició “... con la constitución de América y la del capitalismo colonial/moderno y eurocentrado como un nuevo patrón de poder mundial" (p. 777) que se habría sustentado en la clasificación social de la población de la época sobre la idea de raza que, a partir de diferencias fenotípicas entre los conquistadores y los conquistados -que luego pasarían a ser sustituidas como expresiones físicas de estructuras biológicas diferenciales-, habría dado lugar a “... identidades sociales históricamente nuevas: indios, negros y mestizos” (p. 778) que sustentó la supuesta legitimidad de la dominación europea.

Estos autores agregan que la modernidad, en tanto narrativa europea, ha invisibilizado su lado más oscuro y violento: la colonialidad. Para Walter Mignolo la modernidad surge directamente por el contacto europeo con los pueblos americanos que devino en la emergencia y expansión del circuito comercial del Atlántico y “... la incorporación de lo que será América Latina al mundo dominado por Europa. Es decir, el proceso de producción de la modernidad tiene una relación directa y entrañable con la constitución histórica de América Latina” (Quijano, 1988, p. 11).

Esta idea de la modernidad como “... pretensión eurocéntrica de ser la exclusiva productora y protagonista de la modernidad" (Quijano, 2014, p. 792) implicaría que, en tanto impuesta en nuestro continente, su implantación fue tardía e incompleta. Como lo afirma García Canclini (2001): "Los desajustes entre modernismo y modernización son útiles a las clases dominantes para preservar su hegemonía, y a veces no tener que preocuparse por justificarla, para ser simplemente clases dominantes" (pp. 82-83).

Cabría preguntarse si esta afirmación respecto a la cultura visual tiene alcance también a la arquitectura, al considerar que en esta se desarrollan propuestas modernas asimiladas por estas mismas clases dominantes como expresiones epidérmicas o de "renovaciones estilísticas" que no implicaron necesariamente debates teóricos, al menos en algunos países, ni que fueron resultado de posiciones ideológicas progresistas.

Estas concepciones sobre la modernidad en nuestro continente han llevado a posiciones extremas, como aquellas que plantean que en Latinoamérica esta se dio como simulacro y que, por tanto, no puede haber una verdadera modernidad puesto que le faltarían “... los antecedentes intelectuales y las instituciones que le dieron origen en Europa" (Altamirano, 2002, p. 177). De esta manera lo explica José Joaquín Brunner (1989): 
Todavía en 1950, las tasas de analfabetismo alcanzaban en algunos países a más de la mitad de la población de 15 años y más (Brasil, Perú) o se situaban entre un tercio y la mitad de esa población (Colombia, México, Ecuador). Ese mismo año, la tasa bruta de escolarización primaria alcanzaba en la región apenas al 47,9 por ciento, la de educación media a 6,9 por ciento y la universitaria a 1,9 por ciento. La incorporación de la modernidad se ha presentado pues en la cultura de América Latina como un fenómeno tardío que, para la gran mayoría de los países, recién despliega con posterioridad a 1950, combinando los siguientes elementos:

- Escolarización básica extendida pero de pobre calidad,

- Escolarización media selectiva de orientación mesocrática,

- Masificación abrupta de la enseñanza terciaria en función de la distribución de certificados educativos,

- Acceso correlativo y masivo a la televisión, especialmente después de 1970. (http://www.quadernsdigitals.net/datos_web/articles/telos/telos19/t19medios modernidad.htm)

Sin embargo el propio Brunner u otros como García Canclini o Richard Morse, consideran que estos autores, “... lejos de alentar la búsqueda de lo genuino, lo único, asumen la mixtura, diferenciación y heterogeneidad que constituye la lógica interna de la ciudad y la complejidad de los procesos por los cuales transita la modernidad" (Cicutti, 2007, p. 37). En el otro extremo están quienes sostienen que desde la periferia se dialoga con el centro que se apropia de esa modernidad “... ya sea con imaginación, con irreverencia”, a través de la imitación o “... mediante adaptación o la adopción receptiva; sin meramente imitarlos o simularlos sino en comunicación directa con ellos” (Brunner, 2001, p. 177). Entre ambas visiones se plantean otras intermedias, unas más cercanas al simulacro como el Macondismo y el Marianismo y otras que vislumbran una modernidad aún inconclusa y en proceso de construcción. El Macondismo trata de entender América Latina desde lo mágico-real o misterioso. Por su parte, el Marianismo interpreta al sur de nuestro continente a partir de su sincretismo religioso y fundamentalmente del culto mariano.

Esta visión de la modernidad que se irradia desde la centralidad europea hacia el resto del mundo, da pie a pensar en proyectos tardíos, incompletos o fallidos que se irían resolviendo a medida que se vayan superando esas diferencias con el modelo de referencia. Tal como lo explica Mary Louise Pratt (2000):

A nivel empírico, las descripciones de la modernidad producidas en base al contexto europeo sencillamente no corresponden a las realidades modernas de otras partes del mundo. Dentro de la conceptualización ortodoxa de la modernidad, estas faltas de correspondencia tienen una explicación obvia: el atraso. Dado que la modernidad se difunde desde su centro europeo, es inevitable, se supone, que sólo llegue poco a poco al resto del mundo. (p. 832)

En esa misma línea de que la modernidad europea no es la única, ni necesariamente la mejor, Shmuel Eisenstadt plantea el concepto de modernidades múltiples. Explica cómo 
la modernidad que se originó en Europa, al expandirse al resto del mundo adquirió características distintivas, resultantes de su forma de respuesta a sus propias dinámicas, de manera que la historia de la modernidad puede ser vista “... como la historia de continuos desarrollos, formación, constitución y reconstitución de una multiplicidad de programas culturales, institucionales y de diferentes concepciones de las sociedades como modernidades múltiples" (Reigadas, 2012, p. 22).

Si hay disparidad respecto al inicio de la modernidad, la hay también respecto a su final. Se plantea que un conjunto de fenómenos desarrollados en el siglo XX caracterizarían dicho fin, como

... la emergencia de la sociedad posindustrial, la revolución informática, el desplome del socialismo burocrático, la globalización de los mercados y la pérdida de crédito $-y$ consiguiente incredulidad-frente a las metanarraciones o grandes relatos que sirven de eje discursivo a la modernidad (Altamirano, 2002, p. 174).

Hay, sin embargo, una conciencia más o menos clara de lo que es la modernidad como experiencia que se mueve en el campo de lo sensorial, de lo vital o de lo social, cuando se van incorporando ideas y valores como la ruptura con el pasado, la fluidez, la eficiencia, la velocidad, la higiene, el confort, la libertad, la participación democrática, la razón, la laicidad, la escolaridad general, los desplazamientos libres o el desarrollo. Esta experiencia está dada porque "... la sociedad moderna desarrolla una aguda conciencia sobre sí misma" (Altamirano, 2002, p. 174), tal como magistralmente lo describió Marshall Berman (2004) en su ya célebre reflexión sobre la modernidad:

Hay una forma de la experiencia vital -la experiencia del tiempo y el espacio, de uno mismo y de los demás, de las posibilidades y los peligros de la vida-que comparten hoy los hombres y mujeres de todo el mundo de hoy. Llamaré a este conjunto de experiencia la "modernidad". Ser modernos es encontrarnos en un entorno que nos promete aventuras, poder, alegría, crecimiento, transformación de nosotros y del mundo y, al mismo tiempo, amenaza con destruir todo lo que tenemos, todo lo que sabemos, todo lo que somos. Los entornos y las experiencias modernos atraviesan todas las fronteras de la geografía y las etnias, de la clase y la nacionalidad, de la religión y la ideología; se puede decir que en este sentido, la modernidad une a toda la humanidad. Pero es una unidad paradójica, la unidad de la desunión; nos arroja a todos en una vorágine de perpetua desintegración y renovación, de lucha y contradicción, de ambigüedad y angustia. Ser modernos es formar parte de un universo en el que, como dijo Marx, 'todo lo sólido se desvanece en el aire'. (p. 1)

Por otro lado, la modernidad como experiencia se afianza también en la idea de que el desarrollo de la ciencia y principalmente de la tecnología, determinan que haya “... una acelerada acumulación y uso del conocimiento en todas las esferas de la actividad humana especializada" por lo que con la modernidad “... el mundo se vuelve intensamente autorreflexivo y sujeto a conocimiento" (Altamirano, 2002, p. 174). 
Como estructura institucional, la modernidad se liga a su expresión práctica, es decir a la modernización, considerada como un proceso complejo que, según Samuel Huntington, incluiría, al menos, “... la industrialización, la urbanización, la movilidad social, la diferenciación, la secularización, la expansión de los medios de comunicación” y la modernización política, expresada en la racionalización de la autoridad, la diferenciación de las estructuras políticas y la participación de las masas. Se advierte, sin embargo, que este conjunto de características son insuficientes para identificar “. .. los dispositivos que operan concreta y vitalmente como soportes de transmisión y difusión de la modernidad", por lo que cabría agregar otros elementos tan dispares como

... nuevos cánones del gusto, estilos de sociabilidad y visiones de la naturaleza humana, el desarrollo de los espacios culturales urbanos -como cafés, tabernas, sociedades eruditas, salones, clubes de debate, asambleas, teatros, galerías y salas de concierto-, el establecimiento de hospitales, prisiones, escuelas y fábricas, la difusión del períodico y la aceleración de las comunicaciones, el comportamientio de los consumidores y el marketing de nuevos productos y servicios culturales (Altamirano, 2002, p. 175).

Si bien en muchos casos se asume la modernización como sinónimo de occidentalización, para otros como Huntington, son dos conceptos distintos, ya que si bien hay procesos de modernización en muchas partes del mundo, no implican, necesariamente, procesos de occidentalización. Esta occidentalización estaría constituida por un conjunto de valores e instituciones, como:

1. El legado de la cultura clásica. 2. El Cristianismo occidental. 3. Las lenguas europeas. 4. La separación entre la autoridad temporal y la espiritual. 5. El Estado de Derecho. 6. El pluralismo social y la sociedad civil. 7. Los órganos representativos. 8. El individualismo (García Jurado, 2003, p. 24),

que son rasgos que en su totalidad o parcialmente también los poseen otras civilizaciones no occidentales.

Los procesos de modernización están íntimamente ligados a lo urbano. Es en las ciudades donde se expresa la idea de "civilización", en oposición al mundo rural, centro de la "barbarie". En la ciudad se materializan las políticas modernizadoras, desde las ideas de ornato y progreso conservadoras y liberales de finales del siglo XIX e inicios del siglo XX, el desarrollismo de finales de los sesenta, hasta los modelos de planificación contemporáneas, porque tal como afirma el argentino Adrián Gorelik (1999): "Debatir lo moderno en América Latina es debatir la ciudad" (p. 13).

Algunos de esos modelos de modernización urbana que fueron adoptados y replicados en América, tomaron como referencia el plan del barón Georges-Eugène Haussmann para París, que superpuso una ciudad neoclásica a costa de la destrucción del enclave medieval. El modelo haussmaniano sirvió de modelo para reformas urbanas similares expresadas en propuestas estéticas e higienistas de ensanches, apertura de boulevares y paseos que desembocaban en monumentos conmemorativos a la independencia y sus héroes, que en 
algunos casos significó la eliminación de edificios coloniales y de núcleos históricos, porque, como indica Harvey (1990), la modernización implica también destruir para volver a construir: "La imagen de "destrucción creadora" es muy importante para comprender la modernidad, justamente porque proviene de los dilemas prácticos que enfrentó la implementación del proyecto modernista" (p. 31).

También se liga la idea de modernización a diferentes procesos de adecuación del Estado a ese mundo cambiante, tal como lo define el ecuatoriano Rodrigo Borja (1997) en la Enciclopedia de la Política:

... la modernización es el perfeccionamiento y la racionalización de sus sistemas administrativos, la tecnificación de las funciones de legislar y administrar justicia, el adelanto científico y tecnológico, la formación de recursos humanos calificados, el desarrollo administrativo, la profundización de la democracia hacia las zonas económicas y sociales, el aumento de la productividad en las faenas económicas, el mejoramiento de los regímenes de distribución del ingreso, la integración de los sectores atrasados de la economía a la dinámica de los centros avanzados, el impulso a la industrialización, el crecimiento del sector terciario de la economía, la creación de infraestructuras de transporte y comunicaciones y otros avances en esta línea de pensamiento (p. 652).

El tercer concepto en juego es el modernismo. Berman (2004) lo define como las visiones de transformación del mundo, es decir como el conjunto de tendencias y movimientos que abrazan la modernidad como ruptura de lo clásico y como propuestas de vanguardia, que se expresan estéticamente en la literatura, el arte, la música, la danza, las artes gráficas, el diseño o la arquitectura.

En el caso específico de la arquitectura ha prevalecido el uso de Arquitectura Moderna en lugar de Modernismo, al asociarse este último a la arquitectura desarrollada entre finales del siglo XIX y comienzos del siglo XX en Cataluña, vinculada a otras expresiones europeas similares como el art nouveau, la Secesión vienesa, el Jugendstil, el Arts and Crafts o el Liberty, aunque algunos autores como Goldhagen prefieren utilizar el término modernista a fin de asociarlo con los movimientos análogos de otras disciplinas y al poder reafirmar de esta manera “... la historicidad del movimiento" (Goldhagen, 2008, p. 15).

De alguna manera la Arquitectura Moderna se podría ubicar entre la modernización y el modernismo al poderse expresar tanto como discurso modernizador -“... entendido como los discursos sociales que dan origen a ese torbellino de transformaciones que definen la vida moderna" (Mondragón, 2010, p. 29) - y como discurso modernista, es decir desde las expresiones culturales que son al mismo tiempo resultado y motor de transformación de ese mundo cambiante.

\subsection{De la concepción de estilo a la idea de discurso en la Arquitectura Moderna}

En 1977 Charles Jencks (1984 [1977]) determinó que la defunción de la Arquitectura Moderna había sucedido aproximadamente a las 3:32 de la tarde del 15 de julio de 1972 en la 
ciudad de St. Louis en el estado norteamericano de Misoouri, luego de caer dinamitados varios bloques del conjunto de edificios de departamentos Pruitt-Igoe que habían sido diseñados por el arquitecto japonés Minoru Yamasaki veinte años antes. Estos edificios que en su momento habían sido elogiados por seguir fielmente los principios de los CIAM (Congreso Internacional de Arquitectura Moderna) y que habían sido premiados por el Instituto Norteamericano de Arquitectos, habían sido condenados a su destrucción al haberse comprobado que tenían un índice de criminalidad superior al de otras urbanizaciones, además de que eran sujetos de frecuente vandalismo. Se atribuía esta situación “... a los largos y anónimos pasillos y a la falta de espacios semiprivados controlados”, además a su diseño “... en un lenguaje purista que no concordaba con los códigos arquitectónicos de los habitantes” (Jencks, 1984 [1977], p. 9). Años después se establecía que no solo la Arquitectura Moderna no había muerto, sino que había sobrevivido a su sucesor -el posmodernismo- con buen estado de salud. Irónicamente la destrucción de otro proyecto de Yamasaki, las Torres Gemelas de la ciudad de Nueva York el 11 de septiembre de 2001, se convertiría en el referente para que algunos analistas establecieran el advenimiento de otro período de la historia.

En general, más allá de las discrepancias que existen entre los historiadores respecto a remontar el inicio de la Arquitectura Moderna a los siglos XVIII o XIX, hay un acuerdo en que esta se inicia como ruptura de la tradición y rechazo a toda referencia del pasado, a partir de factores como la incorporación de nuevos materiales de construcción, los cambios en los procesos de edificación, el cuestionamiento de las prácticas arquitectónicas tradicionales y la modificación de las concepciones espaciales y de relación entre la forma y la función. El historiador español Angel Isac (2011) hace un recorrido de las aportaciones de interpretación de la arquitectura del siglo XX desde la historia y la crítica, a las que divide en cinco grandes etapas:

1. La etapa fundacional correspondiente a la perspectiva de quienes narran la visión más canónica del llamado Movimiento Moderno.

2. La que, pasada la Segunda Guerra Mundial, corresponde a la perspectiva crítica del revisionismo organicista, personalizada en la labor de Bruno Zevi.

3. La que en los años sesenta intenta un cierto "neutralismo", una especie de reequilibrio en sus análisis tras las etapas anteriores.

4. La que elaboran los militantes más críticos del posmodernismo.

5. La situación derivada del prematuro hundimiento o descrédito de la perspectiva posmoderna y la aparición de multitud de miradas que dominan el panorama actual.

Dentro de la primera etapa, Isac (2011) ubica las obras de Henry-Russell Hitchcock, Philip Johnson, Nikolaus Pevsner y Sigfried Giedion, quienes “... describen enfáticamente el movimiento de vanguardia, sin la suficiente perspectiva temporal” (p. 36) aunque reconoce que la mayoría de ellos revisarían estas interpretaciones en las reediciones de sus libros. Hitchcock y Johnson dividen esta arquitectura en dos grandes generaciones, la primera, la de los semimodernos, es decir arquitectos entre dos siglos, como Peter Behrens, Otto Wagner, Berlage, Perret o Wright y la segunda, de los modernos, como J. J. P. Oud, Le Corbusier, Walter Gropius, Mies van der Rohe, entre otros. 
La segunda etapa, según Isac, corresponde al revisionismo crítico representado por Bruno Zevi (1980 [1950])) quien en su Historia de la Arquitectura Moderna, frente al "espíritu del tiempo", reivindica la importancia del "espíritu del lugar" y establece que esta arquitectura se inició por factores como la evolución natural del gusto, el progreso científico y técnico en las construcciones, el resultado de nuevas teorías de la imagen estética y por efecto de una transformación social radical.

La tercera etapa, del neutralismo, se inicia con Henry Russell Hitchcock y su Arquitectura de los siglos XIX y XX (1958), una narración histórica de lo moderno, que arranca a finales del siglo XVIII. Se encuentra también el trabajo de Leonardo Benévolo Historia de la Arquitectura Moderna (1980 [1960]), donde ofrece un panorama muy amplio no solo de Europa o los Estados Unidos, sino también de Japón, Brasil y otros países iberoamericanos. En el libro Teoría y diseño arquitectónico en la era de la máquina (1960), Rayner Banham se cuestiona las interpretaciones de Pevsner sobre la Arquitectura Moderna como ruptura con la tradición académica del siglo XIX y como fruto de las ideas de William Morris o de la influencia de la ingeniería. Por su parte Peter Collins en Los ideales de la Arquitectura Moderna: su evolución (1965), desarrolla una interpretación de la cultura arquitectónica moderna que considera se inicia en 1750 y que queda formalizada hacia 1890. Manfredo Tafuri en Teorías e historia de la arquitectura. Hacia una nueva concepción del espacio arquitectónico (1968) retoma la historia del Movimiento Moderno, “... descubriendo sus carencias, contradicciones, objetivos traicionados, errores y su complejidad y fragmentariedad" (Isac, 2011, p. 49), luego en colaboración con Francesco Dal Co, publica Arquitectura contemporánea (Tafuri y DalCo, 1976) donde describen "historias múltiples" de lo moderno en la arquitectura, siendo especialmente críticos con las propuestas de los años sesenta y setenta.

El cuarto enfoque, que se desarrolla desde la perspectiva posmoderna en el campo de la crítica y de la historiografía, conduce a las obras de arquitectos como Robert Venturi, Charles Jencks y Robert Stern, quienes formularon los juicios más severos contra la tradición moderna. En Complejidad y contradicción en la arquitectura (Venturi, 1966) y en Aprendiendo de las Vegas (Venturi, Izenour y Scott Brown, 1977), Venturi opuso nuevos conceptos frente a los desacreditados principios que desde la Arquitectura Moderna se esgrimía a favor de la homogeneidad. En el libro Movimientos modernos en Arquitectura, Charles Jencks (1973) trazó un nuevo horizonte crítico e historiográfico radicalmente enfrentado a las primeras interpretaciones del Movimiento Moderno. En libros posteriores, como El lenguaje de la arquitectura posmoderna (Jencks, 1984 [1977]) y Arquitectura tardomoderna $y$ otros ensayos (Jencks, 1982 [1980]) realiza una negación total del Movimiento Moderno como el "verdadero estilo del siglo XX". Por su parte, Stern en Clasicismo moderno (1988) ofreció una amplia taxonomía con la obra de muchos arquitectos adscritos a alguna de sus arbitrarias adjetivaciones: clasicismo irónico -Venturi, Moore, Graves, Johnson, Gehry, Isozaki, Farrel, Jencks, Stirling-; clasicismo latente -Botta, Roche, Campi-; clasicismo fundamentalista -Rossi, Moneo, Porphyrios-; clasicismo canónico -Terry, Manzano-Monisy tradicionalismo moderno -Graves, Roche, Adam, Stern, Outram, Smith-.

En los años ochenta se iniciaría una última etapa hasta nuestros días, que involucra el desarrollo de historias generales del siglo XX muy complejas y poco excluyentes, como en los trabajos de Kenneth Frampton, Arquitectura Moderna. Una historia crítica (1981) y Wi- 
lliam Curtis, La arquitectura moderna desde 1900 (1982) y otras propuestas interpretativas desde el análisis discursivo, orientadas a superar las concepciones estilísticas.

Muchos de estos enfoques parten de la concepción de la arquitectura como estilo. Christian Norberg-Schulz (1967), al definir el estilo, indica que comprende “... las propiedades formales comunes a un conjunto de obras" (p. 100) aunque aclara su poca validez para situar aquellos proyectos donde falten algunas de las características comunes que se hubieran establecido para un estilo determinado. Este concepto va muy en la línea de Heinrich Wölffing y otros historiadores del arte para quienes el estilo es “... el acercamiento colectivo a unas convenciones artísticas, materiales y técnicas dentro de las cuales emerge, de manera más o menos estable y definible, un patrón formal" (Goldhagen, 2008, p. 17).

Para Norberto Cháves el estilo hace referencia “... a un puro lenguaje formal: una serie de recurrencias morfológicas y sintácticas que trascienden el hecho individual, instituyéndose como principio regulador de la producción cultural y como generador de la unidad y coherencia de su discurso", aunque aclara que esa caracterización si bien es válida es incompleta, ya que el estilo “... articula todos los planos presentes en la obra” y “.... sintetiza lo simbólico, lo estético, lo utilitario, lo técnico, etcétera, determinando sus modos relativamente estables de condicionamiento recíproco" (2005, p. 21). Continúa Cháves explicando cómo en el siglo XX el estilo tiende a desaparecer "... incluso como palabra, al perder su referente” (p. 27), para ser superado por las propuestas de vanguardia, que irrumpen, innovan, experimentan, superan y trasgreden.

La argentina Marina Waisman (1990) pone en evidencia la estrecha relación que existe entre la idea de estilo con la de tipo y estructura, ya que en las tres habría un acento en “... las relaciones entre elementos antes que en los elementos mismos, y en su desarrollo histórico”. Si la estructura es el “... sistema de relaciones que describen el funcionamiento de un fenómeno" (p. 76), el tipo se ha determinado siempre por la comparación entre una serie de edificios, en los que se separan las características constantes que se repiten en todos los ejemplos de una serie, que son aplicables para desarrollar un proyecto arquitectónico, en el que se variar o modificar su esquema. El tipo no es un ente fijo de antemano ni es un estereotipo brindado por la historia de la arquitectura, ni es un modelo base de producción de objetos arquitectónicos, sino que es un objeto o concepto espacial evolutivo a través de la historia, lo que produce objetos que a pesar de provenir del mismo tipo, no son similares. Existiría una clara contradicción en algunos de los más importantes exponentes de la Arquitectura Moderna, puesto que por un lado rechazaron definir a ésta como estilo -al que Le Corbusier calificó como una mentira- mientras por otro lado buscaban establecer normas o patrones que les permitieran llegar a la "perfección". Baste recordar los cinco puntos para una nueva arquitectura establecidos por Le Corbusier, definidos como “... una auténtica estructura formal plagada de estilemas” (Martín Hernández, 1997, p. 98) o los "principios generales comunes" a los que llegaron Henry-Russell Hitchcock y Philip Johnson con ocasión de la exposición sobre la Arquitectura Moderna, denominada The International Style: Architecture from 1922, que se presentó en el MOMA de Nueva York en 1932, esto es: la arquitectura como volumen, la regularidad y el rechazo a la decoración aplicada, los cuales eran "... lo suficientemente generales como para no definir un 'modo de hacer' arquitectura, pero con suficientes ejemplos dispuestos para ser imitados” (Martín Hernández, 1997, p. 98). 
Hitchcock y Johnson sostenían que con esa exposición nacía un "estilo moderno", el cual, según el catálogo de la muestra, "En el tratamiento de los problemas estructurales se aproxima al gótico, mientras que en las cuestiones formales se asemeja más al clasicismo. Se distingue de ambos por la preeminencia que concede al estudio de la función" (Montaner, 2002 (5a. ed.), p. 13). De esta manera se pasaba de la concepción de la Arquitectura Moderna como actitud y expresión de una época para canonizarla en un conjunto de principios que se podían materializar en cualquier contexto social o cultural, bajo el nombre de Movimiento Moderno, al que Montaner (2002) define como:

... la corriente internacional que arranca de las vanguardias europeas de principios de siglo y se va expandiendo a lo largo de los años veinte. Partiremos, por lo tanto, de entender por vanguardia los autores que proponen innovaciones trascendentales entre los años 1910 y 1930 y por Movimiento Moderno, la extensión, internacionalización y producción de estos planteamientos a partir de finales de los años veinte, cuando la dialéctica entre arquitectura y vanguardia se pierde (p. 13).

Aunque el propio Montaner y otros autores consideran que el término Movimiento Moderno ha sido utilizado como "mito o artificio lingüístico" (Montaner, 2002 (5a. ed.), p. 12), ya que ha sido visto al mismo tiempo como "... el destino final de la historia, el producto de todo el pasado" (Cravino, 2005, p. 140) y, a la vez, como una ruptura con ese mismo pasado. Tal como lo indica el argentino José Francisco Liernur (2004): "El Movimiento Moderno constituye una creación historiográfica producida entre 1927 y 1941, que alude a determinadas expresiones de la arquitectura europea y norteamericana de esos años, fuertemente identificadas con los congresos internacionales de Arquitectura Moderna" (p. 141) o Tomás Maldonado para quien este concepto no es más que una noción utilizada por "comodidad crítica e histórica", por lo que sostiene que “... el Movimiento Moderno en tanto tal-debemos decirlo de una vez por todas-, como realidad homogénea, compacta, no ha existido nunca" (Maldonado, 2004, p. 66). Norberto Cháves (2005), considera al Movimiento Moderno como "... el último gesto renacentista de la cultura europea, (que) fracasó antes de nacer", ya que "No pudo materializar; sino anecdóticamente, sus proyectos; y la obra construida, a poco de inaugurarse, fue declarada obsoleta, en algunos casos por los propios autores" (p. 28).

Contraria a esta visión reduccionista de la Arquitectura Moderna, está aquella que la entiende desde su actitud positiva frente al presente y que se aplica, por tanto, a cualquier hecho arquitectónico que la refleje, más allá de su época histórica, es decir, como indica el arquitecto español Helio Piñón (2006), “... cuando la práctica adquiere un sentido específico que depende del uso que el autor hace de los principios teóricos y operativos -de los materiales, según el filósofo alemán Theodor Adorno- que cada época pone a su disposición" y que expresaría en principios estéticos como

... la concepción como construcción -ya no como gestión, con criterios de mímesis, de sistemas canónicos-; la abstracción como un modo de asumir la universalidad, trascendiendo pues lo particular y la forma consistente, equi- 
librada, en el marco de una idea de orden no reductible a la regularidad ni amparada en la jerarquía. (p. 18)

En la misma línea de contraposición a la concepción de la Arquitectura Moderna como estilo, y en el marco de la interpretación de la modernidad arquitectónica desde el análisis discursivo, se encuentra el trabajo de Sarah Williams Goldhagen, profesora de la Universidad de Harvard, quien en el año 2005 publicó en el Journal of the Society of Architectural Historians un importante ensayo al que tituló Something to talk about: Modernism, Discourse, Style. Este ensayo fue traducido por Juan Luis Rodríguez, profesor de la Universidad Católica de Colombia, bajo el nombre de Algo de qué hablar: Modernismo, Discurso, Estilo y fue publicado en la revista Bitácora 12 en el año 2008. En ese artículo plantea la necesidad de sustituir el paradigma de estilo por el de discurso, de manera que sea capaz de responder al fenómeno de la modernidad. Afirma Goldhagen que para muchos, tanto legos como especialistas, es casi inevitable reducir la Arquitectura Moderna a una serie de lugares comunes sobre la forma, tales como:

Cubiertas horizontales, "transparencia" y mucho vidrio: muros de vidrio, puertas de vidrio, divisiones en vidrio; edificios de hormigón reforzado o metal, de limpios y definidos volúmenes; composiciones controladas por el rigor geométrico; estructuras separadas de la piel del edificio que permiten espacios fluidos, articulados ligeramente por divisiones espaciales que apenas tocan los planos horizontales; una distribución dinámicamente asimétrica de la los espacios; una ausencia de ornamento o referencia histórica, calvinista en su rigor y entendida como una abstracción; un énfasis compositivo que resulta del juego enfático entre elementos y volúmenes (2008, p. 15).

En este reduccionismo han caído tanto críticos como historiadores de la arquitectura, quienes han dejado de lado importantes obras solo por el hecho de no cuadrar con esa simplificación formal. Historiadores como Giedion, Hitchcock o Pevsner, influenciados por los trabajos de Heinrich Wölffing para quien “... el estilo de un período -Gótico, Renacentista, Barroco- representa y encarna la florescencia de una mentalidad cultural, el Zeitgeist” (Goldhagen, 2008, p. 17), asumieron “... como su principal tarea, explicar la aparición del nuevo estilo y caracterizar su distinción dentro de la historia del arte” (p. 18). El espíritu de la época según la acepción del filósofo alemán Hegel.

Esta visión de la arquitectura como expresión del ideal de una época la mantendrían algunos de los "maestros" de la Arquitectura Moderna, como Mies van der Rohe quien en 1924 afirmaba que:

La arquitectura es la voluntad de una época trasladada al espacio. Mientras no se reconozca esta verdad tan sencilla, la arquitectura permanecerá insegura y vacilante. Hasta entonces, seguirá siendo un caos de fuerzas sin dirección definida. La cuestión de la naturaleza de la arquitectura tiene una importancia decisiva. Es preciso entender que toda arquitectura está vinculada a su tiempo, 
que es un arte objetivo que solamente puede regirse por el espíritu de su época. Nunca jamás ha sido de otra manera (citado en Roth, 1993, p. 501).

o los firmantes del manifiesto del Primer Congreso Internacional de Arquitectura Moderna (CIAM), celebrado en el castillo medieval suizo de La Sarraz en 1928, donde se indicaba que la tarea de los arquitectos -entre los que se encontraban Le Corbusier, Rietveld, Sartoris y Hannes Meyer- consistía en “... ponerse de acuerdo con las directrices de su época. Sus obras deben expresar el espíritu de su tiempo” (Sartoris, 1978, p. 6). Aunque años más tarde abjurarían de esa visión estilística de la Arquitectura Moderna con afirmaciones como la de Walter Gropius, para quien el estilo sofocaba “... las capacidades creativas en vez de estimularlas" (Patetta, 1984, p. 49) y que "El objetivo de del Bauhaus no fue propagar ningún estilo, sistema, dogma, fórmula o moda" (Benévolo, 1980 (4a. ed.), p. 515) o el alegato de Le Corbusier en una carta dirigida al arquitecto sudafricano Rex Martienssen el 23 de septimebre de 1936:

¡Abolamos las escuelas! (la escuela de Corbu tanto como la escuela Vignola, por favor). Ninguna fórmula, ningún expediente. Estamos en los comienzos del descubrimiento arquitectónico de los tiempos modernos. Que se formulen, desde cualquier parte, francas propuestas. Dentro de cien años podremos hablar de un estilo en general, es decir, la coherencia moral en cada obra creada (Benévolo, 1980 (4a. ed.), p. 515).

Esta concepción del "espíritu de la época" no solo se expresaba en las propuestas formales de la arquitectura, sino también estaba presente en los modelos de análisis históricos necesarios para la comprensión de ese mundo cambiante y moderno. Para tal como lo definía Sigfried Giedeon (2009 [1941]) el historiador de la arquitectura debía estar en estrecho conntacto con las concepciones contemporáneas, de manera que estuviera “... embebido del espíritu de su propia época”, ya que así podía estar en condición de “... detectar aquellos temas del pasado que las generaciones previas habían pasado por alto” (p. 42).

Por su parte, los téoricos de la Arquitectura Moderna se han concentrado en establecer la relación de ésta con la misma modernidad, es decir como resultante lógica del conjunto de cambios que se daban en la sociedad -revoluciones industriales, descubrimientos científicos, innovaciones tecnológicas- aunque para arribar a sus conclusiones se hayan basado en el análisis de las obras que cabían en la mirada estilística, dejando de lado aquellas que por sus características formales resultaban anómalas o anacrónicas, aunque haya otros téoricos que precisamente, al poner en evidencia las diferencias, hayan terminado por "sofocar" el paradigma.

El problema surge al encontrarnos con la obra de arquitectos que, de acuerdo a los parámetros tradicionales de análisis, no son modernas pero tampoco encajan como clásicas, tal como claramente lo indica Santiago de Molina (2014): “... en arquitectura siempre ha existido una estirpe de arquitectos cuya resistencia a este juego provoca el nacimiento de un incómodo pero necesario tercer grupo: los inclasificables" (s/p). Dentro de este grupo de inclasificables se podría incluir a Antonio Gaudí, a los norteamericanos Bruce Goff y Frank Furness, al inglés Edwin Lutyens o al polaco Jože Plečnik, entre otros. Existen tam- 
bién un conjunto importante de edificios de los "maestros" de la Arquitectura Moderna que no encajan en esta simplificación estilística y que, por tanto, fueron excluidos deliberadamente del análisis especializado. Tal como lo pone en evidencia Goldhagen (2008):

Nos encontramos ahora ante el siguiente callejón sin salida. Los edificios modernistas tienen techo horizontal y mucho vidrio, excepto los que no; están concebidos más como volumen que como masa, excepto cuando el espacio pasa a un segundo lugar debido a innovaciones en el programa, los materiales, los sistemas y así sucesivamente; aluden a, o emplean materiales producidos industrialmente, como el hormigón o el metal, excepto aquellos en piedra, madera y ladrillo; son ortogonalmente geométricos, exceptuando muchos casos en que no. Emplean planta libre y estructuras separadas de la piel, exceptuando muchas veces en que no; presentan una distribución asimétrica de espacios y formas, excepto cuando son neoclasicistas; son "abstractos", excepto cuando utilizan simbolismos o aluden a referentes de algún tipo en plantas, cortes, alzados y detalles (p. 26).

Continúa Goldhagen sugiriendo que es necesario, por tanto, superar el paradigma de la Arquitectura Moderna como estilo, para pasar a entenderla como un "... conjunto heterogéneo de posturas individuales y prácticas formales dentro de un campo disciplinar” es decir como un discurso que “... afronte el fenómeno mismo de la modernidad, en lugar de rechazarlo o ignorarlo categóricamente” (p. 16) ¿Pero qué se entiende por discurso? Mondragón (2010) define al discurso como:

... una forma reflexiva de interacción que intenta recomponer la comunicación perdida entre los integrantes de una comunidad. Para intentarlo, se reúnen en torno a un grupo de preguntas que dan lugar a una serie de debates y discusiones, en los cuales, los participantes someten sus argumentos al juicio de la comunidad. A través del discurso, dicha comunidad aspira a alcanzar un consenso, un acuerdo intersubjetivo (p. 13).

Michel Foucault establece que un discurso está constituido por unidades y sistemas. Las unidades son los objetos, las enunciaciones, los conceptos y las estrategias, vinculadas por un "sistema de formación”, es decir por “... una estructura de relaciones que opera como una regla que le otorga lógica al discurso” (Mondragón, 2010, p. 28).

En este sentido, Goldhagen (2008) plantea que el discurso de la Arquitectura Moderna se enmarque dentro de cuatro dimensiones:

Una dimensión cultural centrada en las relaciones entre arquitectura y arte, y entre la arquitectura y sus propias tradiciones. Una dimensión política centrada en la clase de instituciones políticas y económicas que la arquitectura podría y debería impulsar. Una dimensión social centrada en la clase de fenómenos -sociales, culturales, políticos, económicos- que compendian la modernidad; en cómo la arquitectura puede subrayar lo que conviene acerca de lo que se 
considere primordial, y en remediar aspectos generadores de consecuencias indeseables, propias de la modernidad. Y una dimensión formal centrada en el lenguaje arquitectónico: lo que el lenguaje arquitectónico puede y no puede transmitir, y qué clase de lenguaje puede aludir, tanto a las condiciones de modernidad como un todo, como a las posiciones de cada individuo en cada una de las otras tres dimensiones (pp. 36-37).

Desde esta interpretación discursiva se podrá ir superando, por tanto, esa imagen engañosa que se ha tenido de la Arquitectura Moderna, al ir incorporando un conjunto de obras del período -rechazadas como modernas al no encajar en el "estilo"- que respondieron a concepciones y actitudes modernas, al posicionarse como rupturistas del pasado.

\subsection{La conformación de campo disciplinar en la arquitectura}

La noción de campo que desarrolló el sociólogo francés Pierre Bourdieu se fundamenta en la idea "... de que existen leyes generales de funcionamiento de la sociedad que se pueden analizar independientemente" (Vizcarra, 2002, p. 55) y proporciona un instrumento metodológico válido para el análisis de la constitución del campo disciplinar de la arquitectura.

Si bien su análisis original se aplica al campo literario, fue el propio autor quien expresamente se refirió a la posibilidad de extender este concepto a otros campos como el académico o universitario, “... al tratarse de campos análogos en cuanto a su lógica de funcionamiento, lógica práctica y ligada a la acción y no al interés racional” (Cirvini, 2004, p. 279). Para Bourdieu un campo es un microcosmos social relativamente autónomo, dentro del macrocosmos social, donde confluye la posesión de un saber, con lógicas diferentes y leyes sociales que le son propias, donde los participantes “... trabajan constantemente para diferenciarse de sus rivales más próximos, con el objetivo de reducir la competencia y establecer un monopolio sobre un sub-sector particular de campo" y “... para excluir del campo una parte de los participantes actuales o potenciales, especialmente elevando el derecho de entrada, o imponiendo una cierta definición de la pertenencia" (Bourdieu, 2008, s/p).

Al hablar del campo del arte, Bourdieu (1995) lo define como el sistema de relaciones que incluye tanto a las obras como a las instituciones mediadoras y los agentes, quienes están determinados por su posición de pertenencia dentro del campo. Se entiende que ninguna obra, científica o literaria, ni su escritor o su productor, “... se conectan con la sociedad global de manera directa, sino mediados a través de la estructura del campo que le es propio" (Cicutti, 2007,p. 40).

Como se puede advertir, esta definición que Bourdieu hace del campo del arte es perfectamente aplicable a la constitución de la arquitectura, como disciplina autónoma y en tanto campo de producción de bienes simbólicos, a partir del establecimiento de leyes propias o "fundamentales" - un nomos independiente según Bourdieu-implícitas o explícitas, en un mundo donde hay ".. apuestas sociales, luchas, relaciones de fuerza, capital acumulado” (Bourdieu, 2010, p. 37), además de grupos sociales e instituciones que dialogan sobre 
preocupaciones comunes conformados por “... los mecenas del arte (clientes, museos, curadores, galeristas), las compañías editoriales de revistas y libros, la academia, las organizaciones profesionales y no-profesionales" (Mondragón, 2010, p. 27), entre otros. Continúa explicando Bourdieu cómo el campo “... es como un juego, pero que no ha sido inventado por nadie, que ha emergido poco a poco, de manera muy lenta. Ese desarrollo histórico va acompañado por una acumulación de saberes, competencias, técnicas y procedimientos que lo hacen relativamente irreversible" (Bourdieu, 2010, p. 38). Esta diferenciación y proceso de autonomía de cada campo lo explica de la siguiente manera:

... el campo intelectual como sistema autónomo o que pretende la autonomía es el producto de un proceso histórico de autonomización y de diferenciación interna, es legitimar la autonomización metodológica que permite la investigación de la lógica específica de las relaciones que se establecen en el seno de este sistema y lo integran como tal; equivale también a disipar las ilusiones nacidas de la familiaridad, al poner al descubierto que, como producto de una historia, este sistema no puede disociarse de las condiciones históricas y sociales de su integración y condenar por ello toda tentativa de considerar las proposiciones que se desprenden del estudio sincrónico de un estado del campo como verdades esenciales, transhistóricas y transculturales (Bourdieu, 2002 [1966], p. 17).

El segundo concepto que incorpora Bourdieu es el habitus, entendido como “... un cuerpo socializado, un cuerpo estructurado, un cuerpo que se ha incorporado a las estructuras inmanentes de un mundo o de un sector particular de este mundo, de un campo, y que estructura la percepción de este mundo y también la acción en este mundo" (Bourdieu, 1997, p. 145). Añade Bourdieu (1980) que los habitus pueden ser entendidos como:

... principios generadores y organizadores de prácticas y de representaciones que pueden ser objetivamente adaptadas a su meta sin suponer el propósito consciente de ciertos fines ni el dominio expreso de las operaciones necesarias para alcanzarlos, objetivamente 'reguladas' y 'regulares' sin ser para nada el producto de la obediencia a determinadas reglas, $y$, por todo ello, colectivamente orquestadas sin ser el producto de la acción organizadora de un director de orquesta (p. 86).

Explica además que este concepto surge al considerar que los individuos son también producto de condiciones tanto sociales como históricas y que tienen disposiciones y esquemas “... que están ligados a sus trayectorias (a su origen social, a sus trayectorias escolares, a los tipos de escuela por los cuales han pasado)" (Bourdieu, 2010, p. 39) y por tanto, el habitus al ser producto de la historia “... origina prácticas, individuales y colectivas, y por ende historia” (Bourdieu, 1980, p. 88).

La argentina Silvia Cirvini (2004) plantea utilizar la noción de habitus como categoría analítica, al considerar que el campo disciplinar y el habitus, en un momento dado del tiempo, “... mantuvieron una relación de mutua determinación y constitución en la etapa 
fundacional del campo" (p. 279). El habitus permite incorporar el sentido del juego que hace que quienes participan en él se interesen en los desafíos que se plantean, tengan una adhesión y un interés por lo que sucede en ese campo.

La teoría de la acción que desarrolla Bourdieu, vincula las nociones de nomos, campo, habitus, interés e illusio. En esta teoría, Bourdieu se pregunta sobre el "interés" que los agentes pueden tener en hacer lo que hacen y la adhesión no consciente al juego dentro de determinado campo o illusio (del latín ludus juego) que surge de las leyes fundamentales diferentes que cada campo posee (nomos).

La constitución de la arquitectura como disciplina autónoma y la emergencia de la Arquitectura Moderna aparecen estrechamente ligadas en los países del sur del continente americano. La arquitectura encuentra su expresión en la modernidad arquitectónica que se funde en la vorágine de cambios económicos, sociales, tecnológicos y culturales que se dan en el siglo XX -más tarde o más temprano- desde México, los países centroamericanos y caribeños, los del área andina, hasta los del cono sur.

\subsection{La formación universitaria de la arquitectura en el Ecuador}

Tal como lo indica Silvia Cirvini al referirse a la formación de los arquitectos a inicios del siglo XX: "Las alternativas de instituciones de formación profesional en Europa eran: las Academias, las escuelas especiales como los Politécnicos, las Universidades y los talleres de 'maestros', oficiales o libres" (Cirvini, 2004, p. 106). Las Academias conformadas entre los siglos XVIII y XIX, como era el caso de Francia, estaban regidas por los fundamentos de las Escuelas de Bellas Artes y, muchas veces, no contaban con un plan de estudios específico, sino la enseñanza técnica y científica era impartida en cursos específicos y la formación artística, a través de talleres. Por su parte, en Italia tenía primacía la enseñanza de las escuelas politécnicas donde se formaban por igual a los arquitectos y a los ingenieros, como las de Nápoles, Turín, Milán, la Academia de Brera -también en Milán-, Palermo y la Laura en Roma, aunque también había escuelas específicas de enseñanza de arquitectura como la Escuela Superior de Arquitectura de Roma.

Según el historiador ecuatoriano José Gabriel Navarro, la primera escuela del país donde se enseñó arquitectura fue la de Cuenca en 1822, cuando Simón Bolívar, a su paso por esa ciudad, decretó que se entregara la suma de treinta pesos mensuales al afamado escultor Gaspar de Sangurima -conocido como "el lluqui"- con el fin de que creara “... una especie de Escuela de Artes y Oficios". Según Navarro (1991 [1950]), en esa escuela se enseñaban “... las nobles artes de pintura, escultura y arquitectura”, además de oficios como “... carpintería, relojería, platería y herrería” (p. 167). Según José María Vargas, en la Maestranza de Gaspar de Sangurima “... se fabricaron lanzas para los jinetes y herraduras para los caballos de los escuadrones; se compusieron los fusiles dañados (...) se fabricaron los clarines; las cornetas y las cajas de guerra que resonaron en Pichincha, Junín y Ayacucho" (Vargas, 1967, p. 56).

En Quito y Guayaquil la formación de los arquitectos y la constitución de las escuelas y academias de enseñanza de arquitectura siguió caminos diferentes. En el caso de la capital a través, primero, de talleres de enseñanza de dibujo y arquitectura, donde un maestro 
formaba a un conjunto de aprendices, como en la Escuela de Arquitectura y Perspectiva instituida por el artista y arquitecto Juan Pablo Sanz en 1847.

No fue sino a partir del año 1862, durante la presidencia del Ecuador del conservador Gabriel García Moreno, que se fueron introduciendo una serie de reformas a la educación pública bajo un sistema regido por su absoluta dependencia con los principios de la Iglesia Católica, donde "Hasta los textos escolares debían ser designados por los obispos", con maestros jesuitas españoles y hermanos cristianos que habían sido traídos para la enseñanza en las escuelas primarias y secundarias (Kennedy Troya, 1992).

Siete años más tarde, el 13 de febrero de 1869, García Moreno, quien un mes antes había derrocado al presidente Juan Javier Espinosa y Espinosa, expidió un decreto donde, entre otros asuntos, disolvía la Universidad de Quito al considerarla “... un foco de perversión de las más sanas doctrinas" (Decreto Presidencial del 13 de febrero de 1869). La visión dogmática de García Moreno se evidenciaba aún más cuando por orden del Ministerio del Interior se establecía que quien quisiera optar al título doctoral “... debía hacer la profesión de fe católica, previa al juramento profesional, práctica que persistió como obligatoria para todos los doctorados hasta 1896” (Ayón de Messner, 1967, p. 31). Meses más tarde, el 27 de agosto, la Convención Nacional del Ecuador, emitía un decreto donde ratificaba la decisión presidencial y confirmaba la supresión de la Universidad de Quito al considerarse que había “... dejado de ser un establecimiento necesario en el sistema de instrucción pública” y creaba en su lugar la Escuela Politécnica Nacional gratuita, bajo el siguiente considerando:

Que las empresas nacionales sobre construcción de carreteras, caminos de herradura, mejora material de ciudades i puertos así como la necesidad premiosa de desarrollar ciertas industrias llamadas a influir poderosamente en el progreso i felicidad de la republica exigen con urgencia la formación de hombres capaces de desempeñar con acierto i lucimiento los destinos públicos que requieren conocimientos fundamentales en matemáticas, ciencias naturales y otros estudios indispensables para el ejercicio de ciertas profesiones de importancia (Pérez, 1987 [1927], p. 280).

En el artículo primero del decreto se indicaba que esa institución funcionaría en la capital de Estado y que se destinaría exclusivamente “... a formar profesores de tecnología, ingenieros civiles, arquitectos, maquinistas, ingenieros de minas i profesores de ciencias" (Pérez, 1987 [1927], p. 280).

$\mathrm{Al}$ año siguiente se incorporaba como profesor al danés Jacobo Elbert, además de sacerdotes jesuitas alemanes que habían llegado a fundar dicha institución. Se incorporó también para la enseñanza de la arquitectura al alemán Francisco Schmidt, además de científicos en materia de construcciones como los jesuitas Juan Bautista Menten, Joseph Kolberg y Luis Dressel (Fernández García, 2006). Kolberg en 1876 describía a la nueva institución académica de la siguiente manera:

... el Presidente añadió a la Universidad como nueva facultad una Escuela Politécnica, donde no solo se dictaban clases sobre arquitectura, construcción de 
carreteras y ferrocarriles y las otras ciencias de ingeniería (...) sino también sobre matemática teórica, física, química y todas las ciencias naturales, como corresponde a una verdadera Universidad (citado en Leonhardt Abram, 2008, p. 34).

Con esta institución se dio inicio a la formación académica de la arquitectura en el país y, como afirmaba José Gualberto Pérez, "Con tan buenos elementos se puede decir que empezó la época de la verdadera arquitectura en Quito” (Pérez, 1987 [1927], p. 280).

Se conoce también de la enseñanza individualizada y particular de arquitectura, por disposición del gobierno ecuatoriano, a jóvenes seleccionados a cargo del destacado arquitecto británico Thomas Reed, quien había llegado al país invitado por García Moreno, quien le otorgó el título de Arquitecto de la Nación (Saldarriaga, Ortiz Crespo y Pinzón, 2005, p. 32). Thomas Reed llegó al Ecuador precedido por su fama de ser uno de los arquitectos más destacados de la época en Venezuela y Colombia. Durante mucho tiempo se atribuyó a Reed la nacionalidad danesa, debido a que se pensaba que había nacido en la isla caribeña de Saint Croix, bajo dominio danés, sin embargo en la lápida de su tumba, encontrada hace pocos años en el Cementerio de los Extranjeros de Guayaquil, consta que nació en la isla Tórtola, territorio de las Indias Occidentales Británicas.

Años más tarde, durante la presidencia del liberal Eloy Alfaro, el Congreso de la República del Ecuador, mediante decreto del 18 de octubre de 1900, estableció en Quito la Escuela de Bellas Artes que contaba con “... cuatro divisiones: Arquitectura, Escultura, Pintura, Música y Declamación” (Congreso de la República del Ecuador, 1900, p. 9342), sin embargo aún tuvieron que transcurrir algunos años para que esta iniciativa pudiera concretarse.

El 18 de enero de 1904 se creó el Reglamento de la Sección de Bellas Artes anexa al Conservatorio Nacional de Música (Congreso de la República del Ecuador, 1904) en el que se definieron las secciones en las que se dividirían las materias, estas eran: Arquitectura, Dibujo Natural, Dibujo Objetivo (naturalezas muertas), Acuarela, Pintura de Figura Humana, Pintura de Paisajes, Dibujo de Aplicación (todas las ramas del dibujo, litografía, grabado) y Escultura. Sin embargo, no fue hasta 1906, cuando ya se contaba con el plantel docente necesario, que se expidió el Reglamento que constituyó la Escuela de Bellas Artes, independiente del Conservatorio de Música, y se estableció la división de las clases según el rango de enseñanza, en tres secciones:

Sección elemental: incluyendo dibujo ornamental, lineal, geométrico, ejercicios preliminares de la figura humana, primeros ejercicios de paisaje, naturalezas muertas, perspectiva, modelado en barro, etc.

Sección media: figura humana ya con copia, dibujo copiado del yeso, copia de estampas y del natural, clase de grabado litográfico, dibujo figura humana copia, dibujo arquitectónico y mecánico, pintura a la acuarela y pastel, anatomía artística.

Sección superior: Pintura al óleo, escultura con modelo vivo, dibujo topográfico y arquitectónico y estudio de los órdenes y estilos en arquitectura. Las clases estaban siempre separadas entre hombres y mujeres, exceptuando las señoritas que pertenecían a la clase superior y quisieran asistir a los cursos de dibujo con 
modelo vivo, éstas podían concurrir este género junto a los hombres (Congreso de la República del Ecuador, 1906, p. 832).

A estas materias se añadía como novedad la clase de Arquitectura Moderna.

En el artículo 11 del Reglamento de la Sección de Bellas Artes se indicaba que esta decisión se daba "... no por excluir al antiguo sino porque deben responder en todo al espíritu moderno” y se añadía como sustento que:

El arquitecto moderno está a la cabeza de un pequeño ejército de especialistas a los que ordena y dirige febrilmente, el secreto de este estilo moderno son estos tiempos de carrera al millón, en permitirles ciertas libertades sin causar previamente largos estudios y hacer larga práctica (Salgado y Celis, 2012, p. 34).

Respecto a la enseñanza de la arquitectura que se daba en esta escuela, Rafael Rivas Nevárez (2013 [1980]) comentaba:

Todavía la arquitectura se estimaba solamente como una disciplina de orden cultural, necesaria para cultivar el buen gusto y desarrollar la habilidad y destreza en la representación gráfica del ornato. Con ese criterio se enseñaba arquitectura en la antigua Escuela Nacional de Bellas artes, en Quito, conjuntamente con los estudios de pintura, escultura y artes decorativas. Su organización y enseñanza seguía fielmente el modelo de las escuelas similares de Francia o Italia, reconocidas en el mundo de la época (p. 92).

No fue sino hasta el año 1946 cuando con asesoramiento de los arquitectos uruguayos Gilberto Gatto Sobral y Guillermo Jones Odriozola se creó la primera escuela de arquitectura en la Universidad Central del Ecuador a partir de un programa académico trasplantado desde la Facultad de Arquitectura de Montevideo, que en la década de 1930. (Se refiere a la Universidad de la República, en Montevideo.) “... ya había recibido la influencia directa del movimiento moderno de la arquitectura e incluso de los postulados de la Bauhaus y la había consolidado cuando Le Corbusier en 1929 visitó Río de Janeiro y Buenos Aires (Benavides, 1995, p. 68)". A partir de 1951 se dio inicio al proceso de convertir esta escuela en facultad independiente, lo que no se concretó hasta 1956 (Del Pino, 2010).

En Guayaquil, por su parte, se inició para los carpinteros la formación en los principios de la arquitectura y sus procesos de representación, en la Escuela de Artes y Oficios de la Sociedad Filantrópica del Guayas y luego en los talleres de formación que manejaba la organización gremial de los carpinteros de lo blanco y de ribera, esto es que incluía tanto a los constructores de casas como a los de barcos. Posteriormente, en 1929, el arquitecto italiano Francesco Maccaferri creó la escuela de arquitectura en la Universidad de Guayaquil, la que tres años más tarde se integró junto con la recién creada escuela de ingeniería, en la Facultad de Ciencias Físicas y Matemáticas de la misma universidad.

No solo que la formación académica en Quito y Guayaquil siguieron derroteros diferentes, sino también la misma Arquitectura Moderna. Si en la capital su surgimiento fue tardío respecto a los países del cono sur, principalmente, y a la par de los países andinos, en Gua- 
yaquil su emergencia -que corresponde al inicio de la formación académica de la arquitectura- se dio tan tempranamente como en Buenos Aires, Santiago de Chile o Montevideo.

\subsection{La Arquitectura Moderna en América Latina y Ecuador}

A diferencia de las utopías sociales y políticas que dieron origen a la estética del Movimiento Moderno en Europa en los años 20, fue la utopía técnica la que estuvo unida al sueño concreto de realización de la arquitectura en los años 30, 40 y 50 en América Latina (Arango, 1991, p. 94).

El argentino Francisco Bullrich fue el primero en abordar el análisis de la arquitectura moderna latinoamericana a partir de un criterio espacio-temporal lineal. En sus obras Arquitectura latinoamericana, 1930-1970 y Nuevos Caminos de la Arquitectura Latinoamericana, ambas publicadas en 1969, brinda un “...mecanismo creativo para el arquitecto latinoamericano y sus obras, sin establecer una continuidad temporal entre arquitectos y sin sustentar su trabajo en una investigación histórica rigurosa" (Arellano, 2011, p. 7).

Ramón Gutiérrez y Rodrigo Gutiérrez Viñuales (2012), por su parte, hacen un recorrido por la arquitectura latinoamericana del siglo XX, a la que dividen en tres grandes etapas: la primera a la que denominan Espejismos y rupturas (1900-1930), la segunda, Modernismo sin modernidad (1930-1950) y la tercera, La obsesión de la modernidad. Crisis en el movimiento moderno (1950-1970).

En la primera etapa, donde se vivía y pensaba “... en una arquitectura cuyas raíces nos eran exóticas, cuya fundamentación profunda desconocíamos y cuyas propuestas no daban cabal respuesta a nuestras necesidades", dan como ejemplo la incorporación de mansardas de fuerte pendiente, “... utilizadas en lugares donde jamás caería la nieve”, además de crear "... paisajes urbanos de ficción a contrapelo de clima, geografía y modos de vida" (Arellano, 2011, p. 1).

En la segunda etapa, que corresponde a los inicios de la Arquitectura Moderna entre 1930 y 1950, se da el paso lento “... del academicismo clasicista al racionalismo arquitectónico (...) con distintas formas de penetración en cada región del continente”. Afirman también que sus antecedentes estarían "... en la pausada ruptura del modelo académico generado por el eclecticismo primero, luego por los movimientos "modernistas" (art nouveau) y finalmente del neocolonial” (Arellano, 2011, p. 2). En este período se habrían generado procesos de modernización epidérmica, basados en una incipiente industrialización desarrollada durante la época de la Segunda Guerra Mundial como consecuencia de la necesidad de sustituir las importaciones tradicionales de materiales y artefactos de construcción. Además, se producen "arquitecturas paralelas" por parte de arquitectos que cumplen con la demanda del cliente, con obras tanto modernas como eclécticas, pintoresquistas o académicas. No sería sino hasta la década de 1940, cuando se darían accionares modernos homogéneos, resultantes de una mayor conexión “... con las vanguardias europeas y con el exilio de arquitectos renovadores que la guerra civil española y la segunda guerra mundial arrojaron a las costas americanas" (Arellano, 2011, p. 3), aunque en este proceso, según Gutiérrez, habrían quedado fuera los países de la región andina (Venezuela, Colombia, 
Ecuador, Bolivia y Perú) donde se habría prolongado el neocolonial y el pintoresquismo, impidiendo que surgiera el racionalismo hasta la segunda mitad del siglo XX. Sin embargo, sus conclusiones generalizan la situación de cada uno de estos países sin considerar las particularidades internas y los procesos de desarrollos diferentes que se hubieran podido dar en regiones o en ciudades específicas.

Por último, en la tercera etapa, entre los años 1950 y 1970, se habría dado la expansión del Movimiento Moderno “... aunque subsistirían los rezagos del monumentalismo neoacadémico y de la 'arquitectura imperial' que los gobiernos fuertes impulsaban en búsqueda de eternidades clasicistas” (Arellano, 2011, p. 4). Se daría también una variable populista del neocolonial llegada desde Estados Unidos con el chalet californiano que “... marcó la adopción de patrones de muros encalados, techo de teja y otros rasgos formales" (Arellano, 2011, p. 5).

El arquitecto ítalo-argentino Roberto Segre ha sido “... uno de los historiadores de la arquitectura en América Latina más inclinados por desarrollar una literatura defensora del movimiento moderno ortodoxo" (Arellano, 2011, p. 11), con un compromiso con la ideología socialista.

En Otra Arquitectura en América Latina, publicada en 1988, el chileno Enrique Browne, se distancia del sociologismo y el idealismo historiográfico de los años setenta y desde una postura positivista ordena a la arquitectura latinoamericana por obras, desde las "líneas arquitectónicas" y no por autores. Browne formula tres grandes tensiones que existirían en la arquitectura latinoamericana del siglo XX: la primera, entre estilo internacional y arquitectura neovernacular, que se da entre 1930 y 1945, la segunda, los auges y debilitamientos de los estilos iniciales del ciclo, durante el segundo período de 1945-1970 y la tercera, la de sustitución del discurso del desarrollo por el de calidad de vida, de la autonomía disciplinar y de la recuperación de la historia, la tipología, el espacio público y la conservación del patrimonio.

El brasileño Hugo Segawa en su libro Arquitectura latinoamericana contemporánea (2005) defiende una arquitectura y una cultura propias, con una fuerte crítica a la arquitectura del colonialismo europeo o norteamericano (Arellano, 2011, p. 18).

Josep María Montaner (2011) sitúa la eclosión de la arquitectura y el urbanismo modernos en Latinoamérica en 1925, cuando Gregori Warchavchik publicó en Brasil Sobre la arquitectura moderna y prolonga su desarrollo hasta 1969, aproximadamente, cuando se da la incorporación de cambios importantes en las condiciones de los países latinoamericanos, tanto en lo económico como en lo social y cultural.

El chileno Cristián Fernández Cox desarrolla precisiones entre la modernidad y lo que denomina las modernidades, además de las diferentes aportaciones sobre la relación de esta idea con la arquitectura latinoamericana y sobre el estado que hasta el momento había sobre las formas del pensamiento en la arquitectura. Fernández Cox (1991) aboga por la necesidad de encontrar un camino propio para la arquitectura latinoamericana y lo plantea como un desafío aún pendiente de ser respondido. Empieza Fernández Cox reflexionando sobre lo que significa la modernidad en América Latina, a la que define como un concepto contradictorio, y plantea la necesidad de considerar a la modernidad como un asunto aún pendiente y en construcción. Se cuestiona sobre la posibilidad de encontrar una modernidad "otra" que podría surgir de cierta arquitectura, como la moderna, desarrollada desde 
nuestros países latinoamericanos, donde se han destacado figuras que se han convertido en claros referentes, como el mexicano Luis Barragán, el colombiano Rogelio Salmona, el uruguayo Eladio Dieste, entre otros. Finalmente, plantea el uso del concepto "modernidad apropiada" desde la búsqueda de una arquitectura "adecuada", "hecha propia" y "en cuanto propia". A esta idea le contrapone los conceptos de "modernidad revisada" y "modernidad reencantada" como búsquedas de un camino propio dentro de la Arquitectura Moderna. La introducción de la Arquitectura Moderna en los países latinoamericanos siguió procesos diferentes. Si bien se da una emergencia casi general en la década de 1930, asentada "Sobre el ocaso del 'neocolonial', los agónicos estertores del academicismo y al amparo de los preludios art déco" (Gutiérrez, 1992, p. 580), ciertas condiciones locales determinaron que su desarrollo y aceptación fueran variando en función de las condiciones económicas locales, la fuerza de la tradición clásica, la apertura por parte de la academia, el desarrollo tecnológico, los contactos internacionales, entre otros factores.

A continuación se hace revisión del surgimiento de la Arquitectura Moderna en Latinoamérica a través de un recorrido por las primeras obras racionalistas de Argentina, Brasil, Chile, Uruguay, Bolivia, Colombia, Perú, Venezuela, México y Cuba.

Verónica Devalle (2009) establece que el año 1930 debe ser considerado como un punto de quiebre en la historia de la arquitectura de Argentina. En ese año es cuando se da la primera referencia sobre la Arquitectura Moderna en la Revista de Arquitectura, a lo que habría que añadir, según Devalle, factores como la visita de Le Corbusier y “... la caída del régimen democrático que inaugura la llamada 'Década Infame”" (p. 149). Se refiere al período que se inicia el 6 de septiembre de 1930 con el golpe de estado cívico-militar que derrocó al presidente Hipólito Yrigoyen y finaliza el 4 de junio de 1943 con el golpe de estado militar que derrocó al presidente Ramón Castillo.

Ramón Gutiérrez (1992) ubica a “... la precursora tarea de Alejandro Virasoro” que “... encontró fértil respuesta en las décadas del 30 y el 40 en diversas realizaciones racionalistas que compartieron el escenario arquitectónico con las obras del monumentalismo imperial' y el pintoresquismo" (p. 596). La primera obra moderna en Argentina corresponde a la casa bonaerense que Alejandro Bustillo diseñó en 1928 para Victoria Ocampo, la cual es considerada atípica dentro del repertorio arquitectónico de ese arquitecto, quien defendía a ultranza el uso del lenguaje clásico sobre las propuestas racionalistas. Tal como indica Jorge Francisco Liernur (2008):

En el clasicismo, y especialmente en su versión helénica -pensaba Bustillo-, debían buscarse las bases para una arquitectura que mantuviera márgenes de valor y resistiera el paso del tiempo, de este tiempo inquieto y revolucionario, para fundar sobre ellas una nueva -pero no inventada- arquitectura argentina (p. 70).

En Brasil, según Leonardo Benévolo "El vuelco decisivo del movimiento brasileño coincide con la revolución de Getulio Vargas de 1930" (1980, p. 850). Por su parte, Gutiérrez (1992), considera que el arquitecto "... que introduce las premisas racionalistas en sus obras es sin duda el ruso Gregori Warchavchik que había estudiado con El Lissitzki y Tatlin en Odessa y luego en Roma donde trabajó con Marcelo Piacentini” (p. 591). Con este planteamiento 
de Gutiérrez concuerda Hugo Segawa (2013), quien identifica a la propia casa de Warchavchik en Pacaembú, Sao Paulo, diseñada en 1928, como la primera obra racionalista de ese país. Tres años antes, en 1925, el italiano Rino Levi y Warchavchik habían publicado el artículo Acerca da Arquitetura Moderna, que se convirtió en verdadero manifiesto sobre el uso del racionalismo arquitectónico, aunque como indica Hugo Segawa (2013):

The publication of these manifests did not alter the current routine of the architecture in Brazil whatsoever. They were founding texts that were retrieved much later by the historiography of modernism, but they indicated the future activity of these architects who, later on, actually materialized their ideas when designing buildings (p. 33).

La publicación de estos manifiestos no alteró en absoluto la rutina de la arquitectura en Brasil de ese momento. Se trató de textos fundadores que fueron recuperados más tarde por la historiografía del modernismo, que trazan la actividad futura de estos arquitectos, quienes, más adelante, materializaron estas ideas cuando diseñaron sus edificios. (Traducción del autor) Brasil también ha liderado en el continente el reconocimiento de la Arquitectura Moderna desde el año 1948, cuando la Iglesia de San Francisco de Asís en Belo Horizonte, diseñada por Oscar Niemeyer en 1943, fue incorporada al patrimonio arquitectónico de ese país. Tal como lo narra Segawa:

A diferencia de la mayoría de los países europeos o americanos, en Brasil, la institución gubernamental federal encargada de la protección del patrimonio ha sido pionera en reconocer el valor patrimonial de la arquitectura contemporánea. En algunos países de Europa existían reglamentos que no permitían el registro de obras arquitectónicas con menos de 50 años de existencia o cuyos autores estuviesen vivos (Segawa, 2015, p. 69).

Humberto Eliash y Manuel Moreno plantean que contrario a lo sostenido por otros historiadores la irrupción de la Arquitectura Moderna en Chile no se dio “... como producto de nuevos materiales y técnicas constructivas, de la 'modernización' social y política, y de la necesidad de nuevas tipologías urbanas y arquitectónicas por obsolescencia de las anteriores”. Sostienen que esta nueva manera de hacer arquitectura llegó “... como equipaje de las élites culturales que años antes habían viajado y permanecido en Europa impregnándose del Esprit Nouveau y del Zeitgeist que abría nuevas fronteras al arte y la cultura" (Eliash y Moreno, 1991, p. 119). Por su parte, Gutiérrez (1992) sostiene que en ese país, “... el peso de la excelente arquitectura académica chilena postergó de alguna manera la inserción del movimiento moderno" e identifica a las obras de Sergio Larraín García-Moreno y Jorge Arteaga, como el edificio Oberpaur diseñado en 1929 en la línea de los almacenes Schocken de Erich Mendelsohn de 1928, como “... las primeras referencias racionalistas" (p. 591), algo en lo que coinciden Eliash y Moreno (1991).

Algunos autores como Ramón Gutiérrez, destacan el notable desarrollo de la arquitectura racionalista de Uruguay, que en las décadas de 1920 y 1930 “... alcanzará niveles notables no solo en comparación con la evolución arquitectónica del propio territorio, sino en el 
panorama americano" (Gutiérrez, 1992, p. 593). Esta visión moderna de la arquitectura se manifestó en proyectos como la torre del estadio Centenario en 1930, proyecto de Juan Antonio Scasso, el edificio de departamentos Lapido en 1929, de Juan María Aubriot y Ricardo Valabrega (Gutiérrez, 1992), la vivienda del Arquitecto Julio Vilamajó o el edificio Centenario, ambos en 1930, de los arquitectos De los Campos, Puente y Tournier (Rey Ashfield, 2012) o la Intendencia de Montevideo en 1929, de los arquitectos Mauricio Cravotto. Mariano Arana y Lorenzo Garabelli (1991) también concuerdan en que es en el Edificio Lapido (Palacio de la Tribuna Popular) donde se concretan las influencias de las vanguardias racionalistas europeas. William Rey Ashfield (2008), por su parte, pone de relieve a la casa de la familia Rocco, realizada entre los años 1925 y 1926 por el arquitecto Juan Antonio Rius, como una obra pionera “...que se constituyó en un verdadero referente para estudiantes de arquitectura en la década del veinte, quienes reqalizaban una auténtica peregrinación hasta el sitio para observar lo que consideraban un hito moderno, digno de ser dibujado y estudiado" (p. 256).

De Bolivia, Gutiérrez (1992) también considera que su aislamiento cultural y el peso de la arquitectura colonial que se expresó en propuestas neocoloniales, produjo “... un desfase cronológico de más de una década respecto a la impronta racionalista” (p. 590). Considera Gutiérrez que el inicio del racionalismo se evidencia en el edificio central de la Universidad Mayor de San Andrés de La Paz, diseñado en 1948 por el arquitecto boliviano Emilio Villanueva Peñaranda.

Silvia Arango (1989) afirma que la Arquitectura Moderna llegó a Colombia “... en los años 30 dentro de una difusa vigencia de contemporaneidad y actualización, con el modelo concreto de las sociedades que se consideraban más avanzadas" (p. 187) e identifica a la estación de ferrocarril de Buenventura, diseñada por el arquitecto italiano Vicente Nasi en 1930, como la primera obra moderna de ese país, aunque considera que se trata de un precedente aislado.

Respecto al Perú, Gutiérrez (1992) sostiene que “... el apogeo del neocolonial y el neobarroco hispano fue cediendo en las áreas suburbanas limeñas ante el económico y 'aggiornado' estilo 'barco'” (p. 590) y menciona al edificio Raffo, diseñado en 1938 por el arquitecto Guillermo Payet Garreta, como el primer ejemplo -aunque aislado- de racionalismo en la arquitectura. No fue sino hasta años más tarde cuando se empezó a imponer la Arquitectura Moderna con el referente del trabajo del arquitecto Luis Miró Quesada Garland, a pesar de tener que luchar incluso contra disposiciones municipales que imponían el uso del neocolonial. Tal fue el caso de la casa Wiracocha que Miró Quesada proyectó en 1947 cuyo proyecto, en un primer momento, fue rechazado por incumplir las normas de la circunscripción del sector de Magdalena Vieja, hoy Pueblo Libre, de la ciudad de Lima, que obligaban a que todas las casas siguieran las líneas neocoloniales (Miró Quesada, 1987). Ramón Gutiérrez (1992) plantea que la penetración del racionalismo en Venezuela no obedece "... a profundos cambios culturales y sociales, o a variaciones de orden tecnológico propias, sino que se incrusta como un estilo más que expresa la 'vanguardia' dentro de un panorama dominado por el eclecticismo y el oportunismo de la moda" (p. 588). Si bien la Arquitectura Moderna tiene en ese país un representante de la talla de Carlos Raúl Villanueva, Martín J. Padrón (1993) establece que la primera obra moderna de Venezuela corresponde a la casa las Guaycas, ubicada en Campo Alegre, del arquitecto Manuel Mujica Millán. 
Para Víctor Jiménez (2007) la Arquitectura Moderna se inició en México en 1931 con los estudios que Juan O'Gorman proyectó para Diego Rivera y Frida Kahlo. En esta obra identifica influencias tanto de Le Corbusier, con sus proyectos de la casa Citrohän y el estudio para Amadée Ozenfant, como de Konstantin Melnikov con el pabellón soviético para la exposición internacional de París de 1925. Louise Noelle (2015), sin embargo, considera que el primer edificio moderno de México fue la Granja Sanitaria de Popotla en 1925, obra de José Villagrán García. Para la década de los cuarenta, México había asumido el liderazgo de la innovación en arquitectura, seguido de cerca por Brasil donde se daban incorporaciones de formas modernas en proyectos de vivienda (Bergdoll, 2015).

Segre afirma que en el caso de Cuba, "No se produce en forma repentina la superación de los códigos arquitectónicos eclécticos, aún dominantes en la década del 20. La asimilación coherente, en términos expresivos, de los códigos representativos del Movimiento Moderno, recién ocurre en la década del 40" (Segre, 1989, p. 14). Esto habría sido originado, según Segre (2015), por “... los efectos negativos de la Crisis Mundial del 29 y el derrocamiento popular de Machado en 1933 (que) abrieron un opaco período institucional de la historia de Cuba que perduró hasta la década de los años cuarenta” (p. 110). Gutiérrez (1992) identifica al Sanatorio Infantil Antituberculoso de la Esperanza en La Habana del arquitecto Luis Dauval Guerra, a la Escuela de Veterinaria del arquitecto Manuel Tapia Ruano en 1945 y al edificio Solymar de 1933, del arquitecto Manuel Copado, como las más representativas de los inicios de racionalismo cubano. Roberto Segre (2015) data a esta obra en 1945.

En el caso del Ecuador, Ana María Durán (2015) identifica cuatro hechos de interés para la historia de la Arquitectura Moderna que se dieron durante la década de 1930. El primero, la llegada al país en 1939 del arquitecto checo Karl Kohn, considerado como uno de los pioneros de la Arquitectura Moderna ecuatoriana; el segundo, en ese mismo año, la inauguración del Palacio del Comercio; el tercero, la conferencia que dictó en 1940 en Quito el arquitecto Armando Acosta y Lara, Decano de la Facultad de Arquitectura de la Universidad de la República de Uruguay, “... en la que anotó la necesidad de que se creara una escuela de arquitectura en la capital, se proyectara un plan regulador para la ciudad y se promoviera el desarrollo de un gremio de arquitectos" (Durán, 2015, p. 42); y el cuarto, la llegada al país de los arquitectos uruguayos Guillermo Jones Odriozola, encargado de la dirección del primer Plan Regulador de Quito, y Gilberto Gatto Sobral quien creó la Escuela de Arquitectura de la Universidad Central del Ecuador en 1946.

Afirma también Durán (2015) que el surgimiento de lo moderno en la arquitectura de Quito habría sido influyente en el país entero, y se cimentó sobre una escuela moderna, según los preceptos de Jones Odriozola basados “... en el organicismo de Frank Lloyd Wright, o el urbanismo de Lewis Mumford o Patrick Abercrombie, como en las cuatro funciones colectivas de la ciudad moderna o los cinco principios de la arquitectura delineados por Le Corbusier" (p. 42). Sin embargo, no existe ninguna evidencia de esta supuesta influencia quiteña hacia Guayaquil, aunque reconoce que "Los primeros ejemplos de construcción en acero, hormigón y vidrio se erigieron en Guayaquil, desde finales del siglo XIX” (p. 43).

En esa misma línea de considerar tardía la incorporación de la Arquitectura Moderna en el Ecuador se expresan tanto Jorge Benavides, para quien “... el período de insurgencia 
de la arquitectura moderna en Quito comenzó con Jones" (Benavides, 1995, p. 72), como Rubén Moreira y Yadhira Álvarez (2004), quienes consideran que solo “... a partir de la mitad de la década del 40, se puede afirmar que va tomando cuerpo el Movimiento Moderno, mediante la asimilación en nuestro país de las tendencias racionalista y funcionalista, que en Europa había prendido raíces en la década del 20 y que a otros países de nuestra región ya habían arribado" (p. 60).

Por su parte, la ecuatoriana Glenda Puente (2015) concuerda con Durán al afirmar:

A good amount of buildings erected in Quito throughout the 1920s and 1930s had constructive systems made entirely of reinforced concrete and possessed a rational and modern formal language, but because of the pressure from a conservative élite the majority of these contemporary works were forced to be clothed with neoclassical detailing or colonial characteristics (p. 2).

Una buena cantidad de edificios construidos en Quito lo largo de los años 1920 y 1930 utilizaban sistemas constructivos realizados enteramente en hormigón armado, con un lenguaje formal racionalista y moderna, sin embargo, debido a la presión de una élite conservadora, la mayoría de esas obras contemporáneas fueron obligadas a revestirse con detalles neoclásicos o características coloniales. (Traducción del autor) Esto habría sucedido ante el temor de perder el carácter de ciudad colonial, por lo que las propuestas neocoloniales y pintoresquistas estuvieron en boga durante los inicios de los cuarenta.

Se ha identificado al Palacio del Comercio, diseñado en 1935 dentro del estética art déco por norteamericana Hopkins \& Dentz, como el edificio pionero de la Arquitectura Moderna de Quito (Peralta y Moya Tasquer, 2007). Sin embargo se lo considera un ejemplo aislado, “... en una época en la cual en Quito no se hacía arquitectura moderna, se hacían viviendas y edificaciones" (Fabara, Matovelle y Núñez, 2004, p. 38) en las que prevalecía el neocolonial, visto como un historicismo nacionalista, como en la obra de Alfonso Calderón Moreno; proyectos déco en la arquitectura de Leonardo Arcos Córdova o propuestas pintoresquistas en la arquitectura del mexicano Rubén Vinci Kinard.

Las propias normativas urbanas de Quito proponían el uso del hispanoamericano como único "estilo" aceptado para el área del centro histórico. Así, en la Ordenanza de Construcciones del Perímetro Colonial de la Ciudad, expedida en 1947, se obligaba a utilizarlo “... en las portadas, patios, cornisas (sic), rejas, gradas, perfiles de marcos y formas de ventanas: alero saliente en el remate de la fachada, aplicando en general estudios de detalles ornamentales típicos". No fue sino a partir de 1947, según Inés del Pino (2010), cuando los edificios modernos de Quito empezaron a ser nominados para los Premios Ornato, que hasta ese momento habían sido otorgados solo a edificaciones en la línea neocolonial, como en la obra de Calderón Moreno.

La conformación del DOCOMOMO capítulo Ecuador en el año 2008, por un grupo de investigadores de la arquitectura de Quito, Guayaquil, Cuenca y Loja, ha permitido empezar a intercambiar experiencias de análisis de la Arquitectura Moderna del país e incorporar a ciudades sobre las que era muy limitada la información que existía, como Cuenca y Loja. Sin embargo, hay que considerar que la principal tarea de este organismo internacional ha sido más el registro de esa arquitectura que su interpretación histórica. El DOCOMO- 
MO (Documentación y conservación de la arquitectura y el urbanismo del Movimiento Moderno) se estableció en 1988 por los arquitectos Hubert-Jan Henket y Wessel de Jonge, de la Escuela de Arquitectura de la Universidad Técnica de Eindhoven, cuyos principios, recogidos en la Declaración de Eindhoven de 1990, se orientan a dar a conocer los valores de la Arquitectura Moderna alrededor del mundo.

También algunos de los trabajos de titulación de la Maestría en Diseño Arquitectónico de la Universidad de Cuenca han abordado el análisis de edificaciones significativas de la Arquitectura Moderna de Guayaquil, especialmente de las décadas comprendidas entre 1950 y 1970, como la Casa de la Cultura Ecuatoriana Núcleo del Guayas, las Facultades de Arquitectura de la Universidad de Guayaquil y de la Universidad Católica de Santiago de Guayaquil, el Normal Católico de la Sociedad de Beneficencia de Señoras, el Colegio Nacional Dolores Sucre, entre otros.

Si dentro del Ecuador es poco lo que se conoce de su arquitectura, menos aun lo que se ha analizado sobre la arquitectura ecuatoriana por parte de historiadores e investigadores latinoamericanos, además de que quienes lo han hecho muchas veces han llegado a conclusiones erradas al considerar que lo que sucedía en Quito necesariamente era replicable para el resto del país.

Si bien Goldhagen (2008) plantea que el discurso de la Arquitectura Moderna se enmarque dentro de cuatro dimensiones: primero, una dimensión cultural; segundo una dimensión política; tercero, una dimensión social, y cuarto, una dimensión formal; es necesario también el conocer los cambios desde la incorporación de nuevos materiales y sistemas constructivos y de cómo estos modificaron la arquitectura; es decir, una dimensión tecnológica. Por tanto, sin desconocer las formas de apropiación local de los modelos de referencia internacionales, se debe abordar la interpretación de la Arquitectura Moderna de Guayaquil desde la complejidad de su emergencia y desarrollo y desde la articulación entre la cultura, la ciudad y la producción arquitectónica.

\section{Capítulo 2. El discurso moderno y el campo disciplinar: la ciudad}

La ciudad es un invento y un fenómeno y como tal debe ser abordada, pero la ciudad no es solo un concepto, sino también una materialidad física construida en la historia y conformada por edificios, calles y espacio público. Esto es totalmente aplicable para Guayaquil. El trazado de la ciudad de Guayaquil y sus reglamentaciones urbanas han sufrido modificaciones a lo largo de los siglos como resultado de diferentes eventos destructivos y de su vulnerabilidad, lo que ha obligado a los pobladores a repensar y replantear su desarrollo cada cierto tiempo y a corregir los errores del crecimiento urbano. Es así que podemos identificar cuatro momentos en la historia de Guayaquil ligados a estos replanteamientos: el primero, desde su fundación en 1534 hasta su último y definitivo traslado en 1547; el segundo, desde 1547 hasta 1693, cuando se reubica la ciudad sin desaparecer el asentamiento original, como consecuencia de la destrucción de 1687; un tercer momento, desde 1693 hasta el Gran Incendio de 1896, caracterizado por la consolidación y densificación poblacional; y un último momento, a partir de la reconstrucción iniciada en 1897 hasta la actualidad. 
Cuando en 1681 se publicó la Recopilación de leyes de los reinos de Indias, se recogieron disposiciones destinadas a ordenar el territorio conquistado por los españoles, además de las normas urbanísticas utilizadas y que debían configurar las nuevas ciudades que fueran fundadas. Entre las disposiciones urbanas se establecía que el trazado de una ciudad debía ser "a cordel y a regla", que las ciudades debían asentarse en regiones "... de buena y feliz constelación, el cielo claro y benigno, el aire puro y suave, sin impedimento ni alteraciones y de buen temple, sin exceso de calor o frío, y habiendo de declinar, es mejor que sea frío" (art. 34). Sin embargo, los conquistadores españoles al momento de decidir la ubicación de las ciudades no siempre consideraron estos factores. No importaba, por tanto, que estos núcleos urbanos se ubicaran, por ejemplo, en terrenos malsanos, junto a conocidas fallas geológicas o a las faldas de volcanes en actividad, sino su importancia era estimada en función del sistema económico y estratégico y por las necesidades de evangelización a la población indígena que se encontrara.

La localización definitiva de Guayaquil, a mediados del siglo XVI, en plena zona ecuatorial, determina que tenga un clima cálido y húmedo a lo largo de todo el año, matizado, sin embargo, por la influencia de las corrientes de Humboldt y del Niño que marcan dos estaciones claras, una un poco más seca y fresca, de mayo a diciembre, y otra lluviosa y muy húmeda, con altas temperaturas típicas del trópico, que va aproximadamente de enero a abril.

Distintos viajeros que pisaron Guayaquil a lo largo de su historia destacaban su clima cálido, como el polaco Alexandre Johaquin Holinski (1978 [1876]) quien indicaba: "La temperatura es muy caliente durante siete meses (de diciembre a junio), el resto del año es bastante soportable" (p. 46). Al clima de la ciudad se le atribuía su insalubridad y las epidemias frecuentes que sufría su población, sin embargo, tal como lo indicaba el ingeniero británico Charles Reginald Enock en 1914, estas se debían “... más que a sus condiciones climáticas, al atraso y condiciones insalubres, en que vive la gente, sobre todo las clases más pobres" (1981 [1914], s/p). También la localización sobre la placa Sudamericana, bajo la cual se subducta la cercana placa de Nazca, ha determinado que a lo largo de los siglos se hayan sucedido eventos sísmicos de diferentes magnitudes que afectaron de diferente manera a la ciudad y condicionaron su arquitectura.

El contar con un asentamiento restringido a las faldas de los cerros Santa Ana y del Carmen, rodeado de esteros, determinó que las calles del asentamiento original fueran estrechas y que las viviendas estuvieran insignificantemente separadas, además, el tipo de clima y las características del suelo obligó a construir casas livianas de madera y caña, con cubiertas de paja. Estas condiciones facilitaron que cualquier tipo de descuido en los fogones de las cocinas generara un incendio que rápidamente se propagaba en la ciudad, debido a la falta de medios adecuados para combatirlo, y que se convirtiera en una catástrofe de enormes proporciones.

En el proceso de reconstrucción de la ciudad, posibilitado por el segundo boom cacaotero -que se extendió desde 1880 hasta mediados de la década de 1920- se empezaron a desarrollar proyectos de modernización urbana que se dirigían tanto al embellecimiento como al saneamiento como prioridad pública, ya que por su condición climática Guayaquil siempre fue propensa al desarrollo de epidemias como la fiebre amarilla, considerada endémica, que no fue controlada hasta 1918. 
Ya a partir de la década de 1930, y como consecuencia de la grave crisis económica, muchos de los proyectos modernizadores se paralizaron y empezaron a surgir nuevos problemas, producto de los grandes flujos migratorios desde las zonas rurales hacia los más importantes núcleos urbanos, Quito y Guayaquil.

De esta manera en la historia de la ciudad de Guayaquil ha habido una continua necesidad de replantear cada cierto tiempo su crecimiento y desarrollo, de experimentar distintos modelos urbanos y de repensar qué se entiende por modernización.

\subsection{La necesidad de un Guayaquil moderno: crónica de una ciudad fallida}

Antes de su localización definitiva en el Paso de Huaynacápac, la ciudad de Santiago tuvo varias ubicaciones desde su lugar original en la llanura andina de Cicalpa, cerca de la actual ciudad de Riobamba donde fue fundada el 15 de agosto de 1534 (León Borja y Szászdi, 2006). La decisión de su traslado, hasta encontrar la ubicación actual en junio de 1547 (León Borja y Szászdi, 2006), habría respondido principalmente a razones estratégicas de contar con un puerto que facilitara la exportación de productos que se producían en las tierras interiores. El emplazamiento elegido fue a viente kilómetros de la costa sudamericana del Pacífico en la desembocadura del Río Guayas, a 2 $10^{\prime} \mathrm{S} 79^{\circ} 54^{\prime} \mathrm{O}$, con una altitud promedio de cuatro metros sobre el nivel del mar, en la confluencia de los sistemas fluviales de los ríos Daule y Babahoyo -que conforman el Río Guayas- en el sector de Lominchao o Cerrito Verde o Cerro de la Culata, como lo denominaron los conquistadores españoles, que servía de vigía ante los potenciales ataques piratas. Este cambio en la localización significó una modificación fundamental en el propio carácter de la ciudad, al pasar de ser un enclave del altiplano andino a un poblado ubicado al nivel del mar y cercano a la costa Pacífica.

Santiago de Guayaquil fue asentada en un lugar anegadizo y apretujado, rodeado por manglares y pantanos, por lo que tuvo que empezar a poblarse “... en una serrezuela, porque los llanos todos se aniegan (sic)" (Salazar de Villasante, 1563 como se cita en Jiménez de la Espada, 1965 [1885], s/p). La ciudad, por tanto, adoptó una disposición de manzanas irregulares con edificaciones dispersas, lo que llevó a afirmar al dominico español Fray Reginaldo de Lizárraga en 1605, que la ciudad tenía “mal asiento" (1968 [1605], s/p).

Poco se conoce de esta primera etapa de la ciudad aparte de su importancia portuaria y que era también uno de los centros de construcción de navíos de madera más importantes de los mares del sur, lo cual era resaltado por las crónicas de los viajeros que llegaban a estas tierras, quienes también describían que estaba conformada por construcciones precarias de madera o caña y que crecía a ritmo acelerado.

El siglo XVII transcurrió con una sucesión de catástrofes: la invasión e incendio por el pirata holandés Jacques de Clerck, conocido como l'Hermite, entre junio y agosto de 1624, los incendios de 1629, 1632, 1636, 1647 y 1678, las epidemias de 1649, 1653, 1667 y 1670, el saqueo por parte de los piratas Edward Davis, Charles Swan y William Dampier en 1684, otra invasión y saqueo por los piratas George Dew, Pierre Le Picard y François Grogniet en 1687. Estas calamidades, sumado al hecho del crecimiento de la población en un asentamiento estrecho, motivaron a que el Cabildo tomara la decisión de trasladar la ciudad 
un kilómetro al sur del emplazamiento original, en un terreno considerado más apto para la defensa y poco propicio a las inundaciones.

En 1692 el Cabildo aprobó “... la delineación y repartimiento de solares para la ciudad nueva” y se ordenaba que "...se empiece a ejecutar la mudanza en este verano" (Cabildo Colonial de Guayaquil, 14 de julio de 1692). Al año siguiente el presidente de la Audiencia de Quito, Mateo de la Mata y Ponce de León, asumió la responsabilidad de la construcción de la nueva ciudad y “... envió al oidor Cristóbal de Cevallos Morales y Borja para que supervisara las obras y diseñase la planta” (Donoso, 2006, p. 55). Este proyecto adoptó el modelo de damero de manzanas cuadradas con un espacio vacío al centro para la plaza, conformando un conjunto de veinticinco manzanas.

Si bien la idea del traslado implicaba el abandono del asentamiento original, esto no sucedió, ya que dos años después el Cabildo insistía sobre la necesidad de impedir que se siguiera construyendo en el asentamiento antiguo y se privilegiara el nuevo (CCG, 11 de enero de 1695). A pesar de todo la mudanza oficial a la nueva localización se realizó el 2 de febrero de 1695, cuando fue trasladado el Santísimo Sacramento para ser ubicado en la iglesia matriz que aún estaba en construcción al pie de la nueva Plaza Mayor.

En 1696 el Presidente de la Audiencia de Quito se trasladó a Guayaquil para supervisar personalmente el avance las obras y la mudanza de sus habitantes (Donoso, 2006), debido a que algunos de ellos se habían mostrado reacios al traslado. A pesar de los continuos plazos para que los vecinos del viejo asentamiento se trasladaran a la nueva ciudad, esto no se cumplía, por lo que dos años más tarde, el propio rey Carlos II emitió una Cédula Real en la que si bien aprobaba la construcción de la nueva ciudad, dejaba en libertad a los vecinos para que escogiesen si querían permanecer en el lugar antiguo o mudarse (Donoso, 2006). De tal manera, que lo que se había concebido como una nueva ciudad se convertía en una parte importante de esta, con los edificios más representativos, mientras que la parte vieja se mantenía como zona exclusivamente residencial y el área de enlace de los dos sectores empezaba a crecer de manera desordenada.

Finalmente la Ciudad Nueva se terminó de configurar en 1699 cuando se edificó el convento y la iglesia de los franciscanos fuera del trazado original, lo que obligó a extender el trazado dos manzanas más hacia el norte y configuró un rectángulo de treinta y cinco manzanas, de siete de largo por cinco de ancho.

El padrón del año 1738 estableció que para esa fecha la ciudad tenía un total de 673 vecinos, los que según Michael T. Hamerly (1979) correspondían al menos 202 a la Ciudad Nueva y 444 a la Ciudad Vieja. Si se toma como referencia el número de vecinos de cada uno de los dos sectores de la ciudad, se establece que el 69\% de los pobladores habitaba la Ciudad Vieja y apenas el 31\% la Ciudad Nueva, esto es aproximadamente 3.390 al sector antiguo y 1.524 al nuevo. Según el Art. 93 de las Ordenanzas de descubrimientos, nueva población y pacificación de las Indias de 1573, se consideraba vecino al “... hijo o hijas, o hijos del nuevo poblador y sus parientes, dentro o fuera del cuarto grado, teniendo sus casas y familias distintas y apartadas y siendo casado y teniendo cada uno casa de por sí”. La percepción que se tenía sobre la ciudad de esos años a veces resulta exagerada, al pretender compararla con las mejores ciudades del mundo conocido. De esta manera, por ejemplo, el sacerdote jesuita Juan Bautista Aguirre en su Breve diseño de las Ciudades de Quito y Guayaquil escrito a mediados del siglo XVIII, describía su visión del Guayaquil de esa época: 


\begin{abstract}
Guayaquil, ciudad hermosa, de la América guirnalda, de tierra bella esmeralda y del mar perla preciosa, cuya costa poderosa abriga tesoro tanto, que con suavísimo encanto entre nácares divisa congelado en gracia y risa cuanto el alba vierte en llanto;

Ciudad que por su esplendor entre las que dora Febo, la mejor del mundo entero y hay del mundo lo mejor, abunda en todo primero, en toda riqueza abunda, pues es mucho más fecunda en ingenios, de manera que, siendo en todo primera, es en esto sin segunda.
\end{abstract}

Fue uno de los más destacados entre los poetas, teólogos y filósofos coloniales del siglo XVIII. Nació en Daule, población cercana a Guayaquil, el 11 de abril de 1725. Falleció el 15 de junio de 1786 en Tívoli, Italia, donde se había traslado luego de la expulsión de los jesuitas de América. Resulta curiosa también la descripción totalmente desfavorable que hacía de Quito y de su gente, donde destacaba, entre otros aspectos negativos, según Aguirre, la topografía escarpada de la ciudad enclavada en un valle andino rodeado de montañas:

Buscando un lugar maldito

a que echarme su rigor

y no encontrando otro peor, me vino a botar a Quito;

a Quito, otra vez repito, que entre toscos, nada menos, varios diversos terrenos siguiendo hermano, su norma, es un lugar de esta forma, disparate más o menos. Es su situación tan mala que por una y otra cuesta, la una mitad se recuesta, la otra mitad se resbala; ella se sube y se cala 


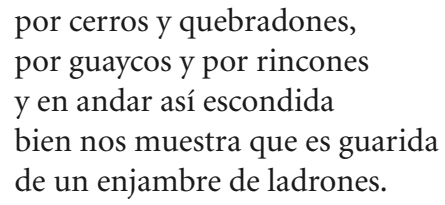

A pesar de esta descripción tan favorable, la ciudad seguía expuesta a diferentes y continuos tipos de desastres, como el que se desató el 3 de agosto de 1764, cuando un gran incendio afectó la parte central, donde estaban levantados los principales edificios públicos y arrasó alrededor de ciento treinta casas. Este hecho obligó a que el Cabildo emitiera una ordenanza orientada a minimizar los daños que otro evento similar pudiera causar a futuro, donde se establecía la definición de calles sin recovecos y se prohibía expresamente la edificación de casas con cubierta de paja. Sin embargo, esta disposición tampoco fue cumplida.

Es interesante la descripción de Guayaquil que en 1772 hacía el geógrafo e ingeniero militar español Francisco de Requena y Herrera y su opinión sobre las condiciones urbanas y sanitarias de los dos asentamientos:

En la segunda (se refiere a la Ciudad Vieja), aunque mejoraron de planta, perdieron lo firme del piso de la primera, en el que podían tener edificios de mampostería: de modo que no consultaron ni la seguridad ni las conveniencias cuando poblaron un campo lleno de terrones en el verano, atascoso y con agua en el invierno, despreciando la utilidad de la antigua situación en la cual un gran estero y los dos cerros referidos les servían de defensa por tierra; y por el lado del río, estaba amurallada por algunos flancos y torreones, cuyos vestigios están acreditando su buena construcción y lo mal aconsejados que estuvieron los moradores para dejar aquella planta, suficiente todavía, bien delineada para abrazar en ella con bastante desahogo toda la Ciudad Nueva (Laviana, 1984, p. 85).

Como se evidencia en el texto de Requena, muchos de los problemas que presentaba en ese entonces la ciudad se debían a la mala decisión que se había tenido al trasladarla hacia terrenos bajos e inundables, donde además se dificultaba la edificación por su poca capacidad portante.

Ya para esta época se empezaron a definir algunas acciones orientadas a mejorar la imagen y el aseo de la ciudad, como aquellas orientadas a "... disminuir la densidad de mosquitos trasmisores del paludismo en las áreas marginales” (Gonzáles, 1986, p. 29), la Ordenanza de Aseo de Calles (CCG, 11 de febrero de 1794), la reparación del matadero municipal (CCG, 15 de enero de 1799), el alumbrado público a base de aceite de ballena (CCG, 14 de noviembre de 1788), la construcción de la Iglesia de la Concepción (CCG, 15 de octubre de 1793) y un Reloj Público en 1793 (CCG, 28 de marzo de 1795). También, dentro del marco de las Reformas Borbónicas que instaló la Gobernación de Guayaquil en 1762, se decidió reforzar la defensa de la ciudad estableciendo la primera compañía militar fija en 1767, que fue aumentada en 1779 y la organización de una milicia en 1774 (Borchart de Moreno y Moreno Yánez, 1995), además de la orientación de la obra pública hacia la 
creación de sistemas de defensa activos en la Ciudad Nueva, como el nuevo fuerte de San Carlos terminado en 1781 (CCG, 8 de junio de 1782) y la Batería de las Cruces en 1800 (Estrada Ycaza, 1972, p. 45).

A finales del siglo XIX el diplomático y explorador francés Charles Wiener expresaba la doble imagen de lo que era la ciudad de la época y lo que había sido a lo largo de ese siglo, una ciudad que se debatía entre la prestancia y la inmundicia:

La primera impresión que causa la vista de este puerto es tan favorable, imponente y risueña a la vez, que uno se siente penosamente afectado al tener que confesar que lo que era tan hermoso a cien metros, sea tan malo de cerca (Wiener, 1884, p. 3).

No debe extrañar esta situación si se considera que entonces la higiene urbana era nula o poco efectiva. Basta leer el artículo 49 de la Ordenanza de Aseo de Calles emitida a inicios del siglo XIX, para darnos una idea de esa situación: "Nadie podrá arrojar a las calles, plazas, acequias ni otros lugares públicos, aguas inmundas; ni tampoco basuras, animales muertos, etc.; fuera de las horas señaladas para el efecto" (Gómez Iturralde, 2007, p. 141). A comienzos del siglo XIX se estaba culminando el proceso de densificación en un área que no había crecido en extensión durante aproximadamente un siglo, aunque la población había pasado de 2.000 habitantes en 1688 a 13.700 en 1803 (Estrada Ycaza, 2001). Para 1861 la población llegaba a 15.367 habitantes y en 1899 ya eran a 60.843 (Estrada Ycaza, 2001), es decir, cuadruplicó su población en un lapso de cuarenta años. Durante ese mismo período pasó de una extensión de 33 ha en 1770, 49 ha en 1857 hasta alcanzar 234 ha en 1900 (Compte, 2013). Para 1830 Guayaquil ya era la segunda ciudad más poblada y para 1880 había superado a Quito en población, por lo que se convirtió en la ciudad con más habitantes del Ecuador (Deler, 2007).

Como medida de precaución ante el aviso de que en Panamá se había presentado una epidemia de fiebre amarilla (Madero, 1955), se creó en 1816 la Junta de Sanidad Provisional encargada de resolver los problemas de aseo y de sanidad pública. Cuatro años más tarde se creó una nueva Junta de Sanidad, con la finalidad de conservar la vacuna de la viruela para aplicarla masivamente a los habitantes, aunque al año siguiente esa vacuna se había perdido al no haber tenido el cuidado suficiente para su conservación (Madero, 1955).

En 1822 nuevamente se creó una Junta de Sanidad, encargada de “... reconocer todos los buques que entraran al puerto” (Madero, 1955, p. 138), la cual al parecer no fue muy efectiva, ya que tres años más tarde se volvió a establecer otra similar con el mismo objetivo de evitar el ingreso de enfermedades a través de este mismo mecanismo. Además de esta iniciativa, se continuó desarrollando un conjunto proyectos de servicio para los habitantes, como la reconstrucción del Hospital de Santa Catalina Mártir (Estrada Ycaza, 1974), una Plaza de Toros en 1808, el Colegio Seminario de San Ignacio en 1816 (Estrada Ycaza, 2001), la Casa Consistorial (CCG, 25 de febrero de 1817), el panteón en 1825, la primera escuela para niñas en 1827 (CG, 8 de junio de 1828) y el nuevo Mercado (Cabildo de Guayaquil, 8 de junio de 1828).

En esa época el drenaje de la ciudad se realizaba mediante la canalización de los desechos domiciliarios hacia el río, a través de los afluentes de los esteros naturales y de zanjas que 
se abrían para este fin. Gómez Iturralde (2007) describe cómo era costumbre el arrojar los desechos domiciliarios hacia el río con “... la creencia que el flujo y reflujo de la marea acarrearía hacia el río la basura y otros desperdicios humanos", aunque "Como este desalojo no era posible, llegaba un momento en que la pestilencia era tan grande, que se veían obligados a limpiarlos con el lodo a la cintura" (p. 138). Esta condición higiénica fue el factor decisivo para que en agosto de 1842 Guayaquil se viera afectada por la aparición de la fiebre amarilla, enfermedad que significó un punto de quiebre para su desarrollo. Como consecuencia de esta nueva situación sanitaria se creó el 5 de noviembre una Junta de Beneficencia con la función de “... auxiliar a los pobres, que por falta de recursos son víctimas de la funesta epidemia que nos aflige" y de reunir los fondos necesarios “... para ayudar a los enfermos desvalidos, o para que la distribuya entre aquellos desgraciados, que a su juicio más necesiten de socorros" (Sánchez Varas, 2008, p. 17).

En febrero del año siguiente, la epidemia ya era mencionada como la principal responsable de la muerte de casi 5.000 personas, la cual era una cifra elevadísima para una ciudad que, de acuerdo al censo de 1840, tenía 13.093 habitantes (Estrada Ycaza, 2001). Debido al gran número de fallecidos y la poca oferta de bóvedas en el cementerio, se llegó a pensar en una gran fosa común.

Si bien el Gobernador Vicente Rocafuerte inició una dura campaña contra la enfermedad, con medidas inclusive curiosas y de dudoso o nulo efecto, como disparos de cañón para “... con el humo de la pólvora purificar la atmósfera” (Madero, 1955, p. 199), la epidemia continuó, pero de manera muy tenue. Felizmente, a inicios de 1845, es decir dos años después de su aparecimiento, había sido controlada, esto a pesar de que, como describía en 1847 el explorador y naturalista italiano Gaetano Osculati (1854), "A cada esquina se encuentran cúmulos de basura y la pestilencia que sale de las cloacas al bajar la marea es verdaderamente insoportable. Estos inconvenientes, junto con el calor sofocante (...) contribuyen a aumentar su insalubridad" (s/p).

Aunque en 1870 se había creado la Empresa de Salubridad Pública, encargada de recoger las excretas de las casas, para luego transportarlas y arrojarlas al Estero Salado, cinco años más tarde aparecieron nuevamente algunos casos de fiebre amarilla que afectaron a la ciudad hasta el mes de noviembre de ese mismo año.

La dualidad con que los viajeros veían la ciudad se evidencia en la descripción que en 1871 hacía el jesuita alemán Joseph Kolberg. Por un lado, comparando la belleza de Guayaquil y su gente con sus referentes europeos:

Llegando del lado del mar, la impresión que produce Guayaquil y sus alrededores es muy alegre; no se cansa uno de admirar el hermoso panorama. Edificios de respetables proporciones se extienden por más de tres kilómetros a lo largo del ancho y elevado muelle, que se distingue por su limpieza; esta larga hilera de edificios, junto a la animada ría, tiene incluso un cierto aire europeo, que hasta ahora yo había echado de menos en América. (...) Gran parte de su esplendor lo debe la ciudad a los muchos europeos que se detienen en Guayaquil; además, los viajes de barco por la costa de aquí al Perú son de no poca importancia, y sobre todo la desierta Lima tiene gran necesidad para su subsistencia, de la rica región costanera del Ecuador (Kolberg, 1996 [1871], pp. 189-190). 
Por otro lado, advertía que esas semejanzas se terminaban una vez que se traspasaba la “... segunda línea de casas que se extienden a lo largo del bello río" (p. 190), por lo que no aconsejaba a los viajeros que se arriesgaran más allá de ellas.

Unos años más tarde, junto con estos proyectos de sanidad pública, se emprendieron otros de índole estética, orientados a evidenciar una imagen de ciudad pujante que rendía tributo a los héroes de su independencia. De esta manera, en 1879, se suscribió el contrato de confección del monumento al Libertador Simón Bolívar con el escultor italiano Geovanni Anderlini. Sin embargo, tuvieron que pasar diez años para que se culminara el monumento que fue colocado en el centro de la antigua Plaza Mayor que a partir de ese momento se denominó Plaza Simón Bolívar.

Paradójicamente la democrática plaza colonial se convirtió en un espacio restringido al que tenían acceso a determinadas horas del día de manera exclusiva las personas que estuvieran “... decentemente vestidas y calzadas” tal como lo establecía el Reglamento del Parque Seminario expedido en 1895 (M. I. Municipalidad de Guayaquil, 1896).

En 1880 y hasta el año siguiente, la fiebre amarilla nuevamente se hacía presente y ocasionó 472 fallecidos (Madero, 1955, p. 259), lo cual para una población de 60.000 habitantes era altamente significativo. Su presencia tampoco quedó inadvertida para Charles Wiener (1879), quien describía que la enfermedad “... empieza siempre por las clases bajas y pasa rápidamente a las elevadas, causando numerosas víctimas en las casas mejor ventiladas” (s/p.).

Ese mismo año, el científico alemán Franz Theodor Wolf presentó un nuevo plano de la ciudad, donde se evidencia un crecimiento sostenido hacia el sur y el oeste, además de su visión de una urbe ordenada que debía crecer mediante la prolongación de la retícula colonial hacia el sur y hacia el oeste. Hacia el norte se evidencia la separación de los dos núcleos coloniales por el Barrio del Puente y un conjunto de quintas insertadas en terrenos bajos, que tenían como límite el camino del panteón.

En 1888 y 1889 dos nuevas epidemias se presentaron. La primera, de sarampión, que atacó principalmente a los niños y ocasionó 556 fallecidos durante los dos meses de su incidencia (Madero, 1955, p. 262) y la segunda, de gripe, que afectó a gran parte de los continentes y se extendió por todo el país en 1892. Ante la incidencia de estas enfermedades se dispuso la aplicación de diferentes remedios terapéuticos y profilácticos, algunos tan curiosos como regar a los enfermos con "agua fenolada o alquitrán" (Madero, 1955, p. 261).

Las obras de canalización y agua potable que se iniciaron en aquella época se veían como las únicas soluciones posibles para evitar la aparición de nuevas enfermedades, tal como lo describía el propio Wolf en 1892:

Así como la población en los últimos 20 años casi se ha duplicado, también el caserío de la ciudad se ha extendido sobre más que el doble de su recinto primitivo, lo que se observa comparando, por ejemplo, el plano que se halla en la Geografía de Villavicencio, con el actual. El cambio y mejoramiento de Guayaquil es tan considerable, qué el que ha visto la ciudad unos 25 años atrás, hoy a su regreso apenas la conocerá. Es una gran ciudad en formación, y será dentro de poco, especialmente concluidas algún día las obras grandes de canalización y agua potable, una de las mejores de Sudamérica (Wolf, 1975 [1892], p. 608). 
Se refiere al plano publicado por Manuel Villavicencio en 1858. Las frecuentes epidemias fueron el factor determinante para que un grupo de médicos de Guayaquil conformaran en 1894 la Academia Libre de Medicina y Ciencias Accesorias de la Ciudad de Guayaquil que, entre sus acciones, definidas en sus estatutos, estableció

a. El estudio teórico y práctico de la medicina en general y de la medicina nacional;

b. El estudio de las enfermedades endémicas propias de Guayaquil y de sus comarcas y de las epidemias que la invaden;

c. El estudio de la climatología;

d. La estadística médica y demográfica de la ciudad (y particularmente del alcoholismo, la sífilis y la enajenación mental);

e. El registro de las necesidades higiénicas de la ciudad (Kingman Garcés, 2006, p. 287).

En ese mismo año se instalaba la primera planta de energía eléctrica y al año siguiente, el 24 de julio de 1895, se daba inicio al servicio de alumbrado público eléctrico en un sector de la ciudad donde el alumbrado de gas, que aún existía, no había llegado (Estrada Ycaza, 2000). Si con las enfermedades no hubiera sido suficiente, el 12 de febrero de 1896 un incendio que se inició alrededor de la una de la mañana en el templo de San Agustín se propagó y dejó como consecuencia doce manzanas incineradas, noventa y tres viviendas destruidas, más de ocho mil personas damnificadas, cinco muertos y más de treinta heridos (Estrada Ycaza, 2007, p. 60). Sin embargo, este no sería el evento más desastroso con el que la ciudad cerraría el siglo XIX.

El 5 de octubre de 1896 será siempre recordado como uno de los días más aciagos en la historia de Guayaquil. Un diario que salió a circulación dos días después destacaba la magnitud de lo sucedido:

Ha tocado para esta ínclita y leal ciudad la hora de la tribulación; de la desolación. Manos criminales han reducido a escombros, en horas para ellas propicia, gran parte de la ciudad, y muchísimas familias, la mayor parte, hállanse hoy sin hogar y $\sin$ pan (...) Si, con ánimo viril, damos un momento de receso al justo dolor, a la profunda atonía de una desgracia sin nombres, procuremos echar una mirada al porvenir y arbitrar inmediatamente los medios de defensa contra un enemigo ya invencible, el fuego (Carbo,1896, citado en Estrada Ycaza, 2007, p. 262).

El incendio, que se cree que fue intencional, se originó en el almacén La Joya, en la esquina de Malecón y Aguirre (Estrada Ycaza, 2007), alrededor de las $23 \mathrm{~h} 40$ del 5 de octubre y se prolongó por dos días hasta la madrugada del 7. Abarcó por el norte hasta el Barrio Las Peñas y por el oeste hasta la calle Chanduy -actual calle García Avilés-.

En el incendio se destruyeron un total de noventa y dos manzanas de las 458 que tenía entonces la ciudad (Estrada Ycaza, 1972), que correspondían a la totalidad existente desde el origen del incendio hacia el norte. Se quedaron sin hogar cerca de 33.000 habitantes, de 
un total aproximado de 59.000 personas que vivían en esa época en Guayaquil, y se contabilizaron una veintena de muertes y decenas de heridos.

En el recuento de lo destruido se incluía el Barrio Las Peñas, la Ciudad Vieja y el Barrio del Puente. Se consumieron por el fuego un total de 1.103 casas y edificios de los 4.265 existentes (Crónica Comercial e Industrial de Guayaquil en el Primer Siglo de Independencia, 1920, p. 67), entre los que se encontraban las principales edificaciones administrativas, además de todos los puentes que existían entre la Ciudad Vieja y la Ciudad Nueva y numerosos pozos que quedaron inutilizados por la ceniza. Se destruyó además importante infraestructura productiva, entre otras: doce casas exportadoras de cacao, las fábricas de Cerveza, de Hielo, de Cigarrillos y de Gas, siete imprentas, seis farmacias, cuatro oficinas bancarias, tres compañías de transporte, además de decenas de almacenes y compañías de comercio.

La destrucción del asentamiento original de la Ciudad Vieja y del espacio entre esta y la Ciudad Nueva, significó, desde lo urbano, el fin del siglo XIX. El incendio determinó la ruptura de la estructura configurada a lo largo de la Colonia y abrió la posibilidad de integrar los dos núcleos urbanos que aún se mantenían sin cambio desde finales del siglo XVII.

Desde diferentes sectores se pedía la inmediata reconstrucción de lo afectado. En diario El Grito del Pueblo del 15 de octubre, se opinaba que era “... la ocasión de construir una ciudad nueva que corresponda a las necesidades de la población” y que "Lo más práctico sería que la Municipalidad procediera en el día a desembarazar de escombros la zona quemada y levantar un plano de esa área con calles de veinticinco metros de ancho, que permitan la circulación libre de las corrientes de aire, y a la vez un método de canalización para los desagües" (Estrada Ycaza, 2007, p. 451).

El 17 de octubre el Cabildo presentó un proyecto de ley a la Convención Nacional, donde se establecía la prohibición de construir en el área afectada hasta que se presentaran y aprobaran las normas para tal efecto. Manifestaba que era necesario “... emprender lo antes posible en la formación de un nuevo plano de la parte incendiada de la ciudad de Guayaquil que corrija los defectos del anterior y la ponga al cubierto de un nuevo desastre", para lo que se encargaría este proyecto " ... a un ingeniero de reconocida competencia”. Se añadía que “... para la fabricación de los nuevos edificios, la Municipalidad dictará una Ordenanza de Ornato y Fábricas", además que los edificios serían sólo de dos pisos y de máximo nueve metros de altura, que no podía utilizarse para su construcción maderas resinosas y que en las paredes colindantes sería obligatorio el uso de cortafuegos (Estrada Ycaza, 2007, p. 452). Diez días más tarde el Cabildo aprobó la Ordenanza de rectificación del plano de la ciudad y fábrica de los nuevos edificios que establecía el trazado de nuevas calles "rectas y amplias", de veinte metros de ancho y la desaparición de los callejones con el fin de evitar la propagación del fuego (CG, 27 de octubre de 1896).

Se decidió también convocar a un concurso de proyectos para la reconstrucción del área afectada, el cual fue ganado por el ingeniero francés Gastón Thoret Jäger, “... por estar más conforme con la facilidad de poderle llevar a cabo tanto por la corrección y delineación de las calles, como por el costo relativamente pequeño de expropiaciones; puesto que por el sistema de compensación se salvan los más notables inconvenientes que presenta el plano citado". 
Thoret planteó una continuación de la cuadrícula ya existente del trazado de la Ciudad Nueva, con la unificación definitiva de los dos núcleos coloniales, por lo que dejaba de lado la antigua imagen desordenada de la Ciudad Vieja. En comunicación dirigida el 10 de noviembre al Concejo Municipal, Thoret explicaba su proyecto de la siguiente manera:

En este estudio me he contraído, sobre todo, a utilizar en lo posible, los trabajos existentes de los acueductos de desagüe, las cañerías de agua potable, las del gas y las líneas de los carros urbanos, buscando a la vez a cambiar lo menos posible la posición de los solares, con el fin de reducir los perjuicios a los propietarios. Por principio no he hecho ningún cambio ni he creado ninguna calle, solo he hecho las delineaciones rectificando o enderezando las calles existentes. Resulta, pues, que la mayor parte de los solares no sufrirán más que un pequeño aumento o disminución; unos pocos cambiarán de sitio, pero guardan su misma orientación (CG. GM, 5 de diciembre de 1896, p. 3214).

Sin embargo hubo críticas sobre el proyecto. En una carta dirigida al Cabildo, Eduardo Game, miembro de la comisión encargada de los proyectos de reconstrucción, indicaba que era "... muy discutible la conveniencia de calles tan anchas en climas cálidos como el nuestro" (CG, 5 de diciembre de 1896). Tampoco los propietarios de los solares afectados por el incendio se encontraban conformes con la propuesta aprobada, por lo que solicitaron que se les permitiera edificar “... sobre el plano antiguo y no sobre el últimamente trazado por el Ingeniero Thoret, que ofrece dificultades, porque el dibujo de este señor, lejos de propender al bien general, viene únicamente a causar un profundo desconcierto en las propiedades" (CG, 13 de marzo de 1897). Sin embargo, a pesar de los reclamos, el 24 de diciembre se suscribió el contrato de inicio de los trabajos de delineación de la ciudad, con el compromiso de terminarlos el 12 de enero del año siguiente (Palacios, 2014).

De esta manera, a comienzos del año 1897, la ciudad se encontró lista para enfrentar la reconstrucción sobre un proyecto que unificaba los dos asentamientos en los que se había dividido la ciudad dese finales del siglo XVII y que, además, resolvía los problemas de un crecimiento histórico desordenado.

La descripción que hacía de la ciudad el ingeniero francés Paul Wéry (1906) en 1906 da una idea del avance del proceso de reconstrucción, tanto en lo urbano como en lo arquitectónico, con la edificación de nuevas casas que reemplazaban a las perdidas en el incendio:

Construcciones espaciosas y bonitas, todas de madera, han reemplazado a las antiguas casas desvencijadas; las calles han sido alineadas y ampliadas y las que antaño eran baches, como el malecón, están ahora revestidas de piedra y son de fácil circulación. (...) Grandes canales a cielo abierto, expuestos al flujo y reflujo de las aguas, pasean de un lado a otro de la ciudad en cada marea los deshechos e inmundicias que han sido botadas, inundando así los barrios por donde pasan con olores nauseabundos. Estos canales han sido parcialmente cubiertos o rellenados. 
Sin embargo, advertía, que aún quedaba mucho por hacer en esa parte de la ciudad “... donde las calles se convierten, a la menor lluvia, en verdaderos pantanos, y donde las casas, muchas de ellas muy antiguas, lo mismo que las casuchas de los más pobres, son de un desaseo repugnante (s/p.).

Menos de seis años después del Gran Incendio, el 16 de julio de 1902 otro incendio de gran magnitud, denominado "del Carmen" porque ese día se celebra el día de Nuestra Señora del Carmen, destruyó “. .. 26 manzanas con 700 casas, dejando 15.000 personas sin techo" (El Grito del Pueblo, 1902). Entre las edificaciones destruidas, además de las viviendas, se encontraban el hospital, la cárcel, la Universidad, el Palacio Episcopal, los colegios La Providencia y Vicente Rocafuerte, las iglesias de San José y San Agustín, entre otras (Estrada Ycaza, 2007).

Esta nueva catástrofe obligó a que la Municipalidad tomara medidas para tratar de evitar que se volvieran a producir estos flagelos, por lo que emitió en 1905 la Ordenanza de Construcción y Ornato que, entre otros aspectos, contemplaba que solo las construcciones realizadas con materiales incombustibles podían tener hasta tres pisos de altura. Adicionalmente prohibía que las construcciones de teatros, templos, capillas y oratorios y otros edificios públicos, fueran hechas con materiales combustibles. En 1905 también fue inaugurada la Planta Proveedora de Agua del Cuerpo de Bomberos, que estaba encargada de proporcionar agua, en suficiente cantidad y presión, para la extinción del fuego (Estrada Ycaza, 2007).

Durante este período continuaron presentándose epidemias, como la fiebre amarilla que ya era considerada endémica. Esto se debía principalmente a la inexistencia de sistemas domiciliarios de desagüe y de canalización de aguas servidas, por lo que los desechos eran arrojados directamente a las calles. Algo había mejorado la situación a partir de la inauguración del sistema de abastecimiento de agua potable, sin embargo, como lo relataba el alemán Hans Meyer en 1907:

La salubridad en Guayaquil es mucho mejor en pleno verano y en el período más fuerte de las lluvias, cuando la gran cantidad de agua ha arrastrado todas las inmundicias; es peor al comienzo de la estación lluviosa, cuando se ponen en actividad millones de mosquitos, y al empezar la estación seca, cuando el sol hace brotar todas las miasmas posibles (1993 [1907], s/p).

Como si esto no hubiera bastado, entre 1907 y 1908 se desató una epidemia de peste bubónica que fue combatida con una campaña de exterminio de los roedores, de donde se originaba el agente transmisor de la enfermedad. Para darnos una idea de la magnitud problema que significaba la invasión de ratas y ratones, el 19 de marzo de 1908 se ejecutaba la orden de incineración de la Casa Municipal y de la Plaza del Mercado que se encontraban infestadas por estos animales. Este nuevo hecho determinó que se empezara a debatir sobre qué tipo de acciones debían tomarse para poder erradicar, de una vez por todas, la imagen de ciudad desaseada y peligrosa para los visitantes por el riesgo de contraer enfermedades mortales. 


\subsection{Utopías urbanas y sociedad moderna: higienización y estética en el Guayaquil del siglo XX}

Sin dejar de atender la prosperidad y embellecimiento de las diversas poblaciones de la República, Guayaquil puso todo su esmero en darle a Bello Edén la supremacía entre todos los países del universo. Todas las calles de la ciudad estaban canalizadas y empedradas. Todas las casas y edificios públicos, tenían desagües, tuberías de fierro para el agua del consumo diario y para el socorro, en los casos de incendios, en pozos dotados de los respectivos aparatos, movidos por la electricidad; luz eléctrica, baños, excusados y teléfonos (...)

El Malecón, en su extensión de siete leguas, tenía setenta metros de ancho y estaba embellecido, de trecho en trecho, con jardines de vistosas y fragantes flores y estatuas de personajes célebres. Cada barrio contenía siete grandes teatros y veinte pequeños, pues el pueblo ya no gustaba de los títeres ni de las maromas: se deleitaba más con los dramas y las comedias (...)

Sin embargo de este visible progreso, aplaudido por todo el mundo, Guayaquil no estaba aún satisfecho de sus obras. Deseaba todavía embellecer más a bello Edén y al mismo tiempo establecer en otras ciudades del universo, reformas y mejoras que les eran necesarias (Gallegos Naranjo, 1901).

La bonanza económica que experimentaba el Ecuador, fruto del auge de la exportación del cacao, posibilitó que se empezaran a pensar en ciudades diferentes, que incorporaran los avances de la modernidad, que rompieran con la estructura y las características coloniales. Unas ciudades soñadas y utópicas.

El lugar central de la utopía es la ciudad. En lo urbano es donde se plasma el discurso crítico frente a la realidad, donde se imagina el cambio social, los sueños de libertad, de justicia y de convivencia equitativa, donde se concreta el deseo de tener un lugar ideal para vivir mejor, que aluda a los proyectos de futuro. La utopía también hace referencia a la necesidad de diseñar ciudades que contrasten el pasado con el futuro y que, en el caso de nuestras ciudades, rompan con la continuidad colonial y den paso a una ciudad moderna que al mirar a Europa como referente, supere el caos, el desorden y el desaseo.

Estos ideales de una ciudad embellecida y con una sociedad moderna los expresaba Manuel Gallegos Naranjo en su obra Guayaquil. Novela fantástica, publicada en 1901, donde describía un país imaginario, cuyo presidente llamado Guayaquil desarrollaba proyectos de embellecimiento para la ciudad de Bello Edén, capital de la república, la que debía convertirse en la ciudad más grande e importante del mundo conocido. Bello Edén no era otra que la propia Guayaquil.

En 1906, cinco años después de publicada esa novela, se presentó en Francia el resultado de un concurso destinado a desarrollar la New Guayaquil en la orilla opuesta del río Guayas, sobre terrenos colindantes con la terminal ferroviaria. El concurso encargado a la Societé des Architectes diplomés par le Gouvernement de París, debía desarrollar una ciudad para 80.000 a 100.000 habitantes a partir de un programa “... espléndido sin ningún obstáculo para una concepción absolutamente libre, casi un programa teórico” (Jaeschke, 1907, p. 74). El 15 de diciembre de ese mismo año se adjudicaron los premios. El primero 


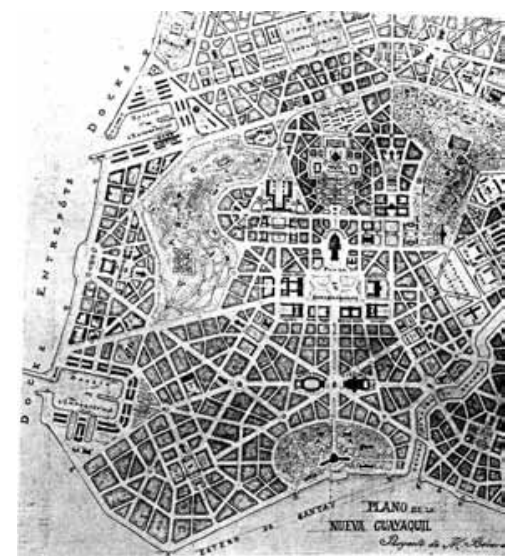

Figura 3. Proyecto ganador del Primer Premio del concurso para la New Guayaquil (Jaeschke, 1907, p. 78)

le correspondió al proyecto de André Bérard (Ver Figura 3), el segundo a Monsieur Duménil, el tercero a Monsieur Morin Goustiaux y el cuarto a Marcel Cochet. En el número 46 de la Revista Técnica de la Sociedad General de Arquitectos de Buenos Aires, publicado en diciembre de 1907, Víctor Julio Jaeschke describía el proyecto ganador:

El proyecto de M. Bérard, se distingue desde el primer vistazo por su aspecto realista y vívido; se creería, casi, al ver esta composición libre y suelta, que uno se halla frente a un plano desarrollado por la acción de los siglos y por las modificaciones que las generaciones sucesivas imprimen a sus centros sociales. También se comprende en seguida las grandes divisiones de la ciudad, donde fácilmente se distingue el barrio del comercio, con sus dos puertos, sus Docks, su Bolsa de comercio. Es uno de los centros de la composición muy juiciosamente colocado en la ribera del río Guayas, el más fácilmente accesible para los buques. Este barrio se relaciona con la ciudad a través del Mercado principal y una gran ruta que conduce de allí al barrio de lujo y de placer, donde el Casino, el Teatro y el Hipódromo jalonan el eje principal de la composición, acertadamente dirigida también hacia el estero de Santay, donde las Islas salpicadas en el río forman, para los ojos del espectador, una alegre visión. A partir de allí, la Avenida axial, 'les Champs Elysees' o 'l'Unter den Linden', de la nueva ciudad suben hasta la Plaza de la Gobernación completamente central y epicentro de los distintos edificios administrativos y, en el eje, la Catedral, no nos olvidemos que estamos en Sudamérica (1907, p. 76).

Como se evidencia, se trataba de una ciudad con referentes europeos que se había abstraído de su entorno físico y climático, sin embargo eso era algo que para algunos de los 
analistas de la época carecía de importancia. Robert de Souza, por ejemplo, en un artículo publicado en Niza en 1911, justificaba este hecho de la siguiente manera:

M. Bérard no ha estado nunca en Guayaquil, y ha trabajado como un compositor de música sin piano, lo cual importa poco al verdadero artista y de ciencia profunda; todos saben que las obras maestras de Bethoven (sic) datan del tiempo en que se encontraba sordo. Así, pues, basta al arquitecto ver en el terreno, un buen plano y M. Bérard lo ha visto tan bien, que los ecuatorianos no encontrarán nada que decir.

En la misma línea, Jaeschke reflexionaba sobre el hecho de que se hubiera realizado una propuesta como si tratara de una locación con características climáticas similares a las europeas, aunque, para él, esto se debía a que

... ninguno de los concursantes ha tenido suficientemente en cuenta las circunstancias de hallarse la ciudad proyectada en un clima á (sic) no dudar muy caluroso. Nos preguntamos si, en una región en la que siempre en medio día se halla el sol en el cénit, ¿no habría verdadera conveniencia en que no se abusara de los espacios abiertos ni de las calles por demás anchas? ¿No convendría más bien crear numerosas calles relativamente angostas y tener en cuenta la dirección de los vientos que más á (sic) menudo soplan con el objeto de asegurar la aereación (sic) y la higiene de las manzanas?

Sin embargo consideraba que era una simple "crítica de detalle" y que siempre sería fácil “... mejorar en este sentido los proyectos premiados" (Jaeschke, 1907, p. 76). Finalmente lamentaba que ese tipo de iniciativa no se hubiera dado en Buenos Aires, sino que hubiera sido “... la pequeña ciudad de Guayaquil en el Pacífico, la que haya tenido que dar el ejemplo de semejante concurso en Sud América” (p. 77).

Ya desde el año 1912 se pensaba en el mejoramiento estético de la ciudad. Para lo cual se conformó la Junta de Embellecimiento de la Ciudad que tenía como fin "La conservación, mejora y administración de los paseos, plazas, alamedas, parques y vías públicas en general, existentes o que en adelante se establecieren", además de "Propender por todos los medios posibles al embellecimiento de la ciudad" (OM, 19 de diciembre de 1912).

Dos años después, en 1914, se suscribió el contrato de saneamiento con la compañía inglesa J. G. White \& Co. Limited, para la realización de “... trabajos de drenaje, construcción de un reservorio entre los cerros Santa Ana y del Carmen, instalación de redes para aguas lluvias y aguas servidas, instalación de redes para el agua potable, relleno y pavimentación de calles y construcción del malecón" (Arosemena, 1991, p. 84).

No fue sino hasta 1915, teniendo en miras la celebración del primer centenario de la independencia, cuando que se volvió a pensar en la posibilidad de una ciudad diferente bajo premisas estético-higienistas. En el Diario Ilustrado del 28 de octubre de 1915 se destacaba esta decisión y se vislumbraba a Guayaquil convertida en "... una de las ciudades más adelantadas y más bellas de la América del sur”, y que esto se podría lograr cuando “... se realice el sueño del patriotismo, que la ve ocupar el primer puesto entre sus hermanas 
del continente", todo esto debido a la incorporación al área urbana de la Quinta Pareja, “... uno de los focos de infección más poderosos" y “... el asilo de gente maleante, que encontraba allí seguro refugio para librarse de las garras de la justicia” (Gómez Iturralde, 2005, p. 478).

El 16 de octubre de ese mismo año, mediante Decreto Legislativo, se declaraba al 9 de Octubre de 1820, día de la independencia de Guayaquil, como Fiesta Nacional y se decidía la conmemoración de su primer centenario, por lo que desde el Cabildo se estableció que para su celebración se orientaría la obra pública hacia el saneamiento, el embellecimiento y el ornato. Para cumplir con este cometido se conformó la Junta Patriótica para la celebración del Centenario del Nueve de Octubre que debía encargarse de la generación de proyectos urbanos de mejoramiento de la infraestructura sanitaria y de propuestas de estética urbana.

El 22 de noviembre se instaló la Junta y nombró como Presidente a Enrique Baquerizo Moreno. Más adelante se encargó al ingeniero guayaquileño Luis Alberto Carbo Noboa y al ingeniero venezolano Francisco Manrique el desarrollo de un proyecto de reforma urbana orientado a acabar la imagen de ciudad colonial y que se diera paso a una ciudad moderna.

Carbo y Manrique presentaron una propuesta de inspiración neoclásica que representaba la aspiración de modernidad de la burguesía ascendente, que confería importancia a los monumentos, pero que incluía también el desarrollo de espacios urbanos planificados e incluyentes.

Aunque salvo por la prolongación en diagonal de la avenida Olmedo se conservaba el damero colonial que se había reafirmado con el proyecto de reconstrucción de Thoret. Entre los componentes principales del proyecto, además de otros de estética y mejoramiento sanitario, estaban los siguientes:

1. La transformación de la calle 9 de Octubre en un boulevard de catorce metros de ancho, iluminado con faroles eléctricos y de gas, pavimentado con concreto y flanqueado por árboles, que se extendía desde el Malecón hasta la nueva Plaza 9 de Octubre.

2. La supresión de la estrecha calle Villamil, con el fin de permitir la prolongación de las calles Pichincha y del Malecón Simón Bolívar, lo cual obligaba a expropiar determinados terrenos. La eliminación de esta calle se orientaba a dejar atrás la ciudad colonial desaseada, de calles angostas y tortuosas, para dar paso a una ciudad moderna donde estaba presente la amplitud, la higiene y el confort.

3. La extensión del muro del malecón y la construcción de un paseo peatonal de tres kilómetros de extensión, a lo largo de la orilla del Río Guayas, paralelo al Malecón, desde el Barrio Las Peñas, al norte, hasta la avenida Olmedo, al sur. No fue terminado hasta 1931 cuando se lo denominó Paseo de las Colonias Extranjeras.

4. La urbanización de los cerros Santa Ana y El Carmen y el mejoramiento del Barrio Las Peñas.

5. La construcción de la Plaza del Centenario de nueve hectáreas de extensión, en un área en la que habría que expropiar catorce manzanas, donde se erigiría una columna recordatoria a los próceres de la Independencia del 9 de octubre de 1820. 


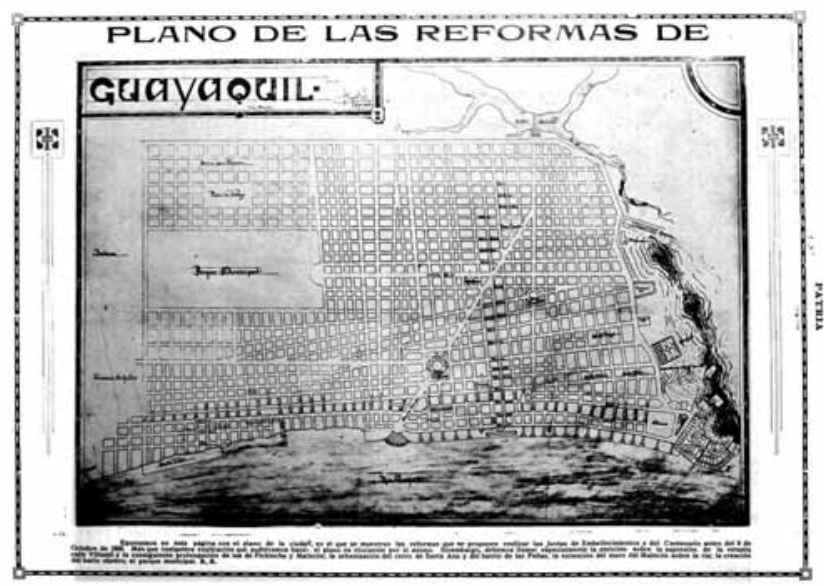

Figura 4. Proyecto de reforma urbana presentado por Francisco Manrique y Luis Alberto Carbo Noboa a la Junta Patriótica para la celebración del Centenario del Nueve de Octubre (Revista Patria número 5, 1918).

6. La prolongación de la avenida Olmedo con su trazado en diagonal, rezago del antiguo foso de San Carlos o Estero de Saraguro, y su intersección con la avenida 9 de Octubre.

7. En cada uno de los remates de las nuevas avenidas propuestas, se debería erigir un monumento conmemorativo a la independencia y a sus actores, además de arborizar el resto de las calles del área central y de dotarlas de mobiliario urbano.

La implementación de este proyecto fue parcial ante la limitación de los recursos y la oposición de los habitantes por el temor que suscitaban las expropiaciones que hubiera sido necesario hacer. Sin embargo sí se pudieron concretar algunas de las propuestas, como la de la Plaza del Centenario, inaugurada el 9 de octubre de 1920 -que se ubicó en el lugar donde el proyecto contemplaba la Plaza Nueve de Octubre- donde se erigió una columna en homenaje a la independencia de la ciudad, diseñada por el escultor catalán Agustín Querol (Ver Figura 4).

Respecto al estado sanitario de la ciudad, continuaban las acciones orientadas a eliminar su condición de "puerto pestífero del Pacífico". En 1916 la Comisión de fiebre amarilla de la Fundación Rockefeller, concluía que Guayaquil era el único centro endémico de esta enfermedad que aún existía en el continente (Mejía Rodríguez, 2004). Sin embargo no fue hasta en 1918, luego de la muerte de la esposa del Cónsul norteamericano a causa de fiebre amarilla, cuando el Presidente de la República Alfredo Baquerizo Moreno solicitó que la Fundación Rockefeller colaborara con el Departamento de Sanidad Ecuatoriana a fin de encontrar un remedio eficaz y definitivo contra la epidemia. Esta institución designó a 
dos de sus miembros, el médico estadounidense Michael O'Connor y el bacteriologista japonés Hideyo Noguchi para que intensificaran las campañas y ahondaran más en sus investigaciones y análisis.

El primer paso que se dio fue la búsqueda del germen infeccioso, con la finalidad de elaborar una vacuna preventiva de inmunidad; el segundo paso, fue poner en cuarentena a todos los infectados; el tercero la fumigación de todos los lugares que las víctimas visitaron antes de contagiarse y el cuarto, la disminución del mosquito transmisor. Mediante experimentos en animales se logró separar el germen de la enfermedad, lo cual condujo a la inmediata elaboración de una vacuna y de un suero curativo. Finalmente, luego de casi doscientos años de lucha contra la fiebre amarilla, la epidemia pudo ser controlada.

\subsection{Transformaciones urbanas en tiempos de crisis}

La presión demográfica que vivió Guayaquil entre 1880 y 1920, en plena etapa del segundo boom cacaotero, impulsó a las élites locales a la ampliación del límite urbano hacia el sur, en terrenos que habían sido de propiedad de la Sociedad Jockey Club. De esta manera se concibió el Barrio del Centenario en 1919, primer ejemplo de urbanización planificada, destinado exclusivamente a "guayaquileños de alcurnia", según estableció su reglamento interno (Lee, Compte y Peralta, 1989, p. 96). La iniciativa de este barrio surgió como resultado del emprendimiento de Rafael Guerrero Martínez y Juan Xavier Aguirre, quienes recibieron la concesión del Concejo Municipal para lotizarlo “... con ochenta viviendas tipo chalet, con antejardín, desarrolladas en dieciséis manzanas, destinadas a familias adineradas de la ciudad" (Compte, 2009, p. 113). Sin embargo en los primeros años apenas se habían construido seis casas, ya que se consideraba que quedaba muy distante del centro de la ciudad, por lo que no se empezó a poblar sino a partir de la década de 1930 (Compte, 2009).

El 22 de mayo de 1929 la Oficina Sanitaria Panamericana declaraba que se había presentado el último caso de fiebre amarilla en la ciudad (Guayaquil, Puerto Limpio de Clase A, 1930) y un año más tarde era erradicada la peste bubónica, que había causado estragos desde 1908, “... como consecuencia de la desratización en el puerto de Guayaquil, por el atrape y especialmente por el envenenamiento sistemático e intenso" (Miño, 1933, s/p.). Todo este conjunto de medidas sanitarias y preventivas trajeron consigo que para el 30 de septiembre de 1930, Francisco Boloña, Ministro de Previsión Social y Sanidad e Higiene, pudiera indicar que “... el Puerto de Guayaquil es y debe ser considerado Puerto Limpio de la Clase A, de acuerdo con los requisitos y las prescripciones del Tratado Sanitario conocido con el nombre de Código Sanitario Panamericano", debido a que "... no existe en el citado puerto, ni en los pueblos vecinos, ningún caso de peste bubónica, cólera, fiebre amarilla, tifus exantemático, ni ninguna otra enfermedad contagiosa en forma epidémica grave susceptible de ser transportada mediante el comercio internacional" (Guayaquil, Puerto Limpio de Clase A, 1930, s/p.).

La grave crisis de la economía del país que se inició en la década de 1920 y que se extendió hasta casi finales de la década de 1940, repercutió fuertemente sobre el desarrollo de la ciudad. Se inició una fuerte ola migratoria hacia los polos urbanos más importantes del país, sobre todo a Guayaquil, por parte de sectores campesinos que se habían visto seria- 
mente afectados por la caída de los precios de los productos agrícolas, dando inicio, de esta manera, a la conformación del subproletariado guayaquileño.

Como consecuencia de esto se iniciaron una serie de asentamientos informales en las zonas periféricas de la ciudad, sobre terrenos sin servicios y con construcciones precarias. Sin embargo, y a pesar de la crisis, se iniciaron un conjunto de proyectos orientados a vincular la ciudad con el resto del país y el mundo. La necesidad de conexión interna posibilitó que en 1929 se estableciera la primera compañía de autobuses urbanos que conectaban el centro de la ciudad con el límite sur (Estrada Ycaza, 1996). En 1932 se inauguró la pista de aviación con un servicio aeropostal regular entre esa ciudad y la capital (Sánchez Varas, 2008) y dos años más tarde la Sociedad Técnica Fénix culminaba la construcción en hormigón armado del tramo norte del Puente 5 de Junio sobre el Estero Salado, que prolongaba la avenida 9 de Octubre.

Dos graves terremotos afectaron la ciudad en este período, el primero, el 13 de mayo de 1942, con epicentro en la Provincia de Manabí, con una magnitud de 7.9º que en Guayaquil generó la destrucción de los edificios donde funcionaban la Clínica Arreaga Gómez, la Sociedad de Beneficencia de Señoras, el Colegio María Auxiliadora, entre otros. El segundo, el 30 de enero de 1943, con epicentro en la Península de Santa Elena, con $6.9^{0}$ de magnitud, donde provocó la muerte de una persona y once heridos. Entre los daños materiales en Guayaquil se contó la caída de la Torre de la Iglesia San José, el agrietamiento en edificios de hormigón armado y la caída de paredes en edificios mixtos.

Una de las obras de más trascendencia de la época el diseño y construcción de la Ciudadela Universitaria para la Universidad de Guayaquil, proyectada por el arquitecto guayaquileño Héctor Martínez Torres, en sociedad con Manuel Gambarrotti y Rafael Rivas Nevárez.

En general el desarrollo de propuestas para campus universitarios en América Latina fue la oportunidad de probar ideas modernas en una escala mayor a la del edificio y de experimentar la visión de una ciudad de trazados regulares, superficies verdes y la zonificación de usos de suelo. A decir de Silvia Arango (2012) los campus universitarios fueron “... la realización más significativa como grupo generacional de los arquitectos y presidentes progresistas" (p. 356).

La idea del campus se empezó a concretar el 2 de enero de 1945, cuando la Asamblea Constituyente autorizó a la Municipalidad para que adjudique a la Universidad de Guayaquil un terreno de $200.000 \mathrm{~m}^{2}$ de extensión en el noreste de la ciudad, en un sector pantanoso aledaño al Estero Salado (Ayón de Messner, 1967). Dos años más tarde, el 23 de junio de 1947, el Consejo Universitario abrió un concurso de anteproyectos para la ejecución de su ciudad universitaria, que fue ganado por Martínez Torres (bajo el seudónimo de "Otro"), con un planteamiento de una avenida longitudinal a la que convergían un conjunto de edificios dentro delclasicismo moderno. Los puestos siguientes fueron ocupados por el arquitecto Guillermo Cubillo, quien consideró que su propuesta fue excluida por ser “... demasiado moderna” (p. 75), el arquitecto colombiano Edmond Baca y el ingeniero quiteño Alberto Asanza.

Tuvo que esperarse hasta 1949, junto con la recuperación económica del país, cuando se dio inicio a las trabajos bajo la dirección del propio Martínez Torres (Ayón de Messner, 1967), quien ocupó dicha dirección por veinte años. En el acto de inauguración se firmó un acta que fue guardada en el obelisco conmemorativo que se erigió en el nuevo campus. 
En el monumento se colocó una placa de bronce con la siguiente leyenda: "En este día octogésimo segundo aniversario de la fundación de la Universidad de Guayaquil, se inauguró la construcción de esta Ciudad Universitaria, obra que inicia una nueva etapa en la vida fecunda de la institución. 1 de Diciembre de 1949” (Ayón de Messner, 1967, pp. 188-189). Durante el período en el que Martínez Torres estuvo al frente de la planificación del campus, desarrolló los proyectos arquitectónicos y la construcción de los edificios de las facultades de Ciencias Físicas y Matemáticas, entre 1950 y 1952; Jurisprudencia y Ciencias Sociales, entre 1952 y 1954; Ciencias Económicas, entre 1953 y 1955; Filosofía, Letras y Ciencias de la Educación, entre 1956 y 1959; Ciencias Médicas, entre 1960 y 1963 y Ciencias Administrativas, en 1969. A estos edificios, se sumaron los de la facultad de Arquitectura, diseño de Xavier Quevedo; Odontología y Ciencias Químicas y Naturales, diseño de Pablo Graff; Ingeniería Química, diseño de Román Font; además del Club Universitario diseñado por Simón Bolívar Jalón Feraud.

A partir de los cincuenta, la ciudad de Guayaquil empezó a modificar su perfil urbano. En el área central se empezaron a derrocar las antiguas edificaciones de vivienda para levantar edificios destinados a actividades comerciales. Los sectores medios se desplazaron hacia la periferia en las nuevas urbanizaciones que fueron levantadas, emulando los modelos de ciudad jardín, mientras los estratos más bajos se asentaron en las zonas bajas e inundables de la sabana, aledaña a los esteros.

Del pequeño asentamiento de mediados del siglo XVI, apretujado y caótico, se dio paso a la ordenada Ciudad Nueva de finales del siglo XVII que no pudo imponerse sobre su precedente y surgió una ciudad bicéfala que se mantuvo hasta finales del siglo XIX, cuando, luego de la obligada reconstrucción luego del Gran Incendio, se unificaron por fin los dos antiguos asentamientos. Sin embargo, durante el siglo XX, tanto el auge económico como la gran depresión del país, determinaron que Guayaquil fuera un atractivo polo de atracción para migrantes de todas las regiones, por lo que la ciudad creció de manera acelerada y sin planificación.

Esta ha sido la crónica de una ciudad donde un modelo urbano ha sustituido a otro, y donde los procesos de planificación se han querido imponer aun cuando hayan quedado rezagados por la propia dinámica del acelerado crecimiento de la ciudad. Es la historia de una ciudad fallida.

\section{Capítulo 3. La arquitectura ecuatoriana como emergente de la cultura de la modernidad}

... el discurso sobre el modernismo en arquitectura fructifica en un amplio rango de respuestas, motivando a sus participantes a adoptar posiciones y preguntas anteriores, refinándolas o reformulándolas, en respuesta, entre otros, a los desarrollos social, cultural, político, económico y tecnológico, todos estos extrínsecos a la arquitectura, pero siempre penetrantes en las siempre permeables y altamente articuladas fronteras de la disciplina (Goldhagen, 2008, p. 35) . 
A finales del siglo XIX, el Ecuador contaba con cerca de un millón y medio de habitantes, de los que aproximadamente setenta mil vivían en Guayaquil. En la región costa se producía el cacao que era el primer producto de exportación y la base de los ingresos económicos del país. Las rentas cacaoteras posibilitaron el surgimiento de una fuerte burguesía guayaquileña, vinculada con el comercio y con los principales bancos privados, además de estar relacionada con una incipiente industria de curtiembres, cemento, bebidas gaseosas, calzado, aserríos de madera, galletas y caramelos, chocolates, fideos, jabones, cervezas, cigarrillos, materiales de construcción, entre otros (Paredes, 2003).

Guayaquil era considerada la “... de mayor riqueza del Pacífico en relación a su tamaño y una de las ciudades más ricas del mundo en proporción a su población (Pepper, 1908, p. 10 ), ya que a través de su puerto se movilizaba “... el 70\% de las exportaciones" de todo el país “... y más del 90 \% de las importaciones” (Arosemena, 1993, p. 22). El auge económico y la prosperidad posibilitó el desarrollo de la obra pública en todo el país, especialmente la vial, que permitió integrar físicamente la región costera con la andina, a través, sobre todo, de la construcción del Ferrocarril del Sur, ideado por García Moreno y terminado durante el período alfarista.

Entre 1917 y 1926 la producción cacaotera disminuyó significativamente por la falta de mantenimiento de las plantaciones y, principalmente, por las plagas, lo que sumado a la baja del precio de ese producto en el mercado internacional, determinó que se afectara seriamente la economía ecuatoriana al destruirse su principal fuente de riqueza. El país inició así un proceso de crisis profunda que perduraría por varias décadas, que se expresó en la reaparición de formas precarias de producción, además del aumento del desempleo y la pobreza. Sin embargo, como indica Willington Paredes (2003), a pesar de la crisis Guayaquil “... siguió siendo el espacio social más desarrollado de la modernidad ecuatoriana que se abrió con la revolución liberal” (p. 127).

A partir de 1929 la Gran Depresión mundial agudizó aún más la situación nacional al ocasionar la disminución de los precios internacionales de los productos agrícolas nacionales de exportación. En apenas tres años, entre 1928 y 1931, la base monetaria ecuatoriana cayó $40 \%$, la reserva monetaria internacional descendió $66 \%$ y el presupuesto del Estado se redujo en 32\% (Arosemena, 2013). Entre 1923 y 1937 la moneda ecuatoriana de esa época, el sucre, se devaluó en 300\% con relación al dólar norteamericano (Arosemena, 2014) y se originó un período de aguda inestabilidad política que significó que entre 1924 y 1948, se sucedieran veinticinco mandatarios, entre jefes de gobierno, presidentes, encargados del poder, gobiernos de facto y juntas provisionales de gobierno, algunos de los cuales duraban pocas semanas e incluso pocos días.

La crisis determinó que muchos procesos de modernización se truncaran, que se agudizaran aún más las contradicciones sociales y surgieran grandes zonas de marginalidad en áreas periféricas de las más importantes ciudades, conformadas por masas poblacionales que buscaban el medio para mejorar sus condiciones de vida.

A pesar de que algunos historiadores como Agustín Cueva (2009) afirman que la modernidad del Ecuador empezó con la Revolución Liberal de 1895, lo cierto es que el Ecuador de inicios del siglo XX seguía conservando su condición de jerárquico en su estructura social, con un sistema de clases heredado de la Colonia, aunque se empezaban a incorporar algunas medidas de modernización social como las leyes de Registro Civil, de Matrimonio 
Civil, la incorporación de la mujer en el mundo laboral, la separación de la Iglesia y el Estado, la implantación de la educación laica, entre otras.

En Guayaquil se pueden ubicar algunos acontecimientos que apuntan a estos mismos años como quiebres de una continuidad tanto cultural como arquitectónica y de profundos cambios sociales. En 1929, por ejemplo, el llamado Grupo de Guayaquil, conformado por los escritores Demetrio Aguilera Malta, Joaquín Gallegos Lara y Enrique Gil Gilbert a los que se sumaron José de la Cuadra y Alfredo Pareja Diezcanseco, publicó el libro de cuentos Los que se van, que se considera el punto de partida de la modernidad literaria ecuatoriana. La Segunda Guerra Mundial posibilitó el inicio de la recuperación y la reactivación del capitalismo agro-exportador guayaquileño y el inicio de un período de estabilidad democrática, al aumentar la demanda de otros productos agrícolas como el arroz, la balsa, el caucho y principalmente el banano a partir de 1948.

En el presente capítulo se abordan los factores políticos, económicos, sociales y culturales que ayudan entender de qué manera surgió y empezó la consolidación de la Arquitectura Moderna. En primer lugar, los cambios en la visión de del desarrollo del país, desde las posiciones conservadoras de finales del siglo XIX, la modernización liberal, el progresismo de izquierda de la llamada Revolución Juliana, hasta el desarrollismo de inicios de la década de 1950. En segundo lugar, la identificación de la irrupción de aquellos dispositivos de nueva sensibilidad, ligados a la naciente modernidad, vinculados a la necesidad de expresar no solo que se era moderno sino que se debía actuar como tal. En tercer lugar, la vinculación entre el cambiante rol de la mujer, a través de su vinculación con el mundo laboral productivo, la concepción del hogar y los cambios que estos generaban en la espacialidad arquitectónica de la vivienda. En cuarto lugar, el paso hacia una visión moderna tanto del arte como de la literatura, generado desde Guayaquil, que fue luego replicado en el resto del país. Finalmente, la figura de Rafael Rivas Nevárez, arquitecto, ilustrador, diseñador, crítico de la arquitectura y caricaturista destacado, cuya obra a la consolidación de la Arquitectura Moderna y al desarrollo de nuevas disciplinas ligadas a la modernidad.

\subsection{Ecuador entre 1860 y 1948: del orden y progreso al caos político y económico}

La independencia del dominio español no nos puso a salvo de la demencia. El general Antonio López de Santana, que fue tres veces dictador de México, hizo enterrar con funerales magníficos la pierna derecha que había perdido en la llamada Guerra de los Pasteles. El general García Moreno gobernó al Ecuador durante dieciséis años como un monarca absoluto, y su cadáver fue velado con su uniforme de gala y su coraza de condecoraciones sentado en la silla presidencial (García Márquez, 1982).

Legítimamente puede afirmarse que la edad moderna del Ecuador empieza con la Revolución Liberal de 1895, ya que hasta entonces este país fue una sociedad de tipo feudal, que pese a haber alcanzado la emancipación política de España en 1822, seguía conservando, sobre todo en la región interandina, las estructuras económicas y sociales heredadas de la Colonia (Cueva, 2009). 
Distintas visiones se desarrollaron en el Ecuador en los casi cien años que se iniciaron en 1860 con la asunción al poder del conservador García Moreno y que se extendió hasta 1948 cuando el país regresó a la constitucionalidad y a la estabilidad luego de décadas de crisis política y económica.

En la sucesión de gobiernos de diferentes ideologías que gobernaron al país durante esos años estuvo presente la idea de progreso y la creación de un mundo nuevo, que se expresó, a decir de García Canclini (1990), en una organización racionalista de la sociedad, en la creación de empresas productivas y eficientes, en una estructura de estado bien organizada, en la industrialización, el fortalecimiento de estados nacionales autónomos, a través de un proyecto que tenía como base económica al capitalismo y que como fin a la incorporación del país a la modernidad.

La patética imagen del cadáver de Gabriel García Moreno, el otrora poderoso presidente del Ecuador, sentado en el sillón presidencial y ataviado con uniforme de gala y la banda presidencial, presidiendo su propio funeral en la Catedral Primada de Quito, luego de caer asesinado el 6 de agosto de 1875 al pie del Palacio de Gobierno frente a la Plaza Grande, da una idea del respeto y temor que infundía aún después de su muerte. Probablemente no haya existido una figura política ecuatoriana tan compleja y contradictoria en toda la historia del país, tal como lo afirma Rosemarie Terán Najas:

La historiografía ecuatoriana ha pintado en general una imagen sombría y contradictoria del presidente Gabriel García Moreno, figura gravitante del escenario político ecuatoriano entre 1860 y 1875, año de su asesinato. Como ningún otro, este personaje ha desatado las posiciones más extremas. Tradicionalmente denigrada por los liberales y por la izquierda, de un lado, y glorificada por la derecha y la Iglesia, de otro, la figura de García Moreno todavía suscita interrogantes que esperan respuestas menos traspasadas por las pasiones políticas. No obstante, pese a las polémicas, es difícil desconocer ahora que su gobierno jugó un papel crucial en la consolidación del Estado Nacional y en la integración territorial del Ecuador (Terán Najas, 2015, p. 72).

Durante los años de gobierno de García Moreno se afianzaron las relaciones con la Iglesia Católica mediante la firma de un Concordato con el Vaticano, orientado a la construcción de una modernidad clerical que, entre otros aspectos, establecía fueros especiales que eran controlados por la Iglesia, la libre migración de comunidades religiosas extranjeras, el financiamiento estatal para las misiones y la reducción de las atribuciones presidenciales sobre la Iglesia (Quintero y Silva Charvet, 2013). Además se entregaba la educación, en todos sus niveles, a diferentes comunidades religiosas (Kingman Garcés y Goetschel, 2014) y se establecía que “... la Religión de la República es la Católica, Apostólica, Romana, con exclusión de cualquier otra” y que “... los poderes políticos están obligados a protegerla y hacerla respetar” (Constitución del Ecuador de 1869). El propio García Moreno sostenía que todos los adelantos “... serían efímeros e infructuosos si no hubiéramos fundado el orden social de nuestra República sobre la roca, siempre combatida y siempre vencedora, de la Iglesia Católica" y que el fin era el restablecer "el imperio de la moral", 
... sin la cual el orden no es más que tregua o cansancio, y fuera de la cual la libertad es engaño y quimera; moralizar un país en el que la lucha sangrienta del bien y el mal, de los hombres honrados contra los hombres perversos, ha durado por espacio de medio siglo, y moralizarlo por medio de la represión enérgica y eficaz del crimen y por la educación sólidamente religiosa de las nuevas generaciones; respetar y proteger la santa Religión de nuestros mayores, y pedir a su influencia benéfica la reforma que las leyes y los gobiernos no pueden conseguir por si solos (García Moreno, citado en Pólit Lasso (comp.), 1923, p. 87).

El proyecto modernizador garciano se orientó a la reforma y el desarrollo de las instituciones ya existentes, poniéndolas en función de su proyecto centralizador. Con el fin de fortalecer un nuevo tipo de estructura estatal, más sólida y ágil, orientó la vinculación del país con el mercado internacional (Ayala Mora, 2011); vigorizó la institución familiar; modernizó la Policía, las Fuerzas Armadas y el régimen penitenciario; amplió las bases de la educación, mediante la creación de escuelas rurales y la modernización de los planes de estudio; llevó adelante un plan vial del país y concibió la línea férrea que comunicaría Quito con Guayaquil; además de la reforma del sistema electoral que implementó el sufragio directo. Por otra parte, estableció que para ser ciudadano se requería ser católico, alfabeto, casado y mayor de veintiún años, además de vetar el derecho de ciudadanía para aquellos que pertenecían a alguna organización prohibida por la Iglesia Católica.

En un mensaje que García Moreno dio a la Convención Nacional de 1869, expuso sus principales ideas para una nueva constitución. Indicaba que el proyecto contenía

... las reformas que en mi concepto demandan más imperiosamente el orden, el progreso y la felicidad de la República. Dos objetos principales son los que he tenido en mira; el primero poner en armonía nuestras instituciones políticas con nuestra creencia religiosa; y el segundo, investir a la autoridad pública de la fuerza suficiente para resistir a los embates de la anarquía. La civilización moderna creada por el catolicismo degenera y bastardea a medida que se aparta de los principios católicos; y a esta causa se debe la progresiva y común debilidad de los caracteres que puede llamarse la enfermedad endémica del siglo (Pólit Lasso (comp.), 1923, p. 318).

La modernidad católica garciana, sin embargo, fue contradictoria, puesto que impulsó la educación técnica, pero limitó la humanística; justificó la implantación del "imperio de la moral" mediante la represión que incluía como práctica los azotes públicos, el fusilamiento y la repatriación; impulsó la modernización del país, pero impuso una ideología de Estado reaccionaria y excluyente, además de ampliar la influencia del clero sobre el Estado. Como indica Ayala Mora (2011), por una parte

...trataba de emular los progresos de la modernidad europea, de otro, imponía el monopolio ideológico de una Iglesia que condenaba el 'modernismo', los derechos del hombre y hasta las máquinas como 'satánicos productos del 
siglo'. Por una parte hacía esfuerzos por educar; por otra, garroteaba escritores, clausuraba periódicos y quemaba 'libros prohibidos'. El proyecto garciano era contradictorio en su base, puesto que se asentaba sobre un desajuste entre la estructura socioeconómica y la esfera político-ideológica (p. 36).

Luego del asesinato de García Moreno en 1875, se sucedieron varios gobernantes y se inauguró un período de inestabilidad política y de grave violencia interna. Primero con Francisco Xavier León y José Javier Eguiguren, encargados del poder hasta diciembre de 1875, luego con Antonio Borrero, entre 1875 y 1876; Ignacio de Veintimilla, entre 1876 y 1883; José María Plácido Caamaño entre 1883 y 1888; Antonio Flores, de 1888 a 1892; y Luis Cordero Crespo de 1892 a 1895. Finalmente, luego de una larga lucha militar entre conservadores y liberales, el 5 de junio de 1895, "En la ciudad de Guayaquil (...) congregado el pueblo en Comicio Público, para deliberar acerca de la situación actual" (Ayala Mora (editor), 1983, p. 202) se proclamó a Eloy Alfaro Jefe Supremo de la República y General en Jefe del Ejército. En los considerandos del Acta de Pronunciamiento se incluía lo siguiente:

1. Que es necesario organizar un Gobierno que sea fiel intérprete del sentimiento general, claramente expresado por los patriotas, que en la Prensa, en los campos de batalla, en las manifestaciones populares, y en el seno del hogar, han trabajado por la reivindicación de la Honra Nacional, ultrajada por un Gobierno traidor a la Patria.

2. Que las ideas liberales, son las que están más en armonía con la civilización y el progreso modernos, y que son ellas las llamadas a hacer la felicidad de la República, la cual ha estado sojuzgada por una camarilla sombría, de especuladores inicuos (Ayala Mora (editor), 1983, p. 202).

De esta manera se daba inicio a uno de los periodos de transformaciones más profundas que haya tenido el Ecuador a lo largo de su historia, cuando el liberalismo, en tanto producto de la modernidad, se convierte también en impulsor de ella.

Tal como afirma el historiador ecuatoriano Jorge Núñez Sánchez (2010), la Revolución Liberal tuvo carácter laico, burgués y nacionalista. Fue laica, en tanto se propuso separar la Iglesia del Estado; fue burguesa, ya que buscaba eliminar las relaciones feudales de trabajo que aún existían; y fue nacionalista, porque buscaba la integración del Ecuador.

Entre los objetivos del Decálogo Liberal de los Radicales ecuatorianos, publicado en ese momento, se incluía el Decreto de manos muertas; la supresión de conventos y monasterios; la implantación de la enseñanza laica y obligatoria; la libertad de los indios; la abolición del Concordato con la Santa Sede; la secularización eclesiástica; la expulsión del clero extranjero; un Ejército fuerte y bien remunerado y la construcción del ferrocarril al Pacífico (Paz y Miño, 2012). Este se constituyó en el referente que guió la Revolución Liberal durante los dieciséis años de vigencia, que tuvo al frente del país a Alfaro entre 1895 y 1901 y entre 1906 y 1911, con un período intermedio con los liberales moderados Leónidas Plaza, entre 1901 y 1905 y Lizardo García, entre 1905 y 1906.

En el mensaje al Congreso de 1897, Alfaro definió algunos aspectos cruciales de su ideario político, como la igualdad de cualquier habitante ante la ley, la abolición de la pena 
de muerte para los delitos políticos y la limitación del poder del clero en los asuntos de Estado.

Uno de los logros de la Revolución Liberal fue la promulgación de la Ley de Matrimonio Civil en 1902, expedida durante la administración de Leónidas Plaza Gutiérrez, que recibió un fuerte rechazo de los sectores conservadores y del clero, quienes consideraban que se estaba legalizando el concubinato. En un manifiesto público, las autodenominadas "Matronas de Quito" se pronunciaban de la siguiente manera:

En silencio, pero llenas de inquietud, esperábamos el fallo de los poderes supremos, acerca de la atentatoria ley de matrimonio civil, tan ofensiva á (sic) la mujer (...) Pero oh ¡desgracia! nuestra inquietud se convirtió en doloroso asombro, cuando supimos que el atentado más grande contra el honor de las familias estaba consumado (Protesta de las Matronas de Quito contra la ley del Matrimonio Civil, 1903, p. 598).

En la Constitución de 1906 se concretan los postulados liberales más radicales. Se suprimió por primera vez en la historia del país la declaración de que la religión del Ecuador era la católica, se reconoció la libertad de conciencia y se estableció la separación de la Iglesia del Estado. Se indicaba también que la educación debía ser “... seglar y laica” (Artículo 16), además de gratuita y obligatoria (Ávila Santamaría, 2012). Como bien indica Leopoldo Benítes Vinueza (1950), "La constitución de 1906 fue obra de clarificación ideológica. Separó la Iglesia del Estado, estableció el laicismo, conformó las libertades públicas y las garantías ciudadanas" (p. 236).

Una de las obras más importantes de Alfaro, y su mayor obsesión como gobernante, fue la unión del país mediante el ferrocarril entre Guayaquil y Quito. Esta gran y compleja obra del que sería llamado "el ferrocarril más difícil del mundo", que comunicaba la capital ubicada a 2800 metros de altitud con la costera Guayaquil, a través de macizos montañosos y topografías imposibles, si bien fue concebida e iniciada por García Moreno, no fue sino con Alfaro cuando se impulsó y concluyó. El día de inauguración de la gran obra del ferrocarril, el 25 de junio de 1908, el general Flavio Alfaro, sobrino del Presidente, pronunció las siguientes palabras:

¡La voz potente de la locomotora acaba de repercutir a las puertas de Quito, la Sultana de los Andes!

El grito de la civilización y del progreso ha subido de las orillas del mar a la bellísima región de las nieves resplandecientes. Estos triunfos no solo alegran el espíritu, sino que dignifican y elevan a los pueblos en la escala de sus aspiraciones infinitas. Hemos obtenido hoy el triunfo más glorioso de nuestra vida republicana.

La grande, la sublime aspiración del pueblo ecuatoriano acaba de realizarla el brazo vigoroso y la perseverancia incontrastable de Eloy Alfaro. La poderosa arteria de hierro, que ha subido hasta el Pichincha, constituye la garantía más eficaz, para la integridad de nuestro suelo querido, del cual no dejaremos usurpar, ni un guijarro de nuestras selvas, ni un vaso de agua de nuestros inmensos 
ríos (Conmemoración del Cincuentenario de la llegada del ferrocarril a Quito, 1958, p. 23).

El ferrocarril inaugurado por Alfaro permitió la apertura del proceso de constitución del Estado Nacional mediante la integración física del país. Carlos Paladines (2007) resume los beneficios que esta gran obra trajo al Ecuador:

... se redujo drásticamente el tiempo y los costos de circulación de bienes y personas de siete y hasta doce días que se requerían, a lomo de mula, para alcanzar la Capital o el Puerto Principal, a un solo día; se triplicó y cuadriplicó el valor de los terrenos ubicados junto a la vía; se logró la apropiación de la tecnología de punta existente en el mundo avanzado de aquel entonces; se disminuyeron las incomodidades que suponía viajar y se aumentó considerablemente el monto de mercancías y más bienes en circulación entre las dos regiones e incluso con el exterior (p. 134).

Sin embargo, la gran obra también había dejado al Gobierno con una enorme deuda. Poco a poco el gobierno liberal empezaba a perder la base social que lo sustentaba, a lo que se sumaba la creciente oposición, no solo de los conservadores, sino también de liberales desencantados.

En 1911 Alfaro quiso imponer la renuncia del poder a Emilio Estrada Carmona, quien había sido elegido presidente con su apoyo. Ante la renuencia de Estrada de acatar esa imposición, Alfaro pretendió dar un golpe dictatorial, sin embargo ante la sublevación de grupos militares que eran contrarios a esa estrategia, tuvo que abandonar el país y exiliarse en Panamá (Ayala Mora, 1983).

El gobierno de Estrada fue breve debido a su prematuro fallecimiento a los pocos meses de su posesión y Carlos Freile Zaldumbide se hizo cargo del poder de manera interina. $\mathrm{Al}$ poco tiempo se dieron alzamientos armados en la costa del país, liderados por Flavio Alfaro, en Esmeraldas, y por el General Pedro J. Montero, en Guayaquil. Finalmente los rebeldes, junto con Alfaro quien había regresado al Ecuador para actuar como mediador, fueron tomados presos. Montero fue asesinado y Alfaro y sus lugartenientes fueron enviados como prisioneros a Quito, donde una turba asaltó el presidio y les dio muerte. Leopoldo Benítes Vinueza (1950), en su gran obra Ecuador: drama y paradoja, describe lo que sucedió:

El cuerpo del caudillo liberal fue arrastrado de un extremo a otro de la ciudad. Se le reventó el cráneo y saltaron los sesos al golpear contra las agudas piedras. $\mathrm{Y}$ en torno de la hoguera encendida en el verde ejido del norte quiteño, en donde hoy se levanta un parque rodeado por un barrio señorial, ardió la pira en que quemaron el cuerpo magro y pequeño del Viejo Luchador (pp. 237-238).

De esta manera trágica se terminaban los años del liberalismo más radical e ideológico, donde se sentaron las bases del proceso de unidad y transformación del país y se dio inicio a un período en el que el país sucumbió a manos del control de la banca y de la plutocracia. 
Luego del asesinato de Alfaro siguió un período de relativa estabilidad política a cargo de liberales moderados cuyo poder, en la práctica, estaba sujeto a las decisiones de la plutocracia de la costa con fuertes vínculos con la banca -principalmente del Banco Comercial y Agrícola de Guayaquil-y la agricultura de exportación. Como bien lo define Ayala Mora (1983):

El período comprendido entre 1912 y 1925 marca el auge del Estado oligárquico en el Ecuador. Las diversas personas y grupos que se turnaron en el poder representaron todos al 'liberalismo plutocrático' o, más concretamente, a las alianzas dirigidas por sucesivos entendimientos entre el grupo vinculado al Banco Comercial y Agrícola y el sector 'placista' dirigido por el caudillo militar vinculado a la aristocracia serrana. Estas fueron las condiciones de la 'estabilidad política'. Empero aunque se dieron incluso propuestas de alternabilidad en el poder de conservadores y liberales, estos últimos lo conservaron todo el tiempo mediante la institucionalización del fraude electoral (p. 155).

Se refiere al General Leónidas Plaza Gutiérrez, quien fue presidente del Ecuador entre el 1 de septiembre de 1901 al 31 de agosto de 1905 y del 1 de septiembre de 1912 al 31 de agosto de 1916. Los diferentes gobiernos que se sucedieron en el poder, tuvieron que enfrentar una guerra civil en Esmeraldas entre 1913 y 1916, el deterioro de las plantaciones cacaoteras y de su mercado de exportación y la creciente dependencia del Estado con la banca privada (Quintero y Silva Charvet, 2013). Este conjunto de factores determinó que se iniciara una época de profunda recesión y de descontento popular que estallaría finalmente en 1922.

En octubre de 1922 se dio inicio a uno de los hechos más dramáticos y vergonzosos de la historia del Ecuador. Los obreros ferroviarios se declararon en huelga en demanda de mejoras en sus condiciones laborales. Al poco tiempo la huelga recibió el apoyo de otras organizaciones de trabajadores anarquistas de la Federación de Trabajadores Regional ecuatoriana (FTRE) y de la poderosos Sociedad Cosmopolita de Cacahueros "Tomás Briones". Al final de ese mes la empresa accedía a la demanda de los trabajadores y la huelga se levantó “...con la victoria obrera y el júbilo popular” (Quintero y Silva Charvet, 2013, p. 334).

Sin embargo, pocos días después, el 7 de noviembre, se iniciaba otra huelga, esta vez de los obreros de la Empresa de Luz y Fuerza Eléctrica y de los trabajadores de la Empresa de Carros Urbanos de Guayaquil, quienes reclamaban “...el incremento de salarios, el cumplimento de la jornada de ocho horas y la estabilidad en el trabajo para todos los trabajadores" (Quintero y Silva Charvet, 2013, p. 334).

Para el 9 de noviembre ya se habían sumado a la huelga la FTRE y sus veinticuatro organizaciones aliadas, además de los trabajadores de la compañía de gas, la curtiembre La Iberia, la fábrica de cerveza, los obreros del servicio de aguas y la Asociación Gremial del Astillero (Quintero y Silva Charvet, 2013). Con el pasar de los días la situación se fue agudizando y el 13 de ese mismo mes se declaraba la huelga general a la que plegaron ortros sectores laborales, por lo que la ciudad de Guayaquil quedó totalmente paralizada.

El 15 de noviembre una gran manifestación de casi treinta mil personas -casi un tercio de toda la población de la ciudad- que congregaba a los obreros y trabajadores en huelga, 
a la que se había sumado el pueblo guayaquileño, se había tomado las calles de la ciudad. No pasó mucho tiempo hasta que la multitud fue reprimida a fuego abierto y a bayoneta por la policía y el Ejército que seguía las órdenes dictadas por el Presidente de la República José Luis Tamayo (Martínez, 1988).

Se cree que fueron cerca de medio millar de muertos los que cayeron ese día y que fueron tirados a la ría. Benjamín Carrión reflexionaba de esta manera sobre lo que significó este hecho:

El 15 de Noviembre de 1922 es, hasta hoy, mis queridos compaisanos de América Latina, la fecha más monstruosa en materia de luchas obreras, de luchas intestinas, de todos nuestros países. Desde el Río Bravo hasta la Tierra del Fuego... ¿No lo sabían ustedes? Pues no lo sabe casi nadie en los países 'hermanos', y cuando uno lo cuenta no se lo quieren creer, no se lo creen (Carrión, [1977] 2010, p. 161).

De este trágico hecho para la historia del Ecuador surgió el argumento de Las cruces sobre el agua de Joaquín Gallegos Lara (1941), una de las más importantes novelas de la literatura ecuatoriana. En el párrafo final se relata cómo el pueblo de Guayaquil, hasta nuestros días, lanza cruces de flores al río Guayas, recordando los muertos que ese día cayeron:

-¿Qué significan esas cruces?

- ¿Cómo no sabe, jefe? ¿No es de aquí?

-De aquí soy, pero he pasado algunos años fuera.

-Ahí debajo, de donde están las cruces hay fondeados cientos de cristianos, de una mortandad que hicieron hace años. Como eran bastantísimos, a muchos los tiraron a la ría por aquí, abriéndoles la barriga con bayoneta, a que no rebalsaran. Los que enterraron en el panteón, descansan en sagrado. A los de acá ¿cómo no se les va a poner la señal del cristiano, siquiera cuando cumplen años? Entonces, Alfonso reparó en la extraña coincidencia: ese día era 15 de noviembre.

La matanza de obreros, trabajadores y del pueblo de Guayaquil, fue la primera ocasión cuando se enfrentaban las fuerzas del naciente capitalismo ecuatoriano y que, según Fernando Tinajero (1987), marcó el ingreso del país al siglo XX. Este hecho fue uno de los factores del fin de los gobiernos liberales plutocráticos y una de las causas de la irrupción de la llamada Revolución Juliana.

El 9 de julio de 1925, un grupo de militares progresistas, apoyados por la clase media, derrocaron a la coalición de liberales y de burgueses comerciales-financieros. El levantamiento juliano fue un movimiento anti-oligárquico que se enfrentó con el poder de la banca guayaquileña y que estableció reformas modernizadoras de fortalecimiento y reorganización técnica del Estado, algunas de carácter fiscal y otras de tipo social, que en general permitieron sentar las bases del Ecuador moderno.

El historiador ecuatoriano Juan Paz y Miño (2013) identifica seis causas de la irrupción de este movimiento político al que se ha considerado continuador del ideario liberal radical: 
primero, la crisis del cacao que arrastró al conjunto de la economía del país; segundo, el predominio bancario privado que sometían a sus intereses “...la esclavitud del Estado" (p. 29); tercera, el dominio plutocrático, que significó la sujeción del gobierno a los intereses de la banca privada; cuarta, el agotamiento del Estado-liberal, que significó el abandono del ideario social, economico y político del liberalismo, además el agotamiento del bipartidismo conservador-liberal; quinta, el ascenso de la lucha social que se expresó en la conformación de organizaciones de trabajadores y de sus luchas para conseguir mejores condiciones laborales, que se expresó trágicamente el 15 de noviembre de 1922; y, sexta, el socialismo y la situación internacional.

Durante el período juliano, que se prolongó hasta 1931, se creó el Banco Central en 1927, la Superintendencia de Bancos, la Contraloría General del Estado, la Procuraduría General de la Nación, la Caja de Pensiones y Jubilaciones, la Dirección General de Aduanas, la Dirección General de Obras Públicas, la Dirección General de Presupuesto, el Instituto Geográfico Militar, entre otras (Fernández, 1979). Se llamó a una nueva asamblea constituyente en 1928 -que estableció el voto de la mujer-; centralizaron la economía y dieron amplios beneficios a los sectores medios; además de que se intentó alentar un proceso de industrialización nacional, aunque fracasó por la posterior crisis. Algunas de estas propuestas fueron parte del proyecto de reforma fiscal y monetaria que desarrolló en el país una misión presidida por el economista norteamericano Edwin Kemmerer, quien en 1922 había realizado labor semejante en Colombia, que concluyó en la creación del Banco Central de ese país (Paredes Ramírez, 2003).

No obstante, y pese a un programa económico que parecía adelantarse a las medidas que llevaron las potencias para superar el crack de la bolsa de Nueva York, la crisis golpeó fuertemente a la economía nacional y el gobierno de Isidro Ayora, principal dirigente juliano, cayó el 24 de agosto de 1931.

El historiador Alan Knight (2015) se pregunta de qué manera la Gran Depresión mundial, un hecho fundamentalmente económico, tuvo en los países americanos repercusiones políticas, culturales, además de, evidentemente, económicas, y si “... la inestabilidad política, la pronunciada construcción del Estado, el dirigismo económico, el autoritarismo, el corporativismo, los frentes populares, el nacionalismo, etc." (p. 348) que se dio en nuestros países, fue consecuencia de la crisis mundial.

Aunque la dependencia ecuatoriana a un solo producto de exportación como el cacao, determinó su gran fragilidad frente a la crisis, el hecho cierto es que antes de que esta se produjera ya la exportación de ese producto había decrecido debido a factores internos, como el descuido de las plantaciones y las plagas.

La crisis cacaotera que se había iniciado realmente en 1914, junto con el inicio de la Primera Guerra Mundial, por el cierre del puerto de Hamburgo, donde ingresaba el producto al mercado europeo, determinó la disminución de los ingresos nacionales y que se iniciara un creciente proceso inflacionario y que el Estado aumentara su dependencia crediticia (Acosta, 1995).

A inicios de los años veinte los ingresos por la venta de cacao habían disminuido significativamente, tanto por la baja de producción interna, como por la caída internacional de los precios del producto, tal como indica Manuel Chiriboga (2013, 2a. edición): 
A la crisis abierta por la sobreproducción mundial de cacao, se agregó muy pronto las crisis del sistema productivo en las haciendas y plantaciones cacaoteras. El carácter casi 'natural' de los sistemas de cultivos en la mayor parte de propiedades; la ninguna utilización de abonos, insecticidas, defoliantes, etc.; la limitada implementación de sistemas de cultivo razonadamente modernos; y el carácter rentístico de buena parte de las propiedades se conjugaron para crear las condiciones que provocaron el resquebrajamiento del primer auge agroexportador del país (pp. 378-379).

Conforme fue pasando el tiempo, el problema en lugar de solucionarse se fue agravando. Entre 1925 y 1938 las exportaciones de cacao bajaron de un millón de quintales a tan solo 220.000 (Arosemena, 1993) y los ingresos por ese mismo producto se redujeron de quince millones de dólares en 1928 a apenas cuatro millones doscientos mil dólares en 1933 (Acosta, 1995).

A la par de la crisis económica se inició un período de profunda y prolongada inestabilidad política que se reflejó en la sucesión, entre 1931 y 1948, de más de veinte presidentes constitucionales, encargados del poder, juntas provisionales de gobierno y jefes supremos de efímera duración.

A inicios de la década de 1940 la situación en el país se agravó al desatarse un conflicto territorial con el Perú, durante el impopular gobierno de Carlos Arroyo del Río, sobre quien siempre pesó la acusación de que había ganado las elecciones de manera fraudulenta.

La guerra, que culminó con el triunfo militar del Perú y con la pérdida de extensos territorios en la región amazónica, se selló en 1942 con la firma en Brasil entre los dos países del Protocolo de Paz, Amistad y Límites de Río de Janeiro, que dejó al Ecuador sin salida directa al río Marañón. En una de sus famosas Cartas al Ecuador, escrita por Benjamín Carrión, luego del conflicto territorial, se resumía el sentimiento ecuatoriano ante ese hecho:

Nunca como hoy, en que la patria derrotada está sufriendo las consecuencias de la desorientación de su vida a causa de errores de propios y extraños, pasados y presentes; nunca como hoy el tiempo más propicio para hacer una especie de 'examen de conciencia nacional' que, seguido de un serio 'propósito de enmienda', nos pueda llevar a la formulación de un acto de fe, de un acto de esperanza, de un acto de amor hacia la patria (2007 [1943], p. 91).

Lo bochornoso del acuerdo logrado, a lo que se sumaba la situación económica manejada por un gobierno que cada día estaba más distanciado de la sociedad, originó una creciente oleada de protestas de estudiantes, organizaciones de izquierda, sectores laborales y diversos grupos sociales. A comienzos de 1944 la Alianza Democrática Ecuatoriana (ADE) -que aglutinaba a los partidos Conservador, Liberal, Socialista y Comunista- se lanzó a las calles de Guayaquil con el apoyo de sectores del ejército y entabló una batalla callejera contra los carabineros, que eran el sostén del gobierno arroyista. El Partido Socialista Ecuatoriano se había fundado en el año 1926 “... como representante de los intereses de los sectores radicalizados de la pequeña-burguesía urbana y de la clase obrera del país” mientras que el Partido Comunista del Ecuador surgió como escisión del anterior, en 1931, “... con un 
programa obrero-campesino bien definido" (Quintero y Silva Charvet, 2013, p. 340). La irrupción de ambos partidos significó una alternativa desde la izquierda al bipartidismo conservador-liberal imperante. Para fines de mayo, y luego de un confuso incidente en el que falleció una niña, el levantamiento en Guayaquil y el país era generalizado, ya que se habían sumado manifestantes de otras provincias. Fernando Tinajero describe los hechos y su desenlace de la siguiente manera:

... el 28 (de mayo), la multitud atacó furiosamente el cuartel de los carabineros, ya identificados como la máscara feroz del arroyismo. Fue tan grande la arremetida que los carabineros no pudieron contenerla; junto al pueblo estaban los soldados de la plaza, y los carabineros quedaron literalmente liquidados (Tinajero, 2015, p. 180).

Derrocado Arroyo del Río, los sectores más tradicionales de la sierra impusieron a José María Velasco Ibarra como presidente, al frente de un gobierno de coalición en el que estaban representadas todas las fuerzas políticas, desde los conservadores hasta socialistas y comunistas.

Fueron estos últimos sectores de izquierda quienes impulsaron una nueva constitución en 1945, una de las más progresistas de la historia del país, ya que como acertadamente afirman Rafael Quintero y Érika Silva, en esta nueva Carta Magna

... se garantizó la igualdad ante la ley, quedando proscritos los privilegios y fueros personales y toda discriminación lesiva a la dignidad humana por motivo de clase, sexo, raza u otra razón; se estableció el derecho de habeas corpus, la autonomía universitaria; el derecho de huelga de los trabajadores; la igualdad de los hijos nacidos fuera de matrimonio en lo que respecta a crianza, educación y herencia; la jornada máxima de 44 horas semanales; se garantizó la protección a la propiedad de las comunidades indígenas que incluso podían recuperar tierras; y, entre otras reformas en la organización estatal, se previó la formación de un Tribunal de Garantías Constitucionales restrictivo del poder del Ejecutivo, y la formación de la Comisión Legislativa Permanente (Quintero y Silva Charvet, 2013, p. 460).

Además de estos avances legales se lograron conquistas en otros campos, como el reconocimiento de la Central de Trabajadores del Ecuador, de la Federación Ecuatoriana de Indios, de la Unión Nacional de Educadores, de la Federación de Estudiantes Universitarios del Ecuador; además de la ratificación del Código del Trabajo que había sido aprobado en 1938 durante el gobierno del General Alberto Enríquez Gallo; y la creación de la Casa de la Cultura Ecuatoriana el 9 de agosto de 1944 (Quintero y Silva Charvet, 2013).

Sin embargo, esta situación de bienestar y de progreso duró poco tiempo, ya que el gobierno de Velasco Ibarra se fue apartando de los ideales de cambio que lo habían llevado al poder. La inestabilidad política regresó y en poco más de cuatro años, entre 1944 y 1948, se sucedieron cuatro presidentes. 
Finalmente la estabilidad democrática se recuperó en 1948, con Galo Plaza Lasso, quien incorporó a su gestión de gobierno el concepto de desarrollo, el cual, como afirma Rodrigo Borja (1997) “... formó parte de las nuevas ideas e inquietudes que agitaron el espíritu de los hombres después del impacto de la conflagración mundial” (pp. 262-263), aunque no fue sino hasta 1954, con la creación de la Junta Nacional de Planificación y Coordinación Económica (Moncada-Sánchez, 1974), cuando se instauró en el país un verdadero proceso de planificación, uno de los pilares de un Estado moderno.

\subsection{Sociabilidad moderna y arquitectura}

Puesto que no hay dicotomía arquitectura-sociedad, sino participación de la arquitectura en la sociedad. La sociedad, al crearse a sí misma, crea también, como una de esas formas de existencia, a la arquitectura, y ésta, al definirse y crearse como especificidad, está participando en la creación de la sociedad. Y todo ello como actividad, como praxis, como historia (López Rangel, 1975, p. 29).

Uno de los aspectos de la modernidad que surge de los cambios de la economía, el régimen del trabajo, la producción industrial y el crecimiento de las ciudades, se expresa en la experiencia de lo cotidiano. En los primeros años del siglo XX algunas conquistas sociales, como un nuevo régimen laboral diario de ocho horas a partir de 1914, abrieron el espacio para que los ciudadanos pudieran disfrutar del tiempo libre. Como afirma Ángel Emilio Hidalgo (2014), de esta manera los guayaquileños empezaron a disfrutar “... del teatro, el cine, las tertulias y las audiciones caseras de música a través de las victrolas, modificaron sus costumbres y redefinieron su relación con la ciudad" (p. 15).

Había necesidad, por tanto, no solo de ser moderno, sino de sentirse y actuar como tales. Como describía Gerardo Gallegos en un artículo de 1919 publicado en la revista Semana Gráfica:

Es la urbe que comienza a dar forma en sus calles, en sus paseos y en sus avenidas al espíritu de su pueblo; a expresar en su aspecto material el alma guayaquileña plena en la tradición que vive en la evocación de sus barrios legendarios, a expresar la inquietud, el dinamismo, la modernidad, en sus edificios de arquitectura siglo actual y en sus anchas avenidas asfaltadas que avanzan de norte a sur y de este a oeste, transformando en muy modernas las antiguas, agrietadas y polvorosas y casi intransitables en invierno calles guayaquileñas (p. 6).

Así empezaron a surgir cambios en la sensibilidad, que se expresó en la moda, en el cultivo del tiempo libre y en la práctica deportiva, “... un modo de vivir 'moderno' que se vio potenciado con la construcción de teatros, canchas de fútbol, de básquetbol, pistas atléticas, piscinas, parques de diversión" (Hidalgo, p. 15).

En 1919, según Julio Estrada Ycaza (2000), el Concejo Cantonal cedió en arrendamiento un terreno municipal para que se estableciera un campo deportivo al sur de la ciudad con instalaciones para béisbol, tenis, fútbol, criquet, equitación, patinaje y tiro al blanco. 
Cuatro años más tarde se estableció una Junta Deportiva Municipal con el fin de fomentar los ejercicios físicos de los ciudadanos y de administrar un Campo Deportivo Municipal en un terreno de cien mil metros cuadrados, que fue inaugurado en 1924 con un gran campeonato de fútbol en el participaron veinticinco equipos.

En la década de 1920 el fútbol se convirtió en el deporte que concentraba a la mayor cantidad de espectadores. Ya para esas fechas era práctica común la celebración de competencias interprovinciales e internacionales en conmemoración de las fiestas de independencia de la ciudad, en la que participaban equipos que habían surgido en diferentes barrios y que empezaban a tener gran popularidad, como el Club Sport Patria, fundado en 1908; el Barcelona Sporting Club, fundado en 1925 por emigrantes catalanes (Estrada Ycaza, 2000); el Club Sport Emelec, fundado en 1929 por el norteamericano George Lewis Capwell, integrante de la Superintendencia de la Empresa Eléctrica de Ecuador (EMELEC); entre otros (Paredes Ramírez, 2003).

Otros deportes populares en esa época eran el básquetbol que surgió en 1924, cuando se tradujeron sus reglas y se generalizó su práctica (Vasconcellos, 2016) y el beísbol que se introdujo alrededor de 1920 por los norteamericanos John y Robert Reed, quienes lograron que los pocos años hubiera un campeonato donde jugaban los equipos Barcelona, Emelec, Oriente y Maldonado (Estrada Ycaza, 2000).

Para esa época había también una extensa red de teatros y cines. En ellos se presentaban espectáculos, óperas, zarzuelas, danzas, recitales de poesía, coros y conciertos, además de películas cinematográficas. Uno de los más importantes fue el Teatro Olmedo, inaugurado en 1900, construido en madera y con una capacidad de mil quinientos espectadores (Compte, 2007); siete años más tarde abría sus puertas el Teatro Edén con un programa de zarzuelas; y en 1910, con la presentación de la película Los últimos días de Pompeya, se inauguró el cine Ambos Mundos (Suárez Ramírez, 2013). También existían varias salas de cine, una en el barrio Las Peñas con el nombre de Colón, otra en la zona central, con el nombre de Montalvo (Estrada Ycaza, 2000), además de los cines Victoria, Ambos Mundos e Ideal y los teatros Olmedo y Edén (Suárez Ramírez, 2013).

El 7 de agosto de 1924 se proyectó por primera ocasión, en funciones simultáneas en los teatros Edén y Colón, la primera película filmada en el país, El tesoro de Atahualpa, producida por la naciente Ecuador Film Company y dirigida y protagonizada por Augusto San Miguel. En el año 2007 el Congreso Nacional del Ecuador declaró al 7 de agosto como Día del Cine Nacional en homenaje a la película de San Miguel, lamentablemente perdida. Al día siguiente el Diario El Telégrafo publicaba la siguiente reseña:

Un éxito ha sido el estreno efectuado anoche en los teatros Edén y Colón, de la primera película nacional de argumento que se presenta en el país. Es cierto que la obra, técnicamente, tiene defectos propios de toda labor que principia, es cierto que gran parte de estas deficiencias que el público ha notado obedecen a que el laboratorio todavía no está instalado con todas las reglas necesarias, el cual impide una perfecta confección de la película. Como es cierto también que nuestros artistas recientemente se inician en el arte de la cinematografía y que, naturalmente, no es posible pedirles el dominio completo. Sin embargo estos pequeños defectos han sido salvados con la excesiva y entusiasta voluntad 
que todos pusieron en la filmación de la cinta y en hacer de ella una obra que sea la esperanza de un futuro más demostrativo de lo que en este género podemos obtener (Citado en Suárez Ramírez, 2013, Tomo I, p. 458).

En 1922 se inauguró el American Park, un gran parque de diversiones junto al Estero Salado, que contaba con piscinas alimentadas con las aguas del estero, un tobogán traído de Alemania, además de una gran sala de espectáculos donde se celebraban concursos de baile y fiestas de beneficencia (Paredes Ramírez, 2003). Pocos años después había incorporado a sus instalaciones una plaza de toros (Estrada Ycaza, 2000).

A partir de 1925, luego de la Revolución Juliana, y dentro de una visión higienista de la sociedad que contempló la erradicación de las enfermedades endémicas, como la fiebre amarilla y la peste bubónica, se incorporó a la educación la idea de higiene, vinculada al aseo del cuerpo, la gimnasia y a la educación sexual. En un informe del Ministerio de Instrucción Pública del año 1930 se destacaba como logro “... la implantación de prácticas higiénicas tan saludables como la del baño semanal obligatorio", aunque, se indicaba que este se realizaba “... con ciertas dificultades" (Sinardet, 1999, p. 415). Estas prácticas de higiene eran fundamentales en una ciudad que se había impuesto como meta la erradicación de enfermedades como la fiebre amarilla y la peste bubónica, que eran consideradas endémicas y que habían sido trágicas en la vida de Guayaquil.

En 1930, justo después de que se acentuara la crisis económica, convergen en Guayaquil una serie de eventos tanto culturales como sociales, que pusieron en evidencia los profundos conflictos sociales, por una parte, y la necesidad de expresión de un sector de la población. En ese año se dio un hecho que tuvo importantes repercusiones en el país y que puso en evidencia las profundas divisiones de clase que existían. Este fue la elección de la Señorita Ecuador, primer certamen de belleza que se hacía en el país con alcance nacional. El concurso, que originalmente era abierto a la participación de mujeres de todo el país, quedó finalmente restringido a cuatro candidatas de Guayaquil, ya que las quiteñas se negaron a desfilar en traje de baño (Goestchel, 2001).

En publicaciones quiteñas de la época se cuestionaba duramente al concurso al considerar que esas "... exhibiciones de cuerpos hermosos en traje de baño" constituían un signo del mundo moderno "... donde conviven desde la sublime Hermana de la Caridad hasta la ridiculez de las aclamaciones y los entusiasmos en pos de las mujeres que descubren y lucen sus cuerpos, porque la naturaleza los ha hecho bellos", cuando, en realidad, las mujeres no debían tener por fin “... ostentar la melena y pintarse los labios, fumar y adquirir maneras hombrunas (...) deben ser intensamente mujeres y ser madres, las madres del hombre según la carne o según el espíritu de la obra social que realice" (El tiempo de las Misses, 1930 en Goestchel, 2001, p. 113).

En el proceso de elección, que se hacía mediante votación popular, quedaron dos claras finalistas Sara Chacón y Blanche Yoder, representantes de la clase media y la aristocracia guayaquileña, respectivamente. No hubo ninguna participante que representara a las mujeres indígenas y negras del país, ya que, de acuerdo a la organización social de la época, ni siquiera eran pensadas como potenciales participantes (Pequeño, 2001). Finalmente la ganadora fue Sara Chacón, cuyo triunfo fue aclamado por la multitud como un triunfo del pueblo sobre la burguesía guayaquileña, como bien indica Andrea Pequeño (2001), 
En este acto se plasma un proceso de movilidad social: el ascenso de una clase emergente que se instalaría poco a poco en la escena pública y en los centros de poder, desplazando con ello a la clase aristocrática y su histórica hegemonía (p. 116).

También en 1930 Electra Ballén se convirtió la primera mujer que cruzó a nado el río Guayas, desde Guayaquil a Durán, en la orilla opuesta. Al año siguiente participó en la titánica prueba náutica de quince millas entre Guayaquil y Punta de Piedra, nadando durante 4 horas y 18 minutos.

El 4 de junio de ese mismo año, el dúo Ecuador, conformado por el ecuatoriano Enrique Ibáñez Mora y el libanés Nicasio Safadi, uno de los más famosos de la época, viajó a Estados Unidos para grabar en la Columbia Phonograph Company el primer disco de música nacional en voces de cantantes ecuatorianos, que “...no solo puso el nombre del Ecuador en el plano internacional, sino que también fomentó un sentido de 'ecuatorianidad' asociado con este género" (Wong, 2011, p. 185). El primer tema que se escogió fue el pasillo Guayaquil de mis amores, compuesto por Ibáñez y Safadi, que se convirtió en el himno popular de la ciudad. Ketty Wong (2004) define al pasillo como un género musical urbano “... que se deriva del vals europeo y llega a territorios ecuatorianos con las guerras independentistas a principios del siglo XIX. (...) El pasillo tradicional es en esencia un poema de amor musicalizado, cuyos textos están influenciados por la poesía modernista” (p. 272).

\subsubsection{Del “templo doméstico" al hogar moderno}

Desde finales del siglo XIX, y en la línea del pensamiento conservador imperante, se exponía lo que se consideraba debía ser una familia y los roles que tanto los hombres y las mujeres jugaban dentro de ella. En la familia decimonónica la autoridad indiscutible la ejercía el padre -el que "ganaba el pan”-, cuyo espacio era el “... extradoméstico, el mundo de la política, de los negocios y del trabajo” aunque “... era dentro de la familia donde desplegaba y ejercía su indiscutible autoridad” (Pachón, 2007, pp. 147).

Dentro de la familia, la mujer recibía el encargo de ser esposa, hija y madre y de formar sus hijos como buenos patriotas. Ante la mujer se inclinaban los políticos y “...los tiranos y los soldados se rinden avasallados". Se consideraba que la Patria era de la mujer, por lo que “... en forma de un crisantemo o de una rosa" se le otorgaba esa flor para que fuera colocada “...en el precioso buquet que embalsama el hogar de hija, de esposa y de madre" (Claridad, Revista Universitaria de Literatura, Arte y Ciencia, Quito, 1926, bimestral, s/p). La mujer era el "ama de casa”, a quien le correspondía la esfera doméstica, considerada el “... espacio femenino por excelencia y el hogar (su) verdadero 'santuario”, el lugar “... donde ella debía desplegar todas sus virtudes como cristiana y sus conocimientos sobre una administración del hogar que debía ser manejado con austeridad, sencillez, orden y aseo". Otra responsabilidad fundamental de la mujer era la crianza y cuidado de los hijos para convertirlos en "buenos cristianos", dentro del "templo doméstico", ya que se consideraba que el niño “... era aquel ser al cual la madre moldeaba y preparaba para lo bueno, lo bello y lo verdadero. En pocas palabras, en ella recaía la responsabilidad de la educación moral de los hijos" (Pachón, 2007, pp. 147-148). 
Se pensaba que los roles que debían cumplir tanto hombres como mujeres eran una asignación "natural" y "divina". En una publicación de 1896 se describía esta asignación de roles que correspondían tanto a las condiciones físicas como a las morales de los hombres y las mujeres:

Por sus cualidades físicas y morales, el hombre está destinado a la vida exterior del trabajo y de la lucha mientras la mujer lo está a la vida íntima de la casa, a los cuidados materiales de ésta y de la familia, y a ofrecer el consuelo y las dulces afecciones del hogar como compensación y remedio a las luchas y sinsabores de la vida. Así pues, mientras el hombre necesita de la mujer para que le sostenga y le conforte en el hogar, la mujer necesita del hombre para que la sostenga y la defienda en esa vida exterior; y claro está que en la sociedad conyugal se satisface esa recíproca necesidad (Rodríguez, Derecho Natural, citado en Paéz, 1918, p. 110).

El padre tenía asignado el rol de ser el jefe del hogar ya que en él predominaba “... la razón, el buen sentido" por lo que le correspondía emprender “... lo verdadero, la realidad de las cosas; a él toca la superioridad del pensamiento", al ser “... el representante de la creación, el autor de la raza en quien se personifica la Autoridad de la comunidad doméstica, la más alta de todas las autoridades humanas, por su legitimidad y su destino" (La Verdad, 1896, $\mathrm{s} / \mathrm{p})$. Por tanto, ante el padre, su familia debía inclinarse y rendirle pleitesía, “...porque es el nombre supremo y misterioso del poder (...) porque proviene de aquel por quien toda paternidad es señalada en los cielos y en la tierra”.

En esa misma línea de pensamiento se desarrollaban los manuales de urbanidad, de amplia circulación a finales del siglo XIX, que tuvieron la función de establecer los lineamientos para el desarrollo de ciudadanos católicos, burgueses, civilizados y urbanos, tal como lo describe Santiago Castro-Gómez (2000):

El manual funciona dentro del campo de autoridad desplegado por el libro, con su intento de reglamentar la sujeción de los instintos, el control sobre los movimientos del cuerpo, la domesticación de todo tipo de sensibilidad considerada como 'bárbara'. No se escribieron manuales para ser buen campesino, buen indio, buen negro o buen gaucho, ya que todos estos tipos humanos eran vistos como pertenecientes al ámbito de la barbarie. Los manuales se escribieron para ser 'buen ciudadano'; para formar parte de la civitas, del espacio legal en donde habitan los sujetos epistemológicos, morales y estéticos que necesita la modernidad (p. 149).

Tal vez el más famoso fue el Manual de urbanidad y buenas maneras del político y escritor venezolano Manuel Antonio Carreño, publicado por entregas a partir de 1853 y que tuvo un enorme impacto y aceptación en los países hispanoamericanos.

Para Carreño, el hombre tenía asignado el rol de ser “....siempre atento, afable y condescendiente con la compañera de su suerte, con aquella que abandonando las delicias y contemplaciones del hogar paterno, le ha entregado su corazón y le ha consagrado su 
existencia entera". El hombre tenía la obligación de guardar "consideración y respeto a la mujer", debía ser siempre "discreto, delicado y decoroso", ya que de esta manera le daba a la mujer ejemplo de “... discreción, delicadeza y decoro que influirán ventajosamente en su conducta para con él mismo, y en el desempeño de los importantes deberes que están especialmente a su cargo, como la primera educación de los hijos, el gobierno de la familia, y la inmediata dirección de los asuntos domésticos".

Carreño explicaba cómo debía conducirse la mujer para ejercer su tarea más importante, la del gobierno de la casa:

En la mujer es el método acaso más importante que en el hombre; pues a más de serle a ella aplicables todas las observaciones que preceden, su destino la llama a ciertas funciones especiales, en que necesariamente ha de ser el método su principal guía, so pena de acarrear a su familia una multitud de males de alta trascendencia: Hablamos del gobierno de la casa, de la inmediata dirección de los negocios domésticos, de la diaria inversión del dinero, y del grave y delicado encargo de la primera educación de los hijos, de que depende en gran parte la suerte de éstos y de la sociedad entera.

El método, junto con el orden y la elegancia eran considerados fundamentales para exponer a las visitas el hogar, cual escenario teatral en el que quienes lo moraban debían comportarse de acuerdo a las rígidas reglas de la etiqueta:

Si examinamos una casa en todas sus interioridades, y encontramos que no hay en ella ningún lugar en que no se halle impreso el sello del orden, del método y de la elegancia, podemos desde luego asegurar que sus habitadores son personas finas y bien educadas.

La sala es el punto general de recibo; y como teatro de toda especie de sociedad, debe estar montada con todo el rigor de la etiqueta. En ella no aparecerán nunca otros objetos que los que sirvan a la comodidad y al recreo de las visitas, los cuales estarán siempre dispuestos con orden y elegancia.

Los muebles y demás objetos que se encuentren en nuestro aposento, deben estar siempre ordenados y dispuestos de manera que hagan una vista agradable; nuestra cama, constantemente vestida y arreglada, nuestra ropa guardada, y la que no pueda estarlo, acomodada en la mejor forma posible y los enseres que sirvan a nuestro aseo y deban estar visibles, colocados en aquellos lugares en que puedan ser menos notados por las personas que hayan de penetrar hasta nuestro dormitorio.

Réstanos declarar que del arreglo de la casa general, es infinitamente más responsable la mujer que el hombre. La mujer consagrada especialmente a la inmediata dirección de los asuntos domésticos, puede emplear siempre en oportunidad todos los medios necesarios para mantener el orden, e impedir que se quebranten las reglas que aquí recomendamos; al paso que el hombre, sobre quien pesa la grave obligación de proveer al sostenimiento de la familia, apenas 
tendrá tiempo para descansar de sus fatigas, y bien poca será la influencia que su celo pueda ejercer en la policía general del edificio.

Dentro de ese arreglo del hogar aparecía en Guayaquil un mueble fundamental en cualquier casa de la ciudad, que reflejaba la simbiosis entre la manera de habitar hispana con la tradición indígena de solución frente a los rigores climáticos, este era la hamaca, un mueble que servía para múltiples funciones y ejercía su dominio en las viviendas, tanto en el salón como en el dormitorio. En ese cómodo y fresco mueble se recibían las visitas, se dormía la siesta y “... se entregaba al amor” (Hidalgo, 2011, p. 77), algo que llamaba la atención a los viajeros que llegaban a la ciudad, como a Alcides D’Orbigny quien describió como se mecían todo el día “... las mujeres en sus movibles lechos" quienes recibían sus visitas “... en hamacas que en lugar de sillas ofrecen a los visitantes” (D’Orbigny, 1997 [1829], p. 144). Otros viajeros, en cambio se sorprendían por la cantidad de hamacas que normalmente había en una casa

Nada sorprende más al extranjero en Guayaquil que el gran número de hamacas, de todo tamaño (de tres a doce pies de largo), que están colgadas en todos los lugares de las casas. Están hechas de paja tosca, pintada de diferentes colores brillantes, tejidas en forma de red, y son un mueble necesario en este clima. Son muy elásticas y se acomodan al cuerpo, están colgadas de tal forma que una persona sentada o echada en ellas puede tocar el piso con la punta del pie y así mantener un balanceo constante que crea una corriente de aire y mantiene alejados a los mosquitos y a otros insectos. Sirven de sofá, silla y sillón (Terry, 1994 [1832], p. 55).

Durante el siglo XIX e inicios del siglo XX la arquitectura de Guayaquil seguía estando conformada mayormente por edificaciones de madera, de planta baja y otras dos plantas superiores y con techos cubiertos de teja, ya que en general eran pocas las edificaciones que conservaban la tradición de techarlas con paja o bijao, por la insistencia de las autoridades de sustituir estos materiales por teja, material que permitía una mejor defensa ante los continuos incendios. Unas pocas casas estaban hechas de ladrillo, mientras las de las zonas más pobres seguían siendo construidas con caña guadúa.

Por lo general la planta baja de las casas era destinada a tiendas o bodegas, mientras las plantas altas servían para vivienda. Así lo describía Adrian R. Terry en 1832: "El piso inferior de la casa está ocupado por almacenes y tiendas de comerciantes. El segundo piso, si es que hay más, se renta a inquilinos, el dueño siempre ocupa en estos casos el piso superior" (1994[1832], p. 56). La poca extensión del área de la ciudad y su continua densificación determinaban que fueran muy pocas las casas construidas con una sola planta.

La distribución de los espacios interiores se desarrollaba por lo general alrededor de un patio hacia el que convergían los diferentes espacios interiores, además de que servía como medio regulador de las condiciones climáticas internas. Por lo general desde el exterior se accedía a un gran salón y desde ahí, mediante corredores, a los diferentes salones y dormitorios.

Las plantas altas de las casas tenían balcones y largas galerías frontales con ventanas de chazas que se prolongaban sobre la vereda y conectaban cada uno de estos espacios con 
los de las casas vecinas. Estas galerías aparecen como constantes en la arquitectura colonial de lugares sometidos a rigurosidades climáticas donde se combinan alta temperatura y humedad como ciertos lugares de Ecuador, Colombia o Cuba, convirtiéndose en un elemento regulador del ambiente interior.

La prolongación de las galerías sobre las veredas generaba largos soportales extendidos por toda la ciudad. Los viajeros que visitaban la ciudad destacaban la posibilidad que los soportales brindaban de "... dar la vuelta a la ciudad sin mojarse ni ensuciarse el calzado" (Mallet, 1816, s/p) y la protección que proporcionaban ante el sol y la lluvia. Hans Meyer destacaba la utilidad de los soportales de esta manera:

Como el piso alto de la gran mayoría de las casas de dos pisos es saliente y descansa sobre vigas saledizas, hay debajo, en ambos costados de la calle, un pasadizo sombroso, donde están situadas las oficinas, los almacenes y las tiendas (“almacenes”), por donde caminan los transeúntes (Meyer, 1993 [1903], s/p).

Tan extendido era el uso de este elemento que la viajera norteamericana Blair Niles (1995 [1923]), consideró que a la ciudad debía llamársela “... la ciudad de las arquerías o portales” (p. 38).

Otro elemento incorporado a la arquitectura de la ciudad fueron las chazas, como se denominan con esta palabra de origen naval a las ventanas de celosías de madera, llegadas a la península ibérica a través de la ocupación morisca. Estas ventanas abatibles permiten tamizar la luz y regular la entrada de aire, además de posibilitar la observación desde el interior hacia el exterior y no en sentido contrario. En algunas casas tradicionales la composición de fachada estaba definida totalmente por este tipo de ventanas, asociadas a las galerías frontales, como en la famosa casa de las Cien Ventanas.

Generalmente las casas se construían con techados altos, además de que era común que en las paredes interiores de las habitaciones se dejara una abertura superior que permitía el flujo del aire, lo que llamó la atención a Blair Niles quien describía de esta manera a la casa donde se alojó en la ciudad:

La casa posada estaba situada en el Malecón. Teníamos un hermoso balcón que dominaba la ría. El piso y las paredes de los cuartos estaban desnudos y el cielo raso a mucha altura, a mayor altura que la extensión o el ancho del cuarto. Después, supimos que esto tenía su objeto: proporcionar mayor circulación de aire y de frescor a la casa (Niles, 1995 [1923], p. 40).

Algunos de estos elementos como el soportal, el patio, los techados altos y las chazas aún se pueden encontrar en la arquitectura popular de la ciudad, edificada por carpinteros y maestros de obra, sin la intervención de arquitectos o ingenieros.

Esta asignación de roles y de funciones que tenían en un hogar los hombres y las mujeres empezó tibiamente a cambiar luego del triunfo de la Revolución Liberal en 1895. Una de las preocupaciones de Eloy Alfaro, líder del liberalismo, era la situación de la mujer y el papel que debía cumplir en la sociedad, más allá de los que tenía asignados dentro del hogar. En un mensaje al Congreso en 1897 exponía su visión sobre este particular: 
Nada hay tan doloroso como la condición de la mujer en nuestra Patria, donde relegada a los oficios domésticos, es limitadísima la esfera de su actitud intelectual, y más estrecho aún el círculo donde pueda ganarse el sustento independiente y honradamente.

Abrirle nuevos horizontes, hacerla partícipe en las manifestaciones del trabajo compatible con su sexo, llamarla a colaborar en los concursos de las ciencias y de las artes; ampliarle, en una palabra, su campo de acción, mejorando su porvenir, es asunto que no debemos olvidar (Núñez Sánchez, 2010, p. 143).

Esbozaba, además, algunas líneas de cómo llevar a la práctica esas ideas, a través, por ejemplo, del acceso a las universidades y de la participación en empleos públicos, lo que hizo efectivo con la contratación de mujeres en las empresas de correos del país y como telegrafistas.

La crisis económica de finales de los veinte, que se expresó en la arquitectura con la emergencia de la Arquitectura Moderna, a la par de la incorporación de la mujer al mundo laboral y de su acceso a la educación, sumado a la generalización en el uso de aparatos eléctricos de uso doméstico, propios de la modernidad, empezaron no solo a cambiar la idea de que la mujer cumplía un rol exclusivamente doméstico al interior del hogar sino que modificaron los propios espacios de las viviendas que tendieron a ser más pequeños y simples. Como acotaba Walter Gropius en 1956:

La obligación de la mujer de obedecer al hombre se desvanece y las leyes de la sociedad les conceden paulatinamente derechos iguales a los de los hombres. A medida que la familia transfiere numerosas tareas domésticas a la maquinaria de producción socializada, se restringe la esfera de actividad doméstica de la mujer y ella busca más allá de la familia una descarga para su necesidad natural de ocupación (Citado en Tomas, 1998, p. 23).

De esta manera, los patios fueron sustituidos por claraboyas, las hamacas por sofás y sillones, las grandes cocinas por otras más pequeñas y funcionales, los techos altos por otros más bajos y la madera por el cemento, considerado más higiénico. El progresivo aumento del equipamiento orientado al confort -la luz eléctrica en los hogares, el teléfono, la radio, los electrodomésticos, el inodoro, etc.- iba restringiendo poco a poco la actividad doméstica de la mujer y permitió convertir al "templo doméstico" decimonónico en el "hogar moderno" del siglo XX.

\subsection{La modernidad artística y literaria: entre la evasión y el compromiso político}

El crítico ecuatoriano Hernán Rodríguez Castelo (1988) sitúa el nacimiento de la modernidad en el arte ecuatoriano en el escenario de la Escuela de Bellas Artes de Quito, fundada en 1904 “... en medio de la paradójica situación de desplegar una pedagogía vinculada a las academias neocláiscas y al mismo tiempo de promover los valores de algunas de las corrientes artísticas modernas" (Pérez T., 2013, p. 115). 
A partir de la llegada del francés Paúl Alfred Bar en 1913, se dio lugar “... a la transición de lo decimonónico a lo contemporáneo” (p. 9) a través de la armonización del lenguaje moderno con la representación de temas locales, tal como lo informaba José Gabriel Navarro, en ese entonces director de la escuela, al Ministro de Instrucción Pública, respecto a la clase dictada por Bar:

... con método esencialmente práctico, ha conseguido enseñarles el sentimiento moderno en la decoración, la aplicación del arte a la industria, la concepción y ejecución bajo el punto de vista de la utilidad. Esta clase tiene un doble objeto: el desarrollar la imaginación creadora del artista, mediante la indagación del sentimiento estético de lo que va a ser motivo de la decoración. La composición decorativa moderna tiene un fin de bella utilidad práctica, cual es la de presentar los mismos objetos de uso y servicio cuotidiano (sic), inclusive la habitación misma del hombre, con el timbre artístico (Citado en Pérez T. , 2013, p. 118).

Rodrigo Gutiérrez Viñuales también destaca la presencia en dicha escuela del catalán José María Roura Oxandaberro, quien a partir de 1915 potenció “... el crecimiento de una nueva generación de dibujantes y caricaturistas” (Gutiérrez Viñuales, 2013, p. 58).

Respecto a la literatura ecuatoriana, Fernando Tinajero (1987) afirma que el Modernismo en el Ecuador “... fue hijo ilegítimo del liberalismo”, debido a que “...fueron las concepciones de modernidad y progreso las que alimentaron la nueva tendencia literaria” (pp. 34-35), lo que lo acerca a nacimientos similares, bajo las mismas tensiones, que se dieron en otros países de América Latina, donde, como bien describía Octavio Paz (1991 [1965]):

Los modernistas no querían ser franceses: querían ser modernos. El progreso técnico había suprimido parcialmente la distancia geográfica entre América y Europa. Esta cercanía hizo más viva y sensible nuestra lejanía histórica. Ir a París o a Londres no era visitar otro continente sino saltar a otro siglo. Se ha dicho que el modernismo fue una evasión de la realidad americana. Más cierto sería decir que fue una fuga de la actualidad local -que era, a sus ojos, un anacronismo- en busca de una actualidad universal. En labios de Rubén Darío y sus amigos, modernidad y cosmopolitismo eran términos sinónimos. No fueron antiamericanos; querían una América contemporánea de París y Londres (pp. 19-20).

Esta irrupción del modernismo literario, que se inició en Hispanoamérica a finales del siglo XIX con la obra de José Martí, Manuel Gutiérrez Nájera, José Asunción Silva, Julián del Casal, entre otros (Salvador, 2013), y que alcanzó su esplendor con Rubén Darío, se inició en Ecuador el mismo año en que Darío editaba Prosas profanas (Hidalgo, 2014), a través de la denominada Generación Decapitada, llamada así porque los cuatro autores que la integraban se suicidaron a temprana edad, Medardo Ángel Silva a los veintiún años, Arturo Borja a los veinte, Humberto Fierro a los treinta y nueve y Ernesto Noboa a los treinta y ocho años. 
Aunque ellos se conocieron en vida e incluso se dedicaron poemas mutuamente, nunca se reunieron para crear propiamente una agrupación literaria. En los textos poéticos de estos autores se dejaba atrás el lirismo decimonónico para adoptar una nueva poesía que reflejaba y cuestionaba la época de cambios en la que vivían como “... testigos privilegiados de la estructura social y cultural de las ciudades más urbanizadas de entonces, particularmente Quito, Guayaquil y Cuenca" (Balseca Franco, 2009, p. 81).

En la poesía modernista de Silva, Noboa, Borja o Fierro se evidencia esa necesidad de abstraerse de la realidad y de buscar, a través de sus versos, empatarse con lo que sucedía en los núcleos urbanos europeos.

Esa abstracción, a veces, se expresaba en un desencanto por la vida, como en el poema Vas lacrimae de Borja

La pena... La melancolía...

La tarde siniestra y sombría...

La lluvia implacable y sin fin...

La pena... la melancolía...

La vida tan gris y tan ruin.

La vida, la vida, la vida!

La negra miseria escondida

royéndonos sin compasión

y la pobre juventud perdida

que ha perdido hasta su corazón.

El desencanto por amores frustrados o no retribuidos que los llevaba a exaltar el desear poner fin a sus vidas, como en el poema El alma en los labios de Silva:

Cuando de nuestro amor la llama apasionada,

dentro de tu pecho amante contemples extinguida,

ya que sólo por ti la vida me es amada,

el día en que me faltes me arrancaré la vida.

La evasión se expresaba también en la obsesión por escapar, como en el poema Emoción vesperal de Noboa:

Hay tardes en las que uno desearía embarcarse y partir sin rumbo cierto, $y$, silenciosamente, de algún puerto, irse alejando mientras muere el día;

Emprender una larga travesía y perderse después en un desierto y misterioso mar, no descubierto por ningún navegante todavía. 
o en el poema Se va con algo mío de Silva:

Se va con algo mío la tarde que se aleja; mi dolor de vivir es un dolor de amar; y al son de la garúa, en la antigua calleja, me invade un infinito deseo de llorar.

Algunas veces la evasión implicaba la creación de paraísos artificiales, a través del uso drogas en alguno de los fumaderos de opio que había en esa época en la ciudad, y que expresaba en poesía, como en Ego sum de Noboa:

Amo todo lo extraño, amo todo lo exótico;

lo equívoco y morboso, lo falso y lo anormal;

tan solo calmar pueden mis nervios de neurótico

la ampolla de morfina y el frasco de cloral.

Sin embargo, hay autores como Fernando Balseca Franco (2009) o Ángel Emilio Hidalgo, que sostienen que los modernistas ecuatorianos no eran escapistas que se aislaban de la realidad, sino que eran “... ciudadanos que intervenían en la esfera pública desde su particular modo de desenvolverse en la sociedad como escritores y artistas" (Hidalgo, 2013, p. 128), por lo que no sorprenden las crónicas urbanas de Silva o la crítica literaria de algunos de los integrantes de los "decapitados".

Como una figura atípica dentro de la vanguardia poética surgió la figura de Hugo Mayo, seudónimo del escritor Miguel Augusto Egas (1895-1988), quien fundó en la década de los veinte, tres revistas literarias Síngulus en 1921, Proteo en 1922 y Motocicleta en 1924, donde, a través de sus poemas “... introduce nuevos temas vinculados con el desarrollo de la modernidad: la velocidad, el maquinismo, la industria” (Verdugo Cárdenas, 1997, p. 64). Sus versos expresan un deseo de nueva espacialidad a través del ordenamiento de las estrofas, como en La Oda Gaseosa:

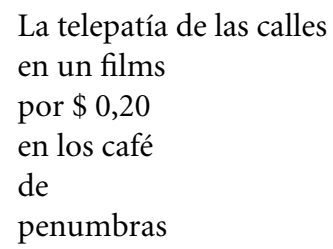

Como reacción a lo sombrío de los poetas modernistas, Hugo Mayo introdujo lo lúdico y el humor, en algunos casos para burlarse de sí mismo y destacar el asombro que suscitaba su poesía entre os intelectuales de la época, como en El Zaguán de Aluminio

A una caverna de voces armoniosas

llevé a Nino Amonolik 
De puro susto, se desmayó, oyendo mis novimorfos poemarios

Años más tarde en Guayaquil, en 1929, como acota Tinajero (2015), “... estallaba otra revolución, sin duda más vigorosa, duradera y profunda que aquella que recurrían a las armas para instalar efímeros gobiernos" (p. 149). Demetrio Aguilera Malta, Joaquín Gallegos Lara y Enrique Gil Gilbert, “... mozalbetes audaces que se habían atrevido a publicar un libro irreverente” (Tinajero, 2015, p. 149) a los que se sumaron José de la Cuadra y Alfredo Pareja Diezcanseco en la llamada Generación del 30, publicaron el libro de cuentos y relatos Los que se van, en el que se releva la marginación de los grupos étnicos y sociales de la costa ecuatoriana, principalmente del cholo y el montubio enfrentados con la ciudad, que se convierte en protagonista de muchos de esos relatos. Como lo explica Miguel Donoso Pareja (2006):

Ubicados en el realismo social, la prioridad temática de estos relatistas fue el habitante del agro costeño, es decir, el montuvio (sic) (del latín montis=montaña y vita=vida); luego, el lugar que este ocupaba (ocupa aún, con los naturales desplazamientos) en las relaciones de producción y, finalmente, la ciudad, esto es, Guayaquil (p. 159).

Pareja Diezcanseco establece cómo la movilización que hubo en Guayaquil en 1922, que culminó en la matanza del 15 de noviembre de ese año, influyó en los escritores de su generación:

Los adolescentes y niños que integrarían el Grupo de Guayaquil contemplaron espantados la matanza de trabajadores. Es de suponer que, parcialmente cuando menos, aquel hecho sangriento y bárbaro influyese en el espíritu de la literatura ecuatoriana de los años treinta. El mayor de los cinco del grupo inicial, José de la Cuadra, tenía diecinueve años; Aguilera Malta y Pareja Diezcanseco, catorce; Gallegos Lara, once, y Gil Gilbert, apenas diez (Pareja Diezcanseco, 1988, p. 692).

Ese libro significó una ruptura de la tradición romántica y modernista hasta ese momento en auge y se convirtió el punto de partida de la modernidad literaria del país.

En el arte de Guayaquil es fundamental la figura del escultor italiano Enrico Pacciani, quien en 1931, junto con el dibujante y pintor ítalo-guayaquileño Antonio Bellolio, fundó la Asociación Ecuatoriana de Bellas Artes Alere Flammam (alentar la llama)-conocida también con el nombre de Sociedad Promotora de Bellas Artes de Guayaquil- con el objetivo de "... estimular el ejercicio de la pintura, la escultura, la caricatura, la arquitectura y la fotografía artística entre la juventud guayaquileña, mediante la organización periódica de diversos torneos culturales" (Guerrero Blum, 2001, p. 81). Esta asociación tuvo su precedente en la primera Escuela de Bellas Artes que Pacciani y Bellolio habían fundado en la ciudad, adscrita al Colegio Nacional Vicente Rocafuerte (Hidalgo (editor), 2004).

En los nueve años que estuvo en actividad, entre 1931 y 1940, organizó quince exposiciones. La primera, el 3 de octubre de 1931, que exhibió las caricaturas tridimensionales en 
cera de Galo Galecio, las pinturas de Bellolio, las esculturas de Pacciani, los ensayos escultóricos de Alfonso Vernimmen y Léntulo Aragundi, los bodegones de Marcos Martínez Salazar y los dibujos estilizados del arte puná del arqueólogo Carlos Zevallos Menéndez. A este primer grupo de artistas se sumaron en 1933 los escritores Demetrio Aguilera Malta, Abel Romeo Castillo, Jorge Carrera Andrade, Aurora Estrada y Ayala, Víctor Hugo Escala, Gonzalo Escudero, Joaquín Gallegos Lara, Enrique Gil Gilbert, Francisco Huerta Rendón, Nicolás Kingman, Miguel Ángel León, Hugo Mayo, Jorge Pérez Concha, Telmo Vaca y Pedro Jorge Vera (Guerrero Blum, 2001), quienes expusieron carteles poéticos. A fines de ese mismo año se incorporaron a este grupo Pedro Manrique Acevedo y Héctor Martínez Torres, en ese entonces estudiantes de arquitectura, quienes exhibieron diversos dibujos y estudios arquitectónicos.

La exposición del año 1937, que congregó a pintores, ceramistas, escultores y dibujantes, terminó en medio de la polémica. Un grupo de representantes de la asociación invitó al presidente de facto, Federico Páez, a que recorriera los trabajos expuestos. Esto molestó a algunos de los artistas identificados con la izquierda ecuatoriana, quienes habían sido víctimas de la persecución del régimen, por lo que abandonaron la organización y fundaron el 25 de noviembre de 1938 la Sociedad de Artistas y Escritores Independientes, con el fin de

... coordinar los esfuerzos de los artistas y escritores; tender a la creación de un arte que, inspirándose en la realidad ecuatoriana, contribuya al desenvolvimiento de una nacionalidad liberada de las fuerzas retardatarias, y divulgar, en el seno del pueblo, la cultura y el arte (Estatutos de la Sociedad de Artistas y Escritores Independientes, 1 de enero de 1939).

La antigua organización continuó en funcionamiento hasta 1940, bajo el nuevo nombre de Asociación Ecuatoriana de Bellas artes, Letras y Ciencias Alere Flammam, con las secciones de Bellas artes, a cargo de Pacciani; Letras, por el escritor Pío Jaramillo Alvarado; y Ciencias, por el médico guayaquileño Leopoldo Izquieta Pérez (Guerrero Blum, 2001). Por su parte la nueva organización quedó presidida por Carlos Zevallos Menéndez y conformada además por Alba Celeste Rivas, Alba Calderón de Gil, Rafael Rivas Nevárez, Antonio Gil Gilbert, Segundo Espinel, Galo Galecio, Bella Amada López, Marcos Martínez Salazar, Alfredo Palacio, Manuel Rendón Seminario, Ángel Felicísimo Rojas, Alfredo Pareja Diezcanseco, Enrique Gil Gilbert y Joaquín Gallegos Lara (Guerrero Blum, 2001). Entre 1938 y 1940 la Sociedad organizó importantes exitosas exposiciones y conferencias. Una de las más novedosas, en mayo de 1939, fue el Primer Salón de Humoristas, con caricaturas de Rafael Rivas Nevárez, Antonio Gil Gilbert y Segundo Espinel. En los años siguientes, 1939 y 1940, organizaron el Primer y Segundo Salón de Octubre, respectivamente, en conmemoración de la independencia de la ciudad, donde se exhibieron pinturas y dibujos de Alba Calderón de Gil, Segundo Espinel, Galo Galecio, Eduardo Kingman, Manuel Rendón Seminario, Eddy Wright y Miguel de Ycaza Gómez; esculturas de Bella Amada López y Alfredo Palacio; caricaturas de Manuel Palacios Offner y Rafael Rivas Nevárez; fotografías de Antonio Hanze Sarquiz; y dibujos arquitectónicos de Marcos Martínez Salazar (Guerrero Blum, 2001). 
Las exposiciones de la Sociedad de Artistas y Escritores Independientes, con su incorporación de la caricatura y la fotografía, y su reconocimiento como nuevas expresiones, tienen una repercusión fundamental en el desarrollo de una escena artística moderna en el Ecuador.

La década de los cuarenta, aún en plena época de crisis, se expresó en el desarrollo de un arte comprometido y de denuncia, vinculado a propuestas indigenistas como en la obra de Oswaldo Guayasamín, Diógenes Paredes, Eduardo Kingman o José Enrique Guerrero, en la sierra y de un arte proletario en la costa, ligado a la margnación urbana, como en la obra de Alba Calderón de Gil (Hidalgo (editor), 2004). No debe de sorprender esta diversidad en las propuestas en un país “... donde la fragmentación y el aislamiento entre las regiones imposibilita, como expresó Jorge Icaza, 'que se pueda hablar de expresión unificada o de un solo espíritu”" (Hidalgo (editor), 2004, p. 40).

Unos años antes, en 1937, César Andrade Faini, pintor nacido en Quito pero quien desarrolló gran parte de su trabajo en Guayaquil, había publicado su tesis de graduación en la Escuela de Bellas Artes de Quito, con el nombre de Miseria social, donde escogía como temática de su obra a "... la prostitución, la mendicidad infantil y las condiciones infrahumanas en que vivían los enfermos mentales" (Hidalgo (editor), 2004, p. 57).

Esta sobrexplotación de la imagen del indio y de la marginalidad generó no pocas críticas, como la de Humberto Vacas Gómez (1945), para quien el abuso y la repetición de esta iconografía generaba “... el peligro que engendre un arte declamatorio, amanerado y anecdótico, de propaganda o ilustración de un estado social. Es decir, se desvirtuará el arte en sus intrínsecos valores creativos" (citado en Hidalgo (editor), 2004, p. 40).

Más adelante, ya dentro del período de estudio, y a la par de otras expresiones culturales como la literatura y la arquitectura, se daría el desarrollo de visiones más contemporáneas a través de precursores como Manuel Rendón Seminario -pionero de la abstracción- y otras más marginales y simbólicas, como en la obra de Eduardo Solá Franco, entre otros.

\subsection{Rafael Rivas Nevárez: caricaturista, diseñador y arquitecto}

Rafael Rivas Nevárez nació en Guayaquil el 2 de septiembre de 1914 y falleció el 1 de enero de 1984. A la par de su formación académica secundaria recibió clases de dibujo en la Escuela de Pintura de la Asociación de Empleados a cargo del artista catalán José María Roura Oxandaberro. Desde muy joven destacó por su enorme capacidad como dibujante y caricaturista.

En 1936, cuando apenas tenía veintidós años de edad, Rivas, junto con Héctor Orcés Mendoza, estableció la empresa $\mathrm{HO}$ orientada al diseño de juguetes de madera. Al poco tiempo se había convertido en una floreciente industria que daba trabajo a cerca de cien artesanos, ya que sus juguetes, diseñados por Rivas, eran exportados principalmente a países vecinos, Colombia y Perú, y a los Estados Unidos. El éxito les llegó cuando en la Navidad de 1940 el Diario El Telégrafo realizó un concurso local en el que entre los premios estaban ciento cincuenta de los juguetes de la fábrica HO.

En una revista norteamericana de la época se relataba cómo se había conformado la empresa 
It is a curious paradox of carácter that the German and japanese nations, which cradled the nazis and the Nipponese warlords, have benn known throught the world for decades as producers of children's toys. When the agressions of these nations killed their gentler industries, there came a chance for New world countries to break in and capture the international trade.

Quick to seize her portion of this chance was Ecuador, a country naturally endowed with choice hardwoods in profusion and variety. Hector Orcés, a young Ecuadorean with the energy and imagination, was already making toys in a small way at Guayaquil. With Little capital he pluged into his self-appointed task of creating a native toy industry, and the business expanded rapidly.

Soon the symbol "HO", Orcés initials, became known in neighborlands, including the United States, as a trade tag for toys of highly original design made from tropical Woods. Orcés had early found in his home town a fellow enthusiast, Rafael Rivas, who was ready to offer his talents in lieu of capital. As a matter of fact, neither young man ever had any money to spare, but Orcés had executive ability and Rivas was a designer of originality and personality (Henriques, 1943, p. 31).

Es una curiosa paradoja que las naciones alemanas y japonesas, que acunaron a los nazis y a los señores de la guerra nipones, hayan sido conocidas en todo el mundo, durante décadas, como productoras de juguetes infantiles. Cuando las agresiones de estas naciones mataron sus industrias más ligeras, hubo una oportunidad para que los países del Nuevo Mundo entraran y capturaran el comercio internacional.

Ecuador es un país dotado naturalmente de maderas duras en profusión y variedad. Héctor Orcés, un joven ecuatoriano con energía e imaginación, fue rápido para aprovechar esta oportunidad, y empezó a hacer juguetes en Guayaquil. Con poco capital emprendió la tarea de crear una industria de juguetes nativa, y el negocio se expandió rápidamente. Pronto el símbolo "HO", iniciales de Orcés, se hizo conocido en países vecinos, incluyendo los Estados Unidos, como una etiqueta comercial para juguetes de diseño, altamente originales, hechos de maderas tropicales. Orcés había encontrado pronto en su ciudad natal a Rafael Rivas, un entusiasta que estaba dispuesto a ofrecer su talento en lugar de capital. De hecho, ninguno de los jóvenes tenía dinero, pero Orcés tenía capacidad ejecutiva y Rivas era un diseñador original y con personalidad (Traducción del autor).

En la fábrica HO, y de acuerdo a los diseños de Rivas, se producían juguetes articulados en madera, algunos con sonido y mecanismos de cuerda y metal, que representaban animales. Estos eran luego pintados a mano y enviados a los diferentes mercados locales e internacionales para su comercialización. El gran aporte de Rivas radicaba en la simplificación de los diseños y la racionalización de las partes componentes de los juguetes, las cuales eran intercambiables (Ver Figura 5).

Lamentablemente la situación local y mundial, y la restricción del mercado norteamericano a causa de la guerra determinó que la producción fuera disminuyendo y finalmente a mediados de la década de 1940 la fábrica finalmente cerró.

En 1938 Rivas fue uno de los fundadores de la Sociedad de Artistas y Escritores Independientes -institución escindida de la Asociación Ecuatoriana de Bellas artes, Letras y Ciencias Alere Flammam - junto con Antonio Gil Gilbert, Segundo Espinel, Alba Calderón de 


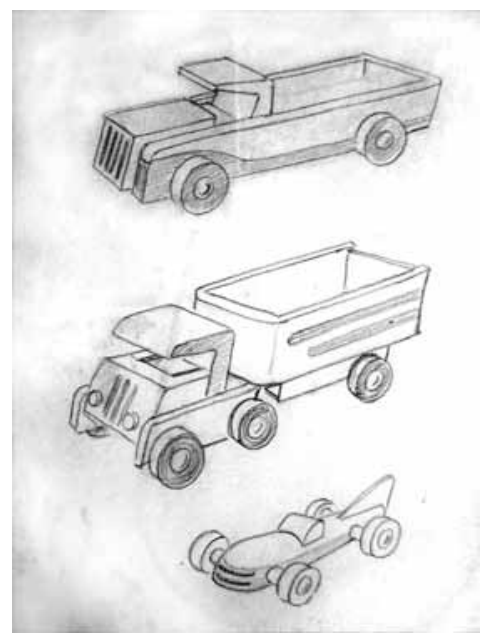

Figura 5. Diseños de Rafael Rivas Nevárez para la fábrica de juguetes HO. Archivo Rafael Rivas Nevárez

Gil, Galo Galecio, Bella Amada López, Marcos Martínez Salazar, Alfredo Palacio, Manuel Rendón Seminario, Carlos Zevallos Menéndez, Ángel Felicísimo Rojas, Alfredo Pareja Diezcanseco, Alba Celeste Rivas, Enrique Gil Gilbert, Joaquín Gallegos Lara y Abel Romeo Castillo. Al año siguiente obtuvo el primer premio en el Primer Salón de Humoristas, que organizó la Sociedad de Artistas y Escritores Independientes de Guayaquil, en el Salón del edificio del Correo de la ciudad, junto con Antonio Gil Gilbert y Segundo Espinel. La obra premiada se titulaba Al muralista le gustó el rojo y representaba a Hitler tiñendo un muro con sangre.

Las caricaturas de Rivas se convirtieron también en un instrumento de propaganda política, desde su compromiso ideológico, y en un catalizador de la opinión pública. No es extraño que esto hubiera sucedido ya que como afirman Ángel Emilio Hidalgo y Guadalupe Álvarez (2004) "La caricatura es el dominio artístico pionero de la discusión social en el Ecuador” (p. 54).

En los dos años siguientes, en 1939 y 1940, volvió a exhibir sus caricaturas en el Primer y Segundo Salón de Octubre en conmemoración de la independencia de la ciudad, junto con Manuel Palacios Offner (Guerrero Blum, 2001).

En esa misma época dio a conocer una de sus caricaturas más célebres, la que realizó a los miembros de la Sociedad de Artistas y Escritores Independientes de Guayaquil, de la cual había sido fundador y en la que permaneció hasta su disolución como miembro y Vocal por la sección de pintura.

Durante sus años de estudiante universitario participó activamente en la política universitaria, alineado con posiciones de izquierda. En el año 1939, representado a la Facultad 
de Ciencias Físicas y Matemáticas, fundó en la Universidad de Guayaquil el semanario $E l$ Universitario, junto con un grupo de estudiantes de las siguientes facultades: Jurisprudencia, Fausto D. Benites, Fernando Barredo Hidalgo, Alejandro Idrovo Rosales; Ciencias Médicas, Efrén Jurado López, Enrique Espinoza Vega, Marco Martínez Macías; Ciencias Económicas, Carlos Intriago Morla (de la Torre, 2013). En el editorial de su primer número se esbozaba su ideario político y clasista:

Hemos sostenido siempre y lo seguiremos sosteniendo cuantas veces sea menester que el universitario no solo ejerce un inalienable derecho, sino que ejercita el primordial de sus deberes al hacer política, al interesarse por la cosa pública, al estudiar cómo esta se encuentra, al analizar la manera cómo a esta se administra, al indicar las soluciones más satisfactorias para que se logre un auténtico progreso que se traduzca en bienestar colectivo (Gómez Iturralde, 2005, p. 327).

En 1942, siendo aún estudiante universitario publicó en la revista de la asociación Escuela de Ingeniería de la Universidad de Guayaquil el artículo La práctica profesional. Nuestra realidad arquitectónica (Rivas Nevárez, 2013 [1942]), donde hacía una crítica sobre la arquitectura de la ciudad y la labor que hasta ese momento realizaban los arquitectos. Sostenía Rivas que “... todavía entre nosotros no se hace arquitectura” (p. 69) y hacía un llamado al papel que debían jugar los arquitectos en la sociedad en función de lo que consideraba debía ser la arquitectura:

La arquitectura tiene también su gramática, tiene también su técnica. El conjunto de reglas, leyes y principios teórico-prácticos de la construcción constituyen la parte científica de la arquitectura. El estudio del medio, las costumbres, la raza, los principios económicos, políticos y sociales son también materia científica del arquitecto. $\mathrm{Y}$ valiéndose de esta gramática como procedimiento de expresión el Arquitecto deja sentir la parte espiritual propia, material netamente temperamental. ¡Necesitamos Arquitectos!

¡Necesitamos Arquitectos! Parece un letrero que deberíamos poner en grandes caracteres pegado sobre nuestra ciudad. Tal vez así, nuestras fábricas de profesionales, que se ha dado en llamar universidades, que cada año aumentan la producción de doctores y profesionales estandarizados, tal vez así, intensifiquen sus actividades y produzcan también arquitectos (p. 71).

En 1944, egresó de la Facultad de Arquitectura de la Universidad de Guayaquil y al año siguiente viajó a Buenos Aires, donde realizó estudios de perfeccionamiento en arquitectura y urbanismo. Se denominaba egresados a aquellos que habiendo culminado el pensum académico aún no obtenían su título universitario, ya que el requisito adicional era realizar una tesis de grado. En muchas ocasiones solían permanecer como egresados durante años hasta emprender su trabajo de grado y obtener el título profesional (Ver Figura 6). 


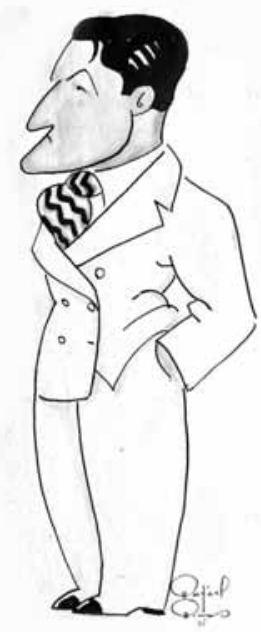

Figura 6. Caricatura

de Abel Romeo

Castillo, Rafael Rivas

Nevárez. Archivo

Florencio Compte.

A su regreso, en 1946, constituyó la Compañía Construcciones y Anexos CASAS, junto con Rodolfo Idrovo, Arturo Cepeda y Hugo Orcés, la cual al poco tiempo desapareció. Un año más tarde fue designado Director del Consejo de Urbanismo de la Municipalidad de Guayaquil y participó como delegado en el VI Congreso Panamericano de Arquitectos que se celebró en Lima entre el 15 y el 25 de octubre, junto con Simón Bolívar Jalón y Manuel Gambarrotti Gavilánez (Alarcón Orquera, 1968). Ese mismo año publicó el ensayo Guayaquil: ciudad enferma, donde hace un repaso de cómo la ciudad ha ido "... siempre a la zaga, recogiendo lo desechado o caduco afuera para utilizarlo” (Rivas 2013 [1946], p. 39) y concluye que "Guayaquil reclama en forma imperativa enfocar su futuro con criterio racional. Requiere la revisión y remodelación de sus estructuras para adaptarlas al espíritu de la época y se prepare hacia el desenvolvimiento de su cultura en el porvenir" (p. 44). Ese mismo año en su artículo La zonificación de Guayaquil desarrollaba sus idea de cómo debía concebirse el nuevo Plan regulador de Guayaquil y reflexionaba sobre la propia idea de ciudad y el urbanismo moderno:

No es simplemente el lugar natal y de residencia de un grupo de hombres que se esfuerzan por vivir cada uno mejor que otro; la vida de relación de cada individuo dentro de ese grupo, sus costumbres y particularidades han determinado fenómenos sociales y económicos comunes, que no afectan a un individuo 
sin hacer sentir sus efectos en la colectividad. La evolución histórica de todas las ciudades nos revela el incesante empeño de las comunas por resolver tales problemas y es justamente esa experiencia, recogida en sus principios básicos, lo que constituye el urbanismo moderno (Rivas Nevárez, 2013 [1946], p. 46).

Como bien destaca José Guerra (2013), los intereses intelectuales de Rivas “... no estaban constreñidos a dibujar caricaturas para las revistas o ejercer su profesión como arquitecto, sino que su perspectiva abarcaba el escenario urbano con sus problemas e inequidades económico-sociales y políticas" (p. 24). A lo largo de su vida publicó algunos artículos y ensayos sobre historia de la arquitectura, su visión de la ciudad, la enseñanza de la arquitectura, entre otros, convirtiéndose así en uno de los pocos críticos dentro de la ya escasa bibliografía que sobre estos temas existe en Guayaquil.

El 25 de junio de 1958 obtuvo su título de arquitecto y recibió el Premio Universidad de Guayaquil a la mejor tesis de grado de arquitectura. Ese mismo año inició su carrera académica en la misma facultad donde había estudiado y tres años más tarde fue electo Subdecano de la Facultad de Arquitectura y Urbanismo de la Universidad de Guayaquil. En 1962 fue electo Decano de la Facultad de Arquitectura de la Universidad Laica Vicente Rocafuerte. Su labor como maestro universitario se dio también, durante muchos años, en la Facultad de Arquitectura de la Universidad Católica de Santiago de Guayaquil, donde dictó la cátedra de Medios de Expresión. Uno de los auditorios de dicha facultad lleva su nombre en reconocimiento a trayectoria y labor académica.

Entre 1953-1958, formó parte de la constructora Edificaciones Ecuatorianas S.A. y de la Urbanizadora del Salado S. A., donde fue parte del equipo que diseñó la ciudadela Urdesa, junto con Alamiro González y Modesto Luque Rivadeneira (Compte, 2007). Tuvo una destacada trayectoria como arquitecto en numerosos proyectos dentro de las líneas de la Arquitectura Moderna, donde incluía “... los aspectos climáticos y el aprovechamiento del clima local para transformarlo en elementos arquitectónicos simples pero de gran utilidad e impacto formal en la trama urbana del centro de Guayaquil” (Guerra, 2013, p. 25). En 1957 se fundó la revista Vistazo de Guayaquil y Rivas, junto con otros destacados artistas de la época como Segundo Espinel y Jorge Swett, se inició como ilustrador de las portadas. Sus trabajos significaron un cambio en la visión de la ilustración, al incorporar propuestas de diseño contemporáneas que superaban las tradicionales.

En 1966, junto con un grupo de artistas, formó la Asociación Cultural Las Peñas, con el fin de difundir el arte, a través de sus diferentes manifestaciones, a través de una exposición al aire libre que se hiciera todos los años en el tradicional Barrio Las Peñas, con motivo de la celebración de la fecha de fundación de la ciudad. Fue también uno de los fundadores del Colegio de Arquitectos del Guayas en 1960 donde llegó a alcanzar la presidencia en 1967. Los años que transcurrieron entre finales de los veinte y principios de los cincuenta fueron la época en que el Ecuador empezó a mirar y a abrirse hacia el mundo, de cambios en la manera de habitar, del desarrollo de vanguardias artísticas locales, a la par de lo que sucedía en el resto de los países europeos y americanos, que “... crean un nuevo lenguaje, imponen un código" y que “... son revolucionarias porque proponen” (Cravino, 2005, p. 138), que se expresaron en expresiones literarias comprometidas y en la incorporación de la fotografía y la caricatura como como categorías artísticas modernas. 
En ese contexto la arquitectura emergió como una disciplina independiente, que se iba ajustando tanto a la modernidad como a la necesidad de dar soluciones a los nuevos desafíos que la crisis del país demandaba.

\section{Capítulo 4. Cambiando la manera de construir}

Hay un poema de las construcciones. Pero, las construcciones son, ellas mismas, poemas. Poemas fracturados con materiales sólidos - piedra, madera, cemento- en vez de con espumas de sueño como los otros. Así, los arquitectos resultan en el fondo tan poetas como los que alinean versos, con la diferencia de que son gentes de más serias costumbres y arreglado modo de vivir. Lo cual no empece (sic) a que forjen obras maravillosas, cuyo arranque inspirante parece como que se encontrara en el laberinto de los delirios oníricos (De la Cuadra, 1933, p. 14).

El 24 de julio de 1895 se inauguró en Guayaquil uno de los símbolos más importantes de la modernidad: el servicio de energía eléctrica (Estrada Ycaza, 2000), y unos años más tarde, en 1904, se estableció la Empresa de Luz y Fuerza Eléctrica que en 1903 había iniciado la instalación de postes para el alumbrado público eléctrico de la ciudad, que sustituyó al antiguo de gas, que a partir de la década de 1860 había sustituido a su vez al de aceite de ballena (Estrada Ycaza, 1996).

El Gran Incendio de octubre de 1896 truncó muchos de los procesos de modernización que se habían iniciado años antes, por lo que hubo necesidad de repensarlos y de replantear el desarrollo de la ciudad. A partir de 1897 se dio inicio a la reconstrucción, por lo que la iniciativa privada se orientó a dotar de vivienda a los miles de damnificados que quedaron, luego de esa enorme catástrofe. La prioridad era construir casas, de la manera más rápida y económica, por lo que se continuó con las mismas técnicas constructivas tradicionales y con patrones espaciales y formales que se habían heredado de la Colonia, con viviendas de una o dos plantas con estructura de madera y paredes del mismo material o de paneles de caña guadúa con o sin recubrimiento de mortero.

El tipo de construcción era artesanal, ya que el proceso de industrialización del país era incipiente y, hasta casi fines del siglo XIX, prácticamente inexistente. Tal como lo indica Víctor Hugo Torres Dávila (2012):

La industria ecuatoriana antes de la revolución liberal apenas se reducía a contados talleres artesanales ligados con la vieja producción textil serrana que, condicionados por el comercio importador y la presión externa, mantuvieron disgregadas sus actividades y ampliaron los requerimientos de consumo de origen europeo. Solamente a finales del siglo XIX se formaron las primeras plantas industriales distintas de los tradicionales talleres manufactureros andinos, las que fueron consideradas como empresas de transición en el sentido de que parecían ser una prolongación de la actividad artesanal, reflejando lo que ha sido considerado como el salto de un modo de producción a otro (p. 25). 
Las primeras industrias del país se instalaron recién a inicios del siglo XX, principalmente en Guayaquil -considerada la capital económica del Ecuador-, y se dedicaban a la producción de “... medios de subsistencia de consumo inmediato” (Torres Dávila, 2012, p. 26), como fideos, galletas, chocolates, cerveza, entre otros. Poco a poco, también, fue desarrollándose una nueva industria: la de la construcción, ligada a la temprana incorporación de la tecnología en hormigón armado en 1905. Las continuas afectaciones que sufrió la ciudad a causa del fuego, que significó que se destruyera parcial o casi totalmente varias veces a lo largo de su historia, posibilitó la expansión del uso del cemento como material de construcción y del hormigón armado como sistema constructivo, considerados más efectivos para evitar la propagación de los incendios. Guayaquil, de esta manera, se convirtió en la primera ciudad del país, y en una de las primeras de América del Sur, en hacer uso de esa innovación técnica en la reconstrucción de los edificios públicos.

La llegada de arquitectos y técnicos europeos, sobre todo italianos, y la constitución de compañías constructoras, que incorporaron la tecnificación y el mejoramiento de los procesos constructivos, empezaron a modificar la manera tradicional de edificar. Poco a poco los carpinteros de ribera fueron sustituidos por albañiles y los maestros mayores por arquitectos, ingenieros y técnicos especializados en hormigón armado.

Por su parte, las ordenanzas y normativas urbanas, como parte de las leyes propias o "fundamentales" -o nomos, según Bourdieu-, se orientaron tanto a establecer disposiciones que evitaran la propagación del fuego, a través de la consolidación del sistema de construcción en hormigón armado en detrimento de la tradicional construcción en madera, como a regular la participación de los carpinteros y a la separación de las dos profesiones que se disputaban el campo profesional, ingenieros y arquitectos.

Una nueva arquitectura, que además de evitar la proliferación del fuego, posibilitaba un mejor control higiénico, fue rápidamente asimilada como distintivo de la modernidad, tal como se describía en el Álbum Sanitario de Guayaquil (Gallegos Naranjo, 1928):

La ciudad de Guayaquil se está transformando, de seis años a esta parte, y son numerosas las modernas e higiénicas construcciones de cemento armado que se han levantado en lugar de las antiguas casas de madera y paredes de quincha, de doble tabique, que forman guarida de ratas y bichos nocivos; casas que están condenadas a desaparecer totalmente (...) al mismo tiempo que (...) se embellece la ciudad con suntuosos edificios, que acrecientan la riqueza nacio$\operatorname{nal}(\mathrm{s} / \mathrm{p})$.

Se refiere al recubrimiento a base de arcilla y paja, a manera de enlucido, que se aplica sobre tabiques de caña guadúa (Guadua angustifolia) en las construcciones tradicionales de madera de la costa ecuatoriana. La incorporación del ascensor a partir de 1924 posibilitó que los edificios poco a poco fueran ganando altura y se modificara el perfil de la ciudad. De esta manera Guayaquil fue cambiando su imagen de ciudad colonial edificada en madera por carpinteros de ribera, a una ciudad de cemento $y$, en el imaginario de la época, moderna. 


\subsection{Los cambios en las normativas urbanas}

Durante el período colonial la máxima autoridad política de la ciudad que regulaba su organización y funcionamiento era el Cabildo, conformado por regidores y presidido por un Alcalde. Luego de la Independencia se modificó la composición de este organismo y se conformó un nuevo cabildo con un presidente a la cabeza. Desde ahí se empezaron a dictar las nuevas disposiciones de control y organización de la ciudad y a emitir normas y reglamentaciones urbanas a través de ordenanzas.

A finales del siglo XIX surgió el concepto de ornato que, junto con la idea de progreso, eran las expresiones de la naciente modernidad. El ornato iba ligado en algunas ocasiones a la idea de higiene pública como el principio que debía regir el sistema de control urbano. En la Ordenanza de Construcción y Ornato del año 1885, por ejemplo, se estableció por primera vez la obligatoriedad de que, previo al inicio de una construcción, se debían presentar los planos del proyecto para ser sometidos a la aprobación de la autoridad municipal (Álava, Baquerizo y Hagó, 1976). Esto fue hecho con la finalidad de regular los procesos de construcción de las nuevas edificaciones que estaban muchas veces en manos de carpinteros inexpertos.

El incendio del Carmen del 16 de julio de 1902, que destruyó setecientas casas en veintiséis manzanas, obligó a que las autoridades tomaran medidas para tratar de evitar que se volvieran a producir flagelos como ese o como el de 1896. Bajo esa consideración la Municipalidad de Guayaquil expidió en 1905 la Ordenanza de Construcción y Ornato (Álava y otros, 1976) que, entre otros aspectos, contemplaba que los planos de los nuevos edificios debían ser presentados en escala 1:50 y estar firmados por un ingeniero, un arquitecto o un maestro carpintero debidamente registrado y que hubiera obtenido una matrícula municipal (Art. 2). Se indicaba también que las construcciones que fueran realizadas con materiales incombustibles podían tener hasta tres pisos de altura y se prohibía que los edificios públicos, como teatros, templos, capillas y oratorios, fueran hechos de materiales combustibles. Se establecía, de manera bastante curiosa, que el propietario tenía la “... libertad de adaptar fachadas de cualquier tipo, mientras el proyecto no sea caprichoso, sin ventilación, ni carácter" (Art. 15).

En 1913 el Coronel de la Armada norteamericano William Crawford Gorgas, Oficial Jefe de Sanidad de la Zona del canal de Panamá, fue comisionado por el Secretario de Guerra norteamericano para que preparara un informe sobre la situación sanitaria de Guayaquil y para que elabore recomendaciones para enfrentar las frecuentes epidemias de peste bubónica, malaria y fiebre amarilla. Entre las conclusiones recomendaba que se debía agregar la siguiente nueva cláusula al ya existente Reglamento de Edificaciones:

Cualquier persona, sociedad o corporación, que intente edificar o hacer algún aumento, alteración o reparación de un edificio en la ciudad de Guayaquil, deberá presentar primero al Jefe de Sanidad para su aprobación, los planos del arquitecto y las especificaciones por triplicado de la construcción o mejora que se va a hacer, las cuales indicarán el nombre del propietario del edificio, junto con las dimensiones generales del mismo, el número y altura de los pisos, la clase de material que se ha de usar y la elevación del edificio sobre la calle (Art. 5). 
Se permitía, sin embargo, que los edificios pequeños de un solo piso, “... que no ocupen más de 800 pies cuadrados de terreno, pueden presentarse dibujos hechos por el que va a edificar, en vez de planos hechos por el arquitecto". Se indicaba también que el piso bajo de todos los edificios debía ser de concreto (Gorgas, 1913, s/p).

En 1914 se emitió una nueva ordenanza que regulaba la construcción de edificaciones que utilizaban el cemento como material de construcción. En el artículo 45 se incluía, que los planos debían ser firmados “... por un ingeniero o arquitecto, quien debe vigilar directamente la obra, garantizando así la perfecta estabilidad del edificio” (Gálvez (edit.), 1930, p. 49).

$\mathrm{Al}$ año siguiente se emitió una nueva Ordenanza de Construcción y Ornato en que la Municipalidad incorporó la posibilidad de construir con cemento armado. En el artículo 19 se explicaban las características de los diferentes tipos de edificaciones que podían ser aprobadas: se consideraban de madera “... cuando el armazón es exclusivamente de madera aunque requiera el empleo de materiales complementarios” y de mampostería, a todas aquellas con “... fundación de cemento armado, de piedras o ladrillos, etc.” (Álava y otros, 1976, p. 118). Se establecía que los planos de construcción solo podían ser realizados “... por Ingenieros o Arquitectos, quienes deben garantizar la estabilidad del edificio" (Art. 41). Era la primera vez que en una disposición municipal se excluía a los carpinteros entre los autorizados para suscribir planos y obtener un permiso de construcción.

En 1923 se expidió la nueva Ordenanza de Construcción y Ornato Público, que en su artículo 47 establecía que en el área central delimitada por las calles Malecón, Pichincha, 9 de octubre, hasta la Plaza del Centenario, solo podían construirse edificios de tres o más pisos (Art. 47), además de que todo edificio público debía ser construido con “... materiales incombustibles e indeformables por la acción del fuego" (Art. 24). De esta manera las regulaciones fueron alineándose con la naciente industria de la construcción y con los técnicos especializados que la implementaba.

Respecto a la adecuación legal con la autonomía del campo disciplinar y la profesión de arquitecto, es recién en 1947 cuando la Sociedad de Ingenieros y Arquitectos del Ecuador, consiguió que la Asamblea Nacional Constituyente dicte la Ley de Defensa Profesional de Ingenieros y Arquitectos, que estuvo en vigencia hasta el 30 de diciembre de 1963, cuando se dictó la nueva Ley de Ejercicio y Defensa Profesional de la Ingeniería y Profesiones Afines. Esta ley, sin embargo, contenía algunas disposiciones “... que perjudicaban el ejercicio profesional del Arquitecto, por lo que se continuó en la lucha para conseguir una verdadera defensa de la profesión" (Mera y otros, 1991, p. 104). Tuvieron que pasar tres años, hasta que en 1966 el Congreso Nacional expidió la Ley del Ejercicio Profesional de la Ingeniería y la Arquitectura, que estuvo en vigencia hasta el año 1974 cuando, finalmente, se expidió la Ley del Ejercicio Profesional de la Arquitectura, que especificaba el ámbito de acción de la labor de los arquitectos y regulaba la conformación de los colegios de arquitectos del país (Mera y otros, 1991). 


\subsection{Entre la construcción artesanal y la construcción tecnificada}

La poca capacidad soportante del terreno pantanoso donde se asentó Guayaquil luego, impidió que se construyeran las edificaciones en piedra o argamasa, según lo indicaba la Real Cédula de 1636. A esto se sumaba el mantenimiento de la tradición constructiva autóctona en madera, la abundante disponibilidad del material, la mano de obra experta de los carpinteros de ribera, la necesidad de proporcionar una respuesta a las rigurosidades climáticas del entorno -caracterizadas por las altas temperaturas y la extrema humedad-, además de responder mejor ante los sismos que la edificaciones de piedra.

La frecuencia de los sismos determinó que se desarrollara una particular manera de cimentación de las casas de madera que las convertía en sismorresistentes. Este sistema se denominó de puntalería, que consistía en trabar los pilares con puntales en forma de $\mathrm{X}$, de manera que se daba rigidez a la construcción y al mismo tiempo se mantenía la flexibilidad del conjunto (Núñez, 1997). Jorge Núñez plantea que este original sistema se originó en los astilleros de Guayaquil, desde donde se extendió al resto del país.

Los diferentes viajeros que arribaron a Guayaquil a lo largo de su historia se admiraban de encontrar una ciudad edificada totalmente en madera. El pirata Woodes Rogers, en su visita a la ciudad en 1709, se sorprendió de que "La mayor parte de las casas de la ciudad son de ladrillo o de madera; las más insignificantes son hechas de caña, y hay algunas muy atendidas" (Rogers, 1936 [1717], s/p).

Aún a comienzos de la década de 1920 la mayor parte de las casas de la ciudad eran de madera, tal como se describía en una publicación de la época:

Las casas de Guayaquil son de madera desde los cimientos, porque estos constan de estantes o pies derechos de madera negra incorruptible, clavados en la tierra; en el suelo se endentan con llaves o riostras de madera de matasarna, que se petrifica, y sobre ellas se forma un entablado; en los pies derechos se aseguran las piezas principales con curvas empernadas, los pisos con clavazón, calafateados con estopa y brea, las paredes entre los estantes son de quincha de palos tejidos con bejucos, y cubiertos con un barro; y las fábricas de las casas con portales, balcones y tejados; la mitad de la ciudad las tiene de dos cuerpos y las demás son de uno, pero hermosas y capaces, con tiendas y almacenes abajo que se pueden reputar como el primer cuerpo; todas tienen las cocinas en alto, pero separadas a doce o quince pasos de la casa, con quien se comunican por un pasadizo descubierto que nombran barbacoa, hecho con el fin de cortarla brevemente en caso que se incendie la cocina para aislarla y apagar el fuego ( 9 de Octubre de 1920 América Libre: obra dedicada a conmemorar el centenario de la independencia de Guayaquil, 1820-1920, 1920, p. 43).

El referente directo sobre la conformación de la arquitectura tradicional es la cultura Manteño-Huancavilca, correspondiente al Período de Integración (500-1532), quienes recibieron el impacto del encuentro con la conquista española. En esa arquitectura se destaca el uso de edificaciones con estructura de madera y paredes de paneles de caña guadúa, con o sin recubrimiento. En aquellas donde se trabaja el recubrimiento generalmente se 
lo hacía con quincha que en ocasiones era decorada con pintura. En ocasiones esta mezcla ya aplicada era sometida al fuego, “... con la intención de volverles resistentes al goteo del techo y las lluvias” (Holm, 1982, p. 278). Los grabados que dejaron los viajeros durante la Colonia muestran esas casas con características similares a las casas campesinas contemporáneas, esto es de estructura de caña levantada sobre palafitos y cubiertas a dos aguas con techumbre de bijao.

A finales del siglo XIX se introdujo el hierro en la construcción, que posibilitó el cubrir grandes luces, además que por su capacidad de ser ensamblado con relativa facilidad, permitía edificar en corto tiempo. El primer edificio de este tipo fue la Aduana de Fierro, que a pesar de su material, no pudo resistir el intenso calor que se generó en el Gran Incendio. Más adelante, en 1905, se construyó con hierro el Mercado Sur, que fue ensamblado en la ciudad por los ingenieros Francisco Manrique y Carlos Van Isschott a partir de las piezas enviadas desde Bélgica por la empresa Verjaeren \& Jaeger Ingenieurs Constructeurs. En el contrato suscrito entre el Concejo Municipal y Manrique y Van Isschott, se daban las indicaciones sobre el tipo de construcción que debía tener:

El edificio se levantará sobre sólidos postes de concreto, que arrancarán desde el suelo, y, que pasando al través del terraplén, se elevarán hasta el nivel que les corresponda para recibir las columnas que ha de soportar el edificio. La extructura (sic) del edificio será de acero, reservándose el empleo de fierro fundido para las columnas por motivo de ornamentación (GM, 1905, p. 547-548).

El tercero y último que se construyó en esa época con estructura metálica fue la Torre del Reloj Pûblico, diseñada en 1921 e inaugurada el 25 de abril de 1922, según el proyecto del italiano Nicola Virgilio Bardellini, la cual tuvo que ser demolida cinco años más tarde al evidenciar graves problemas estructurales.

Desde finales del siglo XIX también se introdujo el cemento como material de construcción. Antes de que se iniciara la producción local de este material, este era importado desde Europa en barricas que llegaban vía marítima. La primera edificación de la ciudad que utilizó ese material fue la Cárcel Pública Municipal, sin embargo existen testimonios de uso de cemento en la construcción de mausoleos del cementerio, como el de la familia Icaza Gainza en 1856.

En 1886 se iniciaron los trabajos de construcción de la nueva cárcel para reemplazar a la antigua, edificada en madera y caña. El diseño y la construcción del nuevo proyecto estuvieron a cargo del arquitecto genovés Rocco Queirolo Pinasco (1841-1903), quien había llegado a la ciudad en 1881 procedente de Lima, contratado como Arquitecto del Municipio, cargo que ejerció hasta 1889.

Queirolo optó por diseñar una edificación con forma de claustro de dos plantas, con muros portantes de ladrillo y cemento y entrepiso de madera. El proyecto original estaba compuesto por cuarenta celdas para hombres; cuatro celdas para mujeres; catorce salas para contraventores; tres salas para contraventoras; siete habitaciones para la administración; una sala de anotación; una sala para el cuerpo de guardia; un salón de visitas; una capilla; tres departamentos de cocina; y dieciséis baños (Revista Olmedo, 1905, Año III, p. 11). 
Luego del Gran Incendio el edificio de la cárcel sufrió graves afectaciones que destruyeron sus pisos y cubierta de madera, por lo que en 1902 se inició su reconstrucción a cargo de Francisco Manrique. Los trabajos, terminados tres años más tarde, convirtieron a la cárcel en la primera y única edificación de la época construida en hormigón armado, algo que la prensa local destacaba:

La nueva cárcel es la primera construcción que se ha hecho en Guayaquil aplicando el sistema de cemento armado, inventado por el ingeniero francés Hennebique; las obras han sido ejecutadas por obreros nacionales dirigidos por maestros especialistas traídos de Caracas por el constructor señor Manrique (Diario El Telégrafo del 10 de octubre de 1905).

Hacía referencia la publicación a las losas de piso y de cubierta del edificio, que se asentaban sobre los muros portantes de ladrillo del proyecto original de Queirolo. En 1921 la edificación se encontraba en estado ruinoso. En el informe que el Presidente del Concejo Municipal presentó dos años más tarde al cuerpo edilicio indicaba que la cárcel se había convertido en el edificio de la ciudad “... más inadecuado e insalubre” (GM, 1921, s/p) (Ver Figura 7).

La necesidad de proteger las edificaciones contra los embates de los frecuentes incendios, además de otras razones higiénicas, determinó que a principios del siglo XX se utilizara en la construcción de edificios de dos y tres plantas, un peculiar sistema de paredes de ladrillo de arcilla con mortero de cal, a pesar de que se mantenía la estructura de madera. Este sistema se denominó mixto y permitió la incorporación de albañiles, además de los carpinteros tradicionales, a los procesos de edificación de la ciudad.

El hormigón armado como sistema constructivo fue incorporándose poco a poco en América Latina desde inicios del siglo XX, luego de que el sistema de vigas fue patentado en 1892 por el francés François Hennebique. Para tener una idea de su uso en el sur de nuestro continente, en Colombia se utilizó en el Hotel Estación en Bogotá en 1932 (Henderson, 2006); en Chile en el edificio de la calle Alameda 1731, en Santiago, en 1910; en Argentina, en la Galería General Güemes de Buenos aires, en 1915. Mientras en Guayaquil se utilizó por primera vez en los cimientos, las columnas, las vigas y la losa de cubierta de las naves de la Iglesia de San José, en 1905, por parte de Francisco Manrique. Héctor Martínez Torres, alumno de Manrique en la década de 1930, contaba que este había sido discípulo de Hennebique durante su época de estudiante en Francia, de quien había aprendido la manera de edificar con hormigón armado (comunicación personal, 24 de agosto de 2005). En 1903 el Padre Maurillo Detroux Mousny, Superior de la Compañía de Jesús, había solicitado a la Municipalidad de Guayaquil la autorización para la construcción de un nuevo templo, ya que el anterior había sido destruido en el incendio del Carmen de 1902. Ya para esa época las ordenanzas exigían que los edificios públicos debían ser edificados con materiales incombustibles, por lo que la Comisión Reconstructora de la Iglesia San José decidió que se lo construya con estructura de hormigón armado (Mesías S.J., 1982). Para ello se contrató a Francisco Manrique quien ya había demostrado su destreza en ese sistema constructivo en la reconstrucción de la Cárcel Pública Municipal. 


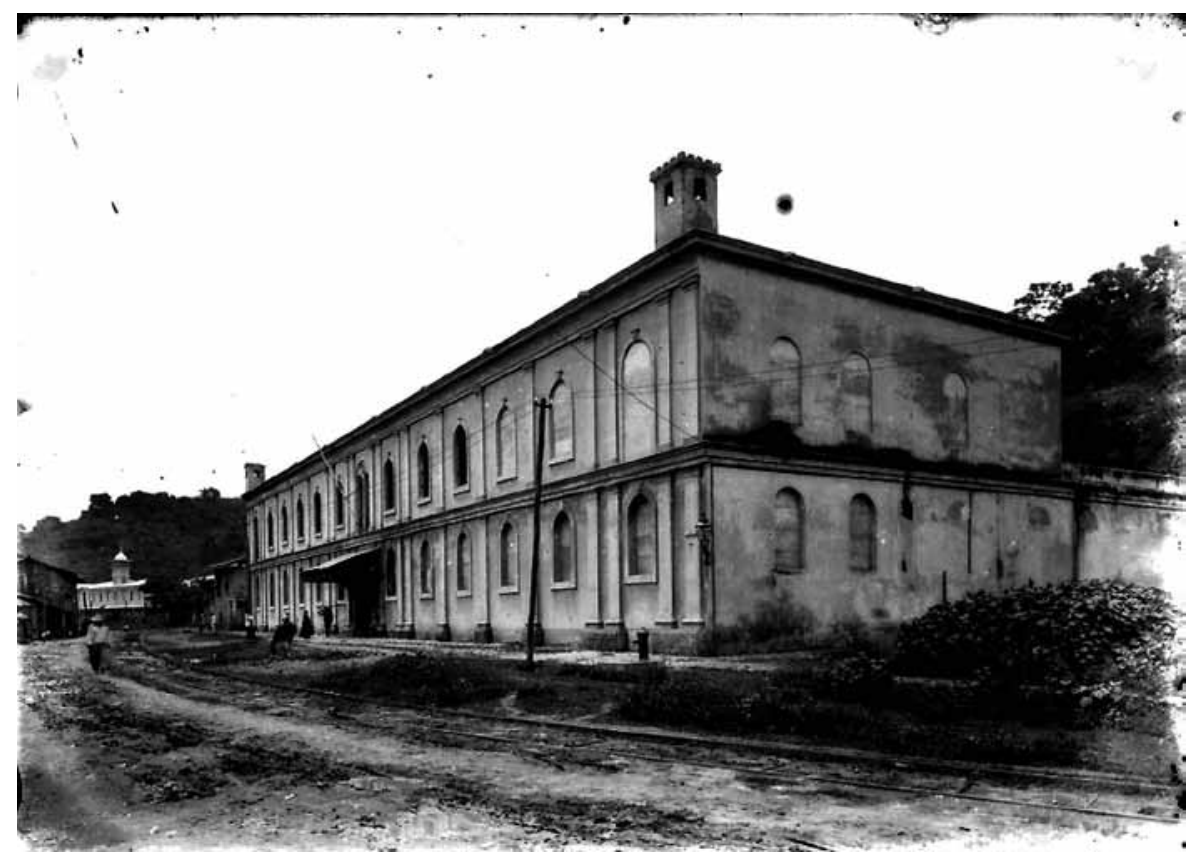

Figura 7. Cárcel Pública Municipal, c. 1920. Archivo Nacional de Fotografía.

El 16 de julio de 1905 se colocó la primera piedra y se dio inicio a la construcción. Dada la dificultad de obtener acero se optó por utilizar rieles de ferrocarril, en tanto el cemento fue importado desde Bélgica, país de origen del superior jesuita (Mesías S.J., 1982). Para facilitar la construcción la Municipalidad autorizó al señor Melquiades Morales “... para que tendiera una línea férrea Decauville en la primera cuadra de la calle Manabí para conducir el material que se emplearía en la construcción" (Estrada Ycaza, 2008, p. 336). Dos años más tarde, el 25 de agosto de 1907 se inauguró la primera nave lateral y el 19 de junio de 1914 el edificio quedó terminado, a excepción de la fachada que fue levantada en 1925 según el proyecto del italiano Francesco Maccaferri (Mesías S.J., 1982).

Resulta interesante la lectura de la descripción de las características constructivas del edificio, hecha por el sacerdote jesuita Jorge Enrique Mesías (1982), según la memoria técnica de Manrique:

La iglesia está plantada sobre cimientos formados por una red de vigas de cemento armado, y que da apoyo a los pilares en todos los cruzamientos de las vigas, de manera que la presión del edificio sobre todo el suelo es casi uniforme y permite repartirla sobre una amplia superficie, a razón de $3 / 4 \mathrm{de} \mathrm{Kg}$ por $\mathrm{cm}$ cuadrado $(\ldots)$ 
Las paredes tienen un espesor de $15 \mathrm{~cm}$ y van reforzadas de 5 en $5 \mathrm{~ms}$ por pilastras que sirven de contrafuertes. Los techos en forma de azotea, con $10 \mathrm{~cm}$ de espesor, se apoyan sobre una red de vigas cuyas dimensiones generales, aparte de su ornamentación, son de 30 por $38 \mathrm{~cm}$. Estas vigas están dispuestas en cruz en cada uno de los cuadrados formados por cada 4 pilastras, a fin de formar los cajones del artesonado y cada una de ellas puede resistir un peso de 8.000 $\mathrm{kg}$ uniformemente repartidos.

La Cúpula en su arranque tendrá un espesor de $20 \mathrm{~cm}$ que irá reduciéndose hasta 10 que será la medida en la clave. Tanto en la pared de la fachada principal, como en los pilares interiores y las vigas, razones de ornamentación han impedido que se les dé el reducido espesor que permite emplear con toda seguridad el cemento armado Hennebique; los pilares que tienen una fuerte sección aparente, son huecos.

La estructura del edificio está constituida en todas sus partes por una envolvente de hormigón o concreto de cemento que reviste una verdadera malla metálica formada por varillas de hierro y acero (s/p) (Ver Figura 8).

Esta iglesia se convirtió, de esta manera, en el primer edificio con estructura de columnas, vigas y losa de hormigón armado de Guayaquil y de todo el Ecuador. Sin embargo se consideraba que el uso del hormigón armado sería costoso ya que requería subsanar “... lo movedizo del suelo". En su lugar se recomendaba utilizar otros sistemas más económicos como el Reinforced lumber, que consistía en paneles con aplicación de un mortero de cemento sobre una estructura de madera o caña cubierta con alambre de púas, destacado en una publicación de 1916 por sus cualidades “... económicas, higiénicas, duración y resistencia" (Diario El Telégrafo, 1916).

La construcción en hormigón armado y mampostería trajo consigo una nueva concepción de la estabilidad de la edificación, además de otros aspectos, como cambios en el perfil de la ciudad, al poder levantar edificios de mayores dimensiones y alturas; que en la arquitectura religiosa se pudieran erigir torres más altas, además de cúpulas; y una mayor inversión en el sector de la construcción, ya que se consideraba que el cemento minimizaba el riesgo. Sin embargo, el aporte que esta nueva arquitectura tuvo para la ciudad no tenía la aceptación de todos los ciudadanos. José De la Cuadra (1933), uno de los más importantes escritores de la época lo expresaba de la siguiente manera:

A esta generación de casas achaparradas sucedió otra, muchos de cuyos esbeltos ejemplares se mantienen en pie, viéndose como chatos y preteridos entre esos castilloides de cemento armado o de hormigón que son las moradas de hoy y que, para mí desentonan en el escenario paisano (p. 14).

Hasta 1922 todo el cemento que demandaba la ciudad era importado desde Dinamarca, Bélgica y Alemania, principalmente de la marca Alsen, producido en la ciudad de Bremen por la empresa W. Biedermann \& Co (Diario El Telégrafo, 1923). Ante las dificultades que demandaba su importación, en ese mismo año José Rodríguez Bonín emprendió en Guayaquil la construcción de la primera fábrica de cemento del país, mediante un contrato 


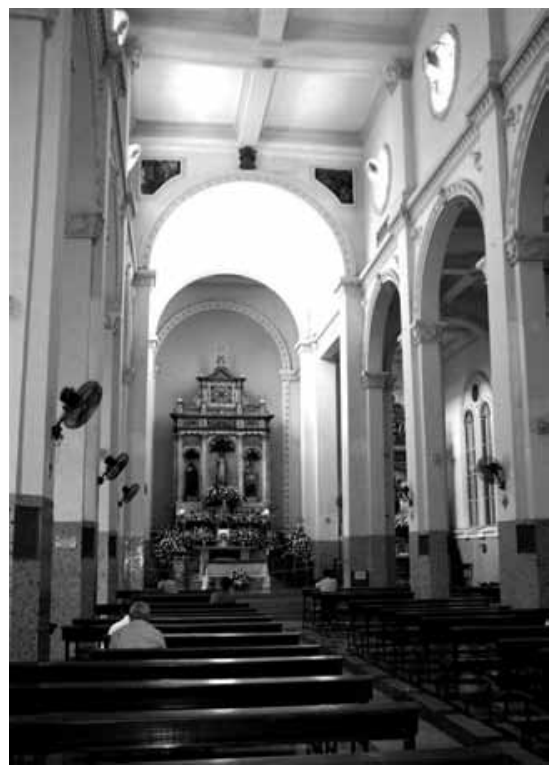

Figura 8. Nave de la Iglesia de San José.

con la empresa alemana Fried Krupp A. G. Grusonwerk, bajo la modalidad llave en mano, es decir, “... que el proveedor asumió la responsabilidad de la construcción, suministro de maquinaria y puesta en marcha de la producción” (Arosemena, 1996, p. 440). La inversión de Rodríguez Bonín se convirtió en la más grande del Ecuador en esos años. Al año siguiente, el 12 de julio de 1923, la fábrica, cuya propiedad la asumió la Compañía Anónima de Industrias y Construcciones, fue inaugurada con el nombre de San Eduardo e inició la producción de cemento tipo Portland que era comercializado en sacos de $45 \mathrm{Kg}$ bajo la marca Cóndor (Estrada Ycaza, 1996). La Compañía Anónima de Industrias y Construcciones fue constituida el 29 de marzo de 1921 por José Rodríguez Bonín, como principal accionista, además de Eduardo Game y Leon Franklin Price (Estrada Ycaza, 1996). No queda claro si esta es la misma Compañía Anónima de Contratos y Construcciones, que en publicaciones de prensa de los años 1923 y 1924 ofrece los servicios de elaboración de planos, presupuestos de obra y construcciones.

En 1924 la fábrica San Eduardo tenía una producción de 2.000 quintales diarios de cemento que era distribuido a diferentes lugares del país (Estrada Ycaza, 1996). Diez años después la empresa, que atravesaba problemas financieros y se encontraba paralizada, fue arrendada a un grupo de inversionistas dirigido por Hope Norton, vinculados a la fábrica de cerveza de la ciudad (Arosemena, 1996), agrupados bajo la razón social Ecuatorian Corporation (Estrada Ycaza, 1996), quienes lograron que se reanudara la producción del 
producto, llamado ahora Rocafuerte, y cambiaron el nombre de la fábrica a La Cemento Nacional. Ya para el año 1935 la producción era de 321.743 quintales anuales y al año siguiente se había incrementado a 375.000 quintales, sin embargo la demanda del producto era mayor de la que la fábrica podía cubrir, por lo que la importación de cemento se mantenía (Arosemena, 1996).

Como parte de las necesidades de este nuevo sistema de construcción, unos años antes, en 1903, el constructor Emilio Estrada Carmona había implementado una fábrica de ladrillos, bajo el nombre de La Victoria, donde además se producían “... tubos de concreto para los desagües, bloques de cemento armado para muros y paredes, mosaicos, yeso y cal" (Arosemena, 1996, p. 439). Estos ladrillos y bloques no solo eran utilizados para las paredes de las edificaciones de hormigón armado, sino también se generalizó su uso en las paredes de las edificaciones mixtas.

Otra incorporación técnica que impulsó el desarrollo de la edificación en cemento fue la introducción del ascensor. La primera construcción que incorporó este avance técnico fue el edificio Illingworth en 1924, que tenía cuatro plantas altas.

La construcción en hormigón armado también permitió que los edificios fueran ganando en altura. En 1923 se inauguró el Diario El Telégrafo de cinco plantas altas -diseñado por Hugo Faggioni- que se convirtió en el más alto del país, hasta la inauguración en 1938 del edificio Vignolo, proyecto del húngaro Fernando Schimanetz, de seis plantas altas.

Para comienzos de los treinta la construcción en cemento estaba plenamente generalizada. El registro de 1932 establecía que había un total de 7264 edificaciones en toda la ciudad, repartidas de la siguiente manera: 4175 de caña, 7 de hierro, 52 de zinc, 2423 de madera, 484 mixtas y 123 de cemento; de los que 2878 eran de un piso, 3640 de dos pisos, 596 de tres pisos, 137 de cuatro pisos, 10 de cinco pisos y 3 de seis pisos (Hidalgo, 1932). El recubrimiento de las paredes de madera o caña picada con planchas de zinc fue utilizado por un corto período a inicios del siglo XX. Sin embargo, por el intenso calor que generaba quedó rápidamente en desuso. Esta nueva situación se destacaba en las publicaciones de la época, como en la Monografía Sintética de la Ciudad:

Una serie de construcciones nuevas i proyectos de obra a ejecutarse en breve, irán modernizando más i embelleciendo el puerto de Guayaquil, que marca en sus edificios la tendencia a sustituir los antiguos de madera, por los modernos e incombustibles de hormigón armado (González, 1939, p. 48).

Resulta interesante la lectura de un texto del norteamericano Albert B. Franklin del año 1942 con su apreciación de la ciudad, donde hace una crítica a los errados procesos de construcción en hormigón armado y los problemas que esto generaba:

La expansión del centro moderno de la ciudad, hace que estas secciones coloniales sean invadidas por edificios de hormigón revocado. En primer lugar, porque las construcciones de hormigón son más estéticas que las de bambú, y en segundo lugar porque son más frescas e higiénicas, la mayoría de los guayaquileños preferiría vivir en edificios de concreto, pero el cemento debe ser importado de los Estados Unidos. 
(...) Nada mejor que el cemento Portland para hacer concreto. Como resultado de la carestía del cemento extranjero, en los primeros tiempos del empleo del hormigón en el Ecuador, varios contratistas hicieron una economía particularmente extraña. Utilizando el cemento en la proporción indebida, de una parte por tres de arena y cinco de grava, trataron de dar belleza permanente a sus construcciones, extendiendo el cemento en la superficie, en vez de mezclarlo debidamente en el hormigón. Los resultados fueron fatales. (Como se cita en Villacrés, 1999, p. 13)

Se refería a los daños que sufrió la ciudad luego del terremoto del 13 de mayo de 1942 que significó la destrucción de seis edificios, que más de cien tuvieran serios daños, además de hubiera cuarenta fallecidos, veintiuno con heridas graves y que cuarenta y tres personas fueran rescatadas de entre los escombros (Villacrés, 1999).

\subsection{De carpinteros de ribera a arquitectos}

La ubicación de Santiago de Guayaquil junto a la confluencia del estuario más grande del Pacífico sur y su cercanía a extensas zonas de bosques maderables de gran calidad, determinaron, casi desde su fundación, su vocación como astillero, lo que permitió que la ciudad se convirtiera en uno de los centros de construcción de navíos de madera más importantes de los mares americanos.

Se tienen noticias de la fabricación de barcos desde 1557, es decir apenas diez años después de su asentamiento definitivo. Ya para el siglo XVIII el astillero de Guayaquil era considerado uno de los más importantes de América del Sur. Se afirmaba que no había ninguno que tuviera “... todas las comodidades y facilidades, y todas las maderas más aptas para ser ensambladas, más finas y más fuertes y durables y más a propósito para construir toda clase de naves" (Cicala, 1987 [1771], s/p).

El trabajo en los astilleros era realizado por carpinteros de ribera, calafates, hacheros, obreros y aprendices -en su mayoría negros, indígenas y mulatos- quienes aprendían su oficio a partir de la práctica constante, de la experiencia y del conocimiento empírico que recibían en la relación maestro-aprendiz. Cualquiera que tuviera una experticia adquirida en el trabajo y el aprendizaje recibido de un maestro era denominado carpintero.

La destreza de los carpinteros en el oficio de la construcción naval era admirada. Así lo expresaba el Corregidor Pablo Sáenz de Durón, cuando informaba a la Corte, que “... todos los oficiales, carpinteros de ribera, calafates y herreros que componen la maestranza de Guayaquil, demás de ser en número bastantes para las fábricas propuestas, trabajan con tanta habilidad y destreza que causa admiración a los más prácticos que allí han ido a fabricar y carenar" (Laviana, 2003, p. 264).

El intenso trabajo del astillero determinó el elevado número de carpinteros vinculados a estos trabajos. En 1688 la Maestranza estaba conformada por 89 personas entre las que había un maestro mayor de fábrica, cinco maestros mayores (de carpintería y de calafateo), oficiales hacheros, calafates, aserradores y herreros (Clayton, 1978). Un siglo más tarde, en 1771, se calculaba en casi 3.000 los carpinteros y en 2.000 los calafateros (Arosemena 
y Gómez Iturralde, 1997), mientras que en 1832, al decaer el número de barcos que se elaboraban en el astillero, su número se había reducido significativamente, ya que apenas había 241 carpinteros y 25 calafates (Hamerly, 1973).

Durante el período colonial era indistinto hablar de carpinteros de ribera y de carpinteros a lo blanco, ya que los edificios eran construidos por las mismas personas que trabajaban en el astillero construyendo barcos. Estos constructores solían aplicar en los edificios los mismos principios navales y los sistemas constructivos que utilizaban en los ensambles de las piezas estructurales y en ciertos elementos arquitectónicos, ornamentales y de acabados, además de usar las mismas maderas. Incluso en la terminología de las edificaciones se usaban palabras de origen naval al referirse los elementos constructivos y arquitectónicos, como crucetas, chazas “... estantes, varengas, llaves y otras” (Requena, 1994 [1774], s/p). El Diccionario de la Real Academia define a la chaza como "El espacio que media entre dos portas de una batería" y a una porta como "Cada una de las aberturas, a modo de ventanas, situadas en los costados y en la popa de los buques, para darles luz y ventilación, para efectuar su carga y descarga y, principalmente, para colocar la artillería". En la arquitectura tradicional en madera, se denominan ventanas de chazas a las que poseen celosías y mecanismos de abatimiento tanto horizontal como vertical.

Estos artesanos expertos interpretaron las necesidades espaciales de los habitantes y configuraron la imagen de la ciudad, aunque su labor recibiera no pocas críticas, como la del ingeniero Francisco Requena, quien en 1774 indicaba: "Las (casas) que se construyen al presente son bastante incómodas porque les falta a los maestros gusto para las fábricas y no conocen absolutamente las reglas de la arquitectura civil" (Requena, 1994 [1774]), todo lo contrario opinaba en 1797, otro viajero quien se sorprendió que aunque “... toda la materia de las casas es de madera, acompaña a su fábrica sobresaliente hermosura y capacidad" (Laporte, 1960 [1797], p. 173).

No fue sino hasta el siglo XVIII cuando se presentó un cambio en el trabajo maderero, al desarrollarse la industria de los aserraderos y la ebanistería, que empezó a producir madera labrada de alta calidad que posibilitó que la edificación empezara a mejorar en sus acabados y que surgieran artesanos especializados en la construcción.

En las crónicas de la época se hace mención a algunos de los carpinteros que fueron configurando la imagen de la ciudad, aunque esta información, eventual y aislada, impide reconocer alguna vinculación entre un edificio y su constructor.

No fue sino hasta finales del siglo XIX cuando ejerció su actividad en la ciudad el primer arquitecto titulado, el genovés Rocco Queirolo (1841-1903), quien aportaría al desarrollo de la construcción con cemento y paredes de mampostería. Esta nueva manera de construir fue aplicada en la nueva Cárcel Pública Municipal en 1886, primer edificio con muros portantes de ladrillo de la ciudad, además de diferentes residencias particulares, como la de la familia Morla alrededor de1890 y de la familia Seminario en 1895. Queirolo proyectó y construyó también, en 1897, el Banco del Ecuador, “... con estructura metálica, importada desde Inglaterra” (Arosemena, 1998, p. 271). También fue pionero en la edificación con piedra en el edificio del Banco de Crédito e Hipotecario, único de esa época con estas características; en el año 1900 el proyecto de la Iglesia San Francisco y dos años más tarde el edificio de la Universidad de Guayaquil. 
También para esta época desarrollaba su labor el italiano Américo Cassara, de quien se conoce el proyecto de la Sociedad Italiana Garibaldi en 1897, construido en sociedad con el ingeniero Zanaboni -demolido a mediados de la década de 1950-, además de su participación en el concurso de proyectos para la reconstrucción de la ciudad luego del Gran Incendio de 1896. De Zanaboni es poco lo que se conoce, salvo un anuncio publicado en 1897 en el diario guayaquileño El Grito del Pueblo, donde se indicaba: "Zanaboni y Dagsso ARQUITECTOS. Ofrecen sus servicios a los propietarios de esta ciudad para levantar planos de casas, formar presupuestos de edificios, construcción y toda clase de trabajos concerniente a la profesión" (Estrada Ycaza, 2007, p. 403).

Una de las consecuencias del incendio del 12 de febrero de 1896 fue la huelga de los maestros carpinteros, quienes pudieron reducir su jornada laboral de once a nueve horas. Además este hecho sirvió de base para que al año siguiente se organizaran gremialmente en la Sociedad de Carpinteros, que estuvo en funcionamiento hasta agosto de 1902, cuando fue declarada en receso (Navas, 1920). Esta fue la primera institución gremial exclusivamente de carpinteros ya que antes, en 1880, se había conformado la Sociedad de Artesanos Amantes del Progreso que incluía también a otro tipo de oficios.

En interesante el censo de Guayaquil del año 1899, realizado por los celadores y miembros de la policía local, se dejaba constancia que para esa fecha había un solo arquitecto en ejercicio -se refiere a Queirolo-, mientras se registraban 44 ingenieros y 13 agrimensores. Además había 210 albañiles y 3619 carpinteros dedicados a la construcción de edificios, ya que adicionalmente se indicaba que los carpinteros navales eran 90 (Hamerly, 2012). También trabajaban ligados 3 electricistas, 54 gasfiteros, 165 pintores, 2 marmolistas y 65 plomeros. Lo que daba un total de 4.186 personas que correspondía casi el $12 \%$ de la población económicamente activa que era un total de 35.489 (Hamerly, 2012).

El 1 de septiembre de 1904, “... un grupo de ciudadanos del arte de Carpintería de Banco i Rivera (sic)" reconstituyeron la organización gremial, ahora con el nombre de Sociedad de Carpinteros de Auxilios Mutuos, con el fin de velar “... por sus buenos hijos” (Navas, 1920, p. 72). En sus estatutos se indicaban como fines específicos, el establecer "el auxilio mutuo en vida y muerte de sus asociados”, “... la unión y armonía de las dos agrupaciones (Rivera y Banco) observando en todos sus actos la verdadera fraternidad", además de "Propender por todos los medios posibles, al mejoramiento intelectual, moral y material de sus socios" (Estatutos de la Sociedad de Carpinteros de Auxilios Mutuos de Guayaquil, 1905, p. 8). Se dejaba claramente establecido que debía estar conformada “... exclusivamente de carpinteros" (Navas, 1920, p. 72). Una de sus conquistas más importantes se dio en 1913, cuando este gremio adoptó la jornada laboral de ocho horas diarias, que fue presentada como proyecto al Congreso Nacional, el que finalmente lo sancionó como ley de la república tres años más tarde (Hidalgo, 2011).

Otra organización gremial vinculada a la construcción fue la Sociedad de Albañiles Libres, establecida a finales del siglo XIX y reinstalada poco después del incendio de febrero de 1896. En el acta de reinstalación, suscrita el día 25 de marzo de ese año por los cincuenta y cinco socios fundadores, se indicaba que esa institución ya había funcionado antes aunque “... hacía algunos años que se hallaba en receso" (Navas, 1920, p. 109).

Entre finales del siglo XIX y principios del siglo XX desarrollaba también su trabajo como arquitecto y constructor el ecuatoriano Emilio Estrada, quien en 1899 diseñó y dirigió la 
construcción del Colegio San Vicente del Guayas, que fue terminado en 1901 y que era descrito como "Elegante, sólido y de arquitectura severa" (Diario El Tiempo, 11 de agosto de 1901). Emilio Estrada Carmona (1855-1911) fue un destacado constructor y político, quien en un exilio de tres años en Panamá aprendió diferentes técnicas de construcción de puentes y edificios. Fue Gobernador de la Provincia del Guayas, hasta el año 1911 cuando fue elegido Presidente de la República, cargo que ocupó por pocos meses hasta su fallecimiento en Quito el 22 de diciembre de ese mismo año (Compte, 2007).

También un carpintero destacado fue el Maestro Juan Bautista Solís quien construyó en el año 1905 la sede de la Sociedad de Artesanos Amantes del Progreso y que catorce años más tarde fue ampliado a un segundo piso por el mismo carpintero.

A comienzos del siglo XX emergió la importante figura del ingeniero venezolano Francisco Manrique Pacaníns, quien incorporó el uso del hormigón armado en la edificación de la iglesia de San José y en las losas de piso y cubierta de la Cárcel Pública Municipal.

En 1909 se establecía que habían en ejercicio veinticinco ingenieros y agrimensores, veintisiete albañiles y doscientos noventa carpinteros (Compañía “Guía del Ecuador” (edit.), 1909) y no se contabilizaba ningún arquitecto. En el registro de ingenieros y agrimensores constaban Carlos Álvarez, Luis Alberto Carbo Noboa, Camilo Coiret, Ricardo Donat, Roberto Espíndola Maldonado, N. Farget, Henrig Fontaine, Ernesto Franco, José Antonio Gómez Gault, Francisco Landín, Otto Lange, Horacio G. Maldonado, Francisco Manrique Pacaníns, Arturo Maury, Mauricio Mogar, John Paget, Conto Luis Pérez, Carlos Horacio Rubira D., Francisco Schlesack, Juan Schotel Jr., Gastón Thoret Jäger, Carlos Van Isschot, Carlos Van Isschot jr., Jacobo Vernimenn y Simón Zenck (Compañía "Guía del Ecuador” (edit.), 1909).

A partir de 1920 empezaron a arribar a la ciudad, arquitectos, ingenieros, escultores y técnicos constructores extranjeros, principalmente italianos, vinculados a las nacientes empresas constructoras de la época, quienes incorporaron el academicismo en los repertorios formales de la arquitectura. Entre ellos destacan los nombres de los arquitectos Francesco Maccaferri y Paolo Russo de la Compañía Italiana de Construcciones, Pedro Fontana del Departamento de Construcciones de la Sociedad Bancaria del Chimborazo y Hugo Faggioni de la Sociedad Técnica Fénix. También de los ingenieros y técnicos constructores Carlo Bartoli, Giancarlo Bonarda y Mario Gherardi, de la Sociedad General de Construcciones; Arnaldo Rufilli, Giovanni Lignarolo, Rodrigo Perrotta, Riccardo Winderling y Luigi Fratta de la Compañía Italiana de Construcciones, además de Oscar Battaglia, Umberto Caccurri, Bruno Faidutti y de los escultores Enrico Pacciani y Emilio Soro Lenti. A estos se sumarían los españoles Juan Orús Madinyá y Joaquín Pérez Nin de Cardona, el alemán Augusto Ridder y el suizo Eugene Schllatter.

Sobre la formación de estos migrantes, principalmente de los italianos, Rafael Rivas Nevárez (2013 [1980]), resaltaba que “... procedía de las antiguas Escuelas de Bellas Artes o bien de las Escuelas Politécnicas, cuando no eran de formación su experiencia provenía exclusivamente de la práctica" (p. 92).

Gran parte de los técnicos italianos se incorporaron a la Casa del Fascio, fundada en junio de 1924 (Estrada, 1993), la cual, junto con la de la ciudad de Manta, constituían los dos núcleos del fascismo en el Ecuador. Para 1933 la sección de Guayaquil se encontraba dirigida por Giovanni Almerini y Paolo Russo y contaba con ochenta y dos miembros 
(Aliprandi \& Martini, 1933), entre los que figuraban Bartoli, Bonarda y Ruffilli, además del arquitecto Antonino Russo y del escultor Pacciani, quien realizó un busto de Mussolini que fue colocado a la entrada de la sede institucional. Como consecuencia de la Segunda Guerra Mundial, el Ecuador organizó la persecución de ciudadanos que provenían de los países del Eje, que fueron ubicados dentro de la denominada Lista Negra (Estrada, 2006), lo que provocó que se limitaran sus actividades comerciales e industriales y que fueran perseguidos, tomados presos y confinados en un improvisado campo de concentración cercano a la ciudad de Cuenca, para luego ser enviados a la panameña isla Taboga, y posteriormente al campo de concentración norteamericano de Cristal City en Texas (Estrada, 2006). Esto ocasionó que cesara su actividad la Compañía Italiana de Construcciones y que abandonaran su oficio muchos de los técnicos extranjeros que proveníande los países del Eje.

En el listado de los ingenieros de la ciudad publicado en el año 1936 en el Álbum Gráfico de Guayaquil, indistintamente se incluían ingenieros, arquitectos y constructores, estos eran: J. Alejandro Hernández, Alfredo Noboa Y., Francisco Manrique, Benigno Abad, Alfredo Tinajero, Paolo Russo, Roberto Espíndola, Giovanni Malnati, Gastón Thoret, Aldo Garatz, Luis Alberto Carbo, Juan Schotel, Ignacio Granja Saona, Enrique Casini, George L. Capwel, Francesco Maccaferri, Luigi Fratta, Diehm Meyer, Coronel Ricardo Astudillo, José Antonio Gómez Gault y Rafael Erazo. A este listado se incorporó poco después el arquitecto húngaro Fernando Schimanetz, quien llegó procedente de Lima para asumir la dirección técnica de la Compañía Italiana de Construcciones.

Ya en la década de 1940 aportaron con su labor profesional el ingeniero austríaco Oscar Etwanick y el arquitecto checo Karl Kohn, uno de los más destacados profesionales del período, quien había llegado al Ecuador huyendo de la persecución nazi en su país natal, ambos radicados en Quito. Además se fueron incorporando los primeros arquitectos graduados en la Escuela de Arquitectura de la Universidad de Guayaquil, entre los que se destaca la figura del guayaquileño Héctor Martínez Torres. A este grupo de arquitectos se incorporaron más tarde aquellos que obtuvieron su título de arquitectos en el exterior, como Guillermo Cubillo y Roberto Béjar, graduados en la Universidad de Chile y Rafael Castro Abad, de la Universidad de la República, en Uruguay.

En el año 1944, quienes se habían graduado en la Facultad de Ciencias Físicas y Matemáticas de la Universidad de Guayaquil, decidieron integrarse y crearon la Sociedad de Ingenieros y Arquitectos de Guayaquil, que tuvo entre sus objetivos, el establecer “... lazos de solidaridad entre todos los profesionales, ordenar de común acuerdo la práctica de sus actividades y establecer normas de ética necesarias para el mejor desarrollo de la profesión” (Rivas Nevárez, 2013 [1980], p. 94). Aunque la intención fue la de congregar a todos los profesionales de la arquitectura y de la ingeniería civil de la ciudad, en la práctica fue constituida por doce ingenieros: César Plaza Ledesma, Leonardo Guarderas, Ambrosio Puga, Arnaldo Ruffilli, José Albán Almeida, Pedro Carbo Medina, Alberto Sánchez Cavanna, Juan Arzube, Pedro Boloña Rodríguez, Nicolás León Pizarro, Juan José Orrantia y Pedro Manrique, y un solo arquitecto, Héctor Martínez Torres, quien además ostentaba también el titulo de ingeniero civil (Acta de constitución de la Sociedad de Ingenieros y Arquitectos de Guayaquil, 9 de marzo de 1944). Poco tiempo después se integraría junto con sociedades similares de otras provincias del país, en la Sociedad de Ingenieros y Ar- 
quitectos del Ecuador. Hay referencias de la conformación de una denominada Sociedad de Ingenieros y Arquitectos del Ecuador que se estableció en Quito en 1892 (Moreira y Alvarez, 2004, p. 22), sin embargo, a pesar de su nombre, solo tenía entre sus miembros a arquitectos de la capital.

Para 1958 los ingenieros eran mayoritarios en la Sociedad, por lo que los arquitectos decidieron establecer una sección específica dentro del núcleo original, solicitando la aprobación de un Colegio de Arquitectos, afiliado a la institución ya existente. Sin embargo, esta iniciativa fue negada por el directorio, conformado mayoritariamente por ingenieros, quienes no encontraron justificación suficiente para tal pedido.

Finalmente, dos años después, el 20 de julio de 1960, fueron convocados todos los arquitectos residentes en Guayaquil, nacionales y extranjeros, para concretar la conformación del Colegio de Arquitectos local. A la reunión asistieron catorce arquitectos: Guillermo Cubillo, Roberto Béjar, René Denís, Xavier Quevedo, Manuel Gambarrotti, Alamiro González, Óscar Granja Torres, Rafael Castro, Pablo Graf, Juan Péndola, Paolo Russo, Juan Orús, Héctor Martínez Torres y Rafael Rivas Nevárez, quienes decidieron conformar una asociación que tuviera como fines “... el mejor desenvolvimiento de la profesión, así como las medidas conducentes para lograr una efectiva defensa del Ejercicio Profesional de la Arquitectura al igual que otros países" (Acta de fundación del Colegio de Arquitectos del Ecuador, núcleo regional del Guayas). Además se decidió nombrar como primer presidente a Cubillo, en ese entonces decano de la Facultad de Arquitectura de la Universidad de Guayaquil.

Dos años más tarde, en 1962, se organizó en Guayaquil el Primer Congreso Nacional de Arquitectos con el objetivo de concentrar en un solo organismo las diferentes agrupaciones gremiales que se habían ido conformando en el país. Además de la delegación local, participaron delegaciones de Quito y Cuenca, quienes acordaron crear el Colegio de Arquitectos del Ecuador, que se convirtió en la primera organización gremial de carácter técnico del país con personería jurídica propia (Rivas Nevárez, 2013 [1980]).

\subsection{La naciente industria de la construcción}

En el registro de la Superintendencia de Compañías de Guayaquil constan un total de veinte compañías constructoras que fueron inscritas entre los años 1901 y 1948, aunque no se establece la existencia de empresas que se dedicaran a esa actividad antes de esa fecha. Se tiene conocimiento, por ejemplo, de la Compañía Nacional de Construcciones, que en el año 1900 presentó una propuesta al Congreso Nacional del Ecuador para la construcción de un muelle en el puerto de Guayaquil “... de fierro, piso de madera y cubierta de fierro acanalado" (Torres, 1900). El contrato aparece suscrito por B. V. Torres en calidad de gerente de la compañía. Además en el Diario El Telégrafo del 27 de octubre de ese mismo año se indicaba que esa misma empresa había construido el edificio del Depósito de Aduana.

Las compañías que aparecen en ese registro, entre 1901 y 1928, son: la Compañía Constructora en 1901; la Compañía de Industrias y Construcciones en 1921; la Compañía Anónima de Contratos y Construcciones en 1922; la Compañía Ecuatoriana de Cons- 
trucciones y la Sociedad General de Construcciones en 1923; La Constructora en 1924; la Compañía Ecuatoriana White en 1924; The Phoenix Construction Company (Sociedad Técnica Fénix) en 1925; y la Sociedad Constructora Calero en 1928.

Durante la década de 1920 tenían copada la construcción de los nuevos edificios de hormigón armado cinco empresas constructoras, tres de ellas conformadas con capitales y técnicos extranjeros: la Sociedad General de Construcciones, la J. G. White and Co. Limited y la Compañía Italiana de Construcciones; y dos con capitales nacionales y la participación tanto de extranjeros como de técnicos ecuatorianos: el Departamento de Construcciones de la Sociedad Bancaria del Chimborazo y la Sociedad Técnica Fénix. Para la década de 1930 habían cesado sus actividades, por diferentes motivos, la Sociedad General de Construcciones, la J. G. White and Co. Limited y el Departamento de Construcciones de la Sociedad Bancaria del Chimborazo.

En el recuento de las compañías y oficinas de construcción que se encontraban en actividad en 1933, se registraban exclusivamente la Compañía Italiana de Construcciones y la Sociedad Técnica Fénix, además de los arquitectos Paolo Russo y Francesco Maccaferri y del técnico Luigi Fratta, como constructores independientes (Aliprandi y Martini, 1933). En ese mismo año la escritora Aurora Estrada y Ayala triunfó en la Primera Exhibición del Poema Ecuatoriano organizado por la Asociación Artística y Cultural Alere Flamman con el poema J. G. WHITE \& CO. LTD:

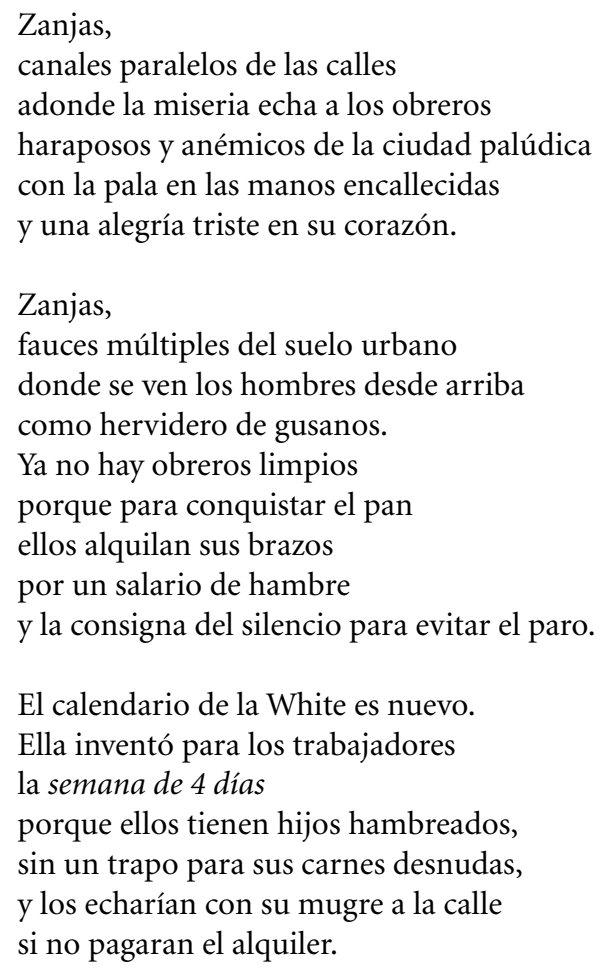


En ese poema se ponía en relieve la deplorable situación laboral de los trabajadores de la empresa constructora J. G. White, responsable de las obras de alcantarillado y pavimentación de Guayaquil. Se tiene registro de la incorporación de esa compañía en Londres y en New York en el año 1900, para el desarrollo de trabajos de ingeniería eléctrica y construcciones en general.

El Diario El Telégrafo del 22 de noviembre de 1913 indicaba que se encontraban muy avanzadas las negociaciones entre el representante del gobierno ecuatoriano del general Leónidas Plaza y Mr. W. Mc Kroski, representante de la compañía J. G. White and Co., para el desarrollo de los trabajos sanitarios de Guayaquil, que competía con la empresa norteamericana Mc. Arthur Brothers. No deja de ser curiosa la reseña del Diario El Mercurio de Chile del 16 de noviembre de ese mismo en la que se indicaba que se había elegido a la compañía inglesa sobre la norteamericana “... por cierta animosidad contra todo lo norteamericano" (s/p).

El 5 de enero del año siguiente se suscribió el contrato entre el gobierno ecuatoriano y George B. Alison, como representante legal de esta compañía, para la ejecución del plan de saneamiento de la ciudad, que incluía el aumento del caudal de agua para la población; la canalización de la ciudad; la nueva pavimentación de toda el área urbana; el ensanche del malecón sobre la playa del río; y la desecación de la sabana pantanosa (Carta de Guayaquil. Labor sanitaria, 1915). Los trabajos se iniciaron ese mismo año y continuaron hasta 1918 a un ritmo muy lento por la falta de provisión de fondos por parte del Estado. Al año siguiente la Municipalidad asumió el contrato hasta la finalización de los trabajos que se dio a mediados de la década de 1920 (Arosemena, 1991). En 1915 Allison asumió ad honorem la dirección de los trabajos de erección de la columna a los próceres de la independencia en la Plaza del Centenario. Al año siguiente, y hasta la culminación de los trabajos en 1917, fue reemplazado en esa labor por Francisco Manrique (Compte, 2007), uno de los técnicos que trabajaba para la White, además del ingeniero ecuatoriano Alfredo Tinajero Albornoz. En 1924 fue inscrita en la Superintendencia de Compañía de Guayaquil, bajo la razón social de Compañía Ecuatoriana White, y se involucró en negocios de importación y exportación de cacao (Arosemena, 1991). La compañía también participó en otro tipo de trabajos, como la construcción del Templo Masónico en 1924; del Bien Público, entre 1925 y 1926 (Guayaquil se embellece, 1926) y la Piscina Pública Municipal en 1929 (La piscina de natación construida por la White, 1929).

Por otra parte, la Compañía Italiana de Construcciones y la Sociedad General de Construcciones, establecidas en 1922 por el ingeniero Carlo Bartoli, tuvieron un origen común, la constructora Compagnia Italiana di Edificazione Milano (IDEM). En el libro América Libre de 1922 aparecen los ingenieros Gherardi y Bonarda junto con un ingeniero de apellido Bellini, integrando el denominado Sindicato Italiano, que en ese año presentaron una propuesta para la construcción del Palacio de la Gobernación. El origen se remonta al 21 de junio de 1921, cuando el financista italiano Leopoldo Girolamo Parodi-Delfino constituyó en Génova la Compagnia Italiana dell'Equatore (CIDE) con la finalidad de iniciar la explotación minera y petrolera del país, además de actividades bancarias, comerciales y de desarrollo de obra pública (Soave, 2008). La CIDE fue disuelta en el año 1937, “... por no llegar a producir utilidades económicas" (Pagnotta, 2012, p. 108). Como parte de la delegación enviada al Ecuador estuvo el Ingeniero Carlo Bartoli, “... del Genio navale della 
marina italiana" (Soave, 2008, p. 69). Dos años más tarde, en 1923, la CIDE constituyó el Banco Italiano, que inició sus operaciones en Guayaquil al año siguiente. Esta institución bancaria cesó su funcionamiento en 1941 como consecuencia de la persecución que hubo en el país a los ciudadanos del Eje (Arosemena, 1998).

La Compañía Italiana de Construcciones se estableció en 1922 por arquitectos, ingenieros y técnicos enviados a Guayaquil por la IDEM, con el auspicio de Parodi-Delfino y bajo la dirección general de Anselmo Anselmi (Aliprandi y Martini, 1930). La lista de los técnicos estaba integrada por los ingenieros italianos Giovanni Lignarolo, Rieppi, Domenico L'Abbate, Oscar Battaglia, Riccardo Winderling, Rodrigo Perrotta, además del técnico en hormigón armado Luigi Fratta y los arquitectos Francesco Maccaferri y Paolo Russo (Compte, 2007). Esta empresa modificó significativamente la manera de edificar en la ciudad ya que se pasó de una manera artesanal de la construcción a procesos más tecnificados, en los que se incorporaron el cálculo estructural y el uso del hormigón armado. Desde su fundación y hasta 1937, el Director Técnico fue el ingeniero Arnaldo Ruffilli. Luego de su separación de la empresa, asumió ese cargo Fernando Schimanetz hasta 1941 cuando la compañía fue disuelta.

Del primer período, bajo la dirección de Ruffilli, y con proyectos de Maccaferri, corresponden el Palacio Municipal, construido entre 1924 y 1929; los edificios Víctor Manuel Janer (Primer Premio Municipalidad de Guayaquil en 1924), Leopoldo Izquieta Pérez (Segundo Premio Municipalidad de Guayaquil en 1924) y los Garajes España en 1925. Con proyectos de Russo, los edificios Venegas-Chevasco, entre 1923 y 1925, y Antón en 1924; el Palacio del Hospital General de Guayaquil en 1923; y los edificios Repetto y Rizzo, en 1924 (Dos años de actividad italiana en Guayaquil (Equador). Febrero 1923 - Febrero 1925, 1925).

Esta compañía también aportó en la construcción de importante obra de infraestructura, como el relleno de sectores centrales de la ciudad (Urbanización de una importante zona de la ciudad por la C. I. de Construcciones, 1926) y la construcción de otras edificaciones públicas, como el Muelle-Aduana, según proyecto de Maccaferri, y el Mercado Central, de acuerdo al proyecto del portugués Raúl María Pereira (Compte, 2007), además de obras privadas, como los Almacenes Generales de Depósito (Dos años de actividad italiana). Sobre ese primer período de la compañía, una publicación de la época se refería de la siguiente manera: "A esta compañía, establecida en 1921, se deben algunos de los más grandes y hermosos edificios de Guayaquil: el Palacio Municipal (la construcción moderna más vasta de la República), el Hospital General, el Mercado Municipal, Garages, casas particulares, etc." (Aliprandi y Martini, 1933, p. 65) (Ver Figura 9).

En 1935, y hasta 1937, se incorporó a la compañía Héctor Martínez Torres, en ese entonces estudiante de la Escuela de Arquitectura. Con proyecto de Martínez Torres son los edificios Diamante Fanni (Segundo Premio Municipalidad de Guayaquil 1936) y Casal Maspons (Primer Premio Municipalidad de Guayaquil 1937). Del segundo período, bajo la dirección técnica y arquitectónica de Schimanetz, son los edificios Vignolo en 1938, Fiore y la Clínica Guayaquil en 1939, y la Sociedad Filantrópica del Guayas en 1940. En ese período el equipo técnico estaba conformado además por el ingeniero italiano Rodrigo Perrotta y los ecuatorianos Pedro Boloña Rodríguez y César Plaza Ledesma (Diario El Universo (editor), 1940). Finalmente la compañía fue disuelta en 1941, luego de que 


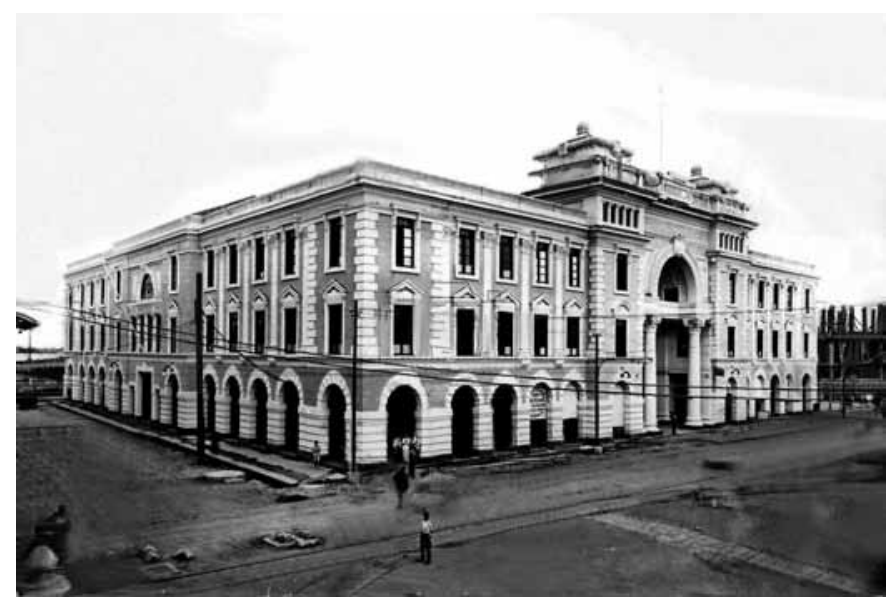

Figura 9. Palacio de la Gobernación. Archivo Nacional de Fotografía.

Schimanetz fue tomado prisionero y llevado al campo de detenidos que se estableció en Cuenca para los ciudadanos del Eje (Estrada, 2006).

La Sociedad General de Construcciones, filial de la IDEM, se estableció en 1922 y desarrolló su actividad hasta 1925. Estaba integrada por Carlo Bartoli, Giancarlo Bonarda y Mario Gherardi. Esta compañía construyó el Palacio de la Gobernación entre 1923 y 1924, de acuerdo al proyecto del alemán Augusto Ridder, modificado parcialmente en su interior y su fachada por Gherardi (Compte, 2007); además los edificios Juan Illingworth, Rogelio Benítes y el Diario El Telégrafo, según proyectos de Hugo Faggioni; Dr. Rendón, Cucalón, Santiago Noziglia y Tous, en 1924; el edificio Guzmán Ycaza, en 1925; y el Pareja-Cucalón, en 1925. La empresa fue disuelta en 1926, cuando Bartoli, Bonarda y Gherardi se trasladaron a Manizales, Colombia, donde se asociaron con el arquitecto italiano Angelo Papio en la empresa constructora Papio Bonarda \& Cía.

La más importante constructora nacional del Guayaquil de esa época fue la Sociedad Bancaria del Chimborazo que se había establecido en Riobamba el 24 de febrero de 1922 ante el Escribano Luis Pástor Cisneros (Cepeda, 2010). Los accionistas principales eran José Rodríguez Bonín y su suegro Eduardo Game Valarezo, Presidente del Directorio y Gerente General del Banco del Ecuador, con sede en Guayaquil, además de Carlos Valdivieso, Ángel Mancheno, Rafael Chiriboga, Gonzalo Chiriboga, Alfredo Chiriboga, Carlos Zambrano, Teófilo Sáenz, Reinaldo Dávalos, Luis Eduardo Game, Fed Nicholls y Julia de Marley, quienes el 15 de marzo de ese mismo año conformaron el directorio y nombraron como primer Gerente a José María Cordovez (Arosemena, 1998). En 1923 la Junta General de Accionistas fundó una sucursal en Guayaquil (Acta de la Sesión del 9 de julio de 1923) y estableció un Departamento de Construcciones que quedó a cargo del arquitecto italiano 
Pedro Fontana. Entre 1923 y 1926 ese departamento desarrolló un número importante de obras de construcción, tanto públicas como privadas, con proyectos y dirección técnica de Fontana; entre otros, los edificios Sotomayor y Luna, en 1923; Madinyá, en 1924; Sociedad de Abastecedores de Carne, Maldonado y Lizardo García, en 1925 (Compte, 2007); además de diez casas en el Barrio del Centenario (Diario El Telégrafo, 1923). En 1926 la compañía entró en proceso de liquidación y fue cerrada de manera definitiva. En publicaciones de la época se concluía que la quiebra se debió al exceso de inversión en la compra y la construcción de edificios, ya que los “... terrenos y edificios son la peor clase de Activos de que un banco puede disponer para el pago de sus obligaciones” (Arosemena, 1998, p. 129). La Sociedad Técnica Fénix fue la primera gran compañía constructora establecida por técnicos ecuatorianos en 1925. Estos eran: Luis Orrantia Cornejo, Presidente, y los ingenieros José Antonio Gómez Gault y Alfredo Tinajero Albornoz quien tenía el cargo de Director Técnico. Además se incorporó como proyectista a Hugo Faggioni. Su primera gran obra fue la Jefatura del Cuerpo de Bomberos en 1927, con proyecto de Tinajero. Luego, por su vinculación con instituciones gubernamentales tanto locales como nacionales, obtuvo importantes contratos para obras públicas de la ciudad, como la Escuela Fiscal Guayaquil en 1929; el Mercado Municipal del Norte y el Colegio Profesional Municipal en 1931; el Muelle-Aduana, entre 1935 y 1938; el Hotel Metropolitano en 1936; el Colegio Nacional Vicente Rocafuerte, proyecto de Faggioni y Fontana, entre 1934 y 1937; el Colegio de Señoritas Guayaquil en 1937, entre otros.

En un anuncio de 1933, la compañía ofrecía sus servicios como “... constructores especializados en hormigón armado”, además se indicaba que poseían “Talleres propios de: Carpintería, Mosaicos, Mármol Artificial, herrería, etc. y un tren completo de maquinarias para el trabajo rápido de construcciones. Siempre listos a financiar cualquier Obra en condiciones ventajosas para el cliente" (Aliprandi y Martini, 1933, p. 76). Finalmente la compañía fue liquidada en 1940, luego de un grave accidente que sufrió Tinajero en uno de los edificios que se encontraba construyendo (Compte, 2007).

Al período comprendido entre 1930 y 1948, corresponden la Constructora Guayaquil en 1933 (Al parecer esta inscripción no se hizo efectiva, por lo que volvieron a registrarse tres años más tarde); CSS Construction Company en 1937; la Compañía General de Construcciones en 1938; la Sociedad Constructora Técnica en 1938; la Constructora Huancavilca en 1939; la Compañía Nacional de Construcciones en 1941 (Se debe referir a una nueva Compañía Nacional de Construcciones, ya que no se registra actividad continuada de la anterior que estuvo establecida desde finales del siglo XIX, hasta esa fecha); Construcciones y Anexos S. A. (CASA) en 1941 (Fue fundada por el arquitecto Rafael Rivas Nevárez, junto con Rodolfo Idrovo, Arturo Cepeda y Hugo Orcés, aunque al poco tiempo fue liquidada); la compañía Construcciones y Tierras Unidas en 1942; la Compañía Constructora Basalt en 1945; Predios y Construcciones S. A. (PRECONSA) en 1946; y la Empresa Constructora Pahira, en 1948 (Mera y otros, 1991).

En este período también tuvo una desatacada participación la compañía constructora Ytaly, establecida en la década de 1930 por Luigi Fratta, como responsable técnico, y Paolo Russo, como proyectista. Entre sus proyectos están la casa de Carlos Frugone y hno., alrededor de 1930; la casa Vincenzo Andretta y el edificio de Clorinda Cardone de Andretta en 1930; la casa Jacobo Thome en 1933; la Iglesia de Nuestra Señora de La Merced, entre 1934 y 1936; 
la Iglesia del Corazón de María, según proyecto de Enrico Pacciani, la casa Pablo Castello en 1935; la Iglesia de Santo Domingo de Guzmán y el Palacete Russo en 1937, entre otros (Compte, 2007). Ya para la década de 1940 había cesado su actividad (Estrada, 2006).

La Compañía General de Construcciones fue fundada en 1937 por los guayaquileños Julio Estrada Ycaza y Emilio Ginatta Hidalgo y el ingeniero Arnaldo Ruffilli. Como Subgerente del Departamento Técnico se incorporó a Héctor Martínez Torres, quien proyectó el edificio Marcet (Primer Premio Municipalidad de Guayaquil 1938) y Tosi (Primer Premio Municipalidad de Guayaquil 1939), el Yacht Club, así como el Palacio Municipal y la Gobernación de Babahoyo, Provincia de Los Ríos, en 1938. También formó parte del equipo técnico el arquitecto Marcos Martínez Salazar (Diario El Universo (editor), 1940). En enero de 1943, debido al retiro de Ruffilli, se liquidó la compañía.

En la década de 1940 cesaron sus actividades la Compañía Italiana de Construcciones y la Compañía General de Construcciones, y, aunque con lentitud, junto con la recuperación económica y la estabilidad política del país, empezaron a surgir nuevas empresas constructoras.

$\mathrm{Al}$ ser una ciudad portuaria, Guayaquil estuvo abierto al mundo y a los cambios tecnológicos, a diferencia de Quito y otras ciudades de la región andina donde hasta la llegada del ferrocarril su contacto con el exterior era más limitado. En Guayaquil la reconstrucción luego del Gran Incendio y la necesidad de evitar que se destruyera nuevamente posibilitó que se incorporaran rápidamente los avances en materiales y técnicas constructivas que llegaban del exterior. De esta manera la madera dio paso al cemento y los carpinteros de ribera a los arquitectos e ingenieros.

\section{Capítulo 5. Guayaquil: la conformación de la modernidad arquitectónica}

Gran parte de los historiadores de la arquitectura de Latinoamérica (Bullrich, 1969; Cetto, 1978; Arango, 1989; Segre, 1990; Gutiérrez, 1992; Gutiérrez y Gutièrrez Viñuales, 2012, entre otros) sitúan los inicios de la Arquitectura Moderna en algunos países de esta parte del continente americano, entre los años 1929 y 1930, al confluir factores como la llegada de revistas especializadas europeas que difundieron las ideas de modernidad arquitectónica, el primer viaje de Le Corbusier cuando visitó Buenos Aires, Montevideo y Sao Paulo, las experimentaciones en torno a nuevos materiales y técnicas constructivas, la influencia de las vanguardias artísticas, la migración de arquitectos y técnicos europeos durante la Segunda Guerra Mundial, el interés sobre el continente americano como un nuevo espacio de experimentación y difusión del racionalismo arquitectónico, además como plantea Roberto Segre (1990) de la asimilación del "estilo" por parte de las burguesías locales. Verónica Cremaschi (2014) advierte que si bien el surgimiento de la Arquitectura Moderna en nuestra región se dio casi a la par en cada uno de los países, este responde a particularidades nacionales, como los movimientos posrevolución en México; la nueva elite producto de la inmigración y a su ascenso, en Argentina; la influencia norteamericana en los países caribeños, etc.

Eliana Cárdenas (1998), por su parte, plantea que hay una necesidad de profundizar en el análisis de la arquitectura y la ciudad latinoamericana con categorías críticas que reconoz- 
can las contingencias que han condicionado su evolución, y de clasificar arquitecturas que no encajan necesariamente en la línea evolutiva de las corrientes internacionales.

En Guayaquil, hasta la primera década del siglo XX la arquitectura seguía teniendo como referente los patrones funcionales y formales de la tradición en madera que provenían de la época colonial, que siguió utilizándose para la reconstrucción de la ciudad luego del Gran Incendio de 1896, sin embargo, poco a poco iba surgiendo una nueva arquitectura ecléctica hecha con materiales incombustibles. Los viajeros que visitaban la ciudad resaltaban su arquitectura de contrastes, donde coexistía una tradicional en madera con una nueva y moderna en cemento armado y de composición clásica realizada gracias a la bonanza cacaotera del país, y de Guayaquil en particular:

En general, la ciudad se caracteriza acertadamente por los llamativos contrastes que ofrece a la vista. En los barrios más antiguos -la llamada ciudad vieja- se encuentran hasta hoy inmuebles capaces de causar horror al trotamundos más curtido. Al ver estos fangos y cuevas humanas, el europeo retrocede con espanto y comprende entonces sin más por qué, en Guayaquil, la peste bubónica y la fiebre amarilla, para no hablar de la malaria, quedaron sin erradicación posible por tanto tiempo. A escasos cincuenta metros de estas fealdades medievales se encuentran, en cambio, edificios muy modernos y calles limpias con tranvías eléctricos y almacenes elegantísimos (Hintermann, 2015 [1927], pp. 54-55).

La inauguración del Palacio Municipal en 1929, proyecto de Francesco Maccaferri -el más importante y último edificio público academicista de la ciudad- se dio a la par de la agudización de la crisis económica iniciada a comienzos de la década de 1920.

En la arquitectura, esta crisis trajo como consecuencia que se racionalizaran los espacios, se simplificaran las formas, se eliminaran los costosos ornamentos y se adoptaran códigos formales modernos en proyectos residenciales a pequeña escala y no en grandes edificios públicos como ocurriría en otros países del continente.

Durante los años de la crisis, entre 1929 y 1948, se dio en la arquitectura una sucesión de propuestas formales que iban desde las eclécticas, las neogóticas, las neocoloniales, las pintoresquistas, el art déco, el art nouveau, hasta otras racionalistas. Los arquitectos e ingenieros pasaban sin problema de un tipo de arquitectura a otra ya que tenían asumido que todas ellas se enmarcaban en la modernidad arquitectónica, en la medida en que eran no clásicas. Era así como en la arquitectura de Maccaferri, el más representativo del período, se encuentran edificios clásicos, art déco, modernistas y otros racionalistas.

Ya para inicios de la década de 1950, junto con la recuperación económica y de la estabilidad política del Ecuador, se consolidaron las propuestas arquitectónicas modernas en las principales ciudades del país y se empezó a modificar el área central de Guayaquil con la incorporación de edificios en altura. Se inició también el desarrollo de la ciudad hacia el norte, con proyectos privados orientados hacia sectores más altos, como Urdesa en 1955 a partir del diseño urbanístico de Alamiro González y Rafael Rivas Nevárez; Miraflores en 1957 con proyecto de Félix Henríques; y Los Ceibos, en 1960, según proyecto de Guillermo Cubillo. Dentro de la arquitectura se destacan también los proyectos que desarrollaron Karl Kohn, Fernando Schimanetz, Héctor Martínez Torres, Marcos Martínez Salazar, Ra- 
fael Rivas Nevárez, Simón Bolívar Jalón, Alamiro González, Juan Orús, Xavier Quevedo, René Denís, entre otros.

En la década de 1970, inicios de la era petrolera, la ciudad había triplicado su población respecto a la de 1950 . Se había producido también la reconquista del casco central mediante la sustitución de los tugurios y su reemplazo por edificaciones en altura para residencia de sectores con alta capacidad adquisitiva o para oficinas y comercio, como el edificio Tous de Denis o el edificio matriz del Banco Central del Ecuador de Cubillo. Los sectores de ingresos más altos y medios, por su parte, se dirigieron hacia el norte y oeste de la ciudad y la integración hacia terrenos pertenecientes a los cantones periféricos de Durán y Samborondón, empezando a conformar, de esta manera, una gran área metropolitana.

\subsection{De la arquitectura tradicional a la arquitectura moderna}

Pocos cambios se dieron en la arquitectura de la ciudad luego del Gran Incendio de 1896. La necesidad de reconstruir la ciudad rápidamente y de que los casi 33.000 damnificados recuperaran sus viviendas, determinó que se mantuviera el tipo de edificación tradicional en madera, de una o dos plantas, con un patio central.

Lo tradicional en la arquitectura, nos remite la idea de adecuación al medio, con soluciones eficientes frente a las condiciones climáticas y al encontrar respuestas prácticas, en lo funcional y constructivo, que resultaron de la confluencia de la espacialidad hispana con la incorporación de materiales y métodos locales -caña, bijao, quincha- y de los sistemas de edificación adaptados originados en la construcción naval.

En los tres años siguientes al incendio, entre 1897 y 1899, apenas se habían podido levantar 384 casas, una número insuficiente si se compara con las 1103 edificios destruidos (Crónica Comercial e Industrial de Guayaquil en el Primer Siglo de la Independencia 1820-1920, 1920), sin embargo empezaban a construirse otros edificios en madera que no eran destinados a vivienda, como el Teatro Olmedo en 1900, con capacidad de 1.500 espectadores (Crónica Comercial e Industrial, 1920, p. 72) o el Colegio San Vicente del Guayas, diseñado y construido por Emilio Estrada en 1901, que ocupaba una manzana completa y estaba dotado, además de las aulas, de un salón de actos con capacidad para ochocientas personas, dormitorios para doscientos internos, comedores, biblioteca pública, un museo de historia natural y un observatorio astronómico.

El hecho de que la ciudad estuviera construida en madera y, sobre todo, la calidad de la edificación que se alcanzaba con ese material, era algo que asombraba a los visitantes como al alemán Hans Meyer: "Al recorrer las calles y plazas frecuentemente creía yo encontrarme delante de un edificio construido de lozas de mármol, más, viéndolas más de cerca se revelaba la supuesta piedra como trabajo de madera marmoleado" (1903, s/p).

Del análisis de la historia de la arquitectura de Guayaquil, en la que recién a finales del siglo XIX se la asocia a arquitectos e ingenieros, es fácil colegir que durante la mayor parte de su desarrollo fue elaborada por los propios usuarios o por artesanos expertos, sin que aparentemente mediaran planos elaborados por profesionales. Esta tradición vernácula se ha mantenido viva en las expresiones populares de reinterpretación de lo "culto" en las edificaciones elaboradas de manera informal y empírica por los propios habitantes como solución 
al problema de déficit habitacional, con el uso de materiales locales -principalmente caña guadúa- y con formas que poco difieren de las que se podían encontrar siglos atrás.

Si bien se ha descrito cómo luego del Gran Incendio se conservan los principios compositivos y constructivos de la arquitectura tradicional, debido, principalmente, a la urgencia de la reconstrucción, poco se ha dicho sobre la manera en que dicha arquitectura, con sus valores formales y técnicos, ha tenido una perdurabilidad en el tiempo en la arquitectura popular o vernácula, en la que no intervienen manos profesionales, ya que la mayoría de los estudios que se plantean sobre la arquitectura de Guayaquil se han centrado en ejemplos y en la valoración de lo culto o estilístico, dejando de lado una importante área de análisis. En amplios sectores de la ciudad de Guayaquil aún perviven estas manifestaciones a través de edificaciones mixtas, esto es con estructura de madera recubierta y paredes de mampostería, y con elementos formales clásicos, aplicados con carácter ornamental o decorativo antes que por ajustarse a la rigidez de la composición académica.

Ya en el siglo XX, cuatro edificaciones marcaron una diferencia en la construcción de madera. La primera, el Mercado Sur, en 1905, inaugurado dos años más tarde; la segunda, las naves de la Iglesia San José y la reconstrucción de la Cárcel Municipal, ambas con losa plana de hormigón armado; además del Laboratorio Químico Municipal, también en hormigón armado, construido en 1911 por la empresa alemana Dobler \& Cía, de Hamburgo (Noboa, 1920).

A inicios de la década de 1920 Guayaquil contaba con 91.482 habitantes y se extendía en poco más de 700 hectáreas. La bonanza económica del segundo auge cacaotero se expresó en la incorporación del academicismo en los repertorios formales de la arquitectura mediante principios traídos por arquitectos e ingenieros extranjeros, principalmente italianos, como Maccaferri, Russo, Fontana, Faggioni, Rufilli, Fratta, Lignarolo, Battaglia, Caccurri, Perrotta, Faidutti, además de otros como el alemán Ridder o el portugués Raúl María Pereira.

Con la consolidación y extensión de la edificación en cemento empezó a coexistir una ciudad de madera, percibida como antigua, con otra construida con nuevos materiales resistentes al fuego y a los insectos, vista como moderna. En la segunda edición de 1920 de Guayaquil a la vista, se describía esta situación de la siguiente manera:

Guayaquil en los últimos años ha progresado considerablemente. A las construcciones antiguas, bajas, hechas de madera, van sucediendo soberbios edificios de cemento armado, altos, soberbios, majestuosos, que bien pueden figurar en las más grandes ciudades de América y Europa (s/p).

La crisis de fines de la década de 1920 coincidió en la arquitectura con la inauguración del Palacio Municipal en 1929, la última gran obra pública que utilizó el academicismo eclecticista como expresión del poder estatal, que empezó a orientar sus propuestas hacia proyectos en donde se obviaran o limitaran las ornamentaciones y detalles.

El proyecto que había marcado la incorporación de los códigos clasicistas fue el Banco del Ecuador diseñado en 1898 por Rocco Queirolo y los últimos grandes proyectos en esta línea fueron el Palacio de la Biblioteca Municipal en 1916 de Pereira; el Palacio Municipal de Maccaferri. Este edificio de madera al poco tiempo de su inauguración empezó a presentar 


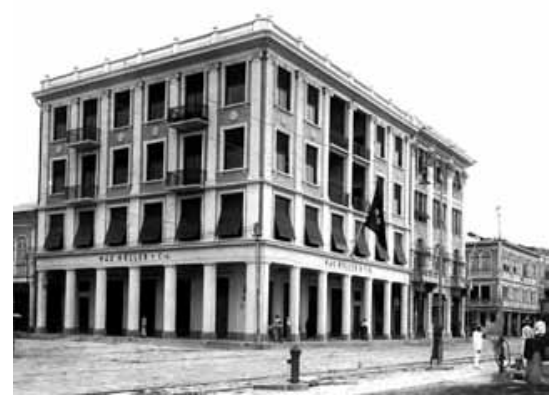

Figura 10. Edificio Max Müller, 1925-1927.

problemas de deterioro debido a fallas en el proceso constructivo, lo que desembocó a que fuera demolido en el año 1938, diseñado en 1922; y los palacios de la Gobernación, proyecto de Ridder, y del Hospital General, con proyecto de Russo, diseñados en 1923.

La transición entre lo académico y lo moderno se dio a través de propuestas eclécticas que, sin embargo, en Guayaquil se dieron muchas veces a la par, ya que los arquitectos, según las demandas de los clientes, podían ser clásicos, eclécticos, modernos, neocoloniales o decantarse por el art déco, lo que los convertía a ellos mismos en eclécticos, como lo indican Ramón Gutiérrez y Graciela Viñuales (1998):

Los arquitectos hacían simultáneamente proyectos en diversos 'estilos', convirtiéndose ellos mismos en eclécticos. Esta notable ductilidad aseguró por un tiempo la satisfacción de la demanda individualista de las pujantes burguesías urbanas, pero a la vez abrió las compuertas a otras manifestaciones que lograron así desbordar los diques que la ortodoxia clásica había construido con tanto esfuerzo (p. 120).

Un edificio trascendental para poder entender la transición de lo clásico a lo moderno es el edificio Max Müller, diseñado en 1925 por el arquitecto suizo Eugen Schllatter. El proyecto de Schllater, modificado significativamente a comienzos del presente siglo, es el de un sobrio y elegante edificio de lenguaje clasicista sin mayor ornamentación, donde se puede suponer la influencia de arquitectos como Otto Wagner, en la Caja Postal de Ahorros de 1909, o Adolf Loos, con el edificio Goldman y Salatsch de 1911 (Ver Figura 10).

A inicios de la década de 1930, a la par de la profundización de la crisis económica, se inició un período de cambios en los edificios que simplificaron sus formas y racionalizaron sus espacios, diseñados por los mismos arquitectos que pocos años antes eran radicalmente clásicos. La Arquitectura Moderna emergió, de esta manera, de la mano de arquitectos como Maccaferri, Martínez Torres, Faggioni o Russo, en proyectos de pequeña escala y 
luego, a medida que el país iba recuperándose económicamente, en edificios públicos de mayores dimensiones, como escuelas, colegios.

La labor de Maccaferri fue fundamental para el desarrollo de la Arquitectura Moderna y para la conformación del campo disciplinar de la arquitectura en Guayaquil. Sus continuos viajes a Milán, donde se había formado como arquitecto, le permitieron estar en contacto con el debate que para ese entonces se daba en esa ciudad, entre quienes defendían una arquitectura clásica proveniente de la tradición lombarda y quienes creían que era necesaria una arquitectura racionalista como expresión de los tiempos cambiantes. En la arquitectura de Maccaferri, sólida desde lo compositivo, se puede advertir los cambios que se iban dando a medida que se profundizaban las diferencias entre estas visiones y se acentuaban los problemas económicos del país.

Para mediados de la década siguiente las edificaciones en hormigón armado se habían generalizado y empezaban a crecer en altura, hasta conformar los primeros "rascacielos" de cinco o seis pisos de alto, tal como lo destacaba una publicación:

La ciudad extendida en un área urbanizada de 7’456.907 m2, que comprende 131 calles, con denominación oficial del I. Concejo, incluidas las del moderno Barrio del Centenario, tiene 8.550 edificios al presente, tomando como base los resultados del censo de 1931 i la estadística de construcciones posteriores. La nueva edificación de cemento armado se va generalizando i, por consiguiente, las casas de este material, de más de 3 pisos son numerosas, contándose algunas de 5 i aún de 6 altos (Hidalgo González, 1939, p. 8).

Tendrían que pasar otros años más, hasta fines de la década de 1940, cuando, con la recuperación económica, la industria de la construcción recobró impulso y empezó a desarrollarse la edificación en altura en el área central de la ciudad, destinada a actividades administrativas, comerciales y financieras.

Uno de los exponentes más importantes de esta naciente Arquitectura Moderna fue Héctor Martínez Torres, primer graduado de arquitecto en la Escuela de Arquitectura de la Universidad de Guayaquil fundada en 1929 por Maccaferri. Héctor Martínez Torres fue hijo de quien fue Presidente de la República Juan de Dios Martínez Mera y biznieto del Maestro Mayor de Carpinteros Juan María Martínez Coello. Entre 1935 y 1937 Martínez Torres trabajó en el Departamento de Diseño de la Compañía Italiana de Construcciones. Entre 1938 y 1940 asumió la Subgerencia del Departamento Técnico de la Compañía General de Construcciones y en 1940 fundó su propia firma de arquitectura y construcción. Una de sus obras de más trascendencia fue el campus de la Universidad de Guayaquil, al norte de la ciudad, en terrenos anexos al Estero Salado. Martínez Torres, en asociación con los arquitectos Manuel Gambarrotti y Rafael Rivas, ganó el concurso para su diseño y construcción en 1947. Finalmente, el 1 de diciembre de 1949 se dio inicio a los trabajos bajo la dirección del Martínez Torres (Ayón de Messner, 1967), quien ocupó dicha dirección por hasta 1969. Entre 1946 y 1973 fue también Director Técnico del Cementerio General de Guayaquil. De su amplia obra como arquitecto destacan el Mausoleo a Eloy Alfaro en 1942; la casa Martínez Torres en 1944; el proyecto de la Ciudadela La Atarazana en 1946; la Penitenciaría del Litoral; la Liga Deportiva Estudiantil en 1954; el edificio de la 
Cámara de Comercio de Guayaquil; el edificio de la Junta de Beneficencia de Guayaquil en 1957; el edificio Marriott en 1960; la Congregación Santiago Apóstol en 1968, entre otros. Martínez Torres fue uno de los arquitectos más prolíficos de la historia contemporánea de Guayaquil. Su trabajo se inició a finales de 1930 y se mantuvo en actividad hasta finales de la década de 1980.

Al trabajo de Martínez Torres dentro del racionalismo se sumaron otros arquitectos e ingenieros de la época como José Antonio Gómez Gault con su proyecto del Club de la Unión en 1937, los hermanos Pedro y Héctor Manrique Acevedo con varios proyectos residenciales principalmente en el Barrio del Centenario; el Hermano Xavier con el proyecto del Colegio San José La Salle; además de Jorge Gagliardo, Pedro Boloña, Rodrigo Perrotta, Bruno Faidutti, Nicolás León Pizarro, Juan José Orrantia, entre otros.

En la década de 1940 se van incorporando también nuevas propuestas como reacción a la arquitectura academicista, que iban desde el neogótico en proyectos como el de la Catedral de Guayaquil, la Iglesia del Sagrario o el Palacio Arzobispal, del catalán Juan Orús; propuestas neomoriscas, como la Torre del Reloj, de Joaquín Pérez Nin de Cardona y el propio Orús; y lo que se denominó el "estilo español californiano", iniciado en 1940 por el Héctor Martínez Torres en las casas Martínez Mera y Enrique Cabanilla; además de los proyectos de Orús y Pérez Nin de Cardona en las casas Briz Sánchez y Villa Herlinda en 1941, respectivamente; hasta el art déco de los proyectos del húngaro Schimanetz como el edificio Vignolo o el edificio Fiore.

Son de destacar también propuestas formales dentro de los principios del art nouveau, que se habían dado años antes, como en la casa y garajes de Walter Guzmán Aspiazu, culminados en 1929 según proyecto de Maccaferri, aunque fue Pérez Nin de Cardona quien había introducido estos principios compositivos en los proyectos de los edificios Benítes Icaza en 1921 y González Alonso en 1924, además del proyecto de la casa Levy en 1925.

Tuvieron que pasar algunos años, hasta 1944, cuando el ingeniero austriaco Oscar Etwanick diseñó el Palacio de las Comunicaciones, como se denominó al nuevo edifico de correos, que se convirtió en el primer edificio público realizado en la ciudad que adoptó el lenguaje racionalista como nuevo símbolo de modernidad del Estado (Ver Figuras 11 y 12).

Finalmente, en 1949, a la par del proceso de recuperación económica del país luego de décadas de crisis, se abría al público el edificio de la Casa de la Cultura Ecuatoriana Núcleo del Guayas, que Guillermo Cubillo había proyectado en 1945 como tesis de graduación. En una publicación institucional de la época se destacaba en el edificio el uso de las líneas "modernas y novedosas", así como por su "sobria arquitectura", se agregaba que en ese proyecto no solo había que admirar su funcionalidad, sino también "...la magnífica distribución que se revela a través de los detalles que completan el conjunto de una obra que será verdadero monumento levantado a la cultura" (Nuestro edificio en marcha, 1948 [2015]). Ese edificio, donde se aprecia la fuerte influencia de la obra de Le Corbusier, marcó la consolidación de la Arquitectura Moderna en Guayaquil (Ver Figura 13). 


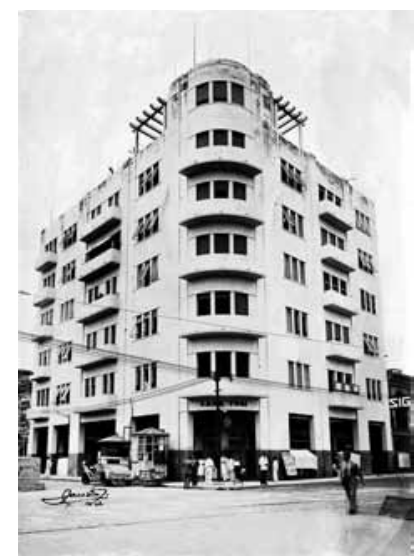

Figura 11.

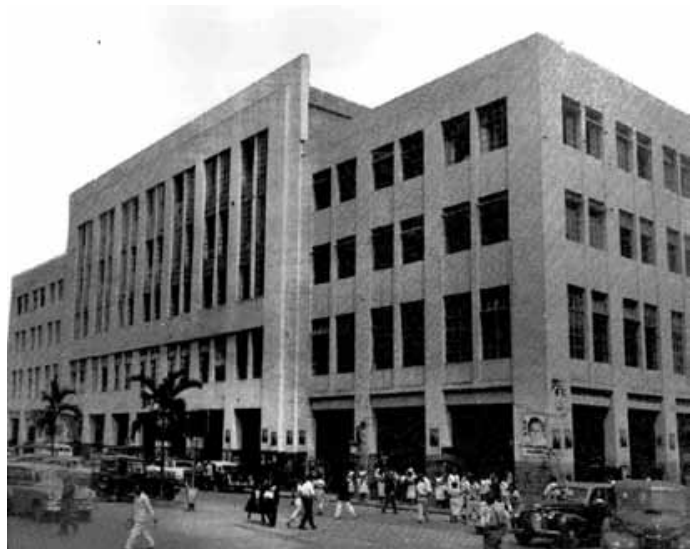

Figura 12.

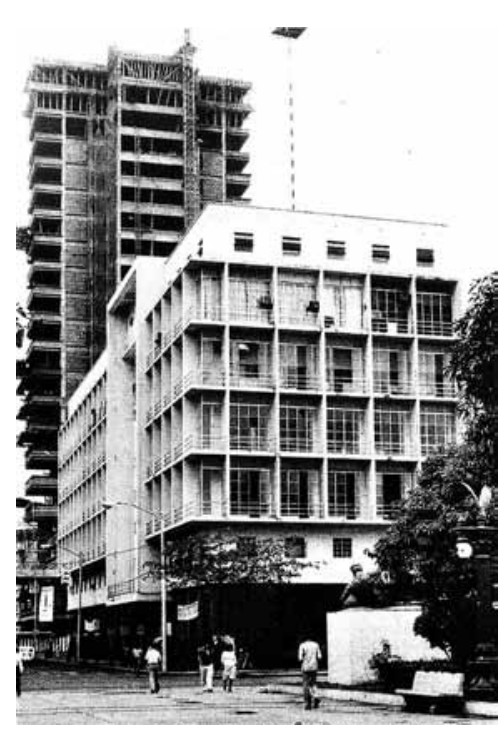

Figura 13.
Figura 11. Edificio Tosi, Primer Premio Municipalidad de Guayaquil 1939. Figura 12. Palacio de las Comunicaciones, 1944. Figura 13. Casa de la Cultura Ecuatoriana Núcleo del Guayas, 1945-1949. Archivo Pablo Lee. 


\subsection{El amplio espectro de la modernidad: neocolonial, art nouveau y art déco}

Cada país, tanto en América como en Europa, trata de conservar en los estilos arquitectónicos, las características nacionales, que han ido formándose a través de los siglos y que constituyen, si así pudiéramos llamar, el alma en piedra de la raza (Proyecto de casa quiteña moderna, 1940, p. 1).

La comprensión de la modernidad arquitectónica como discurso, en lugar de la visión tradicional de "estilo", permite abordar la interpretación de la arquitectura de Guayaquil desde la complejidad de su emergencia y desarrollo, por lo que se pueden incorporar un conjunto de obras importantes que, según la visión tradicional de simplificación estilística, no son modernas aunque tampoco son clásicas, pero que respondieron a concepciones de la modernidad, al posicionarse desde la ruptura del pasado.

Eran propuestas que tomaban como referencia las vanguardias europeas, que fueron utilizadas de manera epidérmica y que iban desde el neogótico en proyectos de nuevas iglesias, casas neocoloniales dentro del "estilo español californiano", hasta otras dentro del art nouveau y art déco.

Verónica Cremaschi (2014) aborda en sus trabajos el análisis del denominado estilo neocolonial como una de las expresiones de la modernidad en la arquitectura de la región. Propone la necesidad de analizar la arquitectura latinoamericana desde su complejidad, por lo que hay necesidad de hablar de modernismos en plural, flexibilizando, de esta manera, la categoría de Arquitectura Moderna.

El neocolonial, que surgió durante la primera mitad del siglo XX en distintas naciones latinoamericanas, alude al conjunto de teorías, proyectos y construcciones que tomaron como modelo las obras producidas durante el período de dominación española en América y otras regiones de influencia hispánica.

Las conmemoraciones de las independencias de los distintos americanos llevaron a reflexionar sobre sus características como naciones, sus identidades nacionales y a la necesidad de encontrar modelos arquitectónicos propios que hicieran frente a los modelos extranjeros que habían predominado desde el momento de la independencia. Muchas de estas respuestas, según Cirvini (2004), se expresaron a través de diferentes variantes: hispanistas, colonial o de fusión y desde lo indigenista o prehispánico.

Esta búsqueda de lo propio se había iniciado desde finales del siglo XIX cuando empezaron a constituirse los estados nacionales a lo largo del sur de nuestro continente. En el imaginario de occidente se configuraban los dos extremos en que se expresaba la cultura latinoamericana moderna: el anclaje a un pasado prehispánico o colonial, o la juventud de los países expresada en la ninguna alusión al pasado. Un ejemplo de ello fueron algunos de los pabellones latinoamericanos de la Exposición Universal de París de 1889, como el de México, “... una suerte de monumento prehispánico que, se suponía, debía expresar el 'carácter' de la Arquitectura de ese país”, mientras en el extremo opuesto estaba el pabellón de Chile, “... una estructura prefabricada desarmable que luego fue transportada y vuelta a montar en Santiago de Chile" (Liernur, 2008, p. 36).

Un pabellón que recibió grandes elogios en dicha exposición fue el ecuatoriano, diseñado por el francés Georges Paul Chédanne, que fue ubicado junto al pilar sur de la Torre Eiffel. 
Georges Paul Chédanne (1861-1940) fue un importante arquitecto francés con obras vinculadas al art nouveau. Entre sus proyectos más destacados están la Embajada de Francia en Viena y las Galerías Lafayette en París. Se lo describía como una síntesis de distintas arquitecturas precolombinas, ya que intentaba reproducir un templo inca, al que se le había agregado una "... copia del tablero superior de la Puerta de Tiahuanaco (Bolivia), un relieve bajo la cornisa característico de Chan-Chan (Perú), y frente a la fachada seis 'sillas manteñas' (Ecuador). Estas sillas, reproducidas a partir de esas típicas esculturas prehispánicas de la provincia costeña de Manabí, fueron lo único verdaderamente ecuatoriano y original" (Schávelzon, 1984, p. 66). Esta especie de pastiche arquitectónico en realidad reflejaba el vago o ningún conocimiento que se tenía en Europa sobre los países latinoamericanos y su historia prehispánica.

Unos años más tarde, en 1900, y nuevamente en París, el Ecuador levantaba otro pabellón, esta vez art nouveau, financiado probablemente por la próspera busguesía cacaotera gauyaquileña, que se “... se había erigido con el objeto de ser trasladado luego a Guayaquil para ser utilizado como Biblioteca Municipal” (Schávelzon, 1981, p. 58), lo cual jamás sucedió.

Ya en 1929, la Exposición Iberoamericana de Sevilla, en la que el Ecuador no tuvo pabellón propio, fue el espacio en que los países latinoamericanos se mostraron ante el mundo a través de pabellones que recuperaban la tradición de la arquitectura prehispánica o del pasado colonial, desarrollados con un sentido nacionalista. De esta manera, por ejemplo, Manuel Amábilis diseñó el pabellón de México con un referente de la cultura tolteca, destacado como unos de los más interesantes por las publicaciones de la época, el de $\mathrm{Ar}$ gentina, inspirado en " ... el estilo virreinal que es el barroco andaluz con la intervención incaica y calchaqui” (Ramírez Nieto, 2009, p. 88) o el de Perú, una mezcla hispánica e incásica, diseñado por el escultor y arquitecto Manuel Piqueras Cotolí.

Entre 1900 y 1915 hubo una gran influencia del art nouveau en las artes gráficas ecuatorianas que se expresó en las portadas e ilustraciones de revistas como La Ilustración, Savia y Mosaicos, con "... rasgos y líneas estilizantes (donde) hay ecos de un sincretismo visual que se expresa en formas simbólicas cercanas a lo que se considera 'americano', con referentes del arte universal” (Hidalgo, 2013, p. 132). También tuvo su expresión en la arquitectura del andaluz Joaquín Pérez Nin de Cardona en los edificios Rogelio Benítes Icaza de 1923, Mariano González Alonso en 1924 y en el proyecto, no realizado, de la casa Levy en 1925. En algunos de los Congresos Panamericanos de Arquitectura se debatía a favor del rescate de los lenguajes arquitectónicos nacionales: neocolonial, neoazteca, neoinca, entre otros, vinculándolos con las necesidades de la modernización, tal como se afirmaba en una de las conclusiones del congreso de Río de Janeiro de 1930, en el sentido de que había que “... fomentar el estudio y la aplicación de la Arquitectura de carácter nacional, de modo que sea capaz de cumplir su finalidad social moderna" y “... que no existe incompatibilidad entre el regionalismo y la tradición con el espíritu moderno, ya que es posible obtener una expresión plástica nacional dentro de las normas y prácticas de común orientación que los programas y los materiales imponen" (Cárdenas, 1998, p. 112).

Algunos autores como Segre, Donoso Vallejo, Ortiz Crespo, Tejeira Davis o Gutiérrez, interpretan al neocolonial como nostálgico, conservador o retrógrado, como un preámbulo a la Arquitectura Moderna o bien como una "bisagra" entre esta y el eclecticismo académi- 


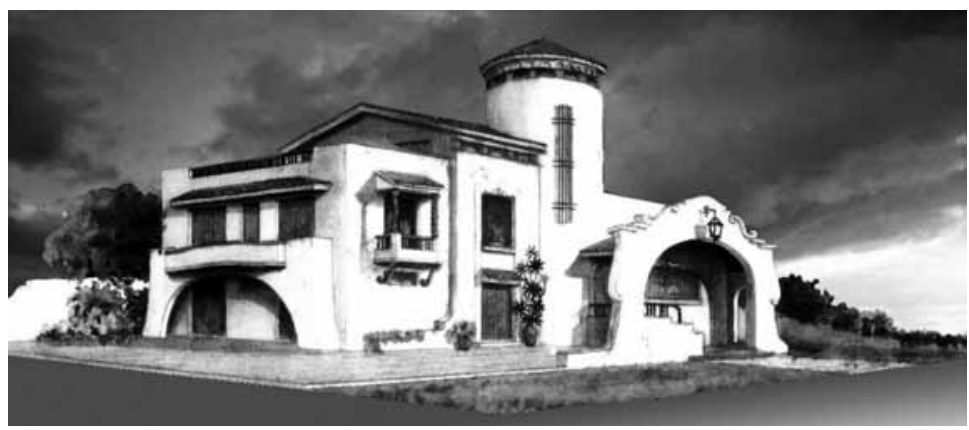

Figura 14. Casa Juan de Dios Martínez Mera. Arquitecto Héctor Martínez Torres, 1940.

co de fin de siglo (Cirvini, 2004). Hay otros, en cambio, como Hereu, Montaner y Oliveras, que consideran que paralelamente a lo que entienden como arquitectura del Movimiento Moderno Internacional, existe una arquitectura "otra" que rescata motivos clásicos y que debe ser considerada moderna por ser fruto de la modernidad.

El origen de la recuperación de lo colonial hay que buscarlo en la región norteamericana de California, que se afirmó como territorio español gracias a las misiones franciscanas construidas entre 1769 y 1823. En 1821 el territorio pasó a formar parte de México, cuyo gobierno acabó con el sistema de las misiones, secularizó las instalaciones y las reconvirtió en estancias privadas que luego cayeron en el abandono (Betti, 2010). Luego de la guerra mexicano-estadounidense, entre 1846 y 1848, California pasó a integrar el territorio de los Estados Unidos. Esta circunstancia histórica determinó que se buscara un estilo "identitario" de la región y el mission style (estilo misionero) se consideró apropiado para recuperar la memoria y volverla a poner en valor.

En 1888 el senador Leland Stanford al momento de la construcción de la Universidad de Stanford, sugirió utilizar como referente los edificios de adobe californianos, lo que fue acatado por los arquitectos de la firma bostoniana Shepley, Rutan y Coolidge.

En Guayaquil la arquitectura neocolonial tuvo una breve expresión a través del "chalet californiano", el cual, a diferencia de otros países latinoamericanos, se dio como una propuesta formal más que como resultado de una reflexión académica o una búsqueda de expresión nacionalista, a pesar de que la ruptura con el eclecticismo hacía que estos arquitectos, al sentirse antiacadémicos, defendieran sus propuestas como modernas (Ver Figura 14).

Su adopción puede ser interpretada como una nueva forma de dependencia que toman como referente a Estados Unidos como nuevo centro de donde emanan las políticas económicas y culturales, tal como lo indica Ramón Gutiérrez: "La penetración del 'californiano' supone una doble vuelta: primero la aceptación de la arquitectura española en Estados Unidos y segundo su reformulación pintoresquista" (1997, p. 66). 
En esta línea se desarrollaron proyectos como la casa para Juan de Dios Martínez Mera, de Martínez Torres, Primer Premio Municipal de Guayaquil en 1940, y la casa Cabanilla, Primer Premio Municipal de Guayaquil en 1943, o los proyectos de Orús y Pérez Nin de Cardona en las casas Briz Sánchez y Villa Herlinda en 1941, respectivamente, e incluso Maccaferri incursionó en lo neocolonial con el proyecto de la casa Bucaram de ese mismo año. En una publicación ecuatoriana sobre arquitectura que circuló en esa época se defendía el uso del neocolonial ya que se consideraba que era "... la última palabra en modernidad, en las grandes ciudades de nuestra América”, además de que se creía que podía ser “... el estilo más económico desde el punto de vista de construcción” (Proyecto de casa quiteña moderna, 1940, p. 1). Eso sí se aceptaba el hecho de que era una arquitectura más californiana que española.

Otro de los arquitectos que desarrolló proyectos en este período fue el catalán Juan Orús, llegado a Guayaquil en julio de 1927, quien entre 1934 y 1936 estableció una oficina de arquitectura y construcción con el andaluz Joaquín Pérez Nin de Cardona, desde donde desarrollaron varios proyectos dentro del californiano y el art déco, como las dos villas para Luis García. Es de destacar también la intervención que Orús realizó en 1937 en la Torre del Reloj de la ciudad, dándole la imagen neomorisca que tiene hasta la actualidad. El proyecto original era del arquitecto Joaquín Pérez Nin de Cardona y del ingeniero Francisco Ramón. Ya de manera independiente, a partir de 1936, desarrolló múltiples proyectos dentro de lo neocolonial y algunas propuestas pintoresquistas, como el Edificio Juan X. Marcos y la casa Gabriel Vilaseca en 1936, el Edificio La Frutal en 1937, el Edificio Janer en 1938, la casa Luis García y Florentino Briz Sánchez en 1941, el Edificio Chiriboga-Valdiviezo en 1944, el Colegio Salesiano Cristóbal Colón entre 1947 y 1951, entre otros. Entre 1941 y 1958 estuvo dedicado a la dirección de la construcción de la Catedral de Guayaquil y al proyecto definitivo de su fachada principal, el cual respetó la concepción neogótica desarrollada en el proyecto original por el italiano Paolo Russo.

En las décadas de 1930 y 1940 se implantó en Estados Unidos y Latinoamérica la arquitecturaart déco, como alternativa al academicismo y una transición entre el eclecticismo y el racionalismo, pero que, contrario a la austeridad y limpieza que preconizaba la Arquitectura Moderna, incorporaba elementos ornamentales estilizados. Aunque como afirma Marina Waisman (1986) “... gran parte de nuestro entorno, en ciudades mayores y menores, lleva la inequívoca impronta del gusto art déco” (p. 3), lo cierto es que algunos de los mas importantes críticos e historiadores de la arquitectura no lo han incluido en sus trabajos al considerarlo “... una vertiente frívola del Movimiento Moderno” (p. 3).

El art déco surgió en la década de 1920 en Europa como un conjunto de manifestaciones artísticas que integraban tanto la arquitectura como la pintura, la escultura, el mobiliario, el diseño de objetos, el diseño de interiores, la cerámica, el diseño gráfico, el diseño de indumentaria y el diseño textil. Su nombre, sin embargo, no fue acuñado sino hasta varias décadas después, luego de la exposición Les Années 25 que se presentó en el Museo de Artes Decorativas de París en 1966 en conmemoración de la exposición de artes decorativas e industriales que se desarrolló en esa ciudad en 1925. Umberto Eco (2007) describe como el art déco recupera motivos “... del Jugendstil -ramos de flores estilizadas, figuras femeninas jóvenes y esbeltas, esquemas geométricos, serpentinas y zigzgas- enriqueciéndolos con 
sugerencias extraídas de las experiencias cubistas, futuristas y constructivistas, siguiendo siempre la consigna de la subordinación de la forma a la función” (p. 371).

Su explosión se dio en los Estados Unidos, especialmente en rascacielos de New York, Miami y Hollywood, esta última considerada “... generadora de tendencia a través de sus escenografías” (Ruffa, 2013, p. 90), desde donde se expandió a Latinoamérica a través del impacto del cine. Como bien indica Jorge Ramos (1986):

El hecho de que el cine, como productor y vehículo sígnico de difusión de imágenes, se incorpora al sistema del art déco, tuvo una importancia extraordinaria. Podríamos decir que se crea al decollywood, con la imprinta de la desmesura, la superproducción en serie, el fulgor y el exitismo, tan propiamente norteamericanos. Participan de esta industria compleja: los sets y decorados, la publicidad gráfica, la moda, el maquillaje, y los soportes arquitectónicos como las salas de proyección, estudios de producción, casas matrices de la industria, cosmética, etcétera (p. 7).

Ramos (1986) también establece cómo los modelos del art déco circularon en América Latina a través de las revistas especializadas de modas, sociales, de arquitectura y de diseño de interiores, las revistas musicales y las operetas, las empresas internacionales de decoración y las compañías de navegación.

Se asocia la arquitectura art déco a una serie de características formales-geométricas o de composición general- como otras más ornamentales. De manera general estas son: una volumetría asociada a la forma piramidal o escalonada; el uso de aplicaciones de decoraciones “ ... en zig-zag, las espirales, las líneas rectas recortadas, las grecas, las líneas curvas y onduladas, las guirnaldas y en general una geometrización tanto de los estilos académicos conocidos, como una geometrización de motivos naturales y florales" (Cerda Brintrup, 2000, p. 3), además de altorrelieves; y la incorporación de materiales como el acero inoxidable o innovaciones técnicas como las luces de neón.

En Guayaquil tuvo su desarrollo a través del trabajo de arquitectos como Schimanetz, Faggioni, Pérez Nin de Cardona, Maccaferri y Martínez Torres. Un caso especial fue su uso en los cines, principalmente en el tratamiento de las fachadas, donde se buscaba su vinculación con la estética hollywoodense, además de, como indica Ezio Godoli (2008), “... se toma conciencia de que las salas de proyección no podían seguir copiando, debido a sus características funcionales, el modelo dominante hasta entonces que era el de la sala de teatro" (p. 143).

Es de destacar el uso del art déco en la obra de Schimanetz, quien llegó a Guayaquil en 1938, precedido de su prestigio alcanzado como diseñador de teatros y cines en Lima junto con el arquitecto peruano José Álvarez Calderón, para asumir el cargo de Director Técnico de la Compañía Italiana de Construcciones, hasta 1941. Durante ese período proyectó el Edificio Vignolo en 1938, el Edificio Fiore y la Clínica Guayaquil en 1939 y la Sociedad Filantrópica del Guayas en 1940. El edificio Vignolo, con sus siete plantas, se convirtió en el edificio más alto del Ecuador de la época. Su programa se desarrolla en una planta baja con cuatro locales comerciales y seis plantas altas con veintiséis departamentos. Al ser incluido el nombre de Schimanetz en 1943 en la Lista Negra que identificaba a los descen- 


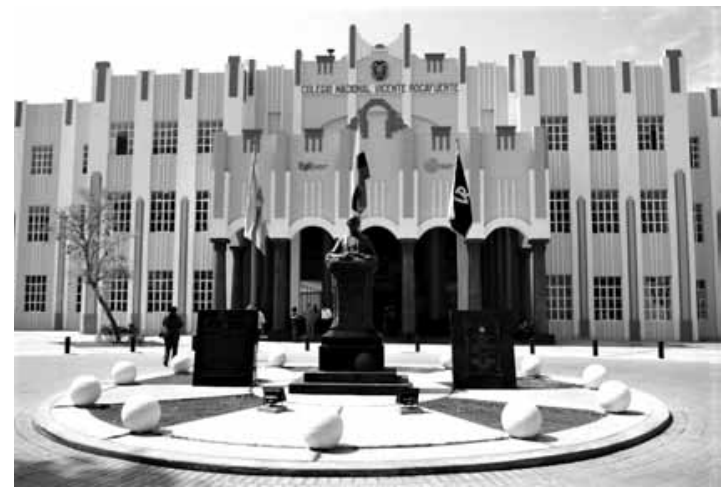

Figura 15.

Figura 15. Colegio Nacional Vicente Rocafuerte, 1937. Figura 16. Monumento a la Aviación Ecuatoriana. Aeropuerto José Joaquín de Olmedo de Guayaquil.

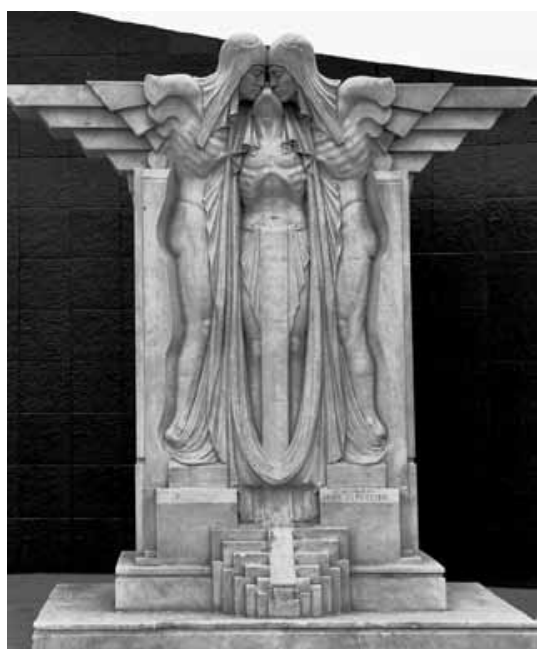

Figura 16.

dientes del Eje, fue llevado a la Isla Taboga y posteriormente al campo de concentración norteamericano de Cristal City, donde permaneció hasta 1946. Posteriormente regresó a Guayaquil donde continuó con su trabajo como arquitecto y constructor.

Otro arquitectos que incursionaron en la arquitectura art déco fue Hugo Faggioni en el proyecto del Colegio Nacional Vicente Rocafuerte de 1937, realizado en colaboración con el italiano Pedro Fontana (Ver Figuras 15 y 16).

El art déco también tuvo su expresión en la arquitectura funeraria, a través del trabajo del italiano Enrico Pacciani. Pacciani, graduado como escultor en la Escuela de Bellas Artes de Génova en 1904, llegó a Guayaquil en 1925 para erigir el monumento funerario de Celeste Castillo y se vinculó desde su llegada en el diseño y ornamentación de algunas iglesias de la ciudad, como María Auxiliadora, San José y Nuestra Señora de la Merced. También tiene ejemplos destacados en la estatuaria pública, como el monumento a la Aviación Ecuatoriana.

Si bien había desarrollado su labor de escultor en los elementos clásicos de algunos edificios de la ciudad y en esculturas públicas, su trabajo más importante se encuentra en el Cementerio General de Guayaquil, con obras como el monumento funerario de Victor Emilio Estrada, los mausoleos de las familias Burbano, Rohde Ortiz, Calero Briones y Valdano Raffo; la Capilla Pérez Perasso, así como numerosas esculturas y lápidas. 


\subsection{La constitución del campo disciplinar de la arquitectura en Guayaquil}

Se ha dicho que ha habido casos en ciudades latinoamericanas donde a mediados de la década de 1920 “... y en una posición periférica dentro del campo" se ubican algunos arquitectos que “... propiciaban un enfoque diferente, más integral y unitario: la expresión formal y la belleza de una obra debía ser el resultado de la respuesta a la función, adaptada al medio, a la época, a los materiales y a la tecnología" (Raffa y Cirvini, 2013, p. 36). Sin embargo, en Guayaquil el surgimiento de la Arquitectura Moderna y la constitución del campo disciplinar de la arquitectura se inician de manera casi simultánea, cuando Francesco Maccaferri fundó en 1929 la primera Escuela de Arquitectura y dos años más tarde diseñaba la primera casa racionalista del país. Esta primera escuela se orientaba hacia el profundo conocimiento de los estilos históricos, aunque como lo indica Silvia Cirvini (2004), esta profesionalización de la actividad arquitectónica, derivada del saber técnico, es un producto neto de la modernidad, en el sentido que Douglas Klegon (1978) define que una profesión “... puede definirse genéricamente como un conjunto cerrado de personas que han adquirido un conocimiento y una destreza certificada que las habilita para una ocupación o para la prestación de servicios (en Serrano, 1994, p. 149). Sin embargo, sus antecedentes deben buscarse en la formación en fundamentos de arquitectura que se dio a los carpinteros a través de la Escuela de Artes y Oficios de la Sociedad Filantrópica del Guayas y de los cursos dictados a los maestros y aprendices en la Sociedad de Carpinteros de Auxilios Mutuos.

La Sociedad Filantrópica del Guayas fue fundada el 21 de noviembre de 1849 por un grupo de artesanos y otros “... dignos ciudadanos, fieles intérpretes de la conciencia popular" (Gómez Iturralde, 2006, p. 30) quienes eligieron como primer presidente a Juan María Martínez Coello, descrito como un "Honrado artesano de oficio carpintero, uno de los más serios y respetados en la sociedad” (Rodríguez, 1926, p. 39). La iniciativa de establecer esa institución fue de Modesto Sánchez Carbo, quien “... se sintió tristemente afectado por la ignorancia del pueblo”, por lo que “... consagró su tiempo y su fortuna a la instrucción popular” (Hidalgo, 2011, p. 15). Sin embargo, no fue hasta 1875, luego de un período de inactividad, cuando se redactaron sus estatutos. Entre los fines que se proponían estaba “... el socorro a la indigencia, la creación y el fomento de establecimientos de educación y beneficencia, la protección a las artes y los oficios” (Gómez Iturralde, 2006, p. 36).

El 21 de enero de 1882, en sesión del Concejo Municipal de Guayaquil se aprobaba la solicitud para que la institución estableciera una escuela de artes y oficios (Gómez Iturralde, 2006), sin embargo tuvieron que pasar ocho años, hasta el 1 de junio de 1890, cuando finalmente se inauguró y orientó su enseñanza a la música, el dibujo lineal, la imprenta, la telegrafía, la carpintería y la encuadernación, aunque más adelante se incluiría también la enseñanza de zapatería (Gómez Iturralde, 2006, p. 54). A comienzos del año siguiente, con motivo de la inauguración del edificio de la nueva escuela, Pedro Pablo Echeverría, uno de los socios de la institución declaraba:

Aquí se forjará, Señores una generación de útiles ciudadanos, aquí vendrá a moralizarse el pueblo, dando forma a la materia, colorido a las ideas de la mente y hablando con los espíritus por medio de ese invento portentoso que se 
llama imprenta. Ya la holganza corruptora no tomará asiento en los hogares y la miseria con su séquito de males huirá de nuestros hermanos. ¿Qué mayor bien, Señores, puede hacerse a la humanidad? (Gómez Iturralde, 2006, p. 59).

Entre las materias que recibían los estudiantes de carpintería que ingresaban estaban algunas orientadas a fortalecer los conocimientos en diferentes técnicas de representación, conocimiento de materiales y fundamentos de la arquitectura, como Topografía Rectilínea, Elementos de Topografía Práctica, Dibujo Lineal y Topográfico, Nociones de Geometría Descriptiva, Estereotomía, Principios sobre la Teoría Estética del Arte Decorativo y conocimiento de sus diversos estilos, Principios del Arte de Construcción, entre otras (Gómez Iturralde, 2006). Para el año 1904 las materias de Geometría y Arquitectura estaban a cargo del Pbro. Marcial Yánez, quien al año siguiente fue reemplazado por Napoleón Veloz, ex alumno de la Institución (Rodríguez, 1926).

En la revista Patria de 1909 se describía de la siguiente manera el ambiente que reinaba en los salones de clase donde se educaba a los jóvenes en el oficio de la carpintería en la Escuela Anzoátegui de Artes y Oficios:

En un taller veremos a los alumnos ejecutar con maestría y facilidad los más difíciles problemas, que la Geometría presenta, y manejar con destreza el compás, el cartabón, el graduador; trazar las molduras rectas y circulares, y todo lo concerniente al orden dórico, jónico, corintio,compuesto (Escuela Anzoátegui de Artes y Oficios, 1909).

El profesor de Geometría y Arquitectura era Santiago García y de Dibujo Nicolás S. Segovia (Compañía "Guía del Ecuador" (edit.), 1909). En las publicaciones de la época se dejaba constancia que

... todos los talleres y clases de esta escuela están perfectamente instalados y provistos de todas las herramientas, útiles e instrumentos necesarios para obtener el mejor resultado en el aprendizaje. Por medio de esta escuela, la Sociedad Filantrópica del Guayas arranca de la indigencia intelectual y material, a todos sus alumnos que aspiran a la adquisición perfectos de los conocimientos de las artes, puesto que no solamente se les da la sufieicente enseñanza, sino que, al terminar sus estudios, junto con el respectivo diploma de Maestros que les entrega el Presidente, reciben del Tesorero, en el mismo acto, una suma de dinero, que representa los ahorros acumulados durante todo el tiempo del aprendizaje (Compañía “Guía del Ecuador” (edit.), 1909, p. 735).

Para 1913 ya se consideraba a la institución una verdadera Universidad Popular, como se la conocía en la ciudad, debido a “... su afán de dar al pueblo la verdadera educación democrática basada en el trabajo" (Escuela Anzoátegui de Artes y Oficios, 1909). En el informe de labores de ese año se daba cuenta de la incorporación de “... 12 carpinteros, 3 mecánicos, 2 tipógrafos y 5 litógrafos" (Rodríguez, 1926, p. 105). 
Un año antes, la Sociedad de Carpinteros de Auxilios Mutuos, que había sido fundada en 1904, empezó a dictar clases nocturnas de aritmética, geometría y arquitectura a sus asociados. En 1914 ampliaba la enseñanza de las mismas materias a los jóvenes que quisieran ingresar al oficio de carpintero en calidad de aprendices (Navas, 1920).

El 15 de septiembre de 1883, mediante decreto expedido por Pedro Carbo, en ese entonces Jefe Supremo de la Provincia del Guayas, se estableció la Universidad de Guayaquil. En el artículo octavo del mismo decreto se definía que debía contar, entre otras profesiones, con la enseñanza de la Ingeniería Civil, que incluiría las materias de "Matemáticas y Trigonometría, Mecánica Teórica y Práctica, Química Experimental, Arquitectura y construcción de puentes, calzadas y ferrocarriles, Parte de Topografía relativa a las nivelaciones, Geodesia y Dibujo arquitectónico y de planos" (Ayón de Messner, 1967, p. 54). En el discurso de instalación de la universidad, Carbo indicaba que iba “... también a enseñarse la Ingeniería Civil, la Agrimensura y la Telegrafía Eléctrica que son tan útiles y provechosas en la vida de los pueblos civilizados" (Ayón de Messner, 1967, p. 63). Sin embargo, a pesar de todo el entusiasmo inicial, solo se abrieron las facultades de jurisprudencia y de medicina (Marín Nieto, 1984).

Unos años más tarde, mediante Decreto Legislativo del 22 de agosto de 1894, se establecía “... una Escuela de Ingeniatura (sic) Civil, Militar y de Minas, que funcionará en el Colegio de San Vicente del Guayas" (Estrada Ycaza, 2000, p. 254), la cual tampoco prosperó. Finalmente, el 29 de mayo de 1897, la Asamblea Constituyente establecía, ahora de manera definitiva, las universidades de Guayaquil y de Cuenca y el 17 de octubre de ese mismo año, en una sesión presidida por el Gobernador de la provincia, se instalaban las autoridades de la nueva institución para dar inicio al curso lectivo de las carreras que hasta ese momento seguían ofreciéndose: Medicina y Jurisprudencia.

A partir de la década de los veinte se iniciaron los congresos académico-profesionales de arquitectura y de urbanismo, que fueron el espacio ideal de contacto entre los arquitectos latinoamericanos. Estos, además del reconocimiento de los nombres y experiencias proyectuales de los profesionales y de las conclusiones sobre las temáticas desarrollas, fueron el lugar de encuentro, de intercambio de ideas y de forjar amistades y relaciones, tal como lo declaraba el delegado de Brasil, Alexandre Albuquerque:

Os congressos (...) têm alta significação moral: unem e estreitam os laços de amizade entre profissionais e das relações sociais e de camaradagem aqui adquiridos, resultam vantagens múltiplas para todos os países da união americana. Estas amizades valem mais, muito mais, que todas as conclusões que forem votadas em as nossas seções plenárias (Faggion Novo, 2016, p. 1386).

Los congresos (...) tienen alta significación moral: unen y fortalecen los lazos de amistad entre profesionales, y las relaciones sociales y de camaradería aquí adquiridas significan múltiples ventajas para todos los países de la unión americana. Estas amistades valen más, mucho más, que todas las conclusiones que fueron votadas en nuestras sesiones plenarias (Traducción del autor).

La primera participación de un arquitecto ecuatoriano en un evento internacional de ese tipo, fue en el Primer Congreso Panamericano de Arquitectos organizado por la Sociedad 
de Arquitectos del Uruguay que se realizó en Montevideo entre el 1 y el 7 de marzo de 1920. Uno de los objetivos del congreso fue el “... contribuir al adelanto de la Arquitectura estimulando los estudios especiales y la cultura artística y científica relacionadas con la profesión de Arquitecto, (...) favorecer la adopción de medidas que dignifiquen la profesión de Arquitecto y crear y mantener vínculos de solidaridad entre las asociaciones de Arquitectos de América fomentando el intercambio intelectual" (Gutiérrez, Tartarini y Stagno, 2007, p. 48). Participaron también en este congreso delegaciones de Argentina, Brasil, Bolivia, Colombia, Cuba, Chile, Estados Unidos, Paraguay y Uruguay.

En este congreso el arquitecto quiteño J. Gualberto Pérez, a pedido de la Sociedad de Ingenieros y Arquitectos del Ecuador, presentó la ponencia Historia de la Arquitectura en la República del Ecuador. En ese trabajo hacía un repaso sobre las características de la arquitectura del país desde el período preincásico hasta la década de 1920 y dedicaba casi la totalidad del texto a ejemplos coloniales y neoclásicos de la ciudad de Quito. Ramón Gutiérrez considera que el trabajo de Pérez no solo era inusual para su época, sino también “... sumamente interesante porque ubica el objeto de su análisis histórico en una perspectiva historiográfica más libre” (Gutiérrez y otros, 2007, p. 10). Respecto al resto del país Pérez afirmaba que “... el arte de construir ha sido, en toda época, el reflejo del de la capital, puesto que para levantar sus edificios han solicitado siempre los proyectos a los arquitectos establecidos en Quito" (Pérez, 1987 [1927], p. 282), al referirse a las ciudades de Ibarra, Latacunga, Ambato, Riobamba y Cuenca, ya que separaba en su análisis a las ciudades de la costa como Guayaquil, Portoviejo, Esmeraldas y Machala donde, según Pérez, “... las construcciones son de madera, y aunque hay muchísimas de buen gusto y que prestan todas las comodidades adecuadas a clima cálido, por su material no tienen todo el valor arquitectónico”. Respecto a Guayaquil resaltaba la existencia de “... buenos edificios de cemento armado", entre los que destacaba “...el Banco del Ecuador, el Banco Comercial y Agrícola, la Plaza del Mercado, la Biblioteca Nacional y varias casas particulares” (p. 282). Se tiene registro de otra participación de arquitectos ecuatorianos en el III Congreso Panamericano de Arquitectos que se celebró en Buenos Aires entre el 1 y el 10 de julio de 1927, aunque no se ha podido establecer el nombre de quienes integraron la delegación (Gutiérrez y otros, 2007). En ese Congreso, que tuvo un carácter marcadamente urbano, se reafirmó también la necesidad de una “... reglamentación profesional, la incorporación de un año de práctica en la arquitectura antes de la graduación, la importancia de los planes reguladores y del Urbanismo como ciencia, la promoción de la vivienda económica por el Estado" (Gutiérrez y otros, 2007, p. 12).

Dos años después del congreso de Buenos Aires, el 5 de abril de 1929, durante el rectorado de Luis Cornejo Gómez de la Universidad de Guayaquil, Francesco Maccaferri creaba la Escuela de Arquitectura. El plan de cinco años de Estudio de esa Escuela, aprobado en sesión de Consejo Universitario del 17 de marzo de 1930, se estructuró de acuerdo a la formación que había recibido su creador, en parte proveniente de tradición del sistema Beaux Arts y otra parte de las politécnicas italianas, es decir orientando su enseñanza hacia el estudio del lenguaje clásico y teniendo como referente, según Héctor Martínez Torres, el tratado de arquitectura de Vignola, pero también con un componente de formación técnica y científica, como era tradición de las escuelas politécnicas italianas como la de Brera, donde Maccaferri había sido alumno. El pensum aprobado constaba de las siguientes materias: 
Primer Año Preparatorio: Dibujo Ornamental de Elementos Arquitectónicos, Dibujo Geométrico de Elementos Constructivos, Teoría de las Sombras, Perspectiva Lineal, Nomenclatura Arquitectónica, Historia de la Arquitectura, Práctica en oficinas y fábricas, Visitas a los trabajos y todas las materias de otras facultades que tengan relación con el curso de Arquitectura.

Segundo Año: Geometría Analítica y Descriptiva, Algebra Superior, Cálculo Diferencial e Integral, Mecánica Analítica, Sísmica, Física, Geología y Mineralogía General, Dibujo Arquitectónico, Construcciones Civiles, Historia de la Arquitectura, Visitas a los trabajos, Nomenclatura Arquitectónica, Práctica en oficinas y fábricas.

Tercer Año: Geometría Aplicada, Mecánica Analítica, Estabilidad de las Construcciones, Grafostática, Física, Sísmica, Mineralogía y Geología Aplicada a las Construcciones, Composición Arquitectónica, Construcciones Civiles, Historia de la Arquitectura, Ortografía, Nomenclatura arquitectónica, Conferencias de carácter artístico y técnico, Práctica en oficina y fábricas, Visitas a los trabajos. Cuarto Año: Perspectiva, Teoría de las Sombras, Estabilidad de las Construcciones, Proyecto Arquitectónico y Constructivo, Construcciones Civiles, Historia de la Arquitectura, Topografía Práctica, Nomenclatura Arquitectónica, Higiene, Contabilidad, Leyes Aplicadas a las Construcciones, Electricidad, Práctica en oficina y fábricas, Visitas a los trabajos, Conferencias de carácter artístico y técnico.

Quinto Año: Perspectiva, Teoría de las Sombras, Estabilidad de las Construcciones, Proyecto Arquitectónico Completo, Construcciones Civiles, Historia de la Arquitectura, Ejercicios Prácticos de Topografía, Higiene, Contabilidad y Leyes Aplicadas a las Construcciones, Práctica en oficina y fábricas, Visitas a los trabajos, Conferencias de carácter artístico y técnico (Acta del Consejo Universitario del 17 de marzo de 1930).

Este conjunto de materias se pueden agrupar en cinco grandes grupos: las de representación artística y arquitectónica, las teóricas, los talleres de diseño y las materias técnicas y científicas y las de ejercicio profesional, de la siguiente manera:

1. Materias de representación artística y arquitectónica: Dibujo Ornamental de Elementos Arquitectónicos, Dibujo Geométrico de Elementos Constructivos, Teoría de las Sombras I, II, III y IV, Perspectiva Lineal, Geometría Analítica y Descriptiva, Dibujo Arquitectónico, Perspectiva I, II y III.

2. Materias teóricas: Historia de la Arquitectura I, II, III, IV y V, Nomenclatura Arquitectónica I, II, III y IV, Higiene I y II, Leyes Aplicadas a las Construcciones I y II, Ortografía, Conferencias de carácter artístico y técnico.

3. Talleres de diseño: Composición Arquitectónica, Proyecto Arquitectónico y Constructivo, Proyecto Arquitectónico Completo.

4. Materias técnicas y científicas: Algebra Superior, Cálculo Diferencial e Integral, Mecánica Analítica, Sísmica, Física, Geología y Mineralogía General, Construcciones Civiles I, II, III y IV, Mecánica Analítica, Estabilidad de las Construcciones I, II y III, Grafostática, 
Física, Sísmica, Mineralogía y Geología Aplicada a las Construcciones, Topografía Práctica, Contabilidad, Electricidad, Ejercicios Prácticos de Topografía.

5. Materias de ejercicio profesional: Práctica en oficinas y fábricas y Visitas a los trabajos.

Como se puede apreciar había un peso muy marcado hacia el manejo de la representación arquitectónica y hacia el conocimiento del comportamiento estructural de las edificaciones y los procesos constructivos que provenían de la enseñanza politécnica. Adicionalmente había otras materias propias del sistema Beaux Arts como Historia de la Arquitectura y las Conferencias de carácter artístico y técnico.

Las clases se iniciaron a mediados de ese mismo año con un solo profesor, el propio Maccaferri, quien dictaba las cátedras de Dibujo Ornamental de Elementos Arquitectónicos, Dibujo Geométrico de Elementos Constructivos, Nomenclatura Arquitectónica e Historia de la Arquitectura y con nueve estudiantes: Héctor Martínez Torres, Pedro Manrique Acevedo, Carlos Manrique, Héctor Manrique Acevedo, Otilia Plaza, Pedro Carbo Medina, Galo Ycaza Valverde, Gabriel Ycaza Valverde y Leopoldo Panchana. Martínez Torres contaba de esta manera lo sucedido ese primer año:

El profesor Maccaferri se dedicó por entero a lo que era su especialidad: la Arquitectura Clásica Griega, con sus cuatro órdenes arquitectónicos. Nos hacía comprar el libro de Vignola, en el que detallaba cada uno de los elementos de estos órdenes. Nuestra tarea consistía en dibujar a escala grande, cada una de las láminas del Vignola, utilizando nuestras cartulinas, reglas T, escuadras, compases, escalímetros, borradores, lápices y tiralíneas que los estudiantes teníamos que llevar todos los días. Como es de suponer, la exactitud y precisión de las complicadas molduras, nos exigía gran esmero y mucho tiempo $(\mathrm{H}$. Martínez Torres, comunicación personal, 24 de agosto de 2005).

Es decir, un proceso de aprendizaje a partir de la imitación y la repetición de los órdenes clásicos, tal como lo explica Ana Cravino (2014):

La noción de imitación o mimesis se encuentra sustentada en dos principios, por un lado la referencia al de origen, y por otro a la tradición. Copiar un modelo al natural o copiar una lámina de un tratado no sólo permitía al alumno adquirir una destreza instrumentar sino también internalizar los principios conceptuales del sistema Beaux Arts, reflexionar sobre la belleza, e iniciarse en la composición (p. 193).

Casi al finalizar ese primer año fueron incorporados como docentes el ingeniero chileno Roberto Espíndola Maldonado, para la materia Algebra Superior, y el venezolano Francisco Manrique para dictar Elementos de Construcción de Obra. Su presencia significó un giro en los estudios hacia las materias técnicas, el cálculo de los edificios y el fortalecimiento de la formación de los estudiantes como constructores. Por su parte Maccaferri quedó a cargo de las materias exclusivamente arquitectónicas. De acuerdo al relato de Martínez Torres: 
Para nosotros, los estudiantes, que en el fondo nos sentíamos algo frustrados porque la Escuela no era lo que esperábamos, la aparición del ingeniero Francisco Manrique fue providencial. Vignola con sus figuritas quedó a un lado, y en su lugar aparecieron Sócrates, Platón y Aristóteles (H. Martínez Torres, comunicación personal, 24 de agosto de 2005).

Al iniciar el segundo año de estudios, en 1931, se habían incorporado algunos cambios al pensum, de acuerdo a sugerencias de Manrique, y quedaron distribuidas las materias de la siguiente manera: Geometría Analítica y Geometría Descriptiva, a cargo de Espíndola, Topografía, dictada por Manrique y Dibujo Arquitectónico, Historia de la Arquitectura y Nomenclatura Arquitectónica, que continuaron dictadas por Maccaferri.

El tercer año, 1932, se inició con la incorporación de un nuevo docente, el ingeniero italiano Arnaldo Ruffilli, quien se desempeñaba como Director Técnico de la Compañía Italiana de Construcciones. Ruffilli se hizo cargo de las cátedras de Estabilidad de las Construcciones y Hormigón Armado. Por su parte, Espíndola había asumido, además, Cálculo Diferencial y Cálculo Integral, que se sumaban a las tres que dictaba en los dos primeros años. Martínez Torres, al respecto, relata lo siguiente:

Allí comenzó el calvario del Ing. Roberto Espíndola Maldonado. Él no era un matemático de profesión. Él había estudiado esas materias treinta años antes, pero en la práctica profesional no se usan. Tuvo que buscar y desempolvar sus viejos libros y ponerse a estudiarlos nuevamente para dictar nuestras clases (...) Como era de suponer, los viejos textos estaban ya algo obsoletos. El Profesor y nosotros nos pusimos a buscar frenéticamente nuevos textos. A veces, en contadas ocasiones, los encontramos en la Librería Janer, la única en la ciudad. Pero, en la mayor parte de los casos, tuvimos que importar de España nuevas obras, porque las que habíamos adquirido no nos satisfacían. Cada cambio de texto significaba otro problema, tanto al profesor, que tenía que revisarlo y estudiarlo para adaptar las clases a un nuevo concepto didáctico, como a nosotros, que teníamos que desandar lo andado, para reiniciar nuestro aprendizaje por otra ruta, lo que nos causaba dificultad y desconcierto (H. Martínez Torres, comunicación personal, 24 de agosto de 2005).

En las otras materias continuaban Manrique que dictaba Elementos de la Ciencia de la Construcción y Maccaferri, que era el único profesor cuya profesión era la arquitectura, a cargo de todas las del área arquitectónica: Composición Arquitectónica, Historia de la Arquitectura y Nomenclatura Arquitectónica.

Al año siguiente, el 2 de junio de 1933, durante el rectorado de Carlos Arroyo del Río y a sugerencia de Manrique, la escuela se subdividió, dando paso a una nueva carrera: Ingeniería Civil, integrándose ambas a la naciente Facultad de Ciencias Matemáticas y Físicas. Las dos carreras se estructuraron con un plan de estudios de tres años de estudios básicos comunes y, posteriormente, dos años específicos para obtener el título de arquitecto o de ingeniero civil. En la invitación que para el acto de instalación de la nueva facultad cursó el rector de la universidad se incluyó el siguiente texto: 
La Universidad de Guayaquil en su deseo de propender al desarrollo de la cultura y de hacer una obra eficiente para la colectividad, acordó la creación de una nueva facultad, que se denominará Facultad de Ciencias Físicas y Matemáticas, y en la cual por lo pronto, se podrá verificar los estudios necesarios para alcanzar los títulos de ingeniero y de arquitecto. Sometida esta iniciativa de la Universidad de Guayaquil al Ministerio de Educación Pública, a quien por ley le corresponde aprobar las resoluciones de las Universidades que crean nuevas facultades, el Ministerio decidió aprobarla. La creación de la nueva Facultad corresponde a una necesidad evidente dentro de las tendencias culturales de la hora presente y dentro de la realidad de nuestro medio (http://iiea. galeon.com/).

Entre los profesores se contaban, además de Maccaferri, con los ingenieros José Antonio Gómez Gault, quien además fue designado Decano, Francisco Manrique, Roberto Espíndola, Arnaldo Ruffilli y al Dr. Cyrano Tama Paz, quienes serían los fundadores. A estos se sumaron el Dr. Luis Espinoza Tamayo, el ingeniero Alejandro Andrade Yánez, para dictar Topografía y reemplazar a Roberto Espíndola en la cátedra de Álgebra, el ingeniero Leonardo Guarderas en Geometría Descriptiva, el ingeniero Ambrosio Puga, además de los alemanes Richard Müller y Wilmhelm Mayer.

De los que originalmente se habían inscrito en la escuela de Maccaferri, apenas sobrevivían cinco, quienes se convirtieron en los alumnos fundadores de la naciente facultad, estos eran Martínez Torres, quien accedió seguir con las dos carreras a la vez, mientras los hermanos Pedro y Héctor Manrique Acevedo -hijos de Francisco Manrique-, Pedro Carbo Medina y Galo Ycaza Valverde, se pasaron a la carrera de ingeniería civil. A estos se incorporaron más adelante, Juan Orrantia González, Alberto Sánchez Cavanna, Nicolás León Pizarro, Hernán de Ycaza Gómez, Eudoro Cevallos de la Jara y José Manuel Albán, en ingeniería civil; y Manuel Gambarrotti Gavilánez, Rafael Rivas Nevárez, Óscar Granja Torres, Marcos Martínez Salazar y Juan Péndola Avegno en arquitectura.

Ya con la nueva facultad y las carreras divididas, se dio inicio al curso académico del año 1933, donde se dictaron como materias específicas de Arquitectura: Perspectiva y Teoría de las Sombras, Proyecto Arquitectónico y Constructivo, Historia de la Arquitectura y Nomenclatura Arquitectónica, a cargo de Maccaferri; y en Ingeniería Civil: Topografía Práctica a cargo de Andrade Yánez, Química porTama Paz, Urbanización y Saneamiento por el Ing. Ambrosio Puga y Electricidad a cargo del Dr. Richard Müller.

En los años siguientes, y dado que Martínez Torres era el único estudiante de arquitectura aunque también seguía la carrera de ingeniería, se dejó a Maccaferri con las únicas materias específicas del área arquitectónica, como Proyecto Arquitectónico Completo e Historia de la Arquitectura, aunque los que siguieron ingeniería recibían también las clases de composición arquitectónica, algo que no le llamaba la atención a Martínez Torres, ya que, según él, los que se graduaban de ingenieros “... también estaban capacitados para diseñar” (H. Martínez Torres, comunicación personal, 24 de agosto de 2005). Sobre esta apreciación de Martínez Torres, Guillermo Cubillo discrepaba totalmente, ya que para él la llegada a Guayaquil de ingenieros, sobre todo en la década de 1920, “... muchos de ellos ingenieros en aguas servidas, alcantarillado, que no tenían la menor idea de Arquitectura” 
desplazó a la arquitectura tradicional e impusieron la construcción de obras “... horrorosas" (Cubillo, 1979, p. 75).

Al respecto, el arquitecto y teórico de la arquitectura Jean Nicolás Durand (1999 [1802]), en su obra Précis des leçons d'architecture données à l'ecole polythechnique, publicada a inicios del siglo XIX, argumentaba a favor de los ingenieros:

Los arquitectos no son los únicos que tienen que construir edificios; los ingenieros de cualquier clase, los oficiales de artillería, etc., experimentan frecuentemente esa obligación; se podría incluso añadir que actualmente los ingenieros tienen más ocasiones de realizar obras que los arquitectos propiamente dichos. En efecto, estos, en el curso de su vida no tienen que construir a menudo más que casas particulares, mientras que los otros, además del mismo tipo de edificios que les puedan ser encargados, igualmente, en las regiones apartadas, donde los arquitectos son muy escasos, se encuentran por su condición llamados a levantar hospitales, prisiones, cuarteles, arsenales, almacenes, puentes, puertos, faros, en fin, una multitud de edificios de máxima importancia; así, los conocimientos y las aptitudes en arquitectura les son por lo menos tan necesarios como a los arquitectos de profesión (p. 25).

Generalmente se pensaba que para ser arquitecto se requería una condición natural o innata, mientras que para la ingeniería se requería de constancia en el aprendizaje, tal como lo describe Silvia Cirvini (2004):

Estas representaciones estaban reforzadas por conceptos que circulaban en la época respecto a las habilidades requeridas en unos y otros: mientras para los arquitectos se hablaba de "talento" o dotes artísticas con las cuales se "nace", para los ingenieros estaba reservada la capacidad para el estudio, la resolución de problemas prácticos a partir del conocimiento científico, tarea que con perseverancia y esfuerzo podía "hacer" o alcanzar cualquier sujeto inteligente. Es decir, "El Arquitecto nace, Ingeniero se hace" (p. 92).

Sobre este debate entre arquitectos e ingenieros, Martínez Torres contaba la siguiente anécdota: un día yo entraba a un restaurante con mi familia y había en una mesa un grupo de personas de donde se levantó el ingeniero Pablo Baquerizo. Así que nos saludamos y me fui a sentar a mi mesa. Después de un rato pasó con su familia un arquitecto joven, apellido Rumbea y me saludó, cuando yo iba a salir se levantó Baquerizo y me dijo ¡Qué gusto de verlo Ingeniero! Entonces Rumbea se levanta también a saludarme y como estaba Baquerizo, dice "Bueno, ahora que estamos aquí reunidos, quiero preguntarle a usted, ¿Qué vale más, un arquitecto o un ingeniero civil?”, entonces le dije “Un ingeniero es el que quiere, un arquitecto es el que puede" (H. Martínez Torres, comunicación personal, 24 de agosto de 2005).

La situación respecto a la formación y al énfasis que en los estudios de arquitectura se ponía a lo técnico sobre lo arquitectónico, empezaba a generar cierto malestar entre los 
alumnos de esa carrera, tal como lo describía Rafael Rivas Nevárez (2013 [1980]), uno de quienes se habían incorporado a estudiar arquitectura:

Un hecho trascendente que demostró la supervivencia de los conceptos clásicos sobre la arquitectura que prevalecían no solamente entre los profesionales, sino en general, en la conciencia social, fue la circulación de libros en español de críticos e historiadores de prestigio. Uno de ellos, Sigfried Giedion en su libro Espacio, tiempo en arquitectura, denunció con acierto y profundidad la situación creada en arquitectura y urbanismo por el incremento de la tecnología. En dicha obra, editada en 1940, justamente en la época que entre nosotros se acentuaba el predominio de la técnica por encima de los valores espirituales (p. 94).

Finalmente, el 19 de abril de 1938, el primer graduado como arquitecto de esa escuela fue Héctor Martínez Torres, quien con su proyecto de Teatro Municipal de Guayaquil, obtuvo también ese mismo día el título de ingeniero civil. Más adelante se fueron incorporando otros egresados quienes según el sistema de estudios, debían acreditar el desarrollo de un proyecto para poder acceder al título de arquitecto, lo cual solía ocurrir a veces años después de haber terminado la carrera. Se consideraba egresados a quienes habían culminado el pensum académico y aún no obtenían su título mientras no desarrollaran un proyecto de fin de carrera. Entre estos primeros graduados estuvieron Rafael Rivas en 1958, Manuel Gambarrotti en 1958, Oscar Granja en 1959, Juan Péndola en 1960, Pablo Graf en 1961 y Félix Henríques en 1964. No fue sino hasta 1970 cuando se graduaron las primeras arquitectas, ellas fueron Josefa Sabando, Clara Luzuriaga, Silvia Pacheco y Lourdes Becerra en la Universidad de Guayaquil (Utreras, 2006) y en ese mismo año, Laura Cordero y Analía Guerrero en la Universidad Católica de Santiago de Guayaquil (Archivo UCSG).

Tendrían que pasar veinte años desde su última participación, para que el Ecuador hiciera presencia en otro Congreso Panamericano de Arquitectos con la participación del quiteño Gustavo Pinto quien asistió al que se celebró en Lima entre el 15 y el 25 de octubre de 1947, al parecer enviado por el Ministerio de Obras Públicas. Al evento, organizado por la Sociedad de Arquitectos del Perú, asistieron además delegaciones de Argentina, Bolivia, Brasil, Colombia, Costa Rica, Cuba, Chile, República Dominicana, Estados Unidos, Guatemala, México, Panamá, Perú, Puerto Rico, Uruguay y Venezuela, además de observadores de España, Francia y Portugal (Gutiérrez y otros, 2007). Se conoce también que a ese congreso asistieron también Rafael Rivas Nevárez, Simón Bolívar Jalón Feraud y Manuel Gambarrotti (Alarcón Orquera, 1968) como delegados de la Asociación Escuela de Ingeniería de la Universidad de Guayaquil. Como elemento innovador, en este congreso se sugirió utilizar el término Arquitectura Contemporánea en lugar de Arquitectura Moderna (Gutiérrez y otros, 2007), ya que se consideraba que lo contemporáneo aludía a “... una voluntad creadora, en marcha, al servicio del bienestar humano" que se obtenía en el equilibrio "de las funciones psico-biológicas del hombre, en el espacio y en el tiempo" (Gutiérrez y otros, 2007, p. 69). También en ese congreso obtuvo Medalla de Oro y Gran Diploma de Honor Guillermo Cubillo por el proyecto de las Escuelas de Artesanos San Felipe y de Minas de la región de La Serena, que había sido realizado durante su trabajo 
como Arquitecto Proyectista del Departamento de Estudios de la Dirección General de Arquitectura del Ministerio de Obras Públicas de Chile (Compte, 2007).

No fue sino hasta años más tarde, el 20 de abril de 1960, durante el rectorado de Antonio Parra Velasco, que esa escuela de arquitectura se independizó de la Facultad de Ciencias Matemáticas y Físicas y se creó con cincuenta y cuatro estudiantes la Facultad de Arquitectura bajo la dirección de Guillermo Cubillo, quien fue designado Decano. A Cubillo se sumaron, como docentes fundadores, los arquitectos Rafael Rivas Nevárez, Oscar Granja, Manuel Gambarrotti, Marcos Martínez Salazar, Xavier Quevedo, René Denís, Rafael Castro Abad, Víctor Leone Di Vanna, Juan Péndola, Héctor Martínez Torres, Enrique Huerta, Alamiro González y Roberto Béjar, además de los ingenieros Raúl Maruri, Arturo Rossi, Carlos Ranaldi, Jorge Núques, Guillermo Castillo, Eduardo Moncayo Mármol, Fabricio Bucco, Luis Rodríguez, Abdón Calderón, Alfonso Loayza y Ludgardo López.

Dos años más tarde, el 17 de mayo de 1962, se fundó la Universidad Católica de Santiago de Guayaquil que contaba, además de las facultades de Jurisprudencia y Filosofía, con la Facultad de Ciencias Físicas y Matemáticas, que comprendía las escuelas de Arquitectura y de Ingeniería, esta última con las carreras de Ingeniería Civil y de Ingeniería Sanitaria (Consejo Universitario de la UCSG, mayo de 1972). Como primer director de la Escuela de Arquitectura fue nombrado el chileno Alamiro González y como subdecano el quiteño Xavier Quevedo. Según González, el programa que fue utilizado provenía del que él había seguido en la Facultad de Arquitectura de la Universidad Católica de Chile (Mera y otros, 1991). Además de González y Quevedo, fueron docentes fundadores el ingeniero Raúl Maruri y los arquitectos Guillermo Cubillo, Roberto Béjar, Rafael Rivas, Enrique Huerta y Marcos Martínez Salazar (Mera y otros, 1991).

De esta manera se fue insertando en la sociedad la imagen de un arquitecto "... liberal, individualista y artista singular, form-giver o creador de un lenguaje personal, que supera los condicionamientos constructivos o las normas o regulaciones de la administración de la ciudad" (Guerra, 2013, p. 28). Un conjunto de profesionales que empezaron a expresarse dentro de las nacientes formas de la Arquitectura Moderna.

\subsection{Francesco Maccaferri, el primer moderno}

Simeone Francesco Maccaferri Colli nació en la pequeña población de Cilavegna, Provincia de Pavia, en la Lombardía italiana, el 18 de febrero de 1897 y falleció en Guayaquil, el 28 de marzo de 1973.

Fue el último de los siete hijos del hogar conformado por el maestro constructor Giovanni Maccaferri y Francesca Colli. Lo habían precedido sus hermanos Battista, Angelo, Antonio, Marietta, Marguerita y Francesca. Recibió los nombres de Simeone, por haber nacido el día en que se conmemora a San Simeón de Jerusalén, y Francesco, en honor a su madre, aunque a lo largo de su vida utilizaría exclusivamente su segundo nombre. Entre los descendientes famosos de su familia se destaca el nombre del pintor Piero Maccaferri Lino -hijo de su hermano Antonio- quien, en la década de 1950 fundó el grupo Sagittario, junto con Ugo Merlo, Fulvio Belmontesi, Giuseppe Franzoso y otros. 
Entre 1914 y 1916 estudió arquitectura en Accademia di Belle Arti di Brera en Milán, institución fundada en 1776 por la emperatriz María Teresa I de Austria. La Escuela Especial de Arquitectura de esa academia, fue establecida por Camilo Boitto en 1897, quien ejerció la dirección hasta 1914. Esa Escuela de Arquitectura fue trasladada en 1931 al Politécnico de Milán. Entre 1917 y 1920 sus estudios fueron interrumpidos luego de ser incorporado al ejército, quien lo trasladó a la colonia italiana de la Abisinia africana -actual Etiopía y Eritrea-. Durante el tiempo de permanencia en el servicio militar fue destacado al departamento de construcciones, desde donde desarrolló diferentes proyectos de arquitectura, como el Palacio de Mando y el Círculo de Oficiales en Senafé, un teatro en Asmara y diseños y construcciones varias en las ciudades de Asmara, Massawa y Senafé, actuales ciudades de Eritrea.

Durante sus años de estudio, tanto en Milán como en Bolonia, Maccaferri colaboró con los ingenieros Caroli y Speranza y con el arquitecto y escultor Aldo Andreani en la ciudad de Mantua, en diferentes proyectos dentro de las líneas clásicas, como un Observatorio Astronómico en la Montaña, la Casa de la Cultura Popular en Milán, el proyecto de una iglesia en Mantua, un Asilo de Mendigos para Caracas, Venezuela y un proyecto de iglesia con refugio alpino en memoria de un capellán muerto en la Primera Guerra Mundial (Aliprandi y Martini, 1933). Adicionalmente diseñó y participó en la construcción de algunos palacios, villas y monumentos en las ciudades de Bari y Bitonto en la región italiana de Apuria (Aliprandi y Martini, 1933).

Luego de haber cumplido su servicio militar, retornó a su país en 1920 y, hasta el año 1921, retomó en la Academia de Brera los estudios de arquitectura que había dejado inconclusos. Esta academia seguía influenciada por los principios de Camillo Boito, que habían sido retomados por sus sucesores, como Gaetano Moretti y Piero Portaluppi, quienes, junto con los milaneses Giovanni Muzio, Emilio Lancia, Gio Ponti, Ottavio Cabiati y Alberto Alpago-Novello, conformaban un grupo que defendía el uso del lenguaje arquitectónico clásico, especialmente el inspirado en la arquitectura lombarda de inicios del siglo XIX, ya que consideraban que representaba la verdadera arquitectura de origen europeo (Benévolo, 1980), en contraparte con la austera Arquitectura Moderna.

Finalmente, el 6 de noviembre de 1922, obtuvo el título de Professore di Disegno Architettonico (Profesor de Dibujo Arquitectónico) conferido por el Regio Istituto di Belle Arti di Bologna-también conocido como Accademia Clementina-, y suscrito por el arquitecto Edoardo Stefano Collamarini, uno de los más importantes de la época de la región EmiliaRomagna. Estos estudios, según las disposiciones italianas de 1923 y 1926, fueron luego equiparados con los de arquitectura impartidos por la Escuela Superior de Arquitectura de Roma, de tal manera que habilitaban el ejercicio profesional.

Luego de la obtención del título de arquitecto, Maccaferri regresó a Milán donde entró a trabajar en el estudio del milanés Piero Portaluppi, quien había sido su maestro en Brera. De Potaluppi conoció la convocatoria del concurso de proyectos para el nuevo Palacio Municipal de Guayaquil, en el que participó y salió ganador. Piero Portaluppi (188-1967) fue posteriormente decano de la Facultad de Arquitectura del Politécnico de Milán -antes Academia de Brera- entre 1939 hasta 1963, de manera casi ininterrumpida. El propio Maccaferri contaba este hecho de la siguiente manera: 
... después de un concurso entre los jóvenes arquitectos, fui preferido y contratado para venir a Guayaquil a trabajar los planos y dirigir la parte artística del Palacio Municipal. El cual proyecto propuesto a la consideración de dicho arquitecto (se refiere a Portaluppi) que me honró sobre manera con su sincera y competente aprobación, publicándose también en revistas italianas (L. Maccaferri, comunicación personal, 7 de julio de 2016).

Este proyecto fue concebido para que desarrollara las actividades administrativas municipales, además de actividades comerciales, por lo que fue diseñado con una galería central, que tomaba como referencia la Galería Vittorio Emmanuel II de Milán, ciudad desde donde se importó la cubierta acristalada del pasaje central construida por la empresa milanesa C. Aiolfi e C.

$\mathrm{Al}$ año siguiente la Compañía Italiana de Construcciones lo contrató para la "dirección y asistencia artística" en la construcción del edificio de la municipalidad, por lo que se trasladó y fijó su residencia en Ecuador. El 31 de julio de 1924 se colocó la primera piedra de la edificación y se dio inicio a la construcción bajo la dirección técnica de los ingenieros Lignarolo y Ruffilli, quienes encargaron la dirección arquitectónica al propio Maccaferri y Paolo Russo. En 1928 se dio por terminada la obra que fue inaugurada al año siguiente, el 27 de febrero de 1929, fecha de conmemoración del Primer Centenario de la Batalla de Tarqui. Una publicación de la época describía al edificio y a la participación de los técnicos italianos en su diseño y construcción, de la siguiente manera:

Como un deber de todo ciudadano amante de la belleza arquitectónica como fundamental principio de la presentación moderna de las ciudades progresistas, no podemos pasar desapercibidos de la importante labor de los personeros del cantón Guayaquil, quienes vienen demostrando real y palpablemente, no solo su amor al terruño, sino también por el buen nombre de ellos que en bien de la colectividad sacrifican las atenciones que deben a sus intereses personales. La obra del Palacio Municipal es el mejor testimonio histórico que dejarán para el futuro. No solo es una casona, por decirlo así, la que se está construyendo, es un Palacio digno de Guayaquil. A este patriótico empeño también se une los profundos conocimientos de los destacados Ingenieros y arquitectos italianos Comm. Domingo L'Abate, Gerente de la Compañía Italiana de Construcciones; Prof. Simeone Maccaferri proyectista y director artístico de los trabajos; y Prof. Paulo Russo arquitecto y director técnico de los trabajos ornamentales; quienes muestran verdadero amor para este terruño que ya no les es extraño, porque en él están radicados. Ellos han puesto el mayor interés en presentar los planos ingeniosamente arreglados para demostrar a las colectividades que son los magos arquitectónicos y que su interés es el mejor embellecimiento de la moderna Guayaquil (El Palacio Municipal, Il Giornale degli italiani, 16 de julio de 1927, s/p).

Su colaboración con esta compañía constructora se mantuvo hasta 1925 en calidad de diseñador y constructor. Durante ese tiempo desarrolló algunos proyectos, como las fa- 


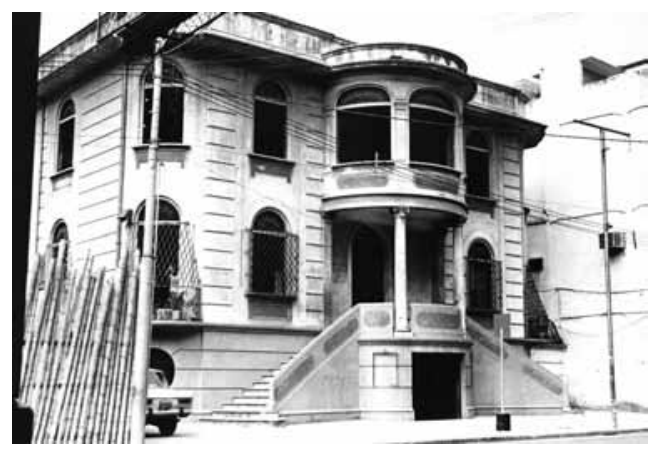

Figura 17. Casa Lisímaco Guzmán Aspiazu, 1935.

chadas, principal y lateral, de la Iglesia San José en 1923 (La nave de la iglesia, con estructura de hormigón armado, había sido construida en 1905 por el ingeniero venezolano Francisco Manrique Pacaníns); el Muelle-Aduana de Guayaquil y los Garajes España en 1924; además de la dirección artística del Palacio del Hospital General -hoy Hospital Luis Vernaza-y el proyecto arquitectónico de la Iglesia del Corazón de Jesús. También colaboró como diseñador en los proyectos de los edificios Víctor Manuel Janer, con el que obtuvo el Primer Premio Municipalidad de Guayaquil del año 1924 y Leopoldo Izquieta Pérez, que obtuvo el Segundo Premio Municipalidad de Guayaquil del año 1924.

En junio de 1925 contrajo matrimonio con la italiana residente en Guayaquil, Bianca Parodi Cerro. Luego de ese acontecimiento regresó a Milán, donde el 13 de abril de 1926 nació su primera hija, Nella. En esa época Milán era el centro de debate ideológico entre las posturas que defendían la continuidad del clasicismo representadas por la asociación Novecento y quienes pensaban que el fascismo italiano podía estar mejor representado por el racionalismo arquitectónico.

En 1927 retornó a Guayaquil y estableció la Oficina técnica y artística de proyectos y construcciones, que se convirtió en el primer estudio de arquitectura que se fundó en la ciudad. Como parte del equipo técnico, trabajaron en su oficina, Héctor Martínez Torres y los ingenieros Rodrigo Perrotta, Pedro Carbo Medina, Leonardo Guarderas, entre otros. Desde su estudio, además, mantuvo la colaboración con la Compañía Italiana de Construcciones en el diseño interior de varios salones del Palacio Municipal, entre 1927 y 1929 (Ver Figura 17).

En el período comprendido entre 1927 y 1938, desde su oficina de diseño, desarrolló diferentes proyectos academicistas, otros eclécticos y algunos dentro del clasicismo moderno, muy en la línea de la visión del grupo Novecento. Dentro del grupo de los proyectos clásicos y eclécticos están la casa para Marcos Plaza, los Servicios Higiénicos Municipales del Parque del Centenario y las Lavanderías y Servicio Higiénicos Municipales de la calle Lorenzo de Garaycoa, en 1927; la casa del Dr. Víctor Palacios y la casa Von Buchwald en 
1928; la casa y garajes de Walter Guzmán Aspiazu entre 1927 y 1929; la casa del Dr. Carlos Coello en 1929; el edificio de la Facultad de Medicina de la Universidad de Guayaquil en 1930; la casa Lisímaco Guzmán Aspiazu en 1935; la Capilla de Nuestra Señora de la Medalla Milagrosa del Hospital Luis Vernaza, en 1935; y el edificio Honorio Cucalón en 1938. En Milán, ciudad a la que retornaba en cada uno de sus viajes, vio de cerca el enfrentamiento conceptual sobre arquitectura que tenían el grupo Novecento, creado en 1922, que cuestionaba al futurismo, y que “... abogaba por una discreta revalorización, quizá algo más populista o menos intelectual, de los elementos de la historicidad clasicista” (Fernández, 2005, p. 363), y el Gruppo 7, nacido en 1926, integrado por Luigi Figini, Guido Frette, Sebastiano Larco, Giuseppe Pagano, Gino Pollini, Carlo Enrico Rava, Giuseppe Terragni y Ubaldo Castagnoli (Benévolo, 1980), quienes defendían una vía italiana al racionalismo como expresión del pensamiento fascista de Mussolini (Fernández, 2005), sin que esto significara una ruptura con la tradición italiana.

En un artículo que el Gruppo 7 suscribió en el año de su fundación en la Rassegna italiana, al que se ha considerado su manifiesto ideológico, se indicaba:

La nueva arquitectura debe ser el resultado de una estrecha adecuación a la lógica, a la racionalidad (...) No pretendemos, en absoluto, crear un estilo, pero a través del empleo constante de la racionalidad, de la perfecta coherencia del edificio con los fines propuestos, estamos seguros de lograr, precisamente por selección, el estilo (...) Es preciso estar convencidos de la necesidad de crear tipos, unos pocos tipos fundamentales (...), es preciso convencerse de que, al menos por ahora, la arquitectura deberá hacerse en parte con renuncias (Gruppo 7, Architettura, en Benévolo, 1980, p. 620).

En 1930 el Gruppo 7 dio lugar al Movimento Italiano per l'Architettura Razionale (MIAR), al cual se adhirieron cuarenta y siete arquitectos de las distintas regiones del país, bajo la consigna de servir a la Revolución Fascista a través de una nueva arquitectura.

Para Leonardo Benévolo (1980) es necesario entender que este debate entre la tradición y la vanguardia que se desarrollaba en la Italia de esa época se daba en el “... aislamiento y la escasez de contactos con Europa” que tenía ese país, además del “... proteccionismo cultural del régimen" (p. 619).

Las primeras obras modernas de Maccaferri corresponden precisamente a esa visión de conservar ciertos elementos compositivos de la tradición italiana, utilizados en un lenguaje moderno. Fue así como fue concebida la casa Icaza Cornejo, diseñada por Maccaferri en 1932 e inaugurada al año siguiente, considerada la primera obra moderna del Ecuador. En la composición simétrica de este proyecto se evidencia la tradición clásica en sus dos largas columnas, sin base ni capitel, que definen el 'piano nobile', con fachadas desprovistas de ornamentación (Ver Figura 18).

En la misma línea de la anterior, esto es como diría Benévolo (1980) en el manejo de un lenguaje "clásico en clave adulterada" son los proyectos que Maccaferri realizó para su familia en 1936 y la casa Parodi, para su suegro, en 1938. De su propia casa realizó un proyecto previo, con capiteles y cornisas, que fue ajustando y simplificando a medida que la crisis económica del país se iba agudizando (Ver Figura 19). 

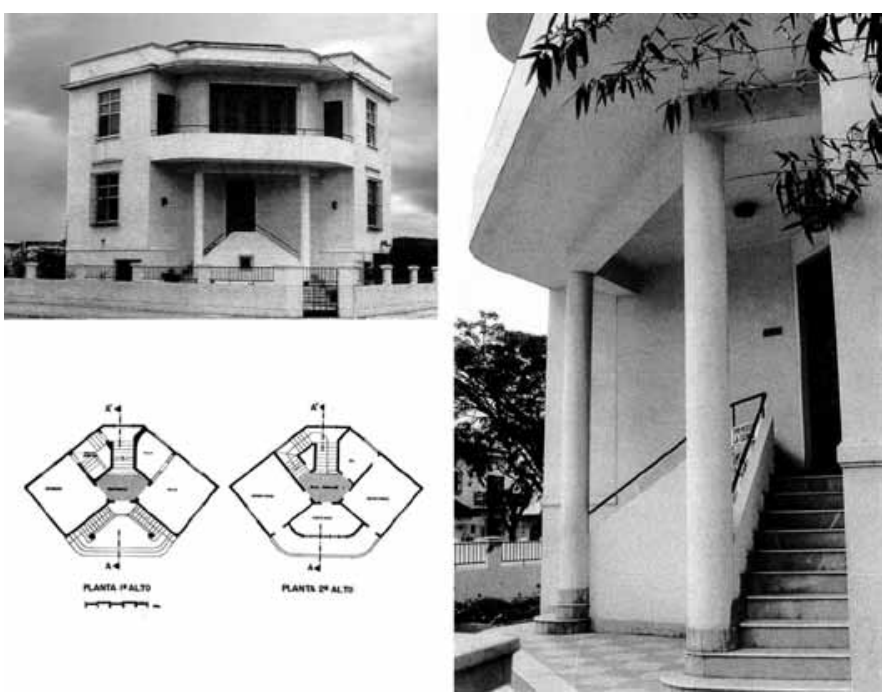

Figura 18.

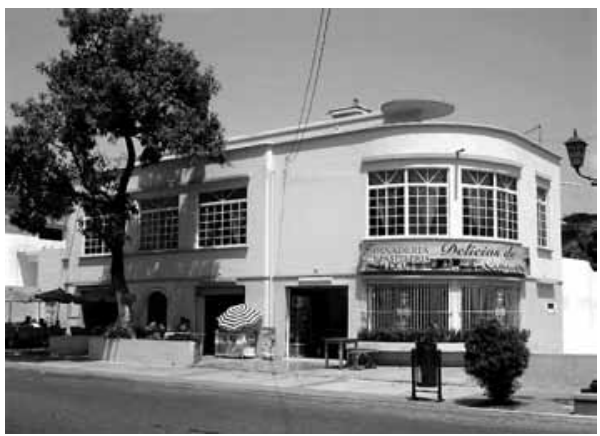

Figura 18. Casa Rodrigo Icaza Cornejo, 1932-1933 (Lee, Compte y Peralta, 1989). Figura 19. Casa Orellana, 1937.

Figura 19.

La casa Orellana de 1937 y la casa Solá de 1938 fueron proyectadas, en cambio, con una composición asimétrica. En la casa Solá con un cuerpo semicilíndrico que se inserta delante del prisma que configura el volumen principal, mientras en la casa Orellana acentuando la esquina con un tratamiento curvo y un remate similar en la cubierta de la terraza (Ver Figura 20).

De su trabajo dentro de líneas modernas están la casa Icaza Cornejo, entre 1932 y 1933, - primer edificio racionalista del país-; la casa Maccaferri en 1936; el edificio Bucaram en 1937; la casa Giovanni Parodi, el edificio Cucalón y el edificio Jouvín, en 1938. Además, 


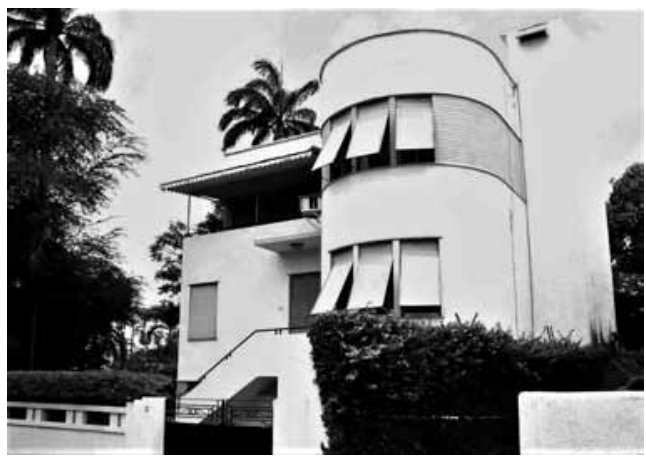

Figura 20. Casa Solá, 1938.

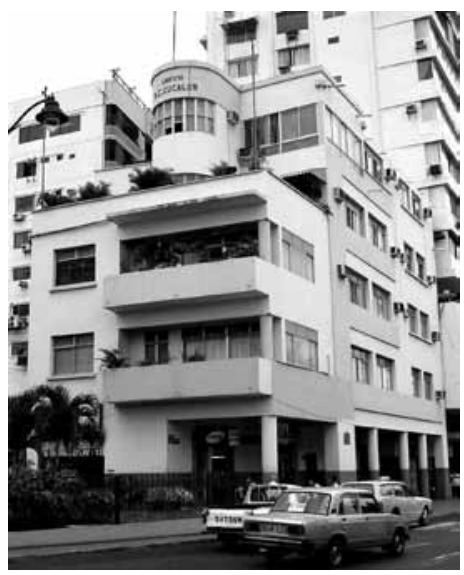

Figura 21. Edificio M. E. Cucalón, 1940.

como parte de su asociación con Eduardo López Proaño para impulsar el desarrollo del Barrio del Centenario, realizó diferentes proyectos como la casa ubicada en El Oro 807, en 1937 y la casa López Proaño, entre 1937 y 1938.

Entre 1929 y 1931 desarrolló su actividad profesional en la población costera de Salinas, donde diseñó y construyó entre otros, las bodegas y dependencia para el Estanco de Sal, entre 1929 y 1931 y la casa Parra en 1930. Un año más tarde, en 1932, la Sociedad Protectora de la Infancia lo convocó para que desarrollara una urbanización aledaña al Barrio del Centenario, en terrenos de su propiedad. Este proyecto contemplaba la edificación de casas de cemento armado de dos plantas en terrenos de alrededor $1.000 \mathrm{~m}^{2}$, sin embargo esta iniciativa no prosperó. También prestó su colaboración como consultor técnico para la Sociedad Constructora Calero y como parte del Comité Ejecutivo para la construcción del edificio del Colegio Nacional Vicente Rocafuerte, en 1935, quien asignó la obra a la Sociedad Técnica Fénix (Aráus, 1991) (Ver Figura 21).

A mediados de 1938 Maccaferri viajó nuevamente a Italia, donde permaneció hasta finales del año siguiente, ya que el 1 de julio de ese año había nacido en Milán su segunda hija, Luciana, por lo que dejó al Ing. Leonardo Guarderas a cargo de su oficina y sus construcciones. Ya para esa época Portaluppi había orientado su trabajo hacia “... proyectos utópicos emparentables por ejemplo con El Lissitzky, tal como el complejo de viviendas y oficinas Hellytown que elabora en 1926" (Fernández, 2005, p. 365) y estaban construidas las obras más emblemáticas de Terragni, como el edificio de viviendas Novocomun de 1928, la Casa del Fascio de 1932 en Como y la casa Rustici, en Milán, de 1933. A su regreso a Guayaquil continuó con su labor de arquitecto y constructor, con proyectos plenamente racionalistas con una clara influencia de los principios del Gruppo 7 en los edificios Andretta, M. E. 
Cucalón, Bucaram, Andretta y la casa Ponce Luque, diseñados entre los años 1940 y 1941. Las nueve de la noche del 13 de mayo de 1942 significó un punto de quiebre en la vida de Maccaferri como arquitecto. Un fuerte terremoto de 7.9 de magnitud Richter afectó la ciudad de (Villacrés, 1999) Guayaquil y ocasionó el derrumbe de varios edificios del área central, entre ellos del edificio Manuel Cucalón, donde funcionaba la Clínica Arreaga Gómez, con el saldo de más de una decena de personas que fallecieron al quedar sepultadas bajos sus escombros. El Diario El Universo (1942, 14 de mayo) que circuló al día siguiente relataba al respecto, lo siguiente:

El más fuerte temblor que Guayaquil haya experimentado en su historia, y que indudablemente, adquirió violencia tal, que la ciudad entera con sus habitantes, y conmovió de terror ante un fin que se creía inevitable, tuvo sus dos horrorosas tragedias en las hermosas y nuevas construcciones de cemento armado que se derrumbaron, como castillos de naipes, sepultando en sus escombros a varias decenas de personas que nunca imaginaron el fin que les esperaba, amparadas precisamente en la clase de construcción que habitaban. (p. 1)

El edificio Cucalón había sido diseñado y asumido su dirección técnica por Maccaferri, por lo que fue señalado como responsable de lo ocurrido. En el mismo Diario El Universo (1942, 14 de mayo) se exigía que se establecieran responsabilidades sobre lo ocurrido de la siguiente manera: "Es muy posible que se quiera explicar técnicamente estos fracasos constructivos, pero Guayaquil entero lo exige y prontamente, pues no establecer responsabilidad en este caso significa que la profesión de ingeniero sigue sometida al más desconcertante empirismo" (p. 1).

Poco después de ocurrido el incidente se presentó ante la Corte Superior de Justicia de Guayaquil, una demanda contra Maccaferri por responsabilidad civil y penal por lo sucedido. Fueron designados peritos los ingenieros Héctor Martínez Torres y Pedro Boloña Rodríguez, quienes habían sido alumnos de quien ahora debían investigar. Martínez Torres narraba de la siguiente manera la situación presentada:

Me llamó el presidente de la Corte Superior de Justicia, el Doctor Alberto Blum Flor y me dijo: 'Se ha presentado una demanda aquí. El señor Cucalón que es el dueño de esa casa que se cayó, demanda al arquitecto Maccaferri por su derrumbamiento. Como tengo que presentar dos árbitros, escogí a usted y al Ingeniero Pedro Boloña que son los mejores y les tengo confianza'. (...) fui a hablar con mi papá y le dije 'Papá, yo me voy a excusar, no voy acepta'. (...) entonces me dijo 'Tú presentaste un juramento al recibir el título de arquitecto, te pusiste la capa y la muceta, asumiste una gran responsabilidad. La responsabilidad tuya era cumplir con tu deber, tú tienes que estudiar eso, ver y dar tu opinión No hacerlo sería una cobardía. Tienes que hacerlo y tienes que afrontarlo'. Entonces acepté y me puse a estudiar con Pedro Boloña (...) Entonces encontrábamos columnas de hormigón armado que estaban destruidas, en polvo todo, no se veía nada, escarbamos restos y encontrábamos pedazos de columnas, pedazos de vigas hechas flecos, los hierros desdoblados, los hierros caídos 
por todos lados, todo hecho como un costal de harina, se hundían las palas, no se veían piedras ni nada, todo era como harina. También veíamos nosotros como las columnas no tenían los estribos.

Se sabe que esos estribos se amarran con una piola o un alambre para que no se muevan, entonces que ocurría, que como seguramente antes no había las aplanadoras, se hacía con un pisón se empujaban entonces cubríamos, los obreros empujaban, y nadie se había fijado en los estribos. El edificio estaba con las columnas partidas, estaban para cualquier lado, entonces lógicamente eso se expande porque ya no puede resistir. Tenían unos hierros de tres octavos, cuando yo en mis obras ponía de 5/8, entonces sabía que era imposible que esas columnas estén así para un edificio de cuatro o cinco pisos.

Llegamos a la conclusión. Fue cuando Pedro me dijo 'tú redacta esto', que yo me quedé pensando porque teníamos veinte días de plazo para presentar eso. Entonces esos veinte días yo me pasé estudiando. Aunque al final no estudié nada por quedarme tomando la decisión. La noche anterior me puse a escribir a máquina, me fui a mi estudio que era en la planta baja, me acuerdo que estaba escribiendo y había como una reja por donde entraba un chiflón de viento que hacía ruido. Entonces empezaban a volarse los papeles y yo los cogía y suspendía el trabajo. Después de cómo una hora que seguí escribiendo entró otro viento y se volaron todos los papeles. Una cosa tan rara que me puse yo nervioso, sentía que del otro mundo me estaban llamando la atención, como que cometía un error. Al día siguiente Pedro pasó a limpio y ahí dejamos.

Al otro día una página entera del Universo con la foto del escándalo que se formó. Primero, 'audacia en los cargos encontrados'; segundo, 'descuido en la construcción', por los anillos que estaban caídos; tercero, 'mala calidad de los materiales'. Así que con cualquiera de las tres razones la casa se caía (H. Martínez Torres, comunicación personal, 24 de agosto de 2005).

Aunque al comienzo se establecieron responsabilidades legales contra Maccaferri, luego se demostró su total inocencia, ya que durante la construcción se encontraba en Italia esperando el nacimiento de su hija, por lo que la dirección de la obra había quedado a cargo de Guarderas. Sin embargo Maccaferri decidió abandonar la profesión y la docencia. No fue sino años más tarde, el 29 de octubre de 1958, cuando retomó la labor académica al ser invitado a formar parte, como uno de los once profesores fundadores, de la Escuela Superior Politécnica del Litoral, para dictar la materia de Dibujo Técnico.

Sin lugar a duda, Francesco Maccaferri es el arquitecto más destacado de Guayaquil de la primera mitad del siglo XX, tanto por la amplitud y calidad de su obra, como por su diversidad compositiva, que van desde el uso del lenguaje clásico, el art nouveau, hasta el lenguaje moderno, del que fue pionero en la ciudad, además de su fundamental aporte en el desarrollo de la arquitectura como actividad académica. 


\subsection{La vivienda de interés social}

La creación de organismos públicos en Latinoamérica orientados a la producción de vivienda surgió de manera desigual en cada uno de los países. En Argentina, por ejemplo, se creó en 1915 la Comisión Nacional de Casas Baratas; en México, en 1938, como una de las prestaciones de la Dirección General de Pensiones Civiles y de Retiro; en Venezuela, en 1928, con la fundación del Banco Obrero. Sin embargo no fue hasta luego de la Segunda Guerra Mundial, que agudizó la crisis económica e incrementó los procesos de migración del campo a la ciudad, cuando se dio una nueva etapa de intervención directa de los estados sobre el tema de la vivienda con el desarrollo de programas masivos de vivienda para obreros y empleados, aunque en la práctica los grandes beneficiados fueron los sectores medios de la población (Pradilla, 1983).

En Ecuador no fue sino hasta el 13 de marzo de 1928, bajo el principio de caridad pública, que se creó la Caja de Pensiones como entidad aseguradora, con el objetivo de "conceder favores" a los empleados públicos, civiles y militares, los beneficios de jubilación, montepío civil, retiro militar y fondo mortuorio. Esta institución también se orientó a la solución del problema habitacional en el país, primero a través de préstamos para la adquisición de vivienda, y luego involucrándose directamente en la planificación y construcción de proyectos (Alcívar y otros, 1980).

Siete años más tarde, se expidió la Ley de Seguro Social Obligatorio, que renunció al principio de caridad, y se creó el Instituto Nacional de Previsión, con la finalidad de establecer la práctica del seguro social obligatorio, fomentar el seguro voluntario y ejercer el patronato del indio y del montubio (Espinoza, 2011).

Uno de los primeros proyectos desarrollado por la Caja de Pensiones a partir de 1938, fue la ciudadela Simón Bolívar en Quito, con doscientas diecisiete viviendas unifamiliares destinadas a la clase media (Ortiz Crespo, 2004).

La respuesta al déficit de vivienda en Guayaquil se inició a finales de la década de 1930, primero con la construcción de barrios obreros y luego, en la década siguiente, con bloques de vivienda multifamiliares. Sin embargo, estos proyectos aislados no formaban parte de una planificación integral ni coordinada entre la administración central y local, además de que se cuestionaba que los proyectos no estuvieran acordes con la realidad local, tanto cultural como climática, tal como lo analizaba Rafael Rivas Nevárez en un artículo publicado a finales de la década de 1940:

La vivienda en una comunidad compleja como la nuestra reúne un juego coordinado de soluciones que no pueden tener una fórmula única o patrón aún cuando estas hayan sido probadas en el exterior y dado resultados en otras partes del mundo. La vivienda de Guayaquil debe resolverse analizando el problema nuestro con soluciones nuestras, empleando por cierto, todos los aportes técnicos que podamos recibir o tomar de otras partes más desarrolladas. (...) El problema de la vivienda ha sido materia de preocupación de nuestro país y de casi todos los países de latinoamérica con similares inquietudes. En varias ocasiones, las cajas de pensión, que con su Instituto de Previsión, ha levantado verdaderos barrios de casitas que ha entregado para el uso de sus afiliados. La 
iniciativa privada de igual mener, en varias ocasiones, han emprendido en el negocio de realizar lotizaciones, urbanizaciones, $y$ ha procedido a la construcción de casas económicas con facilidad de venta, pero con todo esto seguimos con el mismo problema (Rivas Nevárez, 2013, pp. 51-52).

En el Primer Congreso Panamericano de la Vivienda Popular que se celebró en Buenos Aires en octubre de 1939, en el que participó una delegación del Ecuador junto con representantes de Bolivia, Brasil, Colombia, Costa Rica, Chile, El Salvador, Estados Unidos, Guatemala, Haití, Honduras, Nicaragua, México, Panamá, Paraguay, Perú, Uruguay y Venezuela, se analizó el problema de la vivienda, tanto desde lo conceptual como desde lo práctico, además de consideraciones acerca “... de los ingresos de las familias trabajadoras para acceder a una vivienda económica, sobre el papel de los bancos hipotecarios, las cooperativas y las cajas de ahorro, sobre la construcción por acción combinada del estado con el capital privado" (Gutiérrez y otros, 2007, p. 18).

Una de las dificultades con las que encontró el congreso fue la definición de la propia idea de lo popular asociado a la vivienda, por lo que en las conclusiones correspondientes a los Aspectos Sociales, la Comisión Tercera iniciaba: "Que quede a la apreciación de los Estados, el definir el concepto de vivienda popular en sus respectivos países" (citado en Lecuona, 2001), aunque en la mayoría de los países americanos se prefirió usar el término vivienda económica o de interés social. Se concluyó también que el problema de la vivienda popular era parte de un conjunto de problemas sociales entre los que estaban la previsión social, la educación, entre otros; se estableció también que era necesaria una intervención reguladora por parte del Estado con planes de vivienda integrados a planes reguladores regionales o nacionales; se enfatizaba la necesidad de construcción de viviendas individuales o colectivas con la mayor independencia para cada familia (Zonzottera, 2011); y se sugería la conveniencia de crear institutos de vivienda popular en cada uno de los países de América y un Comité Interamericano de la Vivienda Popular, con el fin de intercambiar experiencias que se fueran generando en cada uno de los países adherentes (Herrán, 1939).

Una conclusión adicional fue el de establecer una superficie de $85 \mathrm{~m}^{2}$ para una unidad de vivienda individual, aunque sin definir los ambientes o número de habitantes previstos en dicha unidad (Lecuona, 2001). Este concepto de vivienda mínima era compatible con la visión de los primeros teóricos de la Arquitectura Moderna, quienes querían compatibilizar las actividades propias de habitar con una superficie ideal donde se desarrollaran. Por lo general se asociaba la idea de un espacio mínimo en el diseño de viviendas colectivas, mientras las unidades mayores eran concebidas para familias que pudieran desarrollarse en viviendas individuales que conformaban barrios con un mínimo de servicios y espacios públicos.

En Guayaquil, el proyecto de reforma urbana para la celebración del primer centenario de independencia de la ciudad en 1920 elaborado por Luis Alberto Carbo y Francisco Manrique, contemplaba la creación de un Barrio Obrero hacia el suroeste, apartado del "aristocrático" centro, que ocupaba un área de setenta y un manzanas. El diseño del barrio, de trazado rectangular, se desarrollaba alrededor de una plaza central de seis manzanas de extensión a la que se denominaba Plaza del Trabajo, además de un gran Parque Municipal, 
aledaño al Barrio Obrero, que abarcaba un área de ochenta y cuatro manzanas, con una laguna artificial y columnas esbeltas con motivos clasicistas, al que se ingresaba a través de un gran arco de triunfo. La idea de incorporar un barrio obrero habría respondido a la presión social de los trabajadores, que se habían fortalecido en el contexto de la Revolución Liberal que impulsó la organización popular en organizaciones gremiales, como la Sociedad Hijos del Trabajo en 1896 y la Confederación Obrera del Guayas en 1905. Aunque el proyecto del Barrio Obrero siguió estando presente en los planes municipales por muchos años, nunca se lo llegó a concretar, mientras el Parque Municipal -luego denominado Parque Forestal- fue construido con un área muy inferior a la que Carbo y Manrique habían concebido.

En la década de 1930 se inició un largo período de crisis económica que sobrevino con la estrepitosa caída de los precios del cacao en el mercado internacional. Como consecuencia se aceleró la migración del campo a la ciudad, que experimentó acelerados procesos de urbanización. De esta época es el surgimiento de los primeros asentamientos marginales en sectores periféricos, invadidos y sin servicios, como los llamados Barrios Suburbanos hacia el oeste o el barrio Garay en el sector de la Isla San José en 1938, con viviendas construidas con materiales precarios, y también de la tugurización del área central, mientras las clases más acomodadas se instalaban en zonas aledañas al centro. Rojas y Villavicencio (1988) identifican dos tipos de soluciones para el problema habitacional que se generó a raíz de la migración desde el campo a la ciudad de Guayaquil.

... la primera ofrecida por la propia burguesía y ciertos estratos medios, consiste en aprovechar sus propias casas de habitación subdividiéndolas indiscriminadamente para alquilarla a los recién llegados, lo que da inicio a la formación del "tugurio central" de Guayaquil. (...) La segunda alternativa surge de los propios inmigrantes que ante la imposibilidad de afrontar los elevados alquileres, empiezan a desplazarse hacia el suroeste de la ciudad. (...) Este proceso de asentamiento se realiza en terrenos municipales que por sus características (manglares inundables) poseían renta nula (p. 78).

En 1936 la Caja de Pensiones inició el desarrollo de un barrio para empleados en un terreno de ciento treinta mil metros cuadrados comprado a la Municipalidad en el límite oeste de la ciudad, aledaño al Estero Salado, que años antes había sido rellenado con el fin de urbanizarlo y dedicarlo a zona residencial (Hoyos, 2015). Esto fue el inicio del primer asentamiento planificado de la ciudad, fuera del área central, que se concretó finalmente en la década de los cuarenta, conformado por casas unifamiliares adosadas de una planta con cerramiento exterior y sin soportal. Cinco años más tarde, en 1941, se concluían los trabajos de un muro de ribera hacia el estero que permitiría contar con un malecón perimetral. Al año siguiente se convocaba a licitación la construcción de ciento cincuenta y seis viviendas de cuatro modelos diferentes; sin embargo, la crisis económica paralizó el proyecto y no fue sino hasta 1945 cuando la Municipalidad aprobó el anteproyecto del que se denominó Barrio de Empleados Municipales y expidió una ordenanza especial que, entre otros aspectos, establecía 
... la exigencia del uso de material incombustible que asegure la higiene y salubridad; dimensión de solares de hasta $200 \mathrm{~m}^{2}$ que dé el espacio suficiente para patio y área de jardín; la venta se haría a los empleados del Municipio, preferentemente a aquellos que no tengan casa propia con un plazo de hasta 30 años y por el sistema de amortización; los empleados no podrán, una vez compradas las casas, venderlas a terceros en un plazo de cinco años previa autorización del Concejo; el compromiso por parte de la Municipalidad de licitar los materiales y a aquellos que se iban a importar, solicitar que se liberen de derechos (Ordenanza del Barrio de Empleados Municipales, 16 de enero de 1945).

Finalmente, a partir de 1946 las empresas ganadoras de la licitación para la construcción de las viviendas empezaron a entregar las primeras casas a los adjudicatarios. Estas eran la Compañía Constructora Huancavilca a quien se adjudicó ciento veinte casas y la sociedad Perrotta-Andrade, de los ingenieros Rodrigo Perrotta y Alejandro Andrade Yánez, encargada de las restantes treinta y seis (Hoyos, 2015). En 1947 se contrató a la compañía Antonio Granda Centeno la construcción de ciento veinte casas que fueron concluidas en los siguientes años.

Se identifican en el barrio con tres tipologías de vivienda con antejardín, cerramiento frontal y patio posterior, con dos variantes cada una, que corresponde a si su cubierta es plana o inclinada. Su distribución interior se desarrolla a partir de un corredor, eje central de distribución espacial, hacia donde converge el área de servicios-cocina y dormitorio de servicio-, el área social -sala y comedor-y el área íntima -dos o tres dormitorios y un baño- (Peralta, 2009).

El desarrollo de este barrio al que a partir de 1947 pasó a llamarse Ciudadela Francisco de Orellana, y que no fue concluido hasta 1952 (Hoyos, 2015), significó que, junto con la crisis económica y la concepción moderna de la ciudad, se eliminara el soportal que era el elemento que vincula lo público de la calle con lo privado de la vivienda y que estas viviendas se replegaran hacia el interior.

Otros programas habitacionales orientados a sectores medios, fueron desarrollados por la Caja del Seguro de Empleados Privados y Obreros, creada en 1937, concebidos como unidades vecinales, como el Barrio Grace, destinado para albergar a las familias de los empleados de la compañía norteamericana Grace Line (Compte, Lee y Peralta, 1991), con treinta unidades de una planta con retiros laterales, antejardín y jardín posterior, entre 1939 y 1942; el Barrio Norte con treinta unidades, en 1942; el Pasaje 28 de mayo con treinta unidades adosadas de dos plantas entre 1938 y 1945; y el Barrio Venezuela con cuarenta unidades, entre 1946 y 1952 (Villavicencio, 1989).

En 1946 el departamento técnico de la Caja del Seguro planificó un nuevo barrio para obreros y empleados al que denominó Barrio Obrero o del Seguro, que fue concluido en 1952 (Villavicencio, 1989). Este programa constaba de 641 viviendas adosadas de dos y tres dormitorios de cuatro modelos diferentes, construidas en solares que iban desde los 84 a los 300 metros cuadrados.

La introducción en el país del concepto de casas colectivas de departamentos vino de la mano de Héctor Martínez Torres, quien en el año 1944 viajó becado a Londres donde realizó estudios de postgrado en la especialización de Urbanismo y Planificación Urbana 


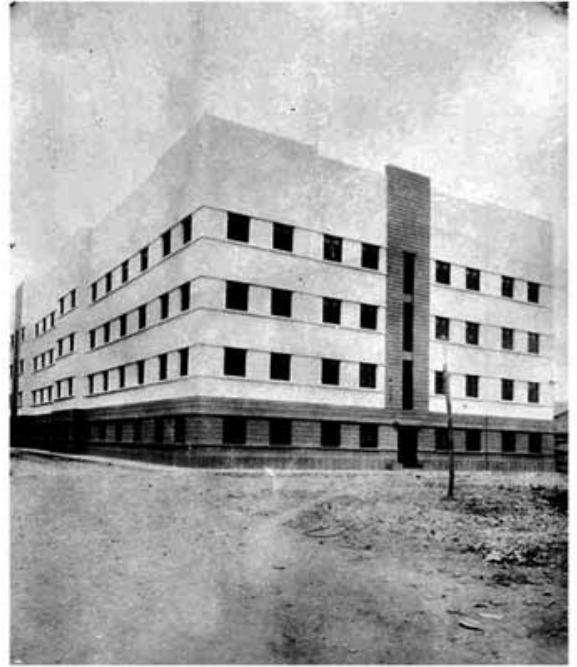

Figura 22. Casas

Colectivas. Archivo

Nacional de Fotografía.

(Compte, 2007). A su regreso a Guayaquil, en 1945, presentó el proyecto de las Casas Colectivas, concebido bajo la idea de otorgar vivienda en alquiler a los sectores más pobres de la población que no tenían recursos para adquirir una casa. El propio Martínez Torres consideraba que el Estado debía construir viviendas “... funcionales, elementales, higiénicas, técnicamente hechas y humanitariamente concebidas” y que debían ser entregadas al pueblo “... en arriendo a precio de costo más el mantenimiento" (Mera, Wong y Yu, 1991, p. 113).

La idea central de una vivienda colectiva es la de estandarizar y compactar los espacios que son destinados a usuarios anónimos tipo. Esta compactación, tal como lo indica Liernur (2014), no hubiera sido posible “... de no mediar importantes transformaciones culturales que permitieron admitir como aceptable e incluso deseable el desarrollo de la vida doméstica en ámbitos de unas dimensiones relativamente más pequeñas, limitación que en etapas anteriores solo era atributo de pobreza" (p. 549).

Las Casas Colectivas, terminadas en 1950, constan de dos bloques de cuatro plantas cada uno separados por una calle peatonal. Cada uno de los bloques tiene 78 unidades de habitación, entre monoambientes y departamentos, de uno o dos dormitorios con un área de construcción que oscila entre $16,5 \mathrm{~m}^{2}$ y $44 \mathrm{~m}^{2}$, desarrollados alrededor de cuatro patios interiores, con un total de 156 unidades de vivienda (Ver Figura 22).

Aunque Anahí Ballent define que una casa colectiva se caracteriza porque introduce espacios de uso e interés colectivo, tratando de explotar “... los beneficios de la vida doméstica intentando promover cierto sentido comunitario entre sus habitantes” (Ballent, 2014, p. 463), lo cierto es que en el proyecto de Martínez Torres lo único comunitario son los pa- 
tios interiores usados para el lavado de la ropa, además de la calle entre los bloques que es utilizada como cancha deportiva.

La modernidad arquitectónica tuvo diversas expresiones en la arquitectura de Guayaquil, desde las propuestas eclécticas y pintoresquistas, pasando por el art déco y el neocolonial hasta las propiamente racionalistas. Cada una de ellas era moderna en la medida en que eran no clásicas.

Si bien no hubo un proceso de reflexión que llevó al desarrollo de la Arquitectura Moderna y aunque esta surgió como una respuesta a las condiciones económicas del momento, tampoco se trataba de propuestas epidérmicas ya que en realidad habían surgido enmarcadas en los debates que sobre la modernidad se gestaba en Europa y por arquitectos formados en la primera escuela de arquitectura de la ciudad, cuyo inicio se dio a la par de la naciente modernidad arquitectónica y en la que jugó un papel destacado, como maestro, Francesco Maccaferri.

\section{Conclusiones}

Aún quedan muchos vacíos en las historias oficiales de la modernidad arquitectónica de Latinoamérica, sobre todo en países como el Ecuador donde no ha existido una tradición historiográfica y el papel de la crítica ha sido marginal. A pesar de la importante bibliografía sobre la arquitectura colonial ecuatoriana, principalmente quiteña, es poco lo que se conoce sobre la arquitectura de otros períodos históricos y menos aún sobre la Arquitectura Moderna del país.

Abordar el proceso de conformación de la Arquitectura Moderna de Guayaquil ha sido el objetivo del presente trabajo de investigación. Su estudio ha requerido que sea realizado desde visiones menos dogmáticas donde ha sido necesario superar la concepción de la Arquitectura Moderna como estilo, ampliar la restrictiva mirada de la tradición disciplinar y prestar más atención a las circunstancias sociales, económicas, culturales, tecnológicas, políticas, etc. en que la modernidad surgió.

Ha sido necesario, también, superar la dificultad que existe en definir a la arquitectura de Guayaquil como moderna, al tomar en consideración las variaciones en cuanto al propio significado del término moderno y a la amplitud y heterogeneidad de la producción arquitectónica del período de estudio. Por lo que fue necesario entender que esta arquitectura se dio en una íntima relación con la historia del país y de la ciudad, que fue precedida por cambios económicos, sociales, culturales y un nuevo ordenamiento de la ciudad, y que se expresó en la libre adopción de tradiciones espaciales así como en el manejo novedoso de la tecnología.

El análisis partió desde el cuestionamiento al concepto de modernidad y a la concepción de la Arquitectura Moderno como estilo. En primer lugar, se tomó como referente la concepción de modernidad del colectivo Modernidad/Colonialidad, para quienes esta se inició con el descubrimiento de América, tanto en lo ideológico como en lo económico, que devino en la emergencia y expansión del circuito comercial del Atlántico y que, en tanto impuesta en nuestro continente, su implantación fue tardía e incompleta. En segundo lugar, 
desde la superación de la Arquitectura Moderna como estilo, para abordarla desde el análisis discursivo, que contemple las diferentes posturas individuales y prácticas formales. Para la arquitectura, la modernidad significó cambios en los procesos de diseño, la incorporación de nuevos materiales de construcción, nuevos procesos constructivos y códigos estéticos revolucionarios. En este contexto, el análisis de la modernidad arquitectónica se hizo desde ese conjunto de variables, además de su relación con las dimensiones económica, social, política y cultural, la constitución del campo disciplinar y la profesión de arquitecto, el desarrollo de programas de vivienda social, la conformación de las organizaciones corporativas y gremiales y el desarrollo del habitus vinculado a la formación académica. Esta investigación puso en cuestionamiento dos paradigmas hasta el momento vigentes. El primero, que la modernidad es, desde una visión eurocéntrica, una línea continua que va desde la antigüedad hasta nuestros días, por lo que en América Latina se habría expresado en un desarrollo tardío, reflejo de ese pensamiento de la centralidad europea, donde el sur de nuestro continente ha sido siempre solo, pasiva y tardíamente, receptor de la modernidad. El segundo paradigma en cuestionamiento fue que la arquitectura moderna es un "estilo", entendido según la tradición de Heinrich Wölffing y otros historiadores del arte como la aproximación a unas convenciones artísticas, materiales y técnicas desde las que emergió, de manera más o menos estable, un patrón formal. El abordaje metodológico partió de la superación de esos dos preconceptos, el de modernidad y el de considerar a la Arquitectura Moderna un estilo. El primero, se enmarca en la comprensión de que la modernidad es una construcción teórica más que histórica. El superar el segundo preconcepto sobre la Arquitectura Moderna, pasó de abordarla como "estilo" -entendido como un paradigma kunhiano que, por sus anomalías requiere sustitución- para abordarla como un discurso, dentro de las condiciones culturales, políticas, sociales, tecnológicas y económicas de la modernidad. Las conclusiones de la investigación permiten ratificar la validez del abordaje metodológico.

El problema de investigación tuvo un abordaje tanto histórico como historiográfico. Para el abordaje histórico se identificaron el conjunto de edificios que pertenecen al período establecido; por su parte, el abordaje historiográfico partió, primero, de la idea de modernidad asumida más como una construcción histórica que como una categoría teórica; y, segundo, de la comprensión de que la arquitectura no solo debe ser considerada como parte de la sociedad, sino también como una praxis social en una íntima relación con la historia del país y de la ciudad, donde el conocimiento de los cambios sociales, económicos, políticos, tecnológicos y culturales ayudarán a comprender las transformaciones en el entorno construido y, a su vez, los cambios en la arquitectura permitirán hacer una lectura de la sociedad, por lo que el objeto de la historia de la arquitectura, en tanto rama específica de la ciencia histórica, es el estudio de las ideas, de las condiciones materiales y socioculturales, de los procesos de concepción y materialización del hecho arquitectónico y de sus repercusiones sociales, culturales y económicas.

Respecto a la hipótesis inicial, esto es de que la Arquitectura Moderna en Guayaquil surgió tempranamente a inicios de la década de 1930 a la par de países como Argentina, Brasil, Chile, Uruguay o México, pudo ser corroborada. Este proceso hay que entenderlo, primero, por las marcadas diferencias entre Guayaquil y Quito o de otras ciudades de la sierra central ecuatoriana, donde el peso de lo colonial si retrasó el surgimiento de una arquitec- 
tura moderna hasta al menos la década de 1940; y, segundo, por la coyuntura de la crisis económica de finales de la década de 1920.

A lo largo de la historia Quito y Guayaquil fueron ciudades muy diferentes, tanto en su proceso histórico como en lo cultural. La primera, conservadora, con una alta población indígena ligada a labores agrícolas y textiles, mientras que la segunda, que sustentó su desarrollo en actividades comerciales, portuarias y de construcción artesanal de barcos, y ya desde el siglo XIX a la agroexportación, siempre fue más cosmopolita y liberal.

En cuanto a la arquitectura, la profunda crisis económica que se prolongó por casi dos décadas, determinó la necesidad de abandonar los costosos ornamentos y adherirse a los principios y formas de la modernidad arquitectónica, de manera más estratégica que ideológica, que se expresó en la simplificación del proyecto arquitectónico, en la forma de los edificios, la racionalización de los espacios interiores y en el abaratamiento de los costos de construcción.

La presente investigación sobre los inicios de la Arquitectura Moderna en Guayaquil permite arribar a las siguientes conclusiones:

Primero, a partir de 1860 con la llegada al poder del conservador Gabriel García Moreno, luego con regímenes liberales y en otros más o menos progresistas que gobernaron al país hasta finales de la década de 1940, estuvo presente un proyecto que tuvo como base económica al capitalismo y como fin la incorporación del país a la modernidad.

Segundo, el Gran Incendio de octubre de 1896, no solo truncó muchos de los procesos de modernización que se habían iniciado años antes, sino también obligó a replantear el desarrollo de Guayaquil. La reconstrucción de la ciudad, de la mano de arquitectos y técnicos europeos, y la constitución de compañías constructoras, que incorporaron la tecnificación y el mejoramiento de procesos constructivos, empezaron a modificar la manera tradicional de edificar. El cemento como material de construcción y el hormigón armado como sistema constructivo, fueron fácilmente aceptados como distintivos de la modernidad, al ser considerados más efectivos para evitar la propagación del fuego y porque posibilitaban un mejor control higiénico. Por su parte, las ordenanzas y normativas urbanas, apuntalaron el sistema de construcción en hormigón armado en detrimento de la tradicional construcción en madera, además de que restringieron la participación de los carpinteros en las actividades de edificación y promovieron en cambio la actividad regulada de los ingenieros y los arquitectos.

Tercero, la disminución de la producción cacaotera, entre 1917 y 1926, sumada a la baja del precio de ese producto en el mercado internacional a partir de 1929, determinó que se afectara seriamente la economía ecuatoriana y se diera inicio a un proceso de profunda inestabilidad política y social que perduraría por varias décadas, por lo que muchos procesos de modernización quedaron inconclusos y se agudizaron aún más las contradicciones sociales del país.

Cuarto, los congresos académico-profesionales de arquitectura y de urbanismo fueron el espacio ideal de debate de cómo afrontar la arquitectura del momento, el lugar de dar reconocimiento a los nombres y a las experiencias proyectuales de quienes desarrollaban su práctica profesional en Latinoamérica de esos años, además del lugar de contacto, de intercambio de ideas y de forjar amistades y relaciones. 
Quinto, en Guayaquil el surgimiento de la Arquitectura Moderna y la profesionalización de la actividad arquitectónica - un producto neto de la modernidad- se iniciaron de manera casi simultánea, cuando Francesco Maccaferri fundó en 1929 la primera Escuela de Arquitectura y dos años más tarde diseñaba la primera casa racionalista del país.

Sexto, el Palacio Municipal, inaugurado en 1929 a la par de la agudización de la crisis económica, fue el más importante y último edificio público academicista de la ciudad. En las dos décadas siguientes la tendencia se dio hacia la racionalización de los espacios, la simplificación de las formas, la eliminación de los ornamentos y la adopción de códigos formales modernos y otras propuestas, dentro del amplio espectro de la modernidad arquitectónica en la medida que no eran clásicas, que iban desde el eclecticismo, neogótico, neocoloniales, pintoresquistas, art déco y art nouveau. Ya para la década de 1950, junto con la recuperación económica y de la estabilidad política del país, se consolidaron las propuestas modernas y se empezó a modificar el área central de la ciudad con la incorporación de edificios en altura.

Adicionalmente, la presente tesis ha pretendido aportar, tanto desde su abordaje metodológico -que, como tal, puede ser replicado en investigaciones similares-como desde el proceso de investigación y sus conclusiones, al campo de conocimiento de la historia de la arquitectura en general y, en particular, para la historia de la arquitectura del Ecuador.

\section{Lista de referencias bibliográficas}

Abad, L., Compte, F., Cepeda, F., Del Pino, I., Tommerbak, M., Rocha, P., . . Kubes, M. (2009). Ciudad y arquitectura republicana de Ecuador 1850-1950. Quito: Pontificia Universidad Católica del Ecuador.

Acosta, A. (1995). Breve historia económica del Ecuador. Quito: Corporación Editora Nacional. Adoum, J. E. (1997). Ecuador: señas particulares. Quito: Eskeletra editorial.

Alarcón Orquera, M. (1968). Personalidades, industrias y comercio en el Ecuador. Guayaquil: Organizaciones Editec.

Álava, J., Baquerizo, H., y Hagó, F. (1976). Evolución histórica de la vivienda dentro del marco del desarrollo urbano en la región de Guayaquil (tesis de grado). Guayaquil: Facultad de Arquitectura. Universidad Católica de Santiago de Guayaquil.

Albuja Aspiazu, E. (1936). Guayaquil (Recuerdos de Antaño) (Ensayo de Novela Histórica Nacional). Guayaquil: Reed \& Reed.

Alcívar, M. y otros (1980). Arquitectura Guayaquil 1930-1960. Guayaquil: Facultad de Arquitectura y Diseño. Universidad Católica de Santiago de Guayaquil.

Aliprandi, E., \& Martini, V. (1930). Gli italiani in Equatore. Rassegna delle vite e delle opere della stirpe italica in terra equatoriana. Guayaquil: Artes Gráficas "Senefelder".

Aliprandi, H., \& Martini, V. (1933). Anuario Ecuatoriano. Guayaquil: Aliprandi \& Martini editores.

Altamirano, C. (2002). Términos críticos de sociología de la cultura. Buenos Aires: Paidós.

Arana, M., \& Garabelli, L. (1991). Reflexiones sobre un período fecundo de la arquitectura en el Uriguay. En R. Echávarri, S. Pereira, \& F. U. (edit.), Arquitectura Latinoamericana. Pensamiento y propuesta (págs. 124-131). Buenos Aires: Ediciones Summa. 
Arango, S. (1989). Historia de la arquitectura en Colombia. Bogotá: Universidad Nacional de Colombia.

Arango, S. (2012). Arquitectura moderna latinoamericana: el juego de las interpretaciones. Anales del Instituto de Arte Americano e Investigaciones Estéticas "Mario J. Buschiazzo", 42, 39-53.

Arellano, A. (2011). América Latina, historiografia y arquitectura. Trienal de Investigaciòn (págs. 1-26). San Cristòbal: Universidad Nacional Experimental del Tàchira.

Arosemena, G. (8 de diciembre de 2013). Las crisis económicas en la historia ecuatoriana. Memorias porteñas y crónicas de Expreso, págs. 2-3.

Arosemena, G. (25 de mayo de 2014). Impacto de la depresión mundial en la economía ecuatoriana. Memorias porteñas y crónicas de Expreso, págs. 2-3.

Avilés, E., y Hoyos, M. (2009). Monumentos, plazas y parques de Guayaquil. Guayaquil: Poligráfica.

Ayala Mora (editor), E. (1983). Nueva historia del Ecuador, Volumen 15. Quito: Corporación Editora Nacional / Grijalbo.

Ayala Mora, E. (1983). De la revolución alfarista al régimen oligárquico liberal (1895 - 1925). En E. Ayala Mora, Nueva Historia del Ecuador. Volumen 9. Época republicana III (págs. 117-166). Quito: Corporación Editora Nacional - Grijalbo.

Ayala Mora, E. (2014). Historia, tiempo y conocimiento del pasado. Estudio sobre periodización general de la historia ecuatoriana: una interpretación interparadigmática. Quito: Corporación Editora Nacional.

Ayón de Messner, D. (1967). Trayectoria histórica y cultural de la Universidad de Guayaquil. 1867-1967. Guayaquil: Departamento de Publicaciones. Universidad de Guayaquil.

Ballent, A. (2014). Casa colectiva, monobloque, propiedad horizontal. Desplazamientos y cruces de modelos en la habitación colectiva. En A. Ballent, \& J. F. Liernur, La casa y la multitud. Vivienda, política y cultura en la Argentina moderna (págs. 461-487). Buenos Aires: Fondo de Cultura Económica.

Balseca Franco, F. (2009). Llenaba todo de poesía. Medardo Ángel Silva y la modernidad. Quito: Santillana. Universidad Andina Simón Bolívar.

Bauman, Z. (2001). La posmodernidad y sus descontentos. Madrid: Akal.

Benavides, J. (1995). La arquitectura del siglo XX en Quito. Quito: Banco Central del Ecuador. Benévolo, L. (1980 (4a. ed.)). Historia de la Arquitectura Moderna. Barcelona: Gustavo Gili. Benévolo, L. (1980 [1960]). Historia de la arquitectura moderna. Barcelona: Gustavo Gili.

Benítes Vinueza, L. (1950). Ecuador: drama y paradoja. México: Fondo de Cultura Económica.

Bergdoll, B. (2015). Learning from Latin America: Public Space, Housing and Lanscape. En B. Bergdoll, C. E. Comas, J. F. Liernur, \& P. d. Real, Latin America in Construction: Architecture 1955-1980 (págs. 13-39). New York: The Museum of Modern Art.

Berman, M. (1989). Todo lo sólido se desvanece en el aire. La experiencia de la modernidad. Buenos Aires: Siglo XXI editores.

Betti, R. (2010). El juego de las referencias: El Neocaliforniano, raíz cultural y utopía doméstica. Documentos de Trabajo. Universidad de Belgrano, 13-21.

Bock, M. S. (1988). Quito, Guayaquil: Identificación arquitectural y evolución socio-económica en el Ecuador (1850-1987). Guayaquil: Instituto Francés de Estudios Andinos/CERG. 
Bock, M. S. (1992). Guayaquil. Arquitectura, espacio y sociedad. Quito: Corporación Editora Nacional.

Boloña, F. J. (1930). Guayaquil, Puerto limpio de clase A. Washington: Oficina Sanitaria Panamericana.

Borchart de Moreno, C., y Moreno Yánez, S. (1995). Las reformas borbónicas en la Audiencia de Quito. Anuario Colombiano de Historia Social y de la Cultura 22, 35-57.

Borja, R. (1997). Enciclopedia de la Política. México: Fondo de Cultura Económica.

Bourdieu, P. (1980). El sentido práctico. Buenos Aires: siglo veintiuno editores.

Bourdieu, P. (1995). Las reglas del arte. Génesis y estructura del campo literario. Barcelona: Anagrama.

Bourdieu, P. (1997). Razones prácticas. Sobre la teoría de la acción. Barcelona: Anagrama.

Bourdieu, P. (2002 [1966]). Campo de poder, campo intelectual. Itinerario de un concepto. Tucumán: Montressor.

Bourdieu, P. (28 de 9 de 2008). Pierre Bourdieu: la lógica de los campos. (E. Aquevedo, Entrevistador)

Bourdieu, P. (2010). El sentido social del gusto. Elemenyos para una sociología de la cultura. Buenos Aires: Siglo XXI editores.

Boyle, B. M. (1977). El ejercicio de la arquitectura en América, 1865-1965. Ideal y realidad. En S. Kostof, El arquitecto: historia de una profesión (págs. 265-296). Madrid: Ediciones Cátedra.

Brunner, J. J. (2001). Modernidad: centro y periferia. Claves de lectura. Estudios Públicos, 241-263.

Brunner, J. J. (26 de 6 de 2015). Medios, modernidad, cultura. Obtenido de researchgate: http://www.researchgate.net/publication/264840926

Bullrich, F. (1969). Arquitectura latinoamericana 1930/1970. Barcelona: Gustavo Gili.

Cárdenas, E. (1998). Problemas de teoría de la arquitectura. México: Universidad de Guanajuato.

Carrión, B. ([1977] 2010). Plan del Ecuador. Quito: Ministerio de Educación del Ecuador.

Carrión, B. (2007 [1943]). Cartas al Ecuador. Quito: Universidad Alfredo Pérez Guerrero.

Carrión, F. (1986). Evolución del espacio urbano ecuatoriano. En c. Fernando Carrión, El proceso de urbanización en el Ecuador (del siglo XVIII al siglo XX) (págs. 145-174). Quito: El Conejo - Centro de Investigaciones Ciudad.

Carvajal, I. (1995). Acerca de la modernidad y la poesía ecuatoriana. Kipus, Revista Andina de Letras, 3, 307-328.

Castro-Gómez, S. (2000). Ciencias sociales, violencia epistémica y el problema de la "invención del otro". En E. L. (compilador), La colonialidad del saber: eurocentrismo y ciencias sociales. Perspectivas latinoamericanas (págs. 145-162). Buenos Aires: CLACSO.

Casullo, N. (1993). El debate modernidad-posmodernidad. Buenos Aires: El Cielo por Asalto.

Cepeda Astudillo, F. (2010). Riobamba. Imagen, palabra e historia. Riobamba: Casa de la Cultura Ecuatoriana, Núcleo de Chimborazo.

Cepeda, F., Compte, F., Del Pino, I., y Ortiz, A. (2012). Italianos en la arquitectura de Ecuador. Quito: Pontificia Universidad Católica del Ecuador - Universidad Católica de Santiago de Guayaquil.

Cerda Brintrup, G. (2000). Arquitectura Déco en Concepción 1920-1940. Arquitecturas del Sur, 1-32. 
Ceriola, J. B. (1910). Guayaquil a la vista. Colección de fototipias con sus correspondientes explicaciones históricas, artísticas y descriptivas. Barcelona: Casa Vda. de Luis Tasso.

Cetto, M. (1978). Influencias externas y significado de la tradición. En R. Segre, América Latina en su arquitectura (págs. 170-185). México: Siglo XXI editores, UNESCO.

Cháves, N. (2005). El diseño invisible. Siete lecciones sobre la intervención culta en el hábitat humano. Buenos Aires: Paidós.

Chávez Franco, M. (1998 [1930]). Crónicas del Guayaquil Antiguo. Guayaquil: Compañía de Cervezas Nacionales.

Chiriboga, M. (2013, 2a. edición). Jornaleros, grandes propietarios y exportación cacaotera 1790-1925. Quito: Corporación Editora Nacional.

Cicala, M. ([1771]1987). Descripción Histórico-Topográfica de la Provincia de Quito de la Compañía de Jesús. Descripción de la ciudad de Guayaquil en general 1767-1771. En J. A. Iturralde, \& G. A. compiladores, Guayaquil y el río, una relación secular, 1767-1844, vol. 1. Guayaquil: Archivo Histórico del Guayas.

Cicutti, B. (2007). Registros urbanos de una modernidad periférica. representaciones y transformaciones materiales en el frente costero de Rosario entre 1920 y 1940. Buenos Aires: Nobuko.

Cirvini, S. A. (2004). Nosotros los arquitectos. campo disciplinar y profesión en la Argentina Moderna. Mendoza: Zeta editores.

Collins, P. (1977). Los ideales de la arquitectura moderna. Su evolución (1750-1950). Barcelona: Gustavo Gili.

Compañía “Guía del Ecuador” (edit.). (1909). El Ecuador. Guía comercial, agrícola e industrial de la República. Guayaquil: Taller de artes Gráficas de E. Rodenas.

Compte, F. (2007). Arquitectos de Guayaquil. Guayaquil: Universidad Católica de Santiago de Guayaquil.

Compte, F. (2007). Metodología para la valoración del patrimonio edificado, caso Guayaquil. Guayaquil: Unievrsidad Católica de Santiago de Guayaquil.

Compte, F. (2009). Estudio para la declaración patrimonial de la arquitectura del Siglo XX del área central de Guayaquil. Guayaquil: Ministerio de Patrimonio del Ecuador - Universidad Católica de Santiago de Guayaquil.

Compte, F. (2010). La Arquitectura Moderna en Guayaquil. AUC, 30-38.

Compte, F., Hidalgo, A., Paredes, W., Stothert, K., y Tutivén, C. (2003). Guayaquil al vaivén de la ría. Quito: Librimundi.

Costa, X. (1999). La coordinación internacional del proyecto de documentación y conservación del Movimiento Moderno. En I. A. (Ed.), La arquitectura moderna en Andalucía, un patrimonio por documentar y conservar. La experiencia DOCOMOMO (págs. 6-11). Sevilla: Consejería de Cultura, Junta de Andalucía.

Cravino, A. (2005). Reflexiones sobre la Teoría y la Crítica. Morón: Praia.

Cravino, A. (2014). Enseñanza de la arquitectura: la rebelión impasible de las disciplinas. Universidad de Buenos Aires, 1897-1956. Buenos Aires: Universidad de Buenos Aires.

Cremaschi, V. (2014). Algunas consideraciones sobre las fuentes teòricas de la arquitectura neocolonial. Huellas. Bùsquedas en Arte y Diseño, No. 8, 102-110.

Cremaschi, V. (2014). El estilo neocolonial como modernismo latinoamericano. Arquitecturas del Sur, Vol XXXII, No. 45, 64-75. 
Crónica Comercial e Industrial de Guayaquil en el Primer Siglo de Independencia. (1920). Quito: Banco del Ecuador.

Cubillo, G. (1979). Introducción y reconocimiento del rol del arquitecto en el medio. Trama, 13-14, 74-75.

Cueva, A. (1997). El método materialista histórico aplicado a la periodización de la historia de la literatura ecuatoriana: algunas consideraciones teóricas. En S. Sosnowski, Lectura crítica de la literatura americana: inventarios, invenciones y revisiones. Caracas: Fundación Biblioteca Ayacucho.

Cueva, A. (2009). Literatura y sociedad en el Ecuador. Quito: Ministerio de Educación del Ecuador.

De la Cuadra, J. (1933). La canción de las casas antiguas del puerto. Semana Gráfica, 14.

de Molina, S. (10 de Marzo de 2014). Cómo ser modernos sin modernidad. Obtenido de Estrategias de arquitectura: http://www.santiagodemolina.com

Del Pino, I. (2010). Arquitectura Moderna en Quito. AUC. Revista de arquitectura, 28, 20-29.

Deler, J. P. (2007). Ecuador. Del espacio al estado nacional. Quito: Corporación Editora Nacional.

Devalle, V. (2009). La travesía de la forma. Emergencia y consolidación del Diseño Gráfico (1948-1984). Buenos Aires: Paidós.

Diario El Universo (editor). (1940). Álbum profesional ecuatoriano. Guayaquil: El Universo. Donoso Pareja, M. (1998). Ecuador: identidad o esquizofrenia. Quito: Eskeletra editorial.

Donoso Pareja, M. (2006). Identidad guayaquileña II parte. En M. Donoso Pareja, \& W. Paredes, Identidad guayaquileña (referentes socioculturales de aproximación) (págs. 115174). Guayaquil: Archivo Histórico del Guayas.

D’Orbigny, A. (1997). Viajes a las dos Américas. En J. a. Iturralde, \& G. Arosemena, Guayaquil y el río: una relación secular. 1767 - 1844, Vol. II. Guayaquil: Archivo Histórico del Guayas.

Dos años de actividad italiana en Guayaquil (Equador). Febrero 1923 - Febrero 1925. (1925). Milano: E. Berardi i Cia.

Durán Calisto, A. M. (2015). Arquitectura contemporánea de Ecuador (1999-2015): el florecimiento de una crisis. RITA, 40-51.

Durand, J. N. ([1802] 1994). Précis des leçons d'architecture données à l'ecole polythechniqu. En P. Hereu, J. M. Montaner, \& J. Oliveras, Textos de arquitectura de la Modernidad (págs. 23-24). Madrid: Nerea.

Eco, U. (2007). Historia de la belleza. Barcelona: Lumen.

Ecuador, C. G. (1909). El Ecuador. Guía comerical, agrícola e industrial de la República. Guayaquil: Taller de Artes Gráficas de E. Rodenas.

Eliash, H., y Moreno, M. (1991). Arquitectura moderna en Chile (1930/1960). Notas para una historia crítica. En R. Echávarri, S. Pereira, \& F. U. (edit.), Arquitectura latinoamericana. Pensamiento y propuesta (págs. 118-123). Buenos Aires: Ediciones Summa.

Espinosa Tamayo, A. (1979 [1918]). Psicología y sociología del pueblo ecuatoriano. Quito: Banco Central del Ecuador / Corporación Editora Nacional.

Espinoza, B. (2011). Las políticas sociales de Ecuador del siglo XX. En Estado del país. Informe cero. Ecuador 1950-2010 (págs. 285-290). Quito: Contrato social por la educación.

Estatutos de la Sociedad de Carpinteros de Auxilios Mutuos de Guayaquil. (1905). Guayaquil: Imprenta La Reforma. 
Estrada Ycaza, J. (1972). Evolución urbana de Guayaquil. Revista del Archivo Histórico del Guayas 1, 37-66.

Estrada Ycaza, J. (1996). Guía histórica de Guayaquil. Tomo 2. Guayaquil: Poligráfica.

Estrada Ycaza, J. (2000). Guía Histórica de Guayaquil, Tomo 3. Guayaquil: Poligráfica.

Estrada Ycaza, J. (2001). Guía Histórica de Guayaquil, Tomo I. Notas de un viaje de cuatro siglos. Guayaquil: Poligráfica.

Estrada Ycaza, J. (2007). Guía Histórica de Guayaquil. Tomo 4. Incendios. Guayaquil: Cecilia Estrada Solá - Arq. Antonieta Palacios Jara.

Estrada Ycaza, J. (2008). Guía Histórica de Guayaquil, Tomo 5. Guayaquil: Poligráfica.

Estrada, J. (2006). Lista Negra en Ecuador: II guerra mundial. Guayaquil: Poligráfica C. A.

Fabara, W., Matovelle, J., y Núñez, A. (2004). Arquitectura Moderna - Década del 50. En I. d. (comp.), Quito 30 años de Arquitectura Moderna 1950-1980 (págs. 38-46). Quito: Trama.

Faggion Novo, L. (2016). Articulaçoes americanas: o urbanismo nos congressos pan americanos de arquitetos (1920-1930). Actas Primer Congreso Iberoamericano de Historia Urbana. Ciudades en el tiempo: infraestructuras, territorios, patrimonio (págs. 1385-1394). Santiago de Chile: Asociación Iberoamericana de Historia Urbana.

Falconí, A. (1929). Álbum-guía de la ciudad de Guayaquil. Guayaquil: Imprenta y talleres municipales.

Fernández Cox, C. (1991). Modernidad apropiada. En D. Serna, Modernidad y posmodernidad en América Latina. estado del debate (págs. 11-22). Bogotá: ESCALA.

Fernández García, A. M. (2006). Arte y artistas españoles en el Ecuador. Liño. Revista de Historia del Arte. Universidad de Oviedo, 111-125.

Fernández Prieto, P. (2013). Art Deco in Havana Housing: Tropical Deco and Stramline. Chicago Art Deco Society, 24-27.

Fernández, R. (2005). Utopías sociales y cultura técnica. Estudios de Historia de la Arquitectura Moderna. Buenos Aires: FADU/UBA.

Frisby, D. (1992). Fragmentos de la modernidad. Madrid: Visor Distribuciones, S. A.

Gallegos Naranjo, M. (1928). Álbum Sanitario de Guayaquil presentado a la Exposición Nacional de Sanidad. Guayaquil: Tipografía Gutenberg.

Gallegos, G. (1919). Guayaquil moderno. Semana Gráfica, 6-14.

Gálvez (edit.), A. (1930). Codificación de ordenanzas municipales. Cooncejo Municipal de Guayaquil. Guayaquil: Talleres Municipales.

García Canclini, N. (2001). Culturas híbridas: estrategias para entrar y salir de la modernidad. Buenos Aires: Paidós.

García Jurado, R. (2003). Samuel Hungtinton y la modernización política. Estudios políticos, Nùmero 33, 11-34.

Giedion, S. (2009 [1941]). Espacio, tiempo y arquitectura. Barcelona: Reverté.

Godoli, E. (2008). Marcelo Piacentini y el art déco en los cines italianos. En A. B. (editor), Art déco y arquitectura. Imágenes de modernidad (págs. 103-142). Barcelona: UNED.

Goestchel, A. M. (2001). Musas, ondinas y misses: estereotipos e imágenes quiteñas en los años treinta del siglo XX. Iconos 20, 110-113.

Gohardani, N. (2014). Architecture in effect: A glance at Critical Historiography. ArchNet, Vol 8, 184-190.

Goldhagen, S. W. (2008). Algo de qué hablar. Modernismo, discurso, estilo. Bitácora 12, 11-42. 
Gómez Iturralde, J. A. (2005). Los períodicos guayaquileños en la historia, 1821-1997. Tomo III 1920-1997. Guayaquil: Archivo Histórico del Guayas.

Gómez Iturralde, J. A. (2006). Historia de la Sociedad Filantrópica del Guayas. Guayaquil: Archivo Histórico del Guayas.

Gómez Iturralde, J. A. (2007). Crónicas, relatos y estampas de Guayaquil. Tomo III. Guayaquil: Archivo Histórico del Guayas.

Gorelik, A. (1999). Ciudad, modernidad, modernización. Universitas HUMANÍSTICA, 11-27.

Gorelik, A. (2011). La memoria material: ciudad e historia. Boletín del Instituto de Historia Argentina y Americana Dr. Emilio Ravignani, No. 33.

Gorgas, W. C. (1913). El saneamiento de Guayaquil. Guayaquil.

Guayaquil se embellece. (21 de marzo de 1926). El Telégrafo, p. 1.

Guayaquil, M. I. (1896). Reglamento del Parque Seminario. En M. I. Guayaquil, Colección de decretos, ordenanzas, resoluciones y contratos. Corresponde al año de 1895 (págs. 44-53). Guayaquil: Editorila de Artes y Oficios de la Sociedad Filantrópica.

Guerra, J. (2013). La visión plástica de la arquitectura del Arq. Rafael Rivas Nevárez. AUC. Arquitectura Universidad Católica, 19-36.

Guerrero Blum, E. (2001). Sociedades ecuatorianas de escritores y artistas. Quito: P. H. Ediciones.

Guerrero, A. (1991). La semántica de la dominación: el concertaje de indios. Quito: Libri Mundi.

Gutiérrez Viñuales, R. (2002). Arquitectura historicista de raíces prehispánicas. Goya, No. 289-290, 267-286.

Gutiérrez Viñuales, R. (2013). Simbolismo y modernidad en sudamérica. Algunas historias reseñables (1895-1925). En A. K. Troya, \& R. G. Viñuales, Simbolismo y modernidad. Ecuador 1900-1930 (págs. 46-67). Quito: Hominem Editores.

Gutiérrez, R. (1992). Arquitectura y urbanismo en iberoamérica. Madrid: Cátedra.

Gutiérrez, R. (1997). Arquitectura latinoamericana. Lima: Epígrafe editores S. A.

Gutièrrez, R., y Gutièrrez Viñuales, R. (2012). Una mirada crìtica a la arquitectura latinoamericana del Siglo XX. De las realidades a los desafios. En E. K. (ed.), 1810-1910-2010. Independencias dependientes. Art and national identities in Latin America. Dresde: Universidad de Dresde.

Gutiérrez, R., y Viñuales, G. (1998). Arquitectura latinoamericana. En R. Gutiérrez (cordinador), Arquitectura latinoamericana en el siglo XX (págs. 119-136). Barcelona: Lunwerg editores.

Gutiérrez, R., Tartarini, J., y Stagno, R. (2007). Congresos panamericanos de arquitectos 1920-2000. Aportes para su historia. Buenos Aires: CEDODAL.

Gutman, M. (1985). En torno a la historia de la arquitectura. Summa, 215/216, 78-80.

Habermas, J. (1989). El discurso filosófico de la modernidad: doce lecciones. Madrid: Taurus.

Habermas, J. (1989). Modernidad: un proyecto incompleto. En N. Casullo, El debate Modernidad Pos-modernidad (págs. 131-144). Buenos Aires: Punto Sur.

Hamerly, M. T. (1973). Historia Social y Económica de la antigua Provincia de Guayaquil 1763-1842. Guayaquil: Publicaciones del Archivo Histórico del Guayas.

Hamerly, M. T. (2012). Recuentos de dos ciudades. Guayaquil en 1899 y Quito en 1906. Un estudio comparativo. Guayaquil: Muy Ilustre Municipalidad de Santiago de Guayaquil. 
Harvey, D. (1990). La condición de la posmodernidad. Investigación sobre los orígenes del cambio cultural. Buenos Aires: Amorrortu editores.

Henderson, J. D. (2006). La modernización en Colombia. Los años de Laureano Gómez, 18991965. Medellín: Universidad de Antioquia.

Henriques, L. D. (1943). Toymakers of Ecuador. The Inter-American, 31-32.

Herrán, T. (1939). Conclusiones I Congreso Panamericano de la Vivienda Popular. Arquitectura. Órgano oficial de la Sociedad de Arquitectos, 19-21.

Heynen, H. (2015). Modernity and modernities. Challenges for the historiography of modern architecture. Conceiving our Modernity: Perspectives of Study in Chinese Modern Architectural History (págs. 20-34). 1st Symposium of Chinese Modern Architectural History \& Theory Forum.

Hidalgo (editor), Á. E. (2004). Umbrales del arte en el Ecuador. Una mirada a los procesos de nuestra modernidad estética. Guayaquil: Museo Antropológico y de Arte Contemporáneo de Guayaquil.

Hidalgo González, P. (1939). Monografía sintética de Guayaquil. Guayaquil, its history, its commerce, its industries, its possibilities. Guayaquil: Imprenta i Talleres Municipales.

Hidalgo, Á. E. (2010). El aparecimiento del saber histórico en Guayaquil: el Centro de Investigaciones Históricas (1930-1962). Revista Ecuatoriana de Historia, 31, 45-77.

Hidalgo, Á. E. (2011). El artesanado de Guayaquil. Gremios, Sociedades Artesananles y Círculos Obreros (1688-1925). Quito: Ministerio Coordinador de Patrimonio.

Hidalgo, Á. E. (2011). Entre dos aguas. Tradición y modernidad en Guayaquil (1750 - 1895). Manta: Mar Abierto.

Hidalgo, Á. E. (2013). Bohemia y sociabilidad entre 1900 y 1930. En A. K. Troya, \& R. G. Viñuales, Simbolismo y modernidad. Ecuador 1900-1930 (págs. 126-135). Quito: Hominem Editores.

Hidalgo, Á. E. (2014). Planificación urbana y utopías modernas (Guayaquil, 1896-1930). Guayaquil: Facultad de Arquitectura y Diseño. Universidad Católica de Santiago de Guayaquil.

Hidalgo, Ä. E. (2014). Sociabilidad letrada y modernidad en Guayaquil (1895-1920). Quito: Corporaciòn Editora Nacional.

Hintermann, H. (2015 [1927]). En el reino del dios sol. Viaje a través del Ecuador y el Perú oriental. Quito: Abya Yala.

Holinsky, A. ([1851] 2001). El Ecuador: Escenas de la vida Sudamericana. En J. E. Ycaza, Guía Histórica de Guayaquil Tomo I. Notas de un viaje de cuatro siglos (págs. 87-95). Guayaquil: Poligráfica.

Holm, O. (1982). La vivienda prehistórica. En D. Nurnberg, Arquitectura vernácula en el litoral (págs. 245-284). Guayaquil: Archivo Histórico del Guayas.

Hoyos, M. (1 de Noviembre de 2015). Orígenes del Barrio Orellana: una historia poco conocida. Expreso, págs. 8-9.

Hoyos, M., y Avilés, E. (2010). Los planos de Guayaquil. Dos siglos de evolución urbana. Guayaquil: Poligráfica.

Informe de la Comisión Municipal encargada del estudio de los proyectos de reconstrucción. (1896). Guayaquil: Gaceta Municipal. Año XII no. 576. 
Isac, A. (2011). La historia de la arquitectura del Siglo XX. Modelos historiogràficos. Lecciones de los Maestros. Aproximación histórico-crítica a los grandes historiadores de la arquitectura española (págs. 35-58). Zaragoza: Fernando el Católico.

Jaeschke, V. J. (1907). El concurso para "Nueva Guayaquil" y nuestras mejoras urbanas. Revista Técnica. Suplemento de Arquitectura Núm. 46, 74-81.

Jencks, C. (1984 [1977]). El lenguaje de la Arquitectura Posmoderna. Barcelona: Gustavo Gili. Jiménez, V. (2007). Los estudios de Juan O'Gorman para Diego Rivera y Frida Kahlo. En Arquitectura moderna en México (págs. 11-24). Buenos Aires: Nobuko.

Kennedy-Troya, A. (2016). Élites y la nación en obras. Visualidades y arquitectura del Ecuador 1840-1930. Quito: Universidad de Cuenca / Casa de la Cultura Ecuatoriana, núcleo del Azuay.

Kingman Garcés, E. (1998). Historia, Arquitectura y Ciudad. PROCESOS, Revista Ecuatoriana de Historia, 77-92.

Kingman Garcés, E. (2006). La ciudad y los otros. Quito 1860-1940. Higienismo, ornato y policía. Quito: FLACSO Sede Ecuador - Universidad Rovira e Virgili.

Kingman Garcés, E., y Goetschel, A. M. (2014). El presidente Gabriel García Moreno, el Concordato y la administración de poblaciones en el Ecuador de la segunda mitad del siglo XIX. Historia y Crítica No. 52, 123-149.

Knight, A. (2015). Panorama general de la Gran Depresión en América Latina. En P. Drinot, y A. K. (coordinadores), La Gran Depresión en América Latina (págs. 347-423). México: Fondo de Cultura Económica.

Kolberg, J. (1996 [1871]). Hacia el Ecuador. Relatos de viaje. Quito: Ediciones Abya-Yala.

La piscina de natación construida por la White. (14 de Octubre de 1929). Diario El Telégrafo, pág. 7.

Laporte, J. d. ([1797]1960). El Viajero Universal o Noticia del Mundo Antiguo y Nuevo. En B. E. Mínima, El Ecuador visto por los extranjeros (viajeros de los siglos XVIII y XIX) (págs. 173-182). Puebla: José M. Cajica Jr.

Laviana, M. L. (1984). La descripción de Guayaquil por Francisco de Requena. Escuela de Estudios Hispanoamericanos de Sevilla, 25-28.

Lecuona, D. E. (2001). Conceptos políticos y sociales sobre el problema de la vivienda en Argentina a mediados del siglo XX. Invi 42, 7-60.

Lee, P., y Compte, F. (1992). Guayaquil: lectura histórica de la ciudad. Guayaquil: Universidad Católica de Santiago de Guayaquil.

Lee, P., Compte, F., \& Peralta, C. (1988). Análisis y valoración de la arquitectura histórica de Guayaquil Siglo XIX - 1950. Guayaquil: Facultad de Arquitectura y Diseño de la Universidad Católica de Santiago de Guayaquil.

Lee, P., Compte, F., y Peralta, C. (1989). Patrimonio Arquitectónico y Urbano de Guayaquil. Guayaquil: Universidad Católica de Santiago de Guayaquil.

Lee, P., Compte, F., y Peralta, C. (1991). Testimonio y memoria de la arquitectura histórica de Guayaquil. Guayaquil: Universidad Católica de Santiago de Guayaquil.

Lee, P., Compte, F., Palacios, A., y Esparza, S. (1987). Inventario de la arquitectura civil, pública y religiosa de Guayaquil Siglo XIX - 1950. Guayaquil: Facultad de Arquitectura y Diseño de la Universidad Catòlica de Santiago de Guayaquil. 
León Borja, D., y Szászdi, Á. (2006). Estudios sobre las fundaciones de Santiago de Guayaquil. Guayas: Archivo Histórico del Guayas.

Leonhardt Abram, M. (2008). Los Andes en el corazón. Intérpretes del paisaje. En A. K. (coordinadora), Escenarios para una patria: paisajismo ecuatoriano 1850-1930 (págs. 26-51). Quito: Museo de la Ciudad.

Liernur, J. F. (2004). Moderna (Arquitectura). En J. F. Liernur, \& F. Aliata, Diccionario de Arquitectura en la Argentina, volumen I-N (págs. 141-157). Buenos Aires: AGEA Clarín.

Liernur, J. F. (2008). Trazas de futuro. Episodios de la cultura arquitectónica de la modernidad en América Latina. Santa Fe: Universidad Nacional del Litoral.

Liernur, J. F. (2010). Orientalismo y arquitectura: el debate sobre la cubierta plana. $R A$ (Revista de Arquitectura) Universidad de Navarra, 61-78.

Liernur, J. F. (2014). Casas y jardines. La construcción del habitar moderno. En A. Ballent, y J. F. Liernur, La casa y la multitud. Vivienda, política y cultura en la Argentina moderna (págs. 543-580). Buenos Aires: Fondo de Cultura Económica.

Liernur, J. F., y Pschepiurca, P. (2008). La red austral. Obras y proyectos de Le Corbusier y sus discípulos en la Argentina (1924-1965). Buenos Aires: Universidad Nacional de Quilmes.

Lizárraga, f. R. (1968 [1605]). Descripción Breve de toda la tierra del Perú, Tucumán, Río de la Plata y Chile. Madrid.

Mallet, J. ([1820] 2001). Viajes por el Interior de la América Meridional, 1808-1820. En J. E. Ycaza, Guía Histórica de Guayaquil Tomo I. Notas de un viaje de cuatro siglos (pág. 70). Guayaquil: Poligráfica.

Marín Nieto, L. (1984). Inauguración del laboratorio Dr. arnaldo Ruffilli. Revista Universidad de Guayaquil, 175-180.

Martín Hernández, M. J. (1997). La Invención de la Arquitectura. Madrid: Celeste ediciones.

Martínez Torres, H. (24 de Agosto de 2005). Martínez Torres y la Arquitectura Moderna de Guayaquil. (F. Compte, Entrevistador)

Martínez, P. (1988). Guayaquil noviembre de 1922. Política oligárquica e insurrección popular. Quito: Cedis.

Mas Llorens, V. (2004). El marco ético de la arquitectura moderna. En principio. Valencia: Universidad Politécnica de Valencia.

Matamoros Jara, C. (24 de julio de 1935). La estatua al Libertador Simón Bolívar, erigida en los países de América y Europa. Diario El Telégrafo, pág. 7.

Mera, G., y otros, y. (1991). Los arquitectos, Movimiento Moderno. Guayaquil 1940-1970. Guayaquil: Facultad de Arquitectura y Diseño. Universidad Católica de Santiago de Guayaquil.

Mesías S.J., J. E. (1982). La Iglesia de San José de los Padres Jesuitas en Guayaquil, en la historia y en la arquitectura. Guayaquil: Editorial Arquidiocesana "Justicia y Paz".

Meyer, H. (1993 [1903]). En los altos Andes del Ecuador. Quito: Abya-Yala.

Mignolo, W. (2000). Local Histories/Global Designs: Coloniality, Subaltern knowledges and border thinking. Princeton: Princeton University Press.

Miró Quesada, L. (1987). Inicios de la Arquitectura Mopderna en Lima. DAU, año 2 - volumen 1, 41-47.

Monard, S. (2010). Karl Kohn. Arquitecto, diseñador, artista. Quito: Pontificia Universidad Católica del Ecuador. 
Mondragón, H. (2010). El discurso de la Arquitectura Moderna. Chile 1930 - 1950. Una construcción desde las publicaciones periódicas. Santaigo de Chile: Tesis doctoral. Doctorado en arquitectura y estudios urbanos. Pontificia Universidad Católica de Chile.

Monlau, P. F. (1856). Diccionario etimológico de la lengua castellana. Madrid: Imprenta y estereotipia de M. Rivadeneira.

Montaner, J. M. (2002 (5a. ed.)). Después del movimiento moderno. Arquitectura de la segunda mitad del sglo XX. Barcelona: Gustavo Gili.

Montaner, J. M. (2011). Arquitectura y crítica en Latinoamérica. Buenos Aires: Nobuko.

Montaner, J. M. (2013 (3a. ed.)). Arquitectura y Crítica. Barcelona: Gustavo Gili.

Moreira, R., \& Alvarez, Y. (2004). Arquitectura de Quito 1915-1985. Quito: TRAMA.

Naranjo, M. G. (1901). Guayaquil. Novela fantástica. Guayaquil: Imprenta Manabita.

Navarro, J. G. (1928). La iglesia de la Compañía de Jesús en Quito. Boletín de la Real Academia de la Historia, tomo 93, 318-324.

Navas, J. B. (1920). Evolución social del obrero en Guayaquil. Guayaquil: Imp. Guayaquil.

Noboa, C. M. (1920). América Libre. Obra dedicada a conmemorar el centenario de la Independencia de Guayaquil 1820-1920. Guayaquil: Prensa Ecuatoriana.

Noelle, L. (2015). Mexico. En B. Bergdoll, C. E. Comas, J. F. Liernur, \& P. d. Real, Latin America in Construction: Architecture 1955-1980 (págs. 216-247). New York: The Museum of Modern Art.

Norberg-Schulz, C. (1967). Intenciones en arquitectura. Barcelona: Gustavo Gili.

Nuestro edificio en marcha. (1948 [2015]). Memorias de Cuadernos del Guayas, 137-138.

Núñez Sánchez, J. (2010). Eloy Alfaro. Pensamiento fundamental. Quito: Editorial Ecuador.

Núñez, J. (1997). Guayaquil, una ciudad colonial del trópico. Guayaquil: Archivo Histórico del Guayas.

Ortiz Crespo, A. (2004). Guía de arquitectura de la ciudad de Quito. Quito: Junta de Andalucía. Municipio del Distrito Metropolitano de Quito.

Osculati, G. (1854). Esplorazione delle regioni equatoriali lungo il Napo ed il fiume delle Amazzoni : frammento di un viaggio fatto nelle due Americhe negli anni 18464748 da Gaetano Osculati . Milano: Presso i Fratelli Centenari e Comp.

Pachón Soto, D. (2008). Nueva perspectiva filosófica en América Latina: el grupo Modernidad/Colonialidad. Ciencia Política 15, 8-35.

Pachón, X. (2007). La familia en Colombia a lo largo del siglo XX. En Y. Puyana, \& M. H. (editoras), Familias, cambios y estrategias (págs. 145-160). Bogotá: Universidad Nacional de Colombia.

Padrón, M. J. (1993). Caracas 1928-1958: permanencias y transformaciones morfológicas durante la primera modernidad urbano-arquitectónica en Venezuela. Anales del Instituto de Arte Americano 29, 87-101.

Paéz, R. (1918). El Divorcio. Asociación Católica de la Juventud Ecuatoriana, No. 3.

Pagnotta, C. (2012). La migración italiana en Ecuador: Quito y Guayaquil como lugares de arribo y asentamiento. En J. R. (editor), Ciudad-estado, inmigrantes y polñiticas, Ecuador 1890-1950 (págs. 97-120). Quito: Instituto de Altos Estudios Nacionales.

Palacios, A. (2014). Gastón Thoret Jäger (1859-1944). Ingeniero, constructor y visionario. Guayaquil: Muy Ilustre Municipalidad de Guayaquil. 
Paladines, C. (2007). La odisea de la modernización en el Ecuador. Dos momentos de su desarrollo. Estudios de Filosofía Práctica e Historia de las Ideas, 129-140.

Paredes Ramírez, W. (2003). Historia Institucional del Banco Central del Ecuador Sucursal Mayor Guayaquil (1927 y 2002). Guayaquil: Archivo Histórico del Guayas.

Patetta, L. (1984). Historia de la arquitectura. Antología crítica. Madrid: Hermann Blume.

Paz y Miño Cepeda, J. J. (2013). La Revolución Juliana en Ecuador (1925-1931). Políticas económicas. Quito: Ministerio Coordinador de Política Económica.

Paz y Miño, J. (2012). Estudio introductorio. En M. C. Social, Eloy Alfaro: Pensamiento y Políticas Sociales (págs. 13-55). Quito: Cassolutions Publcidad.

Paz, O. (1991 [1965]). El caracol y la sirena (Rubén Darío). Cuadriviio. Darío, López Velarde, Pessoa, Cernuda, 9-60.

Pazos Carrillo, S. (2010). Permanencias culturales y culinarias del Manual de Cocina de Juan Pablo Sanz en Quito (Ecuador): protocolos, cocina tradicional y formas de preparación. Quito: Universidad Andina Simón Bolívar, Sede Ecuador.

Pequeño, A. (2001). Historia de misses. Historias de naciones. Iconos 20, 114-117.

Peralta, C. (2009). Estudio para la declaratoria patrimonial de los barrios Orellana y del Salado de la ciudad de Guayaquil. Guayaquil: Ministerio de Patrimonio del Ecuador Universidad Católica de Santiago de Guayaquil.

Pérez, J. G. (1987). Historia de la arquitectura en la República del Ecuador. En Varios, Teoría del Arte en el Ecuador (págs. 273-283). Quito: Banco Central del Ecuador, Corporación Editora Nacional.

Pérez, T. (2013). La Escuela Nacional de Bellas Artes y el arte moderno en Quito a inicios del siglo XX. En L. K. Troya, y R. Gutiérrez Viñuales, Simbolismo y modernidad. Ecuador 1900-1930 (págs. 114-122). Quito: Hominem Editores.

Piñón, H. (2006). Teoría del Proyecto. Barcelona: Universitat Politécnica de Catalunya.

Pólit Lasso (comp.), M. M. (1923). Escritos y discursos de García Moreno. Quito: Tipografía y Encuadernación Salesiana.

Pradilla, E. (1983). El problema de la vivienda en América Latina. Quito: Centro de Investigaciones CIUDAD.

Pratt, M. L. (2000). La modernidad desde las américas. Revista Iberoamericana. Vol. LXVI, Núm. 193, 831-840.

Protesta de las Matronas de Quito contra la ley del Matrimonio Civil. (1903). Boletín Eclesiástico, No. 18, 598.

Proyecto de casa quiteña moderna. (1940). Ecuador. Revista gráfica nacional, Vol. 1, Núm. 1, 1. Puente, G. (28 de mayo de 2015). Modernism in Quito, Ecuador: 1955-1980. Obtenido de Docomomo United States: http://docomomo-us.org/print/1289

Quevedo, B. (1981 [1931]). Notas sobre el caracter del pueblo ecuatoriano. En B. Quevedo, Ensayos sociológicos, políticos y morales. Quito: Banco Central del Ecuador / Corporación Editora Nacional.

Quijano, A. (1988). Modernidad, identidad y utopía en América Latina. Lima: Sociedad y Política/Ediciones.

Quijano, A. (2000). Colonialidad del poder, eurocentrismo y América Latina. En E. Lander, La colonialidad del saber: eurocentrismo y ciencias sociales (págs. 201-246). Buenos Aires: CLACSO, Consejo Latinoamericano de Ciencias Sociales. 
Quijano, A. (2014). Cuestiones y Horizontes. Antología esencial. De la dependencia históricoestructural a la colonialidad/descolonialidad del poder. Buenos Aires: CLACSO.

Quintero, R., y Silva Charvet, É. (2013). Ecuador: una nación en ciernes. Quito: Abya Yala.

Quito, M. d. (1947). Ordenanza de Construcciones del Perímetro Colonial de la Ciudad. Quito: M. I. Municipio de Quito.

Raffa, C., y Cirvini, S. (2013). Arquitectura Moderna: autores y producción en Mendoza, Argentina (1930-1970). AS, 34-47.

Ramírez Nieto, J. (2009). Intervalo nacional-moderno de la arquitectura latinoamericana 1929-1939 (tesis doctoral). Hamburg: HafenCity Universität.

Reigadas, C. (2012). Modernidades múltiples e historia global. Aportes para repensar el lugar de latinoamérica en el mundo. De signos y sentidos / 13, 15-26.

Rey Ashfield, W. (2008). Intuición y emoción: nuevas claves para el análisis de la arquitectura moderna uruguaya. Apuntes, vol. 21, núm. 2, 252-265.

Rey Ashfield, W. (2012). Arquitectura Moderna en Montevideo (1920-1960). Montevideo: Universidad de la República.

Rivas Nevárez, R. (2013 [1942]). La práctica profesional. Nuestra realidad arquitectónica. AUC. Arquitectura Universidad Católica, 69-72.

Rivas Nevárez, R. (2013 [1946]). La zonificación de Guayaquil. AUC. Arquitectura Universidad Católica, 45-48.

Rivas Nevárez, R. (2013 [1980]). La práctica profesional: origen y trayectoria del Coelgio de Arquitectos. AUC 32, 87-100.

Rivas Nevárez, R. (2013). Vivienda social. El problema de la vivienda en Guayaquil. AUC. Arquitectura Universidad Católica, 49-52.

Rodríguez Castelo, H. (1988). El Siglo XX de las artes visuales en Ecuador. Guayaquil: Museo de Arte. Banco Central del Ecuador, Guayaquil.

Rodríguez, C. (1926). Historia de la Sociedad Filantrópica del Guayas. Guayaquil: Sociedad Filantrópica del Guayas.

Rogers, W. (1936 [1717]). Voyage autour du monde commencé en 1708 et finie 1711: par le capitaine Woodes Rogers. Anales de la Universidad Central.

Rojas, M., y Villavicencio, G. (1988). El Proceso Urbano de Guayaquil 1870-1980. Guayaquil: CERG.

Roth, L. M. (1993). Entender la arquitectura. Sus elementos, historia y significado. Barcelona: Gustavo Gili.

Saldarriaga Roa, A., Ortiz Crespo, A., y Pinzón Rivera, J. A. (2005). En busca de Thomas Reed. Arquitectura y politica en el siglo XIX. Bogotá: Archivo Distrital de Bogotá D.C., Corporación La Candelaria.

Salvador, Á. (2013). Modernismo hispanoamericano y modernidad europea. En A. K. Troya, y R. Gutiérrez Viñuales, Simbolismo y modernidad. Ecuador 1900-1930 (págs. 34-45). Quito: Hominem Editores.

Samoná, G. (1984). El París de Haussmann. En L. Patetta, Historia de la Aqruitectura. Antología crítica (pág. 243). Barcelona: Hermann Blume.

Sánchez Varas, A. (2008). Junta de Beneficencia de Guayaquil. 1888-2008. 120 años de servicio. Guayaquil: Maxigraf. 
Santamarìa, L. (2013). Imaginario, identidad y arquitectura. Contexto. Revista de la Facultad de Arquitectura. Universidad Autònoma de Nuevo Leòn, 43-51.

Sartoris, A. (1978). Recuerdos de La Sarraz. Arquitecturas BIS, 2-7.

Schávelzon, D. (1981). El Pabellón de Ecuador en la Exposición Internacional de París, 1900. DANA, Documentos de Arquitectura nacional y Americana, 57-58.

Schávelzon, D. (1984). América latina en París (1889). Los pabellones de la Exposición Internacional de 1889. DANA, Documentos de Arquitectura Nacional y Americana, 65-70.

Segawa, H. (2013). Architecture of Brazil. 1900-1990. New York: Springer.

Segawa, H. (2015). Patrimonio moderno brasileño y latinoamericano: controversias. $E l$ patrimonio moderno en iberoamérica. Protección y coordinación internacional (pp. 69-76). México: Instituto Nacional de Bellas Artes y Literatura - UNESCO.

Segre, R. (1989). Arquitectura y urbanismo de la revolución cubana. La Habana: Pueblo y Educación.

Segre, R. (1990). América Latina. Fin de Milenio. Raíces y perspectivas de su arquitectura. Madrid: Arte y Literatura.

Segre, R. (2015). Arquitectura y urbanismo. Cuba y América Latina desde el siglo XXI. La Habana: Arte y Literatura.

Sinardet, E. (1999). La preocupación higienista en la educación ecuatoriana en los años treinta y cuarenta. Bulletin Institut Français d'Études Andines, 411-432.

Soaje, R. (2015). De Marco Tulio Cicerón a Manuel Antonio Carreño: un estudio sobre los ideales de vida de las élites en tres momentos de la historia. Atenea 511, 189-205.

Soave, P. (2008). La “scoperta" geopolitica dell'Ecuador. Mire espansionistiche dell'Italia ed egemonia del dollaro 1919-1945. Milano: Franco Angelli.

Stevenson, W. B. ([1808] 1960). A historical and desciptive narrative of twenty years residence in South America. En B. E. Mínima, El Ecuador visto por los extranjeros (viajeros de los siglos XVIII y XIX) (págs. 195-237). Puebla: José M. Cajica Jr.

Suárez Ramírez, J. (2013). Cine mudo. Ciudad parlante. Historia del cine guayaquileño. Guayaquil: Poligráfica.

Subirats, E. (2008). Las poéticas colonizadas de América Latina. En B. E. (comp.), La americanización de la modernidad (págs. 77-96). México: Ediciones Era / Centro de Investigaciones sobre América del Norte y Dirección General de Publicaciones y Fomento Editorial, UNAM.

Terry, A. R. (1994 [1832]). Viajes por la región ecuatorial de América del sur. Quito: Abya-Yala. Thill, C., Ontaneda, R., Lince, J. F., y Gilbert, G. (1896). Informe de la Comisión Municipal encargada del estudio de los proyectos de reconstrucción. Guayaquil: M. I. Municipalidad de Guayaquil.

Thompson, J. B. (2002). Ideología y cultura moderna. Teoría crítica social en la era de la comunicación de masas. Coyoacán: Universidad Autónoma Metropolitana.

Tinajero, F. (1987). De la evasión al desencanto. Quito: El Conejo.

Tinajero, F. (2015). Paradojas de nuestra identidad. Quito: Eskeletra editorial.

Tomas, H. (1998). El lenguaje de la arquitectura moderna. La Plata: Universidad Nacional de La Plata.

Torrent, H. (2011). A different reception. Modern brazilian architecture and chilean architectonic culture. $A R Q, 51-57$. 
Torrent, H. (2012). Historiografia y arquitectura moderna en Chile: notas sobre sus paradigmas y desafíos. Anales del Instituto de Arte Americano e Investigaciones Estéticas "Mario J. Buschiazzo", 42, 55-75.

Torres Dávila, V.H. (2012). Estado e industrialización en Ecuador. Modernización, fricciones $y$ conflictos en los años cincuenta. Quito: Abya Yala.

Tournikiotis, P. (2014). La historiografía de la arquitectura moderna. Barcelona: Reverté.

Ubidia, A. (1998). Modernidad y posmodernidad. ICONOS, 54-59.

Un profesor de arquitectura en Guayaquil. (mayo de 1924). Caritas y carotas, s/p.

Urbanización de una importante zona de la ciudad por la C. I. de Construcciones. (31 de mayo de 1926). El Telégrafo, pág. 1.

Utreras, L. (2006). El CAE y los arquitectos al servicio de la Institución. Guayaquil: Colegio de Arquitectos del Ecuador / Colegio Provincial del Guayas.

Vargas, J. M. (1949). El arte quiteño en los siglos XVI, XVII y XVI. Quito: Litografía e Imprenta Romero.

Vasconcellos, R. (23 de octubre de 2016). Hay que demoler los símbolos de Guayaquil. El Universo, pág. 19.

Verdugo Cárdenas, J. (1997). Hugo Mayo: vanguardia, renovación y silencio. Kipus. Revista andina de letras, 63-76.

Villacrés, Á. (1999). Proyecto RADIUS. Herramientas de evaluación del riesgo para el diagnóstico de zonas urbanas contra desastres sísmicos. Guayaquil: M. I. Municipalidad de Guayaquil.

Villavicencio, G. (1989). El desfase de un proceso urbano: El caso de Guayaquil. En CORDES, Guayaquil: Realidades y deafíos (págs. 29-87). Guayaquil: Corporación de Estudios para el Desarollo CORDES.

Villavicencio, G., \& Rodríguez, A. (s/f). Notas para la discusión del problema de la vivienda en América Latina: El Caso de Guayaquil. Quito: Centro de Investigaciones CIUDAD.

Waisman, M. (1990). El interior de la historia. Historiografía arquitectónica para uso de latinoamericanos. Bogotá: ESCALA.

Wéry, P. (1906). La Ville de Guayaquil, capitale du commerce de la République de l'Equateur Amérique du Sud. Paris: Impr. de Chaix.

Wiener, C. (1960). Un francés en Guayaquil. En S. G. Interamericana, El Ecuador visto por los extranjeros (Viajeros de los siglos XVIII y XIX. Puebla: J.M. Cajjica JR. S.A.

Zevi, B. (1980 [1950]). Historia de la arquitectura moderna. Barcelona: Poseidón.

\section{Bibliografía}

Abad, L., Compte, F., Cepeda, F., Del Pino, I., Tommerbak, M., Rocha, P., . . Kubes, M. (2009). Ciudad y arquitectura republicana de Ecuador 1850-1950. Quito: Pontificia Universidad Católica del Ecuador.

Acosta, A. (1995). Breve historia económica del Ecuador. Quito: Corporación Editora Nacional.

Álava, J., Baquerizo, H., y Hagó, F. (1976). Evolución histórica de la vivienda dentro del marco del desarrollo urbano en la región de Guayaquil (tesis de grado). Guayaquil: Facultad de Arquitectura. Universidad Católica de Santiago de Guayaquil. 
Alcívar, M. y otros (1980). Arquitectura Guayaquil 1930-1960. Guayaquil: Facultad de Arquitectura y Diseño. Universidad Católica de Santiago de Guayaquil.

Altamirano, C. (2002). Términos críticos de sociología de la cultura. Buenos Aires: Paidós.

Arana, M., y Garabelli, L. (1991). Reflexiones sobre un período fecundo de la arquitectura en el Uriguay. En R. Echávarri, S. Pereira, \& F. U. (edit.), Arquitectura Latinoamericana. Pensamiento y propuesta (págs. 124-131). Buenos Aires: Ediciones Summa.

Arango, S. (1989). Historia de la arquitectura en Colombia. Bogotá: Universidad Nacional de Colombia.

Arango, S. (2012). Arquitectura moderna latinoamericana: el juego de las interpretaciones. Anales del Instituto de Arte Americano e Investigaciones Estéticas "Mario J. Buschiazzo", 42, 39-53.

Arellano, A. (2011). América Latina, historiografia y arquitectura. Trienal de Investigaciòn (págs. 1-26). San Cristòbal: Universidad Nacional Experimental del Tàchira.

Ayala Mora (editor), E. (1983). Nueva historia del Ecuador, Volumen 15. Quito: Corporación Editora Nacional / Grijalbo.

Ayala Mora, E. (1983). De la revolución alfarista al régimen oligárquico liberal (1895 1925). En E. Ayala Mora, Nueva Historia del Ecuador. Volumen 9. Época republicana III (pp. 117-166). Quito: Corporación Editora Nacional - Grijalbo.

Ballent, A. (2014). Casa colectiva, monobloque, propiedad horizontal. Desplazamientos y cruces de modelos en la habitación colectiva. En A. Ballent, \& J. F. Liernur, La casa y la multitud. Vivienda, política y cultura en la Argentina moderna (págs. 461-487). Buenos Aires: Fondo de Cultura Económica.

Bauman, Z. (2001). La posmodernidad y sus descontentos. Madrid: Akal.

Benavides, J. (1995). La arquitectura del siglo XX en Quito. Quito: Banco Central del Ecuador. Benévolo, L. (1980 (4a. ed.)). Historia de la Arquitectura Moderna. Barcelona: Gustavo Gili. Benítes Vinueza, L. (1950). Ecuador: drama y paradoja. México: Fondo de Cultura Económica.

Bergdoll, B. (2015). Learning from Latin America: Public Space, Housing and Lanscape. En B. Bergdoll, C. E. Comas, J. F. Liernur, y P. D. Real, Latin America in Construction: Architecture 1955-1980 (págs. 13-39). New York: The Museum of Modern Art.

Berman, M. (1989). Todo lo sólido se desvanece en el aire. La experiencia de la modernidad. Buenos Aires: Siglo XXI editores.

Betti, R. (2010). El juego de las referencias: El Neocaliforniano, raíz cultural y utopía doméstica. Documentos de Trabajo. Universidad de Belgrano, 13-21.

Borja, R. (1997). Enciclopedia de la Política. México: Fondo de Cultura Económica.

Bourdieu, P. (1980). El sentido práctico. Buenos Aires: siglo veintiuno editores.

Bourdieu, P. (1995). Las reglas del arte. Génesis y estructura del campo literario. Barcelona: Anagrama.

Bourdieu, P. (1997). Razones prácticas. Sobre la teoría de la acción. Barcelona: Anagrama.

Bourdieu, P. (2002 [1966]). Campo de poder, campo intelectual. Itinerario de un concepto. Tucumán: Montressor.

Bourdieu, P. (28 de 9 de 2008). Pierre Bourdieu: la lógica de los campos. (E. Aquevedo, Entrevistador)

Bourdieu, P. (2010). El sentido social del gusto. Elemenyos para una sociología de la cultura. Buenos Aires: Siglo XXI editores. 
Brunner, J. J. (2001). Modernidad: centro y periferia. Claves de lectura. Estudios Públicos, 241-263.

Bullrich, F. (1969). Arquitectura latinoamericana 1930/1970. Barcelona: Gustavo Gili.

Cárdenas, E. (1998). Problemas de teoría de la arquitectura. México: Universidad de Guanajuato.

Carrión, F. (1986). Evolución del espacio urbano ecuatoriano. En c. Fernando Carrión, El proceso de urbanización en el Ecuador (del siglo XVIII al siglo XX) (págs. 145-174). Quito: El Conejo - Centro de Investigaciones Ciudad.

Carvajal, I. (1995). Acerca de la modernidad y la poesía ecuatoriana. Kipus, Revista Andina de Letras, 3, 307-328.

Castro-Gómez, S. (2000). Ciencias sociales, violencia epistémica y el problema de la "invención del otro". En E. L. (compilador), La colonialidad del saber: eurocentrismo y ciencias sociales. Perspectivas latinoamericanas (págs. 145-162). Buenos Aires: CLACSO.

Casullo, N. (1993). El debate modernidad-posmodernidad. Buenos Aires: El Cielo por Asalto.

Cepeda, F., Compte, F., y Del Pino, I. (2012). Italianos en la arquitectura de Ecuador. Quito: Pontificia Universidad Católica del Ecuador - Universidad Católica de Santiago de Guayaquil.

Cerda Brintrup, G. (2000). Arquitectura Déco en Concepción 1920-1940. Arquitecturas del Sur, 1-32.

Cetto, M. (1978). Influencias externas y significado de la tradición. En R. Segre, América Latina en su arquitectura (págs. 170-185). México: Siglo XXI editores, UNESCO.

Cháves, N. (2005). El diseño invisible. Siete lecciones sobre la intervención culta en el hábitat humano. Buenos Aires: Paidós.

Cicutti, B. (2007). Registros urbanos de una modernidad periférica. representaciones y transformaciones materiales en el frente costero de Rosario entre 1920 y 1940. Buenos Aires: Nobuko.

Cirvini, S. A. (2004). Nosotros los arquitectos. campo disciplinar y profesión en la Argentina Moderna. Mendoza: Zeta editores.

Collins, P. (1977). Los ideales de la arquitectura moderna. Su evolución (1750-1950). Barcelona: Gustavo Gili.

Compte, F. (2007). Arquitectos de Guayaquil. Guayaquil: Universidad Católica de Santiago de Guayaquil.

Compte, F. (2009). Estudio para la declaración patrimonial de la arquitectura del Siglo XX del área central de Guayaquil. Guayaquil: Ministerio de Patrimonio del Ecuador - Universidad Católica de Santiago de Guayaquil.

Compte, F. (2010). La Arquitectura Moderna en Guayaquil. AUC, 30-38.

Compte, F., Hidalgo, A., Paredes, W., Stothert, K., y Tutivén, C. (2003). Guayaquil al vaivén de la ría. Quito: Librimundi.

Costa, X. (1999). La coordinación internacional del proyecto de documentación y conservación del Movimiento Moderno. En I. A. (Ed.), La arquitectura moderna en Andalucía, un patrimonio por documentar y conservar. La experiencia DOCOMOMO (págs. 6-11). Sevilla: Consejería de Cultura, Junta de Andalucía.

Cravino, A. (2005). Reflexiones sobre la Teoría y la Crítica. Morón: Praia.

Cravino, A. (2014). Enseñanza de la arquitectura: la rebelión impasible de las disciplinas. Universidad de Buenos Aires, 1897-1956. Buenos Aires: Universidad de Buenos Aires. 
Cremaschi, V. (2014). Algunas consideraciones sobre las fuentes teòricas de la arquitectura neocolonial. Huellas. Bùsquedas en Arte y Diseño, No. 8, 102-110.

Cremaschi, V. (2014). El estilo neocolonial como modernismo latinoamericano. Arquitecturas del Sur, Vol XXXII, No. 45, 64-75.

de Molina, S. (10 de Marzo de 2014). Cómo ser modernos sin modernidad. Obtenido de Estrategias de arquitectura: http://www.santiagodemolina.com

Deler, J.P. (2007). Ecuador. Del espacio al estado nacional. Quito: Corporación Editora Nacional. Devalle, V. (2009). La travesía de la forma. Emergencia y consolidación del Diseño Gráfico (1948-1984). Buenos Aires: Paidós.

Donoso Pareja, M. (1998). Ecuador: identidad o esquizofrenia. Quito: Eskeletra editorial.

Donoso Pareja, M. (2006). Identidad guayaquileña II parte. En M. Donoso Pareja y W. Paredes, Identidad guayaquileña (referentes socioculturales de aproximación) (pp. 115-174). Guayaquil: Archivo Histórico del Guayas.

Durán Calisto, A. M. (2015). Arquitectura contemporánea de Ecuador (1999-2015): el florecimiento de una crisis. RITA, 40-51.

Eco, U. (2007). Historia de la belleza. Barcelona: Lumen.

Eliash, H., y Moreno, M. (1991). Arquitectura moderna en Chile (1930/1960). Notas para una historia crítica. En R. Echávarri, S. Pereira, y F. U. (edit.), Arquitectura latinoamericana. Pensamiento y propuesta (págs. 118-123). Buenos Aires: Ediciones Summa.

Estrada Ycaza, J. (1972). Evolución urbana de Guayaquil. Revista del Archivo Histórico del Guayas 1, 37-66.

Faggion Novo, L. (2016). Articulaçoes americanas: o urbanismo nos congressos pan americanos de arquitetos (1920-1930). Actas Primer Congreso Iberoamericano de Historia Urbana. Ciudades en el tiempo: infraestructuras, territorios, patrimonio (págs. 1385-1394). Santiago de Chile: Asociación Iberoamericana de Historia Urbana.

Fernández Cox, C. (1991). Modernidad apropiada. En D. Serna, Modernidad y posmodernidad en América Latina. estado del debate (págs. 11-22). Bogotá: ESCALA.

Fernández García, A. M. (2006). Arte y artistas españoles en el Ecuador. Liño. Revista de Historia del Arte. Universidad de Oviedo, 111-125.

Fernández Prieto, P. (2013). Art Deco in Havana Housing: Tropical Deco and Stramline. Chicago Art Deco Society, 24-27.

Fernández, R. (2005). Utopías sociales y cultura técnica. Estudios de Historia de la Arquitectura Moderna. Buenos Aires: FADU/UBA.

Frisby, D. (1992). Fragmentos de la modernidad. Madrid: Visor Distribuciones, S. A.

García Canclini, N. (2001). Culturas híbridas: estrategias para entrar y salir de la modernidad. Buenos Aires: Paidós.

García Jurado, R. (2003). Samuel Hungtinton y la modernización política. Estudios políticos, Nùmero 33, 11-34.

Giedion, S. (2009 [1941]). Espacio, tiempo y arquitectura. Barcelona: Reverté.

Godoli, E. (2008). Marcelo Piacentini y el art déco en los cines italianos. En A. B. (editor), Art déco y arquitectura. Imágenes de modernidad (págs. 103-142). Barcelona: UNED.

Gohardani, N. (2014). Architecture in effect: A glance at Critical Historiography. ArchNet, Vol 8, 184-190.

Goldhagen, S. W. (2008). Algo de qué hablar. Modernismo, discurso, estilo. Bitácora 12, 11-42. 
Gorelik, A. (1999). Ciudad, modernidad, modernización. Universitas HUMANÍSTICA, 11-27. Guerra, J. (2013). La visión plástica de la arquitectura del Arq. Rafael Rivas Nevárez. AUC. Arquitectura Universidad Católica, 19-36.

Gutiérrez Viñuales, R. (2013). Simbolismo y modernidad en sudamérica. Algunas historias reseñables (1895-1925). En A. K. Troya, \& R. G. Viñuales, Simbolismo y modernidad. Ecuador 1900-1930 (págs. 46-67). Quito: Hominem Editores.

Gutiérrez, R. (1992). Arquitectura y urbanismo en iberoamérica. Madrid: Cátedra.

Gutiérrez, R. (1997). Arquitectura latinoamericana. Lima: Epígrafe editores S. A.

Gutièrrez, R., y Gutièrrez Viñuales, R. (2012). Una mirada crìtica a la arquitectura latinoamericana del Siglo XX. De las realidades a los desafios. En E. K. (ed.), 1810-1910-2010. Independencias dependientes. Art and national identities in Latin America. Dresde: Universidad de Dresde.

Gutiérrez, R., y Viñuales, G. (1998). Arquitectura latinoamericana. En R. Gutiérrez (cordinador), Arquitectura latinoamericana en el siglo XX (págs. 119-136). Barcelona: Lunwerg editores.

Gutiérrez, R., Tartarini, J., y Stagno, R. (2007). Congresos panamericanos de arquitectos 1920-2000. Aportes para su historia. Buenos Aires: CEDODAL.

Gutman, M. (1985). En torno a la historia de la arquitectura. Summa, 215/216, 78-80.

Habermas, J. (1989). El discurso filosófico de la modernidad: doce lecciones. Madrid: Taurus.

Habermas, J. (1989). Modernidad: un proyecto incompleto. En N. Casullo, El debate Modernidad Pos-modernidad (págs. 131-144). Buenos Aires: Punto Sur.

Harvey, D. (1990). La condición de la posmodernidad. Investigación sobre los orígenes del cambio cultural. Buenos Aires: Amorrortu editores.

Herrán, T. (1939). Conclusiones I Congreso Panamericano de la Vivienda Popular. Arquitectura. Órgano oficial de la Sociedad de Arquitectos, 19-21.

Heynen, H. (2015). Modernity and modernities. Challenges for the historiography of modern architecture. Conceiving our Modernity: Perspectives of Study in Chinese Modern Architectural History (pp. 20-34). 1st Symposium of Chinese Modern Architectural History \& Theory Forum.

Hidalgo, Á. E. (2011). Entre dos aguas. Tradición y modernidad en Guayaquil (1750 - 1895). Manta: Mar Abierto.

Hidalgo, Á. E. (2013). Bohemia y sociabilidad entre 1900 y 1930. En A. K. Troya, y R. Gutiérrez Viñuales, Simbolismo y modernidad. Ecuador 1900-1930 (págs. 126-135). Quito: Hominem Editores.

Hidalgo, Ä. E. (2014). Sociabilidad letrada y modernidad en Guayaquil (1895-1920). Quito: Corporaciòn Editora Nacional.

Isac, A. (2011). La historia de la arquitectura del Siglo XX. Modelos historiogràficos. Lecciones de los Maestros. Aproximación histórico-crítica a los grandes historiadores de la arquitectura española (págs. 35-58). Zaragoza: Fernando el Católico.

Jiménez, V. (2007). Los estudios de Juan O’Gorman para Diego Rivera y Frida Kahlo. En Arquitectura moderna en México (pp. 11-24). Buenos Aires: Nobuko.

Kennedy-Troya, A. (2016). Élites y la nación en obras. Visualidades y arquitectura del Ecuador 1840-1930. Quito: Universidad de Cuenca / Casa de la Cultura Ecuatoriana, núcleo del Azuay. 
Kingman Garcés, E. (2006). La ciudad y los otros. Quito 1860-1940. Higienismo, ornato y policía. Quito: FLACSO Sede Ecuador - Universidad Rovira e Virgili.

Knight, A. (2015). Panorama general de la Gran Depresión en América Latina. En P. Drinot, y A. K. (coordinadores), La Gran Depresión en América Latina (págs. 347-423). México: Fondo de Cultura Económica.

Lecuona, D. E. (2001). Conceptos políticos y sociales sobre el problema de la vivienda en Argentina a mediados del siglo XX. Invi 42, 7-60.

Lee, P., \& Compte, F. (1992). Guayaquil: lectura histórica de la ciudad. Guayaquil: Universidad Católica de Santiago de Guayaquil.

Lee, P., Compte, F. y Peralta, C. (1988). Análisis y valoración de la arquitectura histórica de Guayaquil Siglo XIX - 1950. Guayaquil: Facultad de Arquitectura y Diseño de la Universidad Católica de Santiago de Guayaquil.

Lee, P., Compte, F., \& Peralta, C. (1989). Patrimonio Arquitectónico y Urbano de Guayaquil. Guayaquil: Universidad Católica de Santiago de Guayaquil.

Lee, P., Compte, F., \& Peralta, C. (1991). Testimonio y memoria de la arquitectura histórica de Guayaquil. Guayaquil: Universidad Católica de Santiago de Guayaquil.

Lee, P., Compte, F., Palacios, A. y Esparza, S. (1987). Inventario de la arquitectura civil, pública y religiosa de Guayaquil Siglo XIX - 1950. Guayaquil: Facultad de Arquitectura y Diseño de la Universidad Catòlica de Santiago de Guayaquil.

Liernur, J. F. (2004). Moderna (Arquitectura). En J. F. Liernur, \& F. Aliata, Diccionario de Arquitectura en la Argentina, volumen I-N (págs. 141-157). Buenos Aires: AGEA Clarín.

Liernur, J. F. (2008). Trazas de futuro. Episodios de la cultura arquitectónica de la modernidad en América Latina. Santa Fe: Universidad Nacional del Litoral.

Liernur, J. F. (2010). Orientalismo y arquitectura: el debate sobre la cubierta plana. $R A$ (Revista de Arquitectura) Universidad de Navarra, 61-78.

Liernur, J. F. (2014). Casas y jardines. La construcción del habitar moderno. En A. Ballent, \& J. F. Liernur, La casa y la multitud. Vivienda, política y cultura en la Argentina moderna (págs. 543-580). Buenos Aires: Fondo de Cultura Económica.

Liernur, J. F. y Pschepiurca, P. (2008). La red austral. Obras y proyectos de Le Corbusier y sus discípulos en la Argentina (1924-1965). Buenos Aires: Universidad Nacional de Quilmes.

Martín Hernández, M. J. (1997). La Invención de la Arquitectura. Madrid: Celeste ediciones.

Mera, G. y otros, y. (1991). Los arquitectos, Movimiento Moderno. Guayaquil 1940-1970. Guayaquil: Facultad de Arquitectura y Diseño. Universidad Católica de Santiago de Guayaquil.

Mignolo, W. (2000). Local Histories/Global Designs: Coloniality, Subaltern knowledges and border thinking. Princeton: Princeton University Press.

Miró Quesada, L. (1987). Inicios de la Arquitectura Mopderna en Lima. DAU, año 2 - volumen 1, 41-47.

Mondragón, H. (2010). El discurso de la Arquitectura Moderna. Chile 1930 - 1950. Una construcción desde las publicaciones periódicas. Santaigo de Chile: Tesis doctoral. Doctorado en arquitectura y estudios urbanos. Pontificia Universidad Católica de Chile.

Montaner, J. M. (2002 (5a. ed.)). Después del movimiento moderno. Arquitectura de la segunda mitad del sglo XX. Barcelona: Gustavo Gili.

Montaner, J. M. (2011). Arquitectura y crítica en Latinoamérica. Buenos Aires: Nobuko. Montaner, J. M. (2013 (3a. ed.)). Arquitectura y Crítica. Barcelona: Gustavo Gili. 
Noelle, L. (2015). Mexico. En B. Bergdoll, C. E. Comas, J. F. Liernur, y P. D. Real, Latin America in Construction: Architecture 1955-1980 (págs. 216-247). New York: The Museum of Modern Art.

Norberg-Schulz, C. (1967). Intenciones en arquitectura. Barcelona: Gustavo Gili.

Núñez Sánchez, J. (2010). Eloy Alfaro. Pensamiento fundamental. Quito: Editorial Ecuador.

Núñez, J. (1997). Guayaquil, una ciudad colonial del trópico. Guayaquil: Archivo Histórico del Guayas.

Pachón Soto, D. (2008). Nueva perspectiva filosófica en América Latina: el grupo Modernidad/Colonialidad. Ciencia Política 15, 8-35.

Padrón, M. J. (1993). Caracas 1928-1958: permanencias y transformaciones morfológicas durante la primera modernidad urbano-arquitectónica en Venezuela. Anales del Instituto de Arte Americano 29, 87-101.

Paladines, C. (2007). La odisea de la modernización en el Ecuador. Dos momentos de su desarrollo. Estudios de Filosofía Práctica e Historia de las Ideas, 129-140.

Patetta, L. (1984). Historia de la arquitectura. Antología crítica. Madrid: Hermann Blume.

Paz y Miño Cepeda, J. J. (2013). La Revolución Juliana en Ecuador (1925-1931). Políticas económicas. Quito: Ministerio Coordinador de Política Económica.

Peralta, C. (2009). Investigación patrimonial en los barrios Orellana y del Salado de Guayaquil. Guayaquil: Ministerio Coordinador de Patrimonio / Facultad de Arquitectura y Diseño de la Universidad Católica de Santiago de Guayaquil.

Pérez, T. (2013). La Escuela Nacional de Bellas Artes y el arte moderno en Quito a inicios del siglo XX. En L. K. Troya y R. Gutiérrez Viñuales, Simbolismo y modernidad. Ecuador 1900-1930 (págs. 114-122). Quito: Hominem Editores.

Piñón, H. (2006). Teoría del Proyecto. Barcelona: Universitat Politécnica de Catalunya.

Pradilla, E. (1983). El problema de la vivienda en América Latina. Quito: Centro de Investigaciones CIUDAD.

Pratt, M. L. (2000). La modernidad desde las Américas. Revista Iberoamericana. Vol. LXVI, Núm. 193, 831-840.

Puente, G. (28 de mayo de 2015). Modernism in Quito, Ecuador: 1955-1980. Obtenido de Docomomo United States: http://docomomo-us.org/print/1289

Quijano, A. (1988). Modernidad, identidad y utopía en América Latina. Lima: Sociedad y Política/Ediciones.

Quijano, A. (2000). Colonialidad del poder, eurocentrismo y América Latina. En E. Lander, La colonialidad del saber: eurocentrismo y ciencias sociales (págs. 201-246). Buenos Aires: CLACSO, Consejo Latinoamericano de Ciencias Sociales.

Quijano, A. (2014). Cuestiones y Horizontes. Antología esencial. De la dependencia históricoestructural a la colonialidad/descolonialidad del poder. Buenos Aires: CLACSO.

Quintero, R. y Silva Charvet, É. (2013). Ecuador: una nación en ciernes. Quito: Abya Yala.

Raffa, C. y Cirvini, S. (2013). Arquitectura Moderna: autores y producción en Mendoza, Argentina (1930-1970). AS, 34-47.

Ramírez Nieto, J. (2009). Intervalo nacional-moderno de la arquitectura latinoamericana 1929-1939 (tesis doctoral). Hamburg: HafenCity Universität.

Reigadas, C. (2012). Modernidades múltiples e historia global. Aportes para repensar el lugar de latinoamérica en el mundo. De signos y sentidos / 13, 15-26. 
Rey Ashfield, W. (2008). Intuición y emoción: nuevas claves para el análisis de la arquitectura moderna uruguaya. Apuntes, vol. 21, núm. 2, 252-265.

Rey Ashfield, W. (2012). Arquitectura Moderna en Montevideo (1920-1960). Montevideo: Universidad de la República.

Rivas Nevárez, R. (2013 [1942]). La práctica profesional. Nuestra realidad arquitectónica. AUC. Arquitectura Universidad Católica, 69-72.

Rivas Nevárez, R. (2013 [1946]). La zonificación de Guayaquil. AUC. Arquitectura Universidad Católica, 45-48.

Rivas Nevárez, R. (2013 [1980]). La práctica profesional: origen y trayectoria del Coelgio de Arquitectos. AUC 32, 87-100.

Rivas Nevárez, R. (2013). Vivienda social. El problema de la vivienda en Guayaquil. AUC. Arquitectura Universidad Católica, 49-52.

Rojas, M. y Villavicencio, G. (1988). El Proceso Urbano de Guayaquil 1870-1980. Guayaquil: CERG.

Roth, L. M. (1993). Entender la arquitectura. Sus elementos, historia y significado. Barcelona: Gustavo Gili.

Salvador, Á. (2013). Modernismo hispanoamericano y modernidad europea. En A. K. Troya y R. Gutiérrez Viñuales, Simbolismo y modernidad. Ecuador 1900-1930 (págs. 34-45). Quito: Hominem Editores.

Samoná, G. (1984). El París de Haussmann. En L. Patetta, Historia de la Aqruitectura. Antología crítica (pág. 243). Barcelona: Hermann Blume.

Santamarìa, L. (2013). Imaginario, identidad y arquitectura. Contexto. Revista de la Facultad de Arquitectura. Universidad Autònoma de Nuevo Leòn, 43-51.

Sartoris, A. (1978). Recuerdos de La Sarraz. Arquitecturas BIS, 2-7.

Segawa, H. (2013). Architecture of Brazil. 1900-1990. New York: Springer.

Segawa, H. (2015). Patrimonio moderno brasileño y latinoamericano: controversias. El patrimonio moderno en iberoamérica. Protección y coordinación internacional (págs. 6976). México: Instituto Nacional de Bellas Artes y Literatura - UNESCO.

Segre, R. (1989). Arquitectura y urbanismo de la revolución cubana. La Habana: Pueblo y Educación.

Segre, R. (1990). América Latina. Fin de Milenio. Raíces y perspectivas de su arquitectura. Madrid: Arte y Literatura.

Segre, R. (2015). Arquitectura y urbanismo. Cuba y América Latina desde el siglo XXI. La Habana: Arte y Literatura.

Thompson, J. B. (2002). Ideología y cultura moderna. Teoría crítica social en la era de la comunicación de masas. Coyoacán: Universidad Autónoma Metropolitana.

Tinajero, F. (1987). De la evasión al desencanto. Quito: El Conejo.

Tinajero, F. (2015). Paradojas de nuestra identidad. Quito: Eskeletra editorial.

Tomas, H. (1998). El lenguaje de la arquitectura moderna. La Plata: Universidad Nacional de La Plata.

Torrent, H. (2011). A different reception. Modern brazilian architecture and chilean architectonic culture. $A R Q, 51-57$. 
Torrent, H. (2012). Historiografia y arquitectura moderna en Chile: notas sobre sus paradigmas y desafíos. Anales del Instituto de Arte Americano e Investigaciones Estéticas "Mario J. Buschiazzo", 42, 55-75.

Torres Dávila, V.H. (2012). Estado e industrialización en Ecuador. Modernización, fricciones $y$ conflictos en los años cincuenta. Quito: Abya Yala.

Tournikiotis, P. (2014). La historiografía de la arquitectura moderna. Barcelona: Reverté.

Ubidia, A. (1998). Modernidad y posmodernidad. ICONOS, 54-59.

Villavicencio, G. (1989). El desfase de un proceso urbano: El caso de Guayaquil. En CORDES, Guayaquil: Realidades y deafíos (págs. 29-87). Guayaquil: Corporación de Estudios para el Desarollo CORDES.

Villavicencio, G. y Rodríguez, A. (s/f). Notas para la discusión del problema de la vivienda en América Latina: El Caso de Guayaquil. Quito: Centro de Investigaciones CIUDAD.

Waisman, M. (1990). El interior de la historia. Historiografía arquitectónica para uso de latinoamericanos. Bogotá: ESCALA.

Zevi, B. (1980 [1950]). Historia de la arquitectura moderna. Barcelona: Poseidón.

\begin{abstract}
The historiography on Modern Architecture in Ecuador is scarce and the that there is little spread. There is abundant research on the colonial, mainly Quito, which has guided the discussion on national architecture since the end of nineteenth century to the present, however, there is little that is known about architecture Modern of the country. Some authors have considered that the weight of colonial architecture In the Andean countries, like Ecuador, he promoted the development of picturesque proposals, Neonational and neo colonial rather than modern, so that rationalism does not arrived but late, however, in Guayaquil, Modern Architecture emerged early at the beginning of the 1930s along with countries such as Argentina, Brazil, Chile, Uruguay or Mexico. This process must be understood, first, by the marked differences between Guayaquil and Quito and, secondly, due to the economic crisis at the end of the 1920s, when there was a need to simplify the forms, rationalize the space and lower construction costs.
\end{abstract}

Keywords: Modernity - Modern architecture - Neoclassical Architecture - Guayaquil Rationalization.

Resumo: A historiografia sobre Arquitetura Moderna no Equador é escassa e os que há pouca disseminação. Há abundante pesquisa sobre o colonial, principalmente Quito, que tem orientado a discussão sobre arquitetura nacional desde o final de do século XIX até o presente, no entanto, pouco se sabe sobre arquitetura Modern do país. Alguns autores consideram que o peso da arquitetura colonial Nos países andinos, como o Equador, ele promoveu o desenvolvimento de propostas pitorescas, Neo-nacional e neo-colonial ao invés de moderno, de modo que o racionalismo não chegou mas atrasado, no entanto, em Guayaquil, Arquitetura Moderna surgiu cedo no início da década de 1930, juntamente com países como Argentina, Brasil, Chile, Uruguai ou México. Este processo deve ser entendido, primeiro, pelas diferenças marcantes entre Guayaquil e Quito e, em segundo 
lugar, devido à crise econômica no final do Década de 1920, quando houve a necessidade de simplificar as formas, racionalizar o espaço e menores custos de construção.

Palvras-chave: Modernidade - Arquitetura Moderna - Arquitetura Neoclássica - Guayaquil - Racionalização.

[Las traducciones de los abstracts fueron supervisadas por el autor de cada artículo] 